Copyright is owned by the author of the thesis. Permission is given for a copy to be downloaded by an individual for the purpose of research and private study only. The thesis may not be reproduced elsewhere without the permission of the author. 


\title{
The Maternity Experience of New Zealand Samoan First-time Mothers
}

\author{
Marianna Ellen Churchward
}

A thesis submitted to the Victoria University of Wellington in fulfilment of the requirements for the degree of Doctor of Philosophy

Victoria University of Wellington 2015 
For Mike, Karlos, Marshall and Isabella $\mathrm{x}$ 


\begin{abstract}
Motherhood is a life-changing event. It is a significant milestone for a woman. This thesis explores the concept of motherhood from the perspectives of Samoan first-time mothers living in New Zealand. The thesis traces their experiences from conception, pregnancy and childbirth through to early motherhood. Their narratives are the focus of the research and are complemented by the viewpoints from some of their own mothers, and maternity health professionals.
\end{abstract}

The overarching question, 'What are the experiences of a group of first-time New Zealand-born Samoan mothers before and after birth?' was framed from a strengthsbased approach and draws on work which defines a strength-based approach to resilience as research that changed traditional deficit perspectives. Rather than focussing on how individuals or families have failed or struggled, emphasis is directed to how they can succeed or how they can manage (Walsh, 2006).

Interviews were conducted in Wellington and Auckland with 11 first-time Samoan mothers prior to childbirth and follow-up interviews with nine of these women within 12 months of the birth of their child. Five Samoan grandmothers, i.e. mothers of these first-time mothers, five midwives and five Plunket nurses were also interviewed.

Four sites of analysis were examined - the embodied experience of conception and pregnancy; the process of labour and childbirth; the new norm of early motherhood, and interpersonal relationships and encounters. Analysis was conducted through the overarching lens of the Samoan concept of the vā (Wendt, 1999), the theoretical frameworks of 'negotiated spaces' (Mila-Schaaf and Hudson, 2009) and sophisticated mediation (Churchward, 2011).

It was found that the first-time New Zealand-born Samoan mothers engaged in a complex and, at times, contradictory process of seeking support during their transition to motherhood. They demonstrated resilience and their skill as sophisticated mediators. The women depended on relationships, some biological and some not, that were reliable and sustainable and the interaction and care that the relationship offered. Intergenerational relationships were important to these first-time New Zealand-born Samoan mothers, particularly ones they had with their own mother, or someone close to them, as it was pivotal in the way in which they constructed their maternity experience. 


\title{
REMEMBERED WITH LOVE
}

\author{
Joseph Churchward (1932-2013) \\ Paul Churchward (1962-2011) \\ James Patrick Churchward (1970-1992)
}

What you leave behind is not what is engraved in stone monuments, but what is woven into the lives of others.

- Pericles 


\section{DEDICATION}

This thesis is dedicated to the women in my family.

To the best mother I know, Anasetasia Maria (Tua) Tupuola Tasi Churchward

A woman of inner strength, beauty, compassion, kindness and love

Mum, though changes have been great, I can still see you $\mathrm{x}$

To the best daughter I know, Isabella Malia McMurrich Churchward Woods

I love your spirit to strive for equality, humility and kindness in our world

Isabella, you make a difference $\mathrm{x}$ 


\section{ACKNOWLEDGEMENTS}

After many years and deep heartache, my sister Lorina, became a mum, finally.

The gift was just right, and his arrival changed lives forever.

Not from your body, but from your soul. You are an awesome mother. $\mathrm{x}$

Thank you to the young women I met who become inspirational mothers, who gave their time and interest in this thesis. Sharing your experiences with honesty showed your desire to help other first-time mothers and I thank you. I am grateful to the wonderful grandmothers (mums of the first-time mothers) who shared their stories. My thanks to the midwives, Plunket nurses, and the Royal New Zealand Plunket Society, who gave their time to this research.

Thanks to my supervisors, Dr Tamasailau Suaali'i-Sauni and Dr Jenny Neale, for your wisdom, patience, unflappability and guidance that helped me get through what seemed a massive task. Thanks for never giving up on me, and for not letting me give up either. Big thanks to my favourite MOGYM, Dr Teresia Teaiwa, for supervising the research in the first six months. Thanks to the staff and students at Victoria University Pacific Studies/Va'aomanu Pasifika. Thanks to my mentor and friend, Dr Lanuola Asiasiga, for the articles, discussions and long reassuring talks.

Thanks to Professor Jaqueline Cumming and my colleagues, past and present, of Health Services Research Centre for providing me with the space to continue my studies, the encouragement, support, advice and friendships, particularly Maggy, Sue, Lynne and Kirsten. Special thanks to my roommate, buddy and athlete extraordinaire, Niks, for putting up with me for so long! Thanks to my PhD supporters especially Paula, Janet, Emelihter and Therese (Palmerston North cheerleader) for your camaraderie. Thanks to the funders the Health Research Council of New Zealand for the PhD scholarship, and Victoria University of Wellington for a PhD completion scholarship. Thanks to Joe and Julian (Churchward/Melhuish).

To my extended family, nieces and nephews, my in-laws the Woods family, and the many, many friends who encouraged me to persevere, and either refrained, or reframed 
the question I dreaded the most 'how's the PhD?'. Thank you for steering to other topics for discussion! Special thanks to Suzanne, Marysia and Louise.

To my brother, Paul and my father, Joseph, who both passed away during the course of this research. While you did not get to see the end result of the noisy tap-tapping of my laptop at home, the hospital and hospice, I thank you both for the love, support and those encouraging words 'carry on with your work'. It helped me get through when things got really tough. To my mum and our family, although our shared grief was deep, you continued to provide me with unconditional support and care. Are we there yet? Yes, we are!

Special thanks to my siblings and their families for being curious, dependable and supportive. My brothers, Joe and Michael, for encouraging me throughout the research process with the best tip of all: 'just get on with it'. To my loyal and vivacious sisters, Maricia, Lorina and Georgie, who kept me focussed on the study, you can phone me now! You are outstanding mothers and the best friends one could have, seriously. Thanks to the partners of my siblings, Paul, Nigel and Elisabeth, who despite working on her own Master's, provided feedback on early draft chapters.

The last words of thanks, appreciation and love belong to the four people in my life who have been the most influential and who have, undoubtedly, made the biggest sacrifice in order for me to fulfil this goal. My patient and very understanding husband Michael Woods and our children, Karlos, Marshall and Isabella, who complete our blended family. It has certainly been one heck of a ride but we made it in one piece, and together! My wish for you all is to follow your dreams and I will stand right beside you, as you have me. I am so fortunate to have had your support that has been rock solid, reliable and honest. Your humour, security and emotional sustenance kept me centred.

\section{Motherbood is transformative whichever way you look at it.}




\section{TABLE OF CONTENTS}

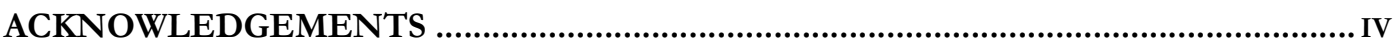

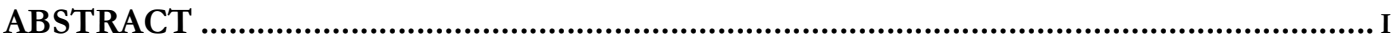

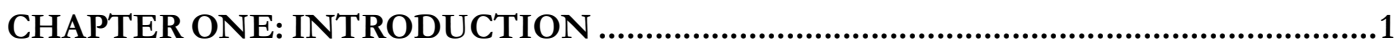

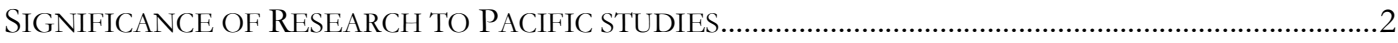

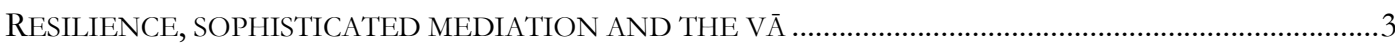

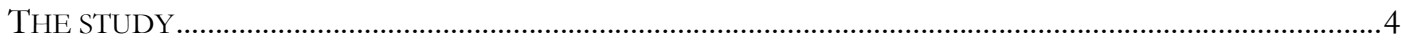

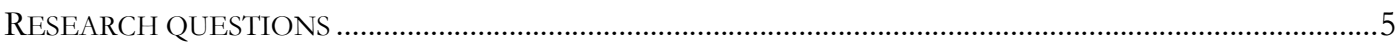

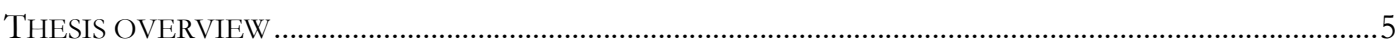

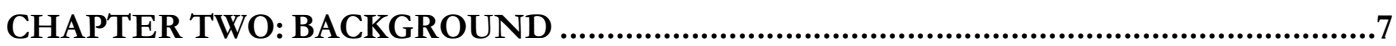

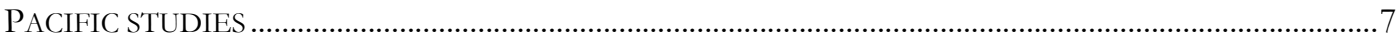

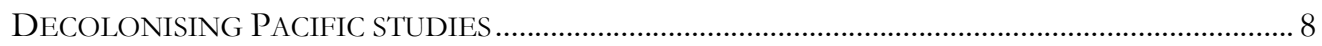

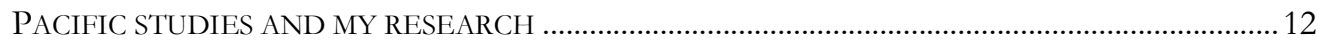

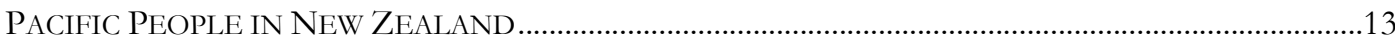

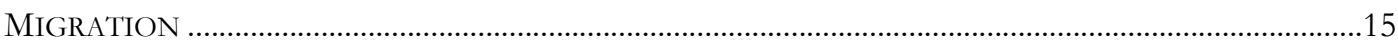

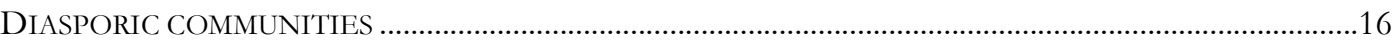

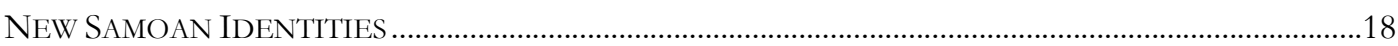

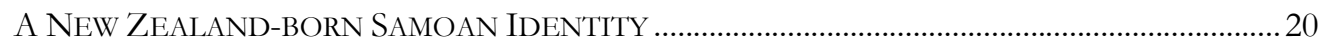

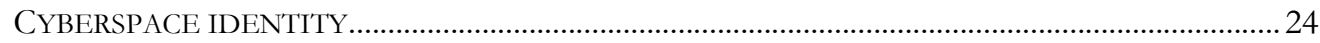

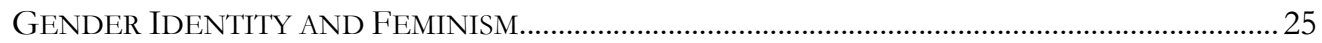

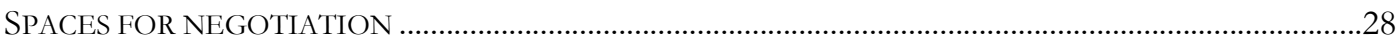

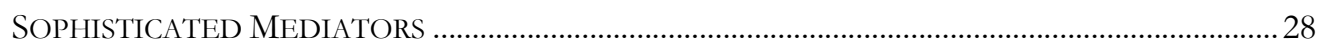

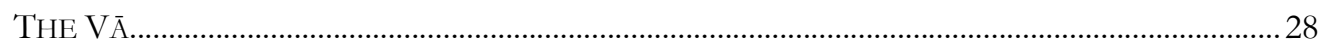

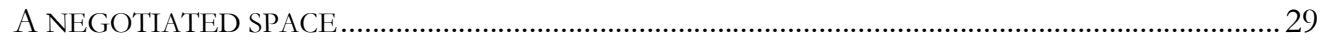

RESILIENCE

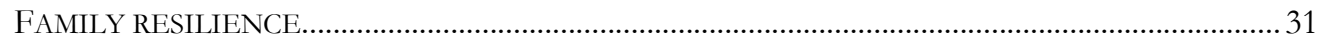

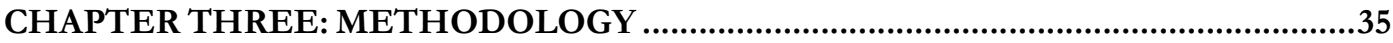

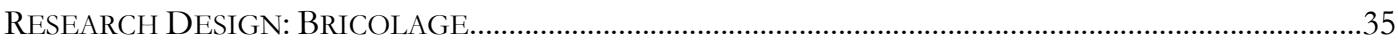

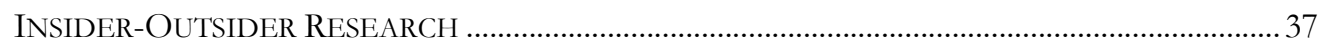

EPISTEMOLOGY AND PACIFIC RESEARCH THEORY ............................................................................ 40

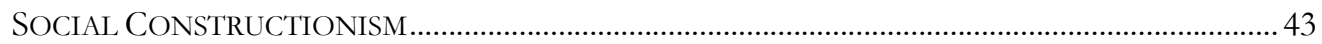

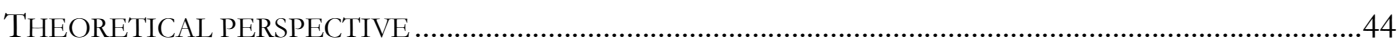

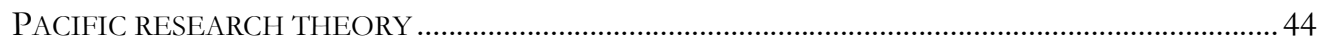

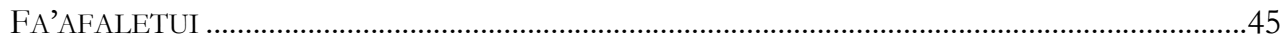

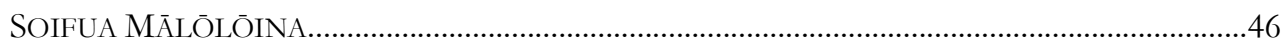

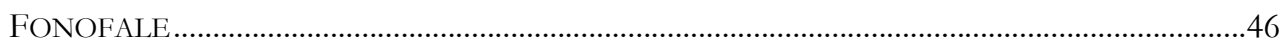

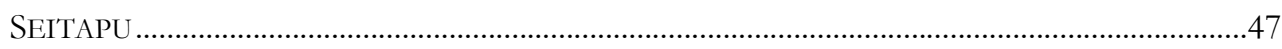

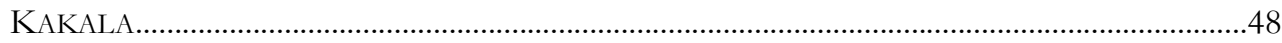

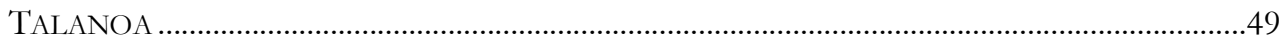

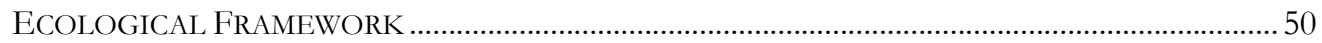

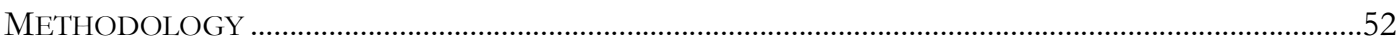

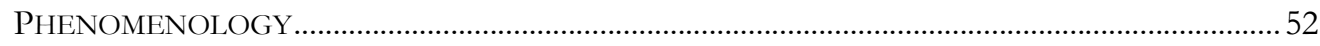

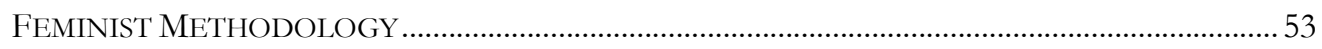

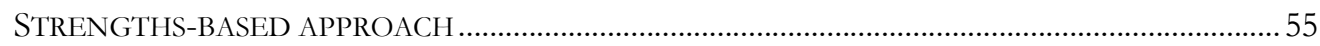




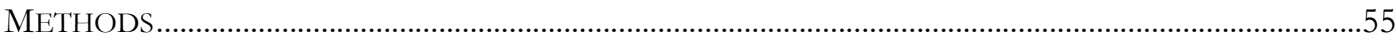

RATIONALE FOR INDIVIDUAL SEMI-STRUCTURED NARRATIVE INTERVIEWS ........................ 55

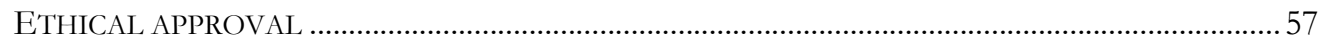

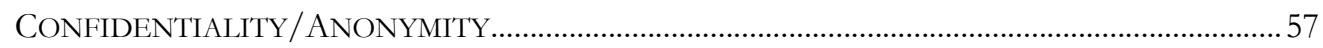

ESTABLISHING GOOD RELATIONSHIPS AND RAPPORT ............................................................. 58

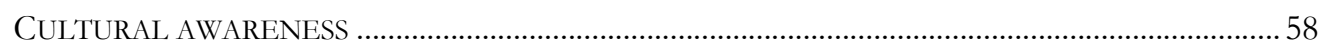

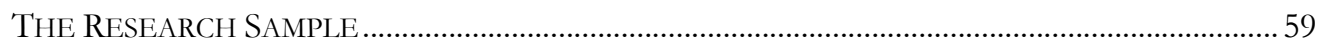

(A) NEW ZEALAND FIRST-TIME SAMOAN MOTHERS: .............................................................60

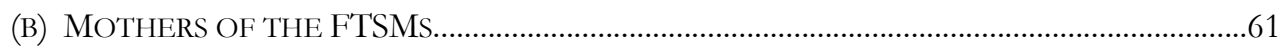

(C) MATERnity HeAlth ProfessionALS..............................................................................61

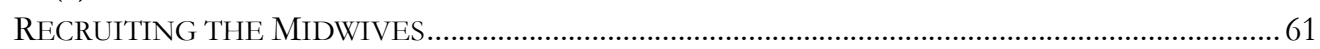

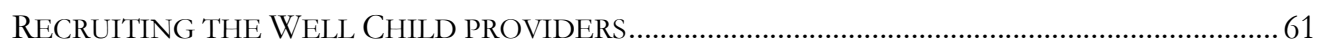

SMALL GIFT AS PART OF MY ETHICAL PRINCIPLES OF RECIPROCITY ....................................... 62

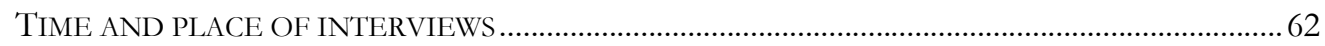

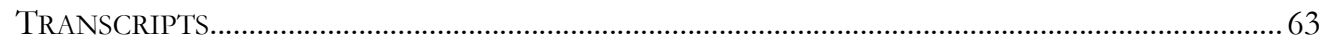

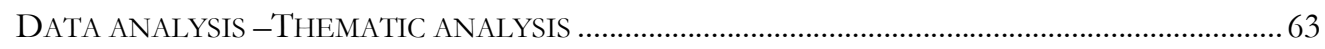

FIRST LEVEL OF ANALYSIS: GETTING FAMILIAR WITH THE DATA ........................................64

SECOND LEVEL OF ANALYSIS: GENERATING INITIAL IDEAS ..............................................64

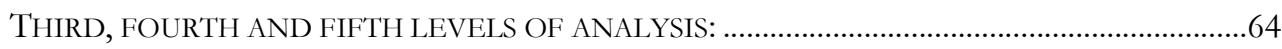

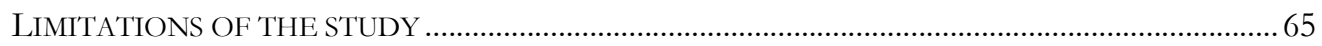

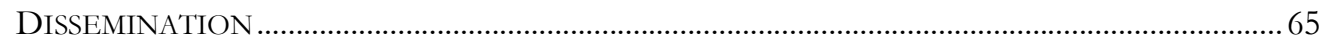

CHAPTER FOUR: CONCEPTION AND PREGNANCY .........................................66

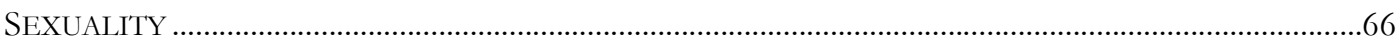

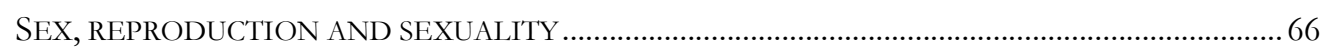

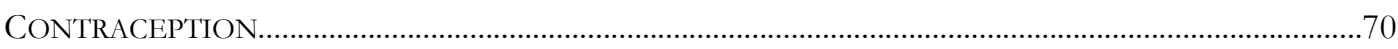

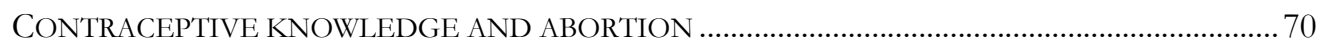

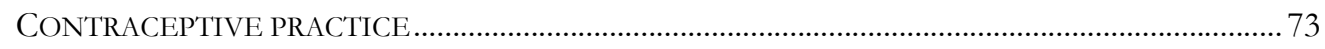

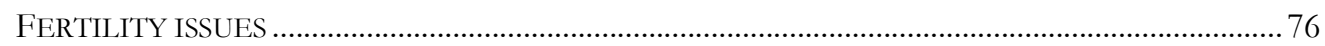

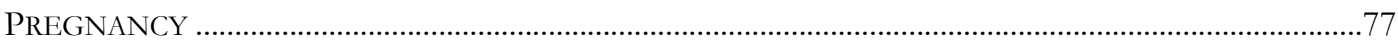

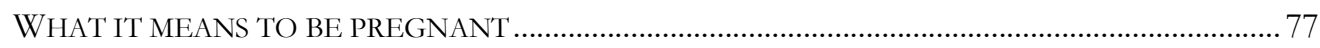

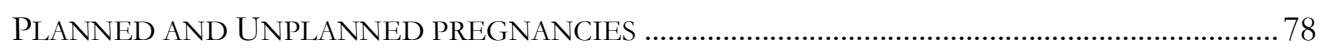

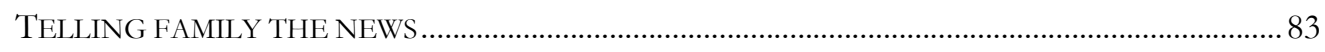

THE PREGNANT BODY: CORPOREALITY AND FEARS OF UNDESIRABILITY ................................ 86

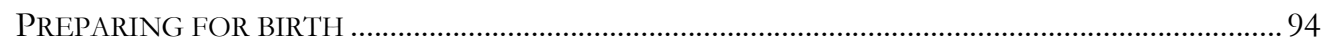

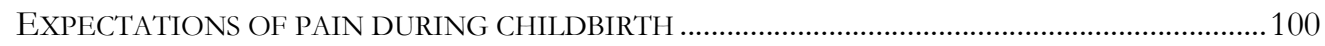

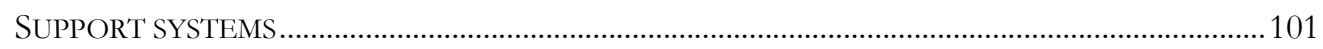

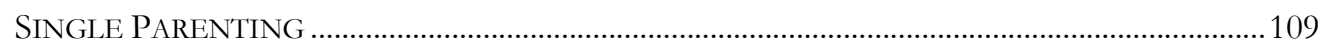

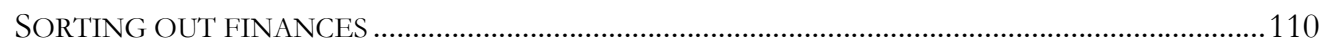

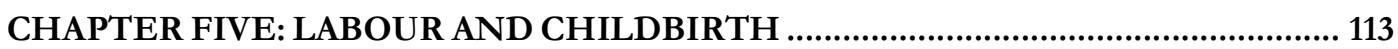

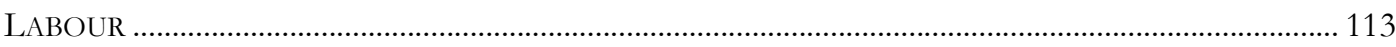

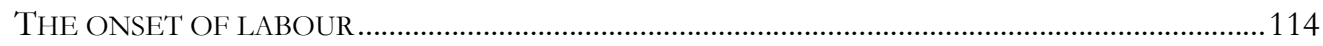

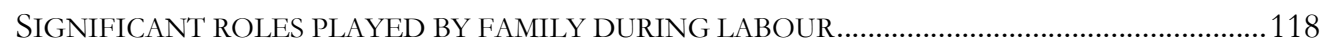

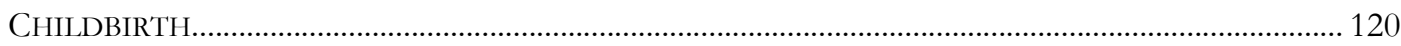

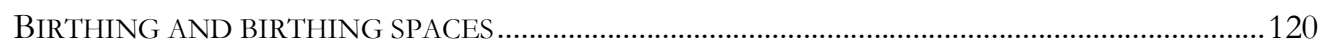

CHILDBIRTH IS A FAMILY AFFAIR - FOR GOOD OR BAD ............................................................. 126

FTSMS REFLECTIONS ON THEIR EXPECTATIONS AND REALITY .............................................128 
CHAPTER SIX: EARLY MOTHERHOOD ....................................................... 130

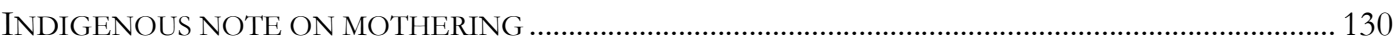

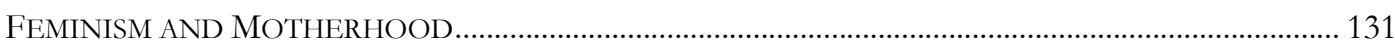

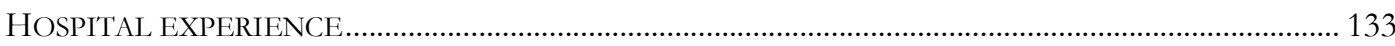

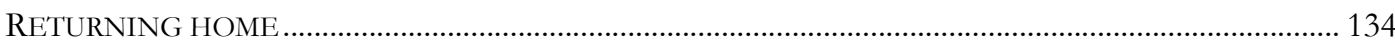

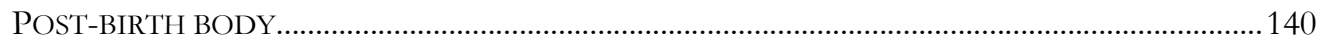

ENGORGED BREASTS AND BREASTFEEDING: NO ONE TOLD ME! NO ONE SHOWED ME!..140

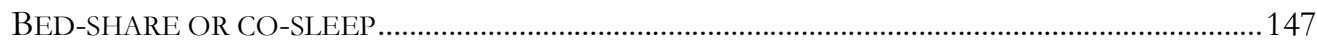

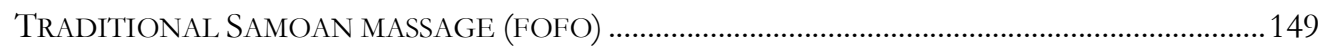

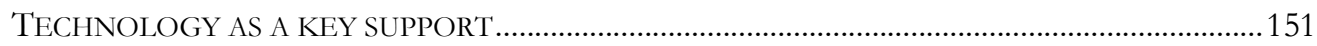

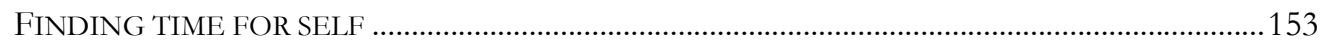

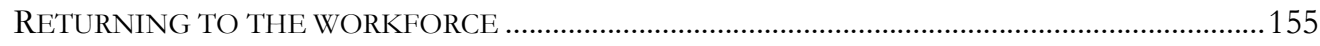

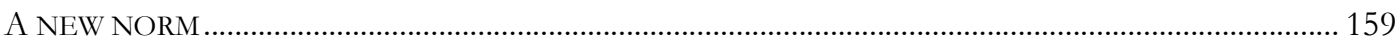

CHAPTER SEVEN: RELATIONSHIPS - INTERPERSONAL AND MATERNITY

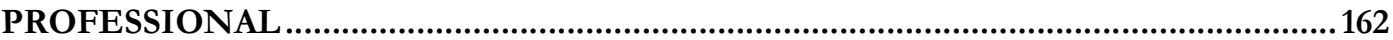

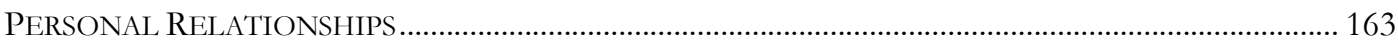

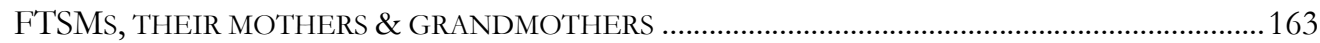

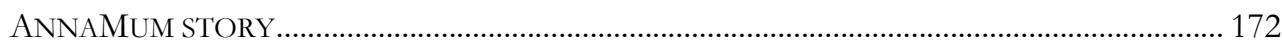

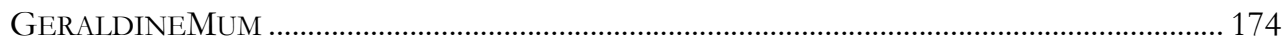

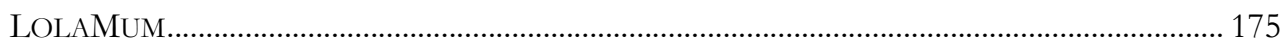

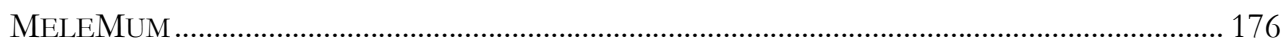

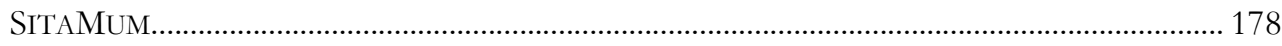

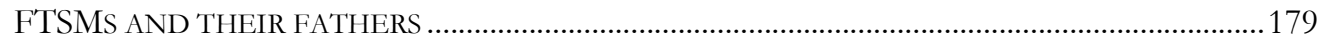

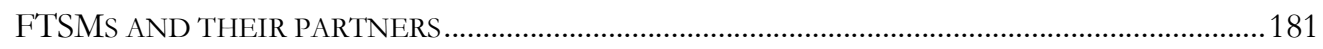

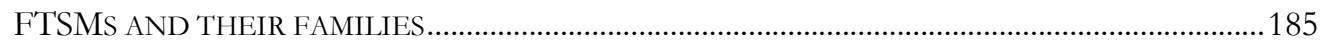

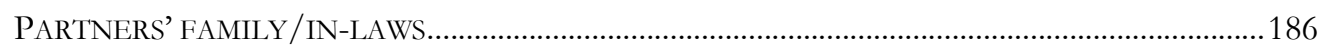

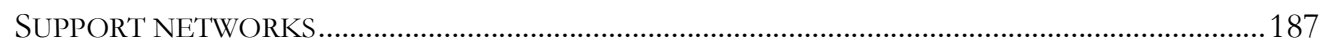

MATERNITY HEALTHCARE PROVIDER RELATIONSHIPS WITH FTSMS ........................................... 190

LMCS AND THE NEW ZEALAND MIDWIFERY SYSTEM.............................................................. 191

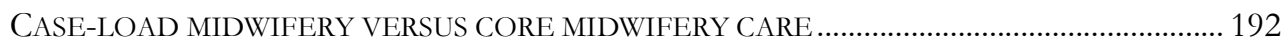

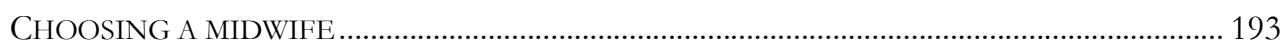

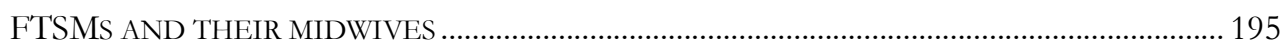

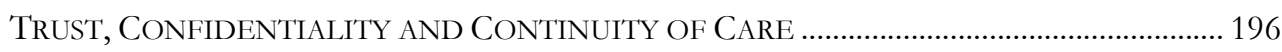

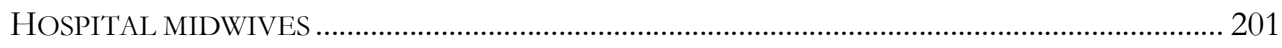

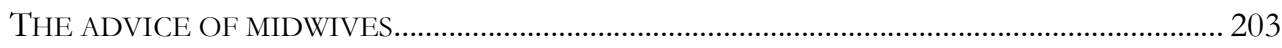

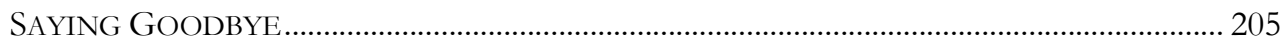

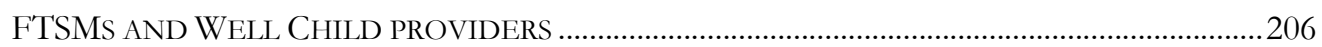

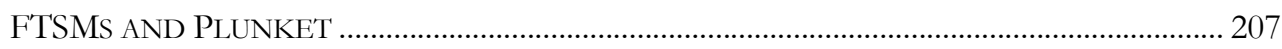

CHAPTER EIGHT: DISCUSSION AND CONCLUSIONS ..................................... 211

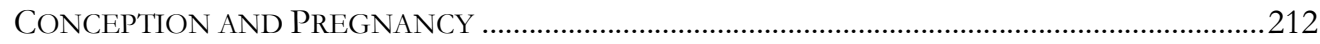

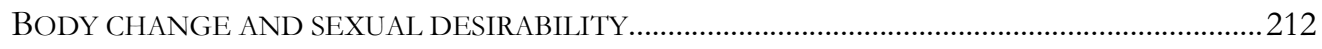

ECONOMIC WELLBEING VS EMOTIONAL WELLBEING ........................................................213

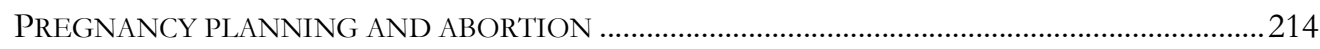

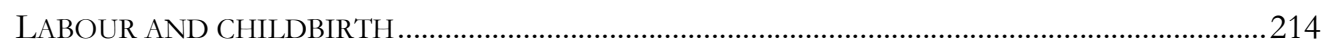

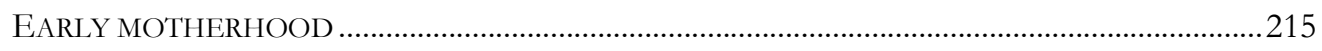

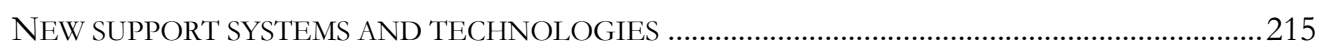

DEALING WITH UNMET EXPECTATIONS (EXPECTATIONS VS ACTUAL EXPERIENCE) ..........216

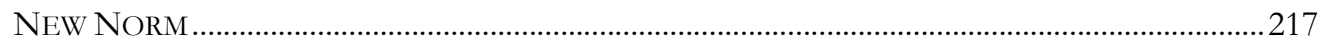


SOPHISTICATED MEDIATION, NEGOTIATED SPACE AND THE VĀ .........................................217

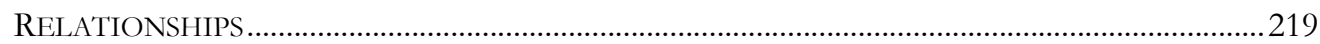

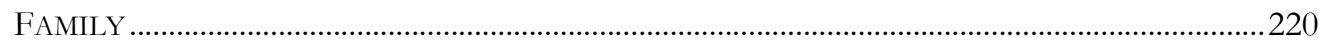

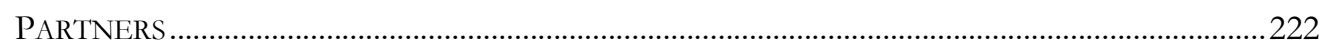

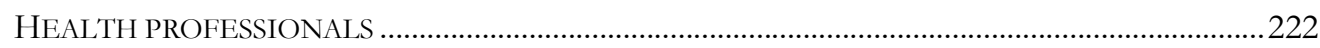

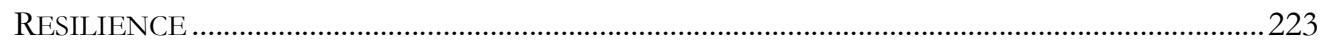

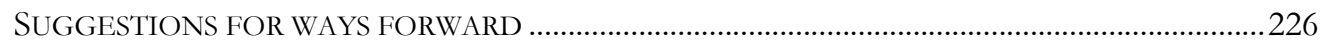

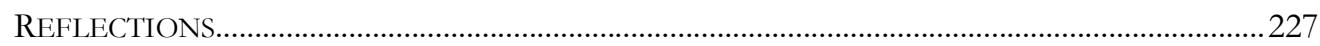

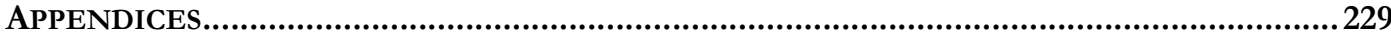

APPENDix ONE: PARTicipant INFORMATION SHEET ................................................ 229

APPENDIX TwO: CONSENT FORM FOR FTSM, AND THEIR MOTHERS ............................ 230

APPENDIX THREE: CONSENT FORM FOR KEY INFORMANTS ..................................... 231

APPENDIX FOUR: INTERVIEW CHECKLIST: FIRST-TIME MOTHERS ANTENATAL ............... 232

APPENDIX FIVE: INTERVIEW CHECKLIST: FIRST-TIME MOTHERS POSTNATAL.................. 234

APPENDIX SIX: INTERVIEW CHECKLIST: MOTHERS OF THE FIRST-TIME MOTHERS ..........2 236

APPENDIX SEVEN: INTERVIEW CHECKIIST: MIDWIVES.........................................2238

APPENDix EIgHT: INTERVIEW CHECKLIST: PLUNKET NURSES ..................................239

APPENDIX NINE: FIRST-TIME MOTHERS RECRUITMENT FLYER ................................240

APPENDIX TEN: GENERAL RECRUITMENT FLYER ..................................................... 241

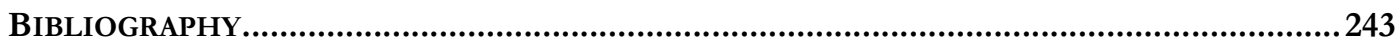

\section{FIGURES AND TABLES:}

Figure 1: ECOLOGICAL MODEL: BRONFENBRENNER'S ECOLOGICAL MODEL DESCRIBING THE ENVIRONMENTAL INFLUENCES ON A CHILD.

FIGURE 2: A SOCIAL ECOLOGICAL MODEL FOR SAMOAN WOMEN'S EXPERIENCES DURING FIRSTTIME MOTHERHOOD...

TABLE 1: FTSMS LENGTH OF TIME SPENT IN HOSPITAL BEFORE RETURNING HOME 134

TABLE 2: FTSMS AND THEIR BABIES AGES; AND LENGTH OF TIME BREASTFEEDING........ 143 


\section{CHAPTER ONE: INTRODUCTION}

Motherhood is a life-changing event. Motherhood is transformative. Experiencing this phenomenon for the first time can have a lasting effect on subsequent maternity experiences, altering life as it was known thereafter. As Oakley says, giving birth is a physiological act in that a woman reproduces the 'species' and performs a physical function to bring the reproduction into fruition. Yet the act is achieved in a context that is shaped by the way society constructs and gives meaning to it (Oakley, 1980). This thesis is interested in the way in which the social spaces of New Zealand-born first-time Samoan mothers (FTSMs ${ }^{1}$ ) experience and give meaning to the first main stages: of pregnancy, labour, childbirth and early motherhood.

This thesis was driven partly out of a personal interest in New Zealand-born Samoan women and motherhood, and out of a research interest in the emotional and mental health issues that can and do arise in the lead-up to motherhood. This interest led to a Master's thesis exploring the experiences of first-time motherhood from the perspective of four first-time Samoan mothers (Churchward, 2011). That work found that these Samoan women were 'sophisticated mediators', who 'although faced with many challenges throughout their pregnancy, childbirth and early motherhood experiences, mediated between, and within, existing cultural belief systems... to acquire or maintain resilience' (Churchward, 2011, p. ii).

The findings of the Master's stimulated my interest to gain a deeper, fuller and broader understanding of what matters, or what happens during motherhood from the perspectives of Samoan first-time mothers. My Master's was a small study, with the aim of exploring key coping strategies that may be linked to the low prevalence rates of postnatal distress (PND) among Samoan women in relation to other Pacific women. The emphasis of the Master's was key risk/protective factors for the prevalence of PND and what coping strategies were adopted by mothers specifically in relation to PND.

One of the most interesting findings from the Master's was the term 'Sophisticated Mediators', women who were mediating between two cultural systems. But it raised more questions for me, particularly around whether the concept of sophisticated

\footnotetext{
${ }^{1}$ The acronym 'FTSMs' is used throughout this thesis identifying the women of focus 'First-time Samoan Mothers'.
} 
mediation was an artefact of this particular group of women, or does this have applicability to other first-time Samoan mothers.

The doctoral study allowed me to shift the emphasis from PND to explore, broaden and deepen my understanding about maternity experience in a wider sense, through perspectives of a larger group of New Zealand Samoan women, to include their mothers and maternity health professionals who work alongside Pacific mothers. It allowed me to explore the richer interpretations of Pacific frames of reference as well; for example, the vā and negotiated spaces. The doctoral study, with its different forms, allowed for more layers of complexity, more perspectives to emerge.

Birth is an important milestone for Samoan families and relatives are encouraged to attend (Kinloch, 1985). Support during childbirth from a chosen family member is the norm but support from a member of the FTSMs wider social network is also commonly practiced. In both situations the process of moving from being pregnant to being a mother is always framed as something that happens within the family context. In this the whole experience of early motherhood, from the time the pregnancy is announced to the time they have the baby, is one that engages an inter-play of relationships, those between the mother and her baby, her partner, her mother, and their wider families.

Samoans, as a significant proportion of the New Zealand Pacific community, have developed a growing presence in all aspects of New Zealand society. Their ability to move between their different Samoan and New Zealand worlds has attracted a significant literature in social anthropology, sociology, education and health.

\section{SignificanCE OF RESEARCH TO PACIFIC STUdies}

Pacific studies is a relatively new academic field of study that arose out of a call by indigenous scholars and social scientists for a discipline that could privilege the concerns of the indigenous communities alongside the research interests of academic scholars (see Background Chapter for a more detailed discussion on Pacific studies as an academic field of study).

The research privileges Samoan women and their maternity experiences. It aims to understand coping strategies utilised by first-time Samoan mothers during pregnancy, childbirth and early motherhood. The literature on motherhood within the Pacific, including New Zealand, is scarce and does not provide an understanding of Samoan women who are positioned within differing cultural frameworks embarking on 
motherhood. The ability of this group of Samoan mothers to negotiate these tensions has received minimal attention and little is known of their experiences.

Drawing from previous limited research with Pacific mothers in New Zealand, the literature (Abbott \& Williams, 2006; Ekeroma, Craig, Stewart, Mantell, \& Mitchell, 2004; Everard, 1997) paints a dreary account of the experiences of motherhood for Pacific women; one plagued with not coping, not accessing services, of concealed pregnancies, single motherhood, dysfunctional coping mechanisms, and high postnatal distress (PND). Pacific women were highlighted as showing extremes in terms of the prevalence of postnatal depression: that it was either very high (30.9 percent) or very low (7.9 percent) dependent on the specific Pacific ethnic group (Abbott \& Williams, 2006).

Depression was found to be higher in New Zealand-born Pacific women than those born in the islands (Kokaua, Schaaf, Wells, \& Foliaki, 2009). Findings from my Master's showed that the FTSMs, in general, had very positive attitudes towards unplanned pregnancy and motherhood, and had well established support systems enabling them to successfully manage and cope with postnatal stresses and challenges. While this Master's research yielded some valuable insights into the phenomena of pregnancy, childbirth and early motherhood for Samoan women, it was with a small group of women from one area in New Zealand. Investigation with a larger sample that included Auckland city participants (which has the largest population of Samoans) and including interviews with key health professionals was an opportunity to evaluate the nuances and significance of the claims about 'sophisticated mediators' and resilience.

\section{RESILIENCE, SOPHISTICATED MEDIATION AND THE VĀ}

The concept of the Samoan self as a 'relational self' is clear in much of the literature on Samoan wellbeing in New Zealand. 'Teu le và' means caring and maintaining relationships, and keeping them strong. Relationships are the pinnacle of fa'asamoa (or Samoan cultural principles) and carry within them ideas of the vā. The vā, as a relational space (Wendt, 1999), is explained in the next chapter and is central to this thesis. It is a concept that focuses attention on the significance of relationships and the belief that it is central to all human activity.

Pacific writers have taken this notion of the vā and focused attention on the acts of negotiation that always takes place within (Mila-Schaaf \& Hudson, 2009a). To 'teu le vā', one has to first accept that a relationship (vā) exists and understand the character of the relationship (Anae, 2010, also see; Anae, Coxon, Mara, Wendt-Samu, \& Finau, 2001; Wendt, 1982). This is particularly relevant for understanding the birth of a new baby 
where new relationships and connections will form. I argue that taking care of the relationships between the FTSMs and others is critical. These relationships locate themselves largely in the family environment, but as Bronfenbrenner's ecological model illustrates (see Chapters Three and Eight), also include a wide array of other environments, all closely interlinked during the early motherhood stage of a first-time mother's experience.

Samoan women have been negotiating between their Samoan and New Zealand worlds since contact (Anae, 1998; Southwick, 2001; Tupuola, 1998). The experiences of New Zealand-born Samoan women living in New Zealand today suggest palpable shifts in ways these negotiations take place. My research explores this claim in relation to firsttime mothers and contributes to the movement towards nurturing and creating a New Zealand-born world view', one that privileges the location of their voices as New Zealand FTSMs.

\section{THE STUDY}

The research focuses on New Zealand-born Samoan women living in New Zealand and their maternity journeys as they experienced it for the first time. It explores the interplay of relationships and coping strategies utilised by these first-time mothers through pregnancy, labour, childbirth and early motherhood. The research contributes to the growing body of literature within Pacific studies by offering specific knowledge of the experiences of motherhood from a Pacific ethnic group. Literature on motherhood within the Pacific, including New Zealand, does not yet provide an understanding of Samoan women who are positioned within differing cultural frameworks as they embark on motherhood. The ability of this group of Pacific mothers to negotiate these tensions has received little scholarly attention and their specific experiences mediating the different worlds that come together during their transition from single womanhood to early motherhood.

What began as an investigation of the intersection between resilience and risk factors for Samoan women living in Aotearoa/New Zealand during pregnancy, childbirth and early motherhood, changed slightly during the course of the research life. The spaces for negotiation, the vā, that flows and intersects throughout this thesis has been drawn out to help nuance the kind of resilience against adversity generated and experienced by the FTSMs. 


\section{RESEARCH QUESTIONS}

The research questions of the study are:

- What are the experiences of a group of first-time New Zealand-born Samoan mothers before and after birth?

- What factors did first-time Samoan mothers consider significantly influential during their transition to motherhood?

- What are the implications for policy and maternity health service delivery for first-time mothers?

The overarching goals of this research are to articulate how Samoan first-time mothers give meaning to their experiences of pregnancy, labour, childbirth and early motherhood; how they reconstruct their world and themselves following childbirth; how they identify coping strategies, and how their expectations of birth and motherhood contrasted with their reality postbirth. The wider goal of the study is to contribute to further development of the field of Pacific studies by extrapolating from this empirical knowledge information of relevance to existing public policy around maternal mental health and wellbeing in New Zealand for Pacific women.

\section{THESIS OVERVIEW}

The thesis explores differing Samoan and New Zealand knowledge constructions of pregnancy, childbirth and early motherhood from New Zealand-born Samoan women who are first-time mothers, grandmothers, and maternity health professionals. The central thread within this thesis is the first-time Samoan mothers' voices.

The thesis has eight chapters. The introductory chapter provides an outline of the key concerns of the thesis, and its significance to Pacific studies research. A description of the goals, research objectives and rationale for the study, the research questions that guided the fieldwork, data collation and analysis are included.

Chapter two sets out the background conceptual context for the thesis by providing relevant demographics; a brief account of Samoan migrant history to New Zealand; academic analyses of the New Zealand-born Samoan identity; and a review of the field of Pacific studies, of the literature on both individual and family resilience, and of the key concepts of the vā, negotiated space, and sophisticated mediation. 
Chapter three outlines the methodological issues and theoretical underpinnings of this thesis, including the methods utilised to undertake the research, ethical issues, recruitment approach and analytical frame.

The next four chapters have been organised according to the four maternity stages of the FTSMs' early motherhood journey. Chapter four starts with the transition of not being pregnant to then conceiving and experiencing pregnancy. In tracing this transition, the chapter explores the FTSMs' contraceptive use and asks questions about whether the pregnancy was planned or unplanned.

Chapter five explores the FTSMs' experiences of labour and childbirth. It signals the importance of birthing spaces and reflects on the vā that operates within these spaces, and discusses the support strategies adopted by the FTSMs within these spaces.

Chapter six presents the FTSMs' experiences of the postbirth period up to the first 12 months of early motherhood.

Chapter seven discusses the intergenerational and professional relationships that exist in the transition to motherhood and the evolving and constantly negotiated nature of those relationships.

Chapter eight concludes the thesis by drawing together the key findings from the study. The chapter provides recommendations and suggestions for future research, and discusses the limitations of the research. 


\section{CHAPTER TWO: BACKGROUND}

\section{Pacific STUdies}

Whether our work matters to the people we work on or work with, at the end of the day, whether we are studying/writing about/reflecting on the Pacific in the Pacific or far, far away, our work must matter to us... (Teaiwa, 2006, p. 72)

Defining Pacific studies within a research context ensures there is a commitment to indigenous ways of knowing that is not only interdisciplinary in nature but also involves comparative analyses (Diaz, 2004; Teaiwa, 2010a). Metaphorically, it has been referred to as a 'canoe through which extensive and systematic interdisciplinary and academic focus on the Pacific has taken place - one that finds a new generation of Pacific Islander scholars' (Diaz \& Kauanui, 2001, p. 322). Wesley-Smith offers a way to understand the complexities of not only defining what Pacific studies might look like, but provides a way forward by exploring ways of researching the Pacific/about the Pacific/within the Pacific (Wesley-Smith, 1995).

Pacific studies embraces differing perspectives and world views, encouraging interdisciplinary work but, in order to succeed in this approach, as Hviding comments, it should 'cause the epistemological, methodological, and institutional boundaries between disciplines to be disturbed' (Hviding, 2003, p. 43). Pacific studies does not totally reject the values of Western social science but advocates for indigenous knowledge and ways of knowing. In addition, Teaiwa argues that to be interdisciplinary, account and make a commitment for indigenous ways of knowing, and involve comparative analysis' as 'comparative analysis' is the backbone of Pacific studies (Teaiwa, 2009, p. 2). This thesis straddles an approach to Pacific/Samoan ways of knowing with Western social science. It draws from several disciplinary knowledge bases in the commitment to and recognition that interdisciplinarity is about far more than simply adopting certain approaches and tools used by other disciplines; it involves research problems to which no single discipline has an answer' (Hviding, 2003, p. 62).

Critical self-analysis is part of what constitutes Pacific studies (Teaiwa, 2009). Meleiseā succinctly outlines this viewpoint: 
It is time for us to get past pre-formulated solutions and a mentality that would blame everything on to imperialism and the colonial inheritance. It is so much easier to blame the world system for all our problems. It is more difficult to look carefully at what we had once and have now. It is more painful to face and carefully compare our very limited choices. It is harder to look critically at the way in which we ourselves have made choices prior to, during, and since the colonial period. It is harder still to ask why we made these choices and ask whether we might have other options. (Meleiseā, 1987, p. 152)

The key point made by Meleiseā is about improving ourselves by acknowledging our past, we accept our problems in a way that can help us to move forward, to reflect and take responsibility for ourselves. In line with Teaiwa's formulation of Pacific studies having an indigenous focus, Konai Thaman provides a practical 'how to do' in her comments below:

Focus on the impact of colonialism on people's minds, the ways of knowing, their views of who and what they are, and what they consider worthwhile to teach and to learn. Challenge the dominance of Western philosophy, content and pedagogy in the lives and the education of Pacific peoples. Reclaim indigenous Oceanic perspectives, knowledge and wisdom that have been devalued or suppressed. (Thaman, 2003, pp. 16, 17)

Pacific scholars of each Pacific Island have, and continue to, write in-depth about what constitutes Pacific Studies, or to unravel the complexities that have shaped and continue to sculpt Pacific Studies. The collective knowledge that covers a broad range of perspectives, opinions, articulations, facts and truths, has, at the very least, stimulated discussions that can only increase and further develop knowledge about the Pacific and, therefore, add to the growing literature/thinking about Pacific studies (FairbairnDunlop, 2008b; Hviding, 2003; Nabobo-Baba, 2006; Thaman, 2003, 2008).

The development of Pacific studies evolved out of a need for cultural revival, reassertion of cultural identity, or a reclamation and reassertion of cultural identity, not only for the past but for the future (Firth, 2003).

\section{DeColonising PaCific STUdies}

Decolonising Pacific studies is a way of gaining emancipation from governing discourses, a way to challenge the dominance of Western philosophy, reclaiming indigenous perspectives and knowledge, and reasserting cultural identity (Firth, 2003; 
Thaman, 2003). Thaman writes that 'a paradigm shift and a search for multiple perspectives and alternative ways of looking at the world will enrich and enhance our understanding of Pacific studies, not diminish or degrade it' (Thaman, 2003, p. 13). Similarly, Pacific anthropologist and novelist Epeli Hau'ofa suggests a change of perspective and mind-set provides a place from which we can get closer to a view of ourselves in a context of time and place (Hau'ofa, 1994). Vilsoni Hereniko recalls his experience of his mind being 'colonized' by church and schools where reading and writing was taught to the demise of 'oratory' history (Hereniko, 2000). The value of written history over oratory history or, referred to by Wendt as "whitefication" of the colonised by a colonial education system' (Wendt, 1982, p. 209). This concerned Hereniko until he used the written word as a tool that 'displaced the stories of my colonizers and replaced them with those of my ancestors' (Hereniko, 2000, p. 83).

In his influential and provocative essay 'Our Sea of Islands', often referred to, Hau'ofa argues that 'smallness is a state of mind' and that language has the power to disempower or reinforce established 'social stratification along ethnic divisions' (Hau'ofa, 1994, p. 152; Wesley-Smith, 1995). In critically reflecting and questioning his own self-confessed misgivings and narrow views of the Pacific, he uncovered the dangers of living within the boundaries set by others. He claimed 'language' maintains the power difference and inequity between dependency and independency, particularly in relation, or in response to, the operational workings of the Pacific region. Only after critiquing his own thought processes, did Hau'ofa realise that his perceptions about the Pacific Islands and their dependency were created, dominated and taught by Western scholars and stunted any ideas of self-determination or autonomy for the Pacific, with silencing of indigenous knowledge and history by the oppressive nature of colonialism (Hereniko, 2000). Hau'ofa, who was lecturing at the University of the South Pacific, was confronted by the disheartened reactions of his students, and questioned his unwitting promotion of 'neocolonialism' (Hau'ofa, 1994). Lecturing young people about the hopelessness of their countries placed Hau'ofa at a crossroads between viewing the Pacific through a Western lens rather than a Pacific lens. Only then did Hau'ofa challenge, deconstruct, reframe his 'new perspective' of the Pacific and present it to others (Hau'ofa, 1994, p. 151). Hau'ofa firmly believed in his new perspective and his commitment to telling others at the possible expense of unpopularity and academic isolation. In choosing the term 'perspective', Hau'ofa avoids the premise that there is only one truth, and purposely promotes the concept that there is more than one, or at the very least, an acceptance that 'truth' not only comes from a range of sources and perspectives but is fluid (Crotty, 1998; Hereniko, 2000). A new vision was created. Hau'ofa's self-evaluation gave promise to Pacific researchers and educators so that we 
continue to develop, evolve and be critical and open to critique throughout our careers (as he did), to continue to be curious and promote healthy critical discussions.

Hau'ofa's new perspective encouraged researchers, students and teachers of Pacific studies to view our history from our standpoint and to perceive and think beyond the boundaries, physically or metaphorically set by others. Hau'ofa demonstrates the impact of the term smallness and eventually debunks the linguistic view that had misrepresented the actual vastness of not only the seas but of the economic and geographical positions of the Islands in relation to immigration and reciprocity between diasporic peoples. Hau'ofa references the negativity that is often attached to the Pacific Islands receiving aid and remittances from larger countries. The dependence of these countries had become, as Hau'ofa argues, neocolonist and 'internalised' knowledge transmission across generations perpetuated the state and mind-set of 'smallness' (Hau'ofa, 1994, p. 152).

In defence of remittances sent to the families in the 'homeland', Hau'ofa argues these are reciprocal exchanges rather than one-way traffic and the 'social centrality of the ancient practice of reciprocity' warrants the act as 'interdependence' for both parties rather than dependence of one (Hau'ofa, 1994, p. 157). This resonates with many diasporic communities. In essence, Hau'ofa deliberately sets his 'new perspective' from a strengths-based position of viewing the Pacific Islands to correct the misinterpretation. He replaces Pacific with the word Oceania as Pacific is synonymous with smallness:

The world of Oceania is neither tiny nor deficient in resources. It was so only as a condition of the colonial confinement that lasted less than a century in a history of millennia. (Hau'ofa, 1994, p. 156)

In redefining or replacing 'Pacific' with Oceania, Hau'ofa demonstrates and symbolises not only the geographical vastness of the Pacific but also the human connections, the collective nature that Oceania provides through kinship and family ties (Diaz, 2004; Hau'ofa, 1994; Teaiwa, 2001; Wendt, 1982). Hau'ofa states that anyone who has lived in, 'and is committed to Oceania is an Oceanian', perhaps a decolonised identity (Hau'ofa, 1998, p. 402).

In New Zealand, many Pacific families continue to support family members in Samoa and other Pacific nations and, in return, relatives maintain 'ancestral roots and land for travellers to return to permanently or to strengthen their bonds, their souls, and their identities before they move on again' (Hau'ofa, 1994, p. 157). There are stories of 
struggle and success. Many families are successful in providing for their families not only in New Zealand but have the economic capability to support families back in their homelands. Others, for many reasons, struggle with coping in the new environment, different cultural practices and beliefs and may find themselves in dire situations.

In a similar vein as Hau'ofa's new perspective, Gegeo highlights the tension between Western and indigenous ways of knowing but, in particular, with regard to rural development in the Pacific (Gegeo, 1998). The 'I know best' of the colonial governments at the time ignored any type of collaboration with the local people regarding development of their land even though the traditional owners articulated concerns. Gegeo argued for the 'silent voices to be recognised as legitimate and deserving to be heard' (1998, p. 309). Gegeo defines indigenous knowledge as an integration of 'traditional' and 'introduced' knowledge. In relation to the Kwara'ae peoples theorising about rural development, Gegeo specifies that indigenous epistemology' refers to a cultural group's ways of thinking and of creating and reformulating knowledge using traditional discourses and media of communication (for example, face-to-face-interaction) (Gegeo, 1998).

Indigenous knowledge and epistemology are important in developing and making sense of how knowledge is produced, constructed within a specific indigenous context and contemporary present (Nabobo-Baba, 2006; L. T. Smith, 1999; Tui Atua, 2005). Smith identifies that 'the struggle for the validity of indigenous knowledge may no longer be over the recognition that indigenous peoples have ways of viewing the world which are unique, but over proving the authenticity of, and control over, our own forms of knowledge' (1999, p. 104). Smith proposes that future indigenous peoples continue to seek, defend and protect indigenous knowledges and cultures.

Understanding what indigenous knowledge is or how it is constructed, is a concern about the loss of indigenous and traditional knowledge, in particular the passing down or transfer to a new generation (Gegeo, 1998; Tui Atua, 2005). Tui Atua Tupua Tamasese Taisi Efi advocated for a collective effort to ensure the preservation of cultural knowledge, particularly for the maintenance of Pacific indigenous knowledges 'outside of our homeland' (2005, p. 67):

What matters in the pursuit of indigenous Pacific knowledges is that it survives - and survives because it gives us meaning and belonging. Everything else is clutter. (Tui Atua, 2005, p. 68) 
In addition, Hereniko proposes the researcher should abide by an integrity and commitment to transformative research; not easy in practice.

The researcher in the Pacific who is not committed to empowering the native people as they struggle to transform social injustices and inequalities is, ultimately, an agent of the status quo. (Hereniko, 2000, p. 88)

In her work with Samoan women in New Zealand, Tupuola questioned the promotion of Western theories blanketing indigenous experiences. Her decision to use Samoan terms was met with resistance from many Samoan and non-Samoan academics. They challenged her commitment to prioritising Samoan methodologies, terms and knowledge over Western theories and thought, even going as far as branding her work as 'unscholarly' (Tupuola, 2002, p. 167). Tupuola suggests this problematisation of maintaining the dominance of Western terms and concepts can be overcome, or at the least, minimised:

Indigenising Western psychological terms is one approach suggested here for emphasising the local and creating alternative forms of knowledge. (Tupuola, 2002, p. 168)

Teaiwa argues similarly on the continuation of promoting indigenous knowledges in ways which should promote Pacific investigations:

What I do know is that we must not stop our investigations, explorations, ruminations in Pacific studies simply because the world marketplace of knowledge does not value the region as we do. Neither must we give in to the tempting rhetoric of Pacific exceptionalism our greatest crime would be to ghettoize ourselves... it is better to have attempted an inappropriate analogy and a false homology than to have ignored all possible points of comparison. (Teaiwa, 2006, p. 83)

\section{PACIFIC STUDIES AND MY RESEARCH}

Instead of focussing on how individuals or families have failed, it is important for Pacific studies research to find ways to redirect attention to how they can succeed or how they manage and succeed (Glassman \& Eisikovits, 2006). Several key factors motivated me to position my research in Pacific studies. Previous research with Samoan mothers produced more questions than answers and further piqued my curiosity and desire to learn more about the phenomena of pregnancy, childbirth and motherhood 
from the perspective of Samoan first-time mothers. Intergenerational knowledge and how it is shared with others is connected to how knowledge is constructed and this warranted further exploration.

Wesley-Smith (1995) advocates a new emphasis on interdisciplinary forms of scholarship and, in doing so, identifies three rationales (pragmatic, empowerment and laboratory) for studying the Pacific. I am interested in informing policy decisions and addressing public health concerns in relation to the health and wellbeing of Samoan women. This is practical and situated alongside Wesley's pragmatic approach which advocates 'national interest' (Wesley-Smith, 1995, p. 120). The intention of the study is to better the lives of Pacific women, which a strength-based approach to research fits. In addition to the empowerment rationale, it may also mean the research enquiry reflects an honest approach and a 'willingness to be critical' in the examination of issues from as many perspectives as possible. Furthermore, although Pacific studies may be 'small fry' (Teaiwa, 2009), research is also about strategy and like 'David and Goliath' it is not size that matters but being smart about what is to be achieved. As my research has progressed, the more specific the contribution to the broad and diverse nature of Pacific studies has become evident.

Each of Wesley-Smith's (1995) rationales for studying the Pacific have their own constituency and legitimacy. Wesley-Smith believes that Pacific studies should encourage and develop a 'true' interdisciplinary approach to research in which the defining object of inquiry should empower the region and, according to Hviding, in a way that can include a range of processes across the cultural, the social, the political and the ecological (2003, p. 66). Pacific studies takes account of 'globalisation' in terms of where we are in the world, as there may be a danger of valuing and recognising 'mainly Anglo-American knowledge, values and practices' over 'indigenous knowledge and wisdom' (Thaman, 2003, p. 7).

\section{Pacific People in New Zealand}

Samoan women are part of an ethnic minority group within New Zealand. Currently, the estimated resident population of New Zealand is 4.47 million (Statistics New Zealand, 2013a). Of those, almost 296,000 people identified with one or more Pacific ethnic groups (7.4 percent of the total population)(Statistics New Zealand, 2013a). The rate of growth has slowed recently with 14.7 percent growth between 2001-2006 compared with 11.3 percent between 2006-2013 (Statistics New Zealand, 2013b). The slowest growth rate was for Samoans (9.9 percent) compared to the largest increase in growth for Tongans (19.5 percent). 
The label 'Pacific' is a pan-Pacific classification that encompasses groups, people, and countries whose homes are located in the Pacific Ocean. The Pacific population is as diverse as it is similar. Describing people within a socially constructed term as 'Pacific' is a way of distinguishing this group from other ethnic groups. It is important to account for the diversity of cultures and peoples both within the Pacific classification as used in New Zealand, and within the ethnic specific groups themselves. This is particularly important to recognise and acknowledge when creating policies or services that are ethnicity based.

The Pacific population in New Zealand incorporates at least 13 distinct languages and cultural groups and includes people born in the Pacific Islands and in New Zealand. The many Pacific ethnicities are represented primarily by Samoan, Cook Islands, Tongan, Niuean, Fijian and Tokelauan groups, with smaller numbers from Tuvalu, Kiribati, Papua New Guinea, Vanuatu, the Solomon Islands and the small island states of Micronesia (Statistics New Zealand, 2008b). This can be seen as an example of the migration and globalisation phenomenon described by Castles and Miller where societies have become increasingly ethnically diverse and cosmopolitan (2009).

Demographically, Pacific people in New Zealand are characterised by high fertility rates, intermarriage, relatively high population growth and a youthful population. The Samoan ethnic group has remained the largest Pacific group, at just under half (48.7 percent) of the total Pacific population in New Zealand, with well over half (62.7 percent) being born in New Zealand (Statistics New Zealand, 2013b). The majority of all Samoans live in the North Island: Auckland region (67 percent) and Wellington region (16 percent) (Statistics New Zealand, 2008c). Pacific peoples are a young population with the lowest median age at 22.1 years, in comparison to Māori at 23.9 years and the general population (European) at 41.0 years (Statistics New Zealand, 2013b). Samoan women have high rates of fertility - they made up two-fifths (41.9 percent) of the total of Pacific women giving birth in 2011 (New Zealand Health Information Service, 2014). Mindful of the Pacific people's youthful population and high fertility rates, an increase in the population is more likely, as are the maternity services required for this population.

The social structure of Samoan society is underpinned by fa'asamoa ${ }^{2}$, an unwritten, yet understood and widely practiced, set of cultural conventions (Ngan-Woo, 1985). The

\footnotetext{
${ }^{2}$ Samoan way of life.
} 
governing system of fa'asamoa involves a system of rank and status that supports family and village life (Suaali'i-Sauni, 2007). Three principles underpin this system: ava (respect), fa'aalaolo (reverence) and alofa (love, compassion and concern). These form the basis of spiritual and cultural living within the fa'asamoa and are the prime motivational forces that safeguard family wellbeing (Fairbairn-Dunlop, 1998; NganWoo, 1985). The maintenance of fa'asamoa is seen as critical for future generations. It is up to the current generation to be tenacious in the future preservation of fa'asamoa. Religion plays a central part in the lives of Samoan people. The 2013 census reported 83.4 percent of the total Samoan population in New Zealand declared an affiliation to at least one religious denomination, while the Pacific and New Zealand populations with religious affiliation reported 79.7 percent and 55 percent respectively, a slight decrease across all groups (Statistics New Zealand, 2014a). Religious affiliations, language retention and knowing the self in relation to others - the vā - are elements critical to Samoan peoples and their traditions and culture.

\section{MigRATION}

Māori are the tangata whenua (people of the Land) of New Zealand. While there are no exact dates for the arrival of Māori, it is thought to be sometime between 950-1130AD. They were believed to be descendants of the Lapita people of Polynesia (Robinson \& Robinson, 2005). New Zealand was one of many islands, including Samoa, Tonga and Fiji, settled by Māori. In 1642, Dutch explorer Abel Tasman 'discovered' New Zealand, but it was not until 1769 that the British took possession of the land. It was some 71 years later in 1840 when the Treaty of Waitangi was signed between Māori rangatira (chiefs) on behalf of the Māori people and the British Crown (Pākehā) (Robinson \& Robinson, 2005). The Treaty covers a broad statement of principles and has evolved over time. One in seven people (14.9 percent) living in New Zealand in 2013 belonged to the Māori ethnic population, which shows a steady increase over the last two decades (Statistics New Zealand, 2014b).

The $20^{\text {th }}$ century has been characterised by global migratory patterns resulting in substantial social, cultural and economic changes in New Zealand. Within the Pacific, the migratory patterns were occurring even earlier, with Samoans networking with their neighbouring islands as voyagers with '4000 years of Pacific maritime history' (Salesa, 2003, p. 171). There continues to be a steady flow of migration, albeit controlled, from Samoa. Pacific scholars mark the end of World War II as the beginning of a new pattern in migration. In the late 1940s, very small populations of Pacific-born people lived in New Zealand. From the 1950s, the first significant wave of migrants began to settle in New Zealand as employers looked to the Pacific for unskilled and semi-skilled 
workers, and the demand for workers continued, particularly for low-skills labour, through to the 1960s (Fairbairn-Dunlop \& Makisi, 2003). This saw an increase in migration, particularly from Samoa, and more families migrating (Department of Labour, 2012). Key factors such as economic and health benefits and access to secondary and tertiary education drove much of the migration from Samoa to New Zealand. This coincided with the increase in seasonal-work schemes. The 1960s to mid1970s were considered by some as the 'peak years' of Pacific migration, community growth and consolidation (Fairbairn-Dunlop \& Makisi, 2003). The migration patterns continue but the make-up of the Samoan population in New Zealand has shifted to more New Zealand-born Samoans rather than new migrants.

\section{DIASPORIC COMMUNITIES}

The term diaspora derives from the Greek work speiro, meaning 'to sow', and the preposition dia, meaning 'over' - to sow over (Shuval, 2000). The term refers today not only to such groups as Jewish, Greek and Armenian people who live away from the place they see as their ancestral homeland, but to a much broader domain of people, including immigrants and expatriate political refugees. The term 'diasporic communities' is sometimes used interchangeably with 'ethnic minority communities' and/or 'overseas communities' (Tölölyan, as cited in Brubaker, 2005). As a social construct, the term diaspora has shifted, evolved, and stretched its meaning to accommodate various disciplinary understandings (Brubaker, 2005; Shuval, 2000).

Brubaker (2005) identifies three core elements in the concept of diaspora: (1) dispersion in space; (2) orientation to a 'homeland'; (3) boundary-maintenance. The first element refers to the forced or otherwise dispersion from their homeland. Here dispersion can happen even within state borders. The second element, orientation to a real or imagined 'homeland', includes 'maintaining a collective memory or myth, including regarding the ancestral homeland as the true, ideal home'; the third element involves 'the preservation of a distinctive identity vis-à-vis a host society or societies' (Brubaker, 2005, pp. 5-6). The interesting question with diaspora, as Brubaker notes below, is to what extent will successive generations maintain orientations to the homeland and to traditional boundaries, and to what extent will they redefine these boundaries and relationships with the 'homeland' but still stay connected and/or self-identify with it?

That migrants themselves maintain boundaries is only to be expected; the interesting question, and the question relevant to the existence of a diaspora, is to what extent and in what forms boundaries are maintained by second, third and subsequent generations (Brubaker, 2005, p. 7). 
Tölölyan (2012) argues to be 'careful' not to locate the diasporic's home in the ancestral homeland too easily. He referenced conversations from second- and fourth-generation immigrants' stories in the USA in which they articulated their positions in relation to the 'homeland' as commented by a participant: 'Israel is the homeland of my ancestors, not my homeland. After the USA, it is the world's second most important country for me, and its prosperity and security matter to me' (Tölölyan, 2012, p. 10). Other students articulated their reservations about claiming a diasporic identity: 'I know I'm Jewish. You know I am Jewish. The trouble is, the second I admit that, my mother and grandmother also know just what kind of Jew I should be, whom I should date, what I should do. I can't afford to be Jewish' (Tölölyan, 2012, p. 10). While the homeland and diasporic identity still matter, the students would not subscribe fully to them as they define, confine and prescribe their behaviour. This raises questions about how New Zealand-born Samoans might position themselves within the diaspora (Anae, 1998; Tiatia, 1998; Tupuola, 2004b).

Gershon (2007) argues that families sustain the diaspora and vice versa. The existence of a diaspora is in the culturally specific ways in which families circulate that knowledge. Gershon (2007) views Pacific Island diasporas as shaped by the culturally specific structures of family. She points to the way in which second-generation migrants are considered 'Samoan by those outside of the Samoan migrant communities, and considered not Samoan enough from the perspective of those constituting Samoan communities' (Gershon, 2007, p. 488). This contradiction is echoed by other scholars exploring Samoan identity formation (Anae, 1998, 2002; Macpherson, 1999; Macpherson \& Macpherson, 2000; Tiatia, 1998; Tupuola, 2004b).

Life for diasporic women, particularly those who are new migrants to a country, can be very difficult. Not only do they struggle with material and spiritual separation from their homelands and all the familiar supports there, but they are at the same time coping with the immediate demands of family and work life in their new 'homeland'. While immigrants may experience loss and nostalgia they are 'enroute to a new home in a new place' (Clifford, 1994, p. 307), therefore 'the discourse of diaspora will necessarily be modified as it is translated and adopted' (Clifford, 1994, p. 306).

It is important to understand what is meant by naming the Pacific communities of New Zealand a diaspora. In the diasporic space, Pacific peoples, Samoans included, are sometimes actively negotiating, sometimes more passively engaging, in shifts and 
changes to what is Pacific or Samoan for them and their families (Anae, 1997; MilaSchaaf, 2010; Southwick, 2001; Tiatia, 1998; Tupuola, 1998).

\section{NEW SAMOAN IDENTITIES}

In his description of 'New Samoan Identities'. Macpherson writes about many migrant Samoans who were re-evaluating what it meant to 'be Samoan'. Macpherson argues that the way in which 'Samoanness' was embraced by those early migrant groups was diverse.

Reflected in the content and the ways they transmitted 'Samoanness' to their New Zealand-born children. Some attempted to establish their language, lifestyle and world view in their children. Others attempted to distance their children from all of these. (Macpherson, 1984 as cited in Macpherson, 1999, p. 56)

The implication for many of the children of these Samoan families was that some could identify closely and could engage fluently with traditional markers of Samoan culture and identity, and others could not. Macpherson argues that ethnic identity categories, such as that of being Samoan, are problematic as they suggest a certain fixedness that is fluid in reality. Naming a Samoan identity has been made necessary, first by colonialism and, more recently, by migration. Its central elements have been constructed by a population faced with a need to define itself in terms that reflect the new and shifting conditions of their lives (Macpherson, 1999, p. 52).

Discrimination against Samoans in New Zealand in the early 1970s led many Samoans, particularly the earlier migrants, to distinguish and distance themselves from the more recent arrivals who, according to Macpherson, were 'typically associated with criminal conduct' (1999, p. 55). In his work on Samoan ethnic identities, Macpherson identifies what he called Samoan sub-identities. The key one was the 'afakasi or part-Samoan, part European identity, harking back to colonial times where 'afakasi was associated with political, social and economic privilege. Macpherson refers to the formation of a social group made up of Samoan/part-European migrants, named the 'Pioneer Society' that implied that as part-Europeans they were more familiar with the ways and norms of New Zealand society and therefore were less likely to be involved with Samoans who participated in anti-social and criminal activity (Macpherson, 1984). There is anecdotal evidence of a Wellington club called the 'Pioneer Club' that was made up of about six or seven recent migrant couples who were part of the 'first wave' of Samoan migrants in the 1950s. The intention of the group was to maintain social ties with the Samoan 
community by holding large social gatherings. The group formally established themselves and had a chairperson, treasurer and members. The group members were from 'afakasi, part European/Samoan' families. The members came to New Zealand to finish their education and were all employed working in health, banking, corporate, and the advertising fields (Churchward, A., \& Meredith, S., personal communication, 2014).

Identity, ethnic or social, is fluid and dependent on context and time; it is not fixed or static through a person's life (Bedford \& Didham, 2001). It is a concept that is constantly shaped, influenced by the environment and the world we live in (Macpherson, 1999). Multiple identities are no longer restricted to migrant communities. Key Pacific authors have discussed in depth the issues of identity formation and ethnicity (for example see Anae, 1997; Anae, 1998; Keddell, 2006; Mila-Schaaf, 2010; Mila-Schaaf \& Hudson, 2009a; Tiatia, 1998; Tupuola, 1998, 2004b, 2006). Phinney remarks that ethnic self-identification is complex: 'Adolescents and adults can be assumed to know their ethnicity; the issue is thus one of choosing what label to use for oneself. Although this appears to be a simple issue, it is in fact quite complex, inasmuch as one's ethnicity, as determined by descent (parental background), may differ from how one sees oneself ethnically.' (Phinney, 1990, p. 503). Individuals need a sense of group identification to maintain or achieve a sense of well-being (Lewin 1948 as cited in Phinney, 1990, p. 501) and positive social identity (Tajfel \& Turner, 1979, p. 8).

The importance of social identity in New Zealand is emphasised by Samoan families. 'Individuals need a firm sense of group identification in order to maintain a sense of well-being' (Lewin 1948 as cited in Phinney, 1990, p. 501); and 'strive to achieve or to maintain positive social identity' (Tajfel \& Turner, 1979, p. 8). Phinney argues the process of identity formation is similar to ego formation and happens at a time when people are questioning, identifying or making decisions about 'the role of ethnicity in their lives' (Phinney, 1990, p. 502). Identity formation is vibrant, changeable over time and context. It is socially established and maintained through interaction (Phinney, 1990). A firm sense of group identification means that the group had to be seen to be positive.

Macpherson (1984) provides an explanatory model for understanding the changing shape of migrant Samoan ethnicity by using the example of the relationship between family, language and culture. He argues that in one environment there is a primary alignment in Samoan families with Samoan values and institutions. In this environment children are more likely to be similar to their Samoan-born peers. The environment is dominated by Samoan language, values, personnel and activities in which parents and 
others in the environment actively promote the importance of Samoan culture. Samoan culture is explicitly and implicitly represented as being 'morally and socially superior' to non-Samoan cultures. The second environment involves families that do not place Samoan values as highly and they are not as stringently or deliberately promoted nor criticised. Samoan culture exists alongside non-Samoan culture and children regard Samoan culture as one of several other cultures they live within. There is a common belief that they are Samoan and that it is a valued identity but is one among others. The final environment is almost the antithesis of environment one, in that a conscious effort is made by families to curtail the amount of their exposure to and involvement with Samoan values and institutions in an attempt to promote non-Samoan culture. Children are more likely to try varying degrees of opposition to anything Samoan. The environment is dominated by non-Samoan language, values, activities and personnel. The three environments or spaces described by Macpherson highlight the importance of family and home life in constructing ethnic and social identities.

The mode of transmission of the Samoan language and cultural knowledge from migrant parents to their New Zealand-born children, can foster or hinder their child's identification with 'being Samoan' (Macpherson, 1984). Macpherson's provocative article title: 'Will the "real" Samoan please stand up?' makes the point about the complex tensions and emotions associated with social and ethnic identity labels (Macpherson, 1999). It is illustrative of the perceived tension between New Zealand-born and Samoan-born Samoans. It strikes at the very nature of what it takes to be a 'real' Samoan, and perhaps more importantly, who decides the identity or ethnicity of a person. Macpherson argues that ethnic categories are problematic and will not necessarily reflect cultural realities within them; Samoan identities are fluid, and there is disagreement between migrant Samoans and their New Zealand-born children regarding constructing a national identity, with no agreement as to the symbolic meaning of culture (Macpherson, 1999).

\section{A NEW ZEALAND-BORN SAMOAN IDENTITY}

A New Zealand-born Samoan identity emerged from the distinctions felt by New Zealand-born Samoans about having more in common with each other than they did with Samoan-born Samoans. Macpherson suggests this may have emerged due largely to family orientations and, especially, loss of fluency in the language. This gives rise to the belief that New Zealand-born Samoan children are not 'true Samoans' as they 'have not mastered the knowledge, skills and language' (Macpherson, 1999, p. 57; Tiatia, 1998). 
The term 'fia Pālagi' or trying to be Pālagi ${ }^{3}$ is usually derogatory and used by older generations or island-born Samoans. In their study examining Samoan youth and their relationships with their families, Fa'alau and Jensen found that youth born in New Zealand or of mixed ethnicity reported feelings of 'alienation' due to feeling that they had to prove to others how Samoan they were (2006, p. 19).

Wendt considers assertions of a 'true' Samoan as essentialist, and dangerous:

To advocate that in order to be true Samoan, for example, one must be full-blooded Samoan and behave, think, dance, talk, dress and believe in a certain prescribed way, and that the prescribed way has not changed since time immemorial, is to be racist, callously totalitarian and stupid. This is a prescription for cultural stagnation, an invitation for a culture to choke in its own body odour, juices and excreta. (Wendt, 1982, p. 207)

Understandings of what it meant to be Samoan are constantly being redefined as engagement with new contexts, realities and imperatives occur, particularly for those born in New Zealand. During her research with young Samoan women living in New Zealand, Tupuola found that her participants were resistant to having an ethnic label 'imposed' upon them by their elders and peers. They were also critical of being labelled 'adolescent' (Tupuola, 1998). The suggestion was, like Albert Wendt, that such labelling was dangerous in that it presumed a homogenous essentialist starting point.

Many of these young women also refuted the ethnic label New Zealand-born Samoan', arguing that it dangerously essentialised and homogenised youth of Samoan ancestry in New Zealand. Moreover, identity is a sociocultural political construction, non-static in nature. (Tupuola, 2004b, p. 88)

Tupuola (2004b) describes these young people as 'edgewalkers': they are positioned between the edges of many identities and therefore walking the edges of these - ethnic, religious, generational, gender, class, and sexual identities, for example. The participants in her research illustrated their fluidity of identity and were confident in negotiating multiple cultures with 'relative ease' (Tupuola, 2004b, p. 88). Anae advocates that it was an identity that her participants described as reflective of their roles as mediators,

\footnotetext{
${ }^{3}$ Definition of Pālagi (it is the shortened version Papālagi) meaning: a foreigner (Pratt 1892); European, white man (Milner 1966) (Pratt 1892; Milner 1966, as cited in Asiasiga, 2007, p. 8).
} 
intermediaries, guardians, and bridges between their New Zealand and Samoan worlds, more than anything else.

The construction of a New Zealand-born identity... is that New Zealand-borns see themselves as "bridges", "mediators", "intermediaries", and "guardians" for the world of their Samoan parents and grandparents in relation to the wide society. (Anae, 1998, p. 352).

The first generation of New Zealand-born Samoans, argues Anae, paved the way for future New Zealand-born Samoan generations. The second and third generations of New Zealand-born Samoans learn to manage their dual responsibilities and relationships from the experience of their New Zealand Samoan parents. They are sensitive to the cultural needs of their parents, grandparents and families while positioning themselves within New Zealand society with conviction and ease (Anae, 1998). I argue that the older generation are also finding their 'space' within New Zealand society and, depending on the time they have spent here, they too are positioning themselves within a society.

According to Anae, the New Zealand-born Samoan label accommodates the 'pāpalagi life-ways and fa'asamoa experiences', the latter underpinned by family and church. The Christian church plays an important role in the lives of many New Zealand-born Samoans and is a central part of everyday Samoan family life in Samoa. The church operates for many Island-born or recent migrants in New Zealand as the space for reconnecting with and/or maintaining the Samoan language and culture in the diaspora, in New Zealand. Abel et al found that:

Pacific peoples in New Zealand continue to have strong family and church networks that support the continuation of many 'traditional' beliefs and practices. In the late 1990s, however, there was evidence of some inter-generational tension between Island-raised parents, who held firmly to these beliefs and practices, and their New Zealand raised children, who have begun to challenge them. (2001, p. 1137)

The Samoan community is a significant community in terms of size (compared to the other Pacific ethnic groups) and influence. They are part of the new New Zealand that Anae argues is not only becoming more 'brown' but also more educated, politically astute (on national and local levels) and even financially comfortable (Anae, 2004). 
Mila-Schaaf's (2010) research with successful, second-generation Pasifika professionals also points to a new and burgeoning Pacific middle class in New Zealand. These professionals, she argues, have been able to successfully negotiate their identities within the different cultural spaces they moved within. What allows them to successfully negotiate is what she calls 'polycultural capital' (2010, p. 2). Polycultural capital is associated with cross-cultural resources, knowledge, skills and agency. It is also associated with agency to draw purposively and strategically from more than one cultural way of knowing and interpreting the world. This strategic way of operating interculturally could not be accurately characterised in terms of cultural loss, liminality or marginalisation and was described by many participants as preferable to monocultural alternatives. (Mila-Schaaf \& Robinson, 2010, p. 14)

From her small study with those who had a Pākehā mother and a Samoan father growing up in the 1970s, Keddell found that her participants 'exercised the situational ethnicity' as articulated by her participant (B) who felt 'more Samoan with my Samoan family' and 'more Pālagi or European with my European friends' (Keddell, 2006, p. 54). The participant was not valuing one culture over another, nor was he presenting himself as being 'true' or 'false', rather both of his selves were true and the ability to move between cultures appropriately in different contexts did not threaten either, she argued (Keddell, 2006). Situational ethnicity is interesting as it postulates that identity is a social construct and moulded by structural forces which may be needed in order to gain political, emotional or material gain.

While New Zealand-born Samoans do have to negotiate what are often two opposing world views, not all experience a 'cultural dilemma or identity crisis', just as not all of them see themselves as a 'bridge' between the two cultures (Tupuola, 1998, p. 62). Margaret Southwick describes how 'mediating between discontinuous worlds' can create just as much tension as struggling to fit both worlds into their realm. Eventually, some are forced to choose one over the other in order to 'fit in' (Southwick, 2001, p. 80). Southwick describes how one of the women in her study was able to be successful in her mediation of these tensions:

She has found a way of mediating the tensions between her two worlds by simply acknowledging that they are different worlds and is very clear about not getting the roles muddled up. She makes no attempt to integrate them. They are separate and different and she moves with confidence between them. It is very likely that this clarity is what enables her to stand her ground. (Southwick, 2001, p. 98) 
Macpherson succinctly articulates the way New Zealand Samoans are constructing their own identity:

Samoan culture exists not in one place or the other but in a space between them where all of the different ways of being Samoan are contested and mediated. Young Samoans have the social space and confidence to redefine what it means to be Samoan and to challenge the notion that this must rest on what their parents have defined as core competencies. Freed of these constraints some migrant and New Zealand-born Samoans are taking elements of Samoan culture, filtering them through their own experiences and building them into a new and distinctive 'identity'. The process of redefinition is all around us in a range of forms. (Macpherson, 1999, p. 58)

New Zealand-born Samoans living in New Zealand of each new generation find meaning in their various identities in ways that are today arguably more negotiated, flexible and encompassing of many identities. For New Zealand-born Samoan women, gender and sexual identities may be negotiated alongside their ethnic and cultural identifications with their Samoan families and New Zealand society.

\section{CYBERSPACE IDENTITY}

The internet, social media, other media tools (cell phones) have changed the way in which modern Pacific countries and the Pacific diaspora stay connected, but are a new space with which to explore identity. Today, Samoan people all over the world connect in so many different ways, but especially through the internet. Discussion forums have been available for several years including Pacific specific forums such as Kava Bowl and Kamehameha Roundtable which form part of several online meeting places for the 'Polynesian diaspora', including those who live in New Zealand (Franklin, 2003). Franklin examined discussions within these forums and found recurring topics around 'identity' and how this relates to living overseas. Redefinition of what it means to be Tongan or Samoan in a diasporic context, understanding that cyberspace provides another platform or space with which Pacific peoples can discuss, challenge, express identities in a globalising and digital age, is important. The new 'space' created by technological advancement may have implications for Pacific concepts and the redefinition of connection and relationships

As Franklin found, new communication technologies have created new forums for expressing and asserting one's identity, for maintaining boundaries and for promoting 
ethnic and family inclusiveness. This new technology is used as much for professional educational information purposes as it is for social networking.

Changes in the way in which the vā is nurtured, and cared for, is interesting in the age of cyberspace and social media and how this impacts on the way in which Samoan people now stay 'connected' with each other. Relationships that were nurtured and maintained in 'physical place and real time' are now enabled through "cyberspace" in cyber-place and cyber-time' (Koya-Vaka'uta, 2012). The internet, social media, other media tools (cell phones) enable people to connect in several ways. The majority of Samoans living in New Zealand are young and have been brought up in the technological world of the web. There is not a lot of literature available examining the ways in which young people utilise such forms of communication. The cyberspace that allows for intergenerational family relationships will see new patterns of connections and relationships forming. Koya-Vaka'uta described these new redefined relationships as 'peculiar', (in reference to Facebook or Bebo websites) citing that 'none of first generation members (aged 37 -50) comment or rebuke the younger group online. Can we interpret this silence as acceptance of new terms of engagement online? Or a silent disapproval? Could this be because of perceived public 'space where the wider circle of friends' are able to view these discussions? Such 'sharing' of these topics and issues is inappropriate in real-time cultural family relationships but cyber-space enables a differential set of rules of interaction' (Koya-Vaka'uta, 2012, p. 4). Online reprimand may result in the first generation being defriended.

\section{GENDER IDENTITY AND FEMINISM}

The relationship between gender identities and feminism is for many Pacific women more academic than real. Issues of gender equality or equality between the sexes were issues canvassed by feminists, especially 'white' feminists, in ways considered culturally inappropriate for Samoan women.

An issue for contemporary feminism is the debate over difference, more so in relation to 'women of color' who have objected to the partiality of white, middle-class feminists who assume to include all women they speak of as 'we' (Hill Collins, 1989). An attempt in the mid-1970s was made to formalise a critical framework regarding the oppressive position of women in the Pacific at a conference facilitated by Vanessa Griffen (cited in Marsh, 1999). In the late 1980s, Vanessa Griffen, again, engaged with Pacific women in a workshop specifically aimed at assessing the needs and concerns in their lives (1989). The title of the workshop, Women, Development and Empowerment: A Pacific Feminist Perspective' generated powerful discussions and explored Pacific women's 
positions in political, social, economic, spiritual and cultural arenas. The narratives from these workshops provide a fascinating insight into the development of Pacific feminist thought based on the experiences of women living in the Pacific within the realms of culture, colonialism, and gender oppression (for example, see Griffen, 1989).

One of the main objectives of the Pacific workshops was to discuss what a 'feminist perspective' was and what meaning and relevance this held for women's lives in the Pacific (Griffen, 1989). The term 'feminism' initially conjured up 'irritations, negative responses and resistance' from the Pacific women as it was seen to be representative of Western women with Western ways, seen as individualistic and materialistic as opposed to 'communalist and spiritualist' (Jolly, 2005, p. 139). These were common contrasts perceived by Western and Pacific women involved in these movements. Where the first is imputed to be individualistic and antagonistic toward men, the latter is seen to stress community and gender complementarity. Because of this, Pacific women often refused the label feminist (Jolly, 2005, p. 139) and so did not explicitly employ feminist labels.

In addition, feminism was seen as being about discrimination against women and some of the Pacific women at the workshops actually did not see themselves as being oppressed (Griffen, 1989). There was shared agreement of the need to develop an approach that could pick up on the issues of inequality experienced by Pacific women. Some credit was given to a 'feminist ideology' that could be used to analyse the wider issues of Pacific women's struggles, e.g. ideas of structural inequality. Moreover, a Pacific meaning of 'sisterhood' was considered a significant concept to adopt as a way of gaining unity (Griffen, 1989). The value of the 'sisterhood' sentiment that had, according to bell hooks (hooks, 2000), been forgotten about by feminism could now be proclaimed anew in this Pacific space as a commitment to building 'sisterhood' and 'making feminist political solidarity between women as an ongoing reality' (hooks, 2000, p. 17).

The Black feminist movement faced similar issues to the Pacific feminist movement. Black Feminist Thought emerged from the oppression of African-American women in their struggle to create their own standpoint (hooks, 2000). In the last 30 years, 'feminists and women of color' have built, and continue to do so, a large body of work focussing on the concept of 'intersectionality' (Hill Collins, 1989, 1990), where interrelationships and the 'co-constructed nature of analytical categories such as race,

\footnotetext{
${ }^{4}$ Women of color, includes those commonly deemed as "black," that is, women of African and African American origin (Marsh, 1999).
} 
gender, sexuality, and class' are at the core of analysis (Kahaleole Hall, 2009, p. 16). The term 'womanism' was used to encourage African-American women to 'value their own subjective knowledge base' as women and to self-define their standpoint as African-American women (Hill Collins, 1989, p. 750). Womanism considers the intersection of multiple forms of oppression (including class, ethnicity and gender) that affect women in different ways (Campbell \& Wasco, 2000). Pacific women can be said to engage with feminism or at least with some feminist ideals without perhaps articulating it as such:

Pacific cultures all have a feminist strain. Women in the Pacific have always had a particular place - we call it 'farihana' which means 'the house we are going to live in'. The man (male) world is represented by the word 'tohkamo'. (Lata, Tongan participant as cited in Griffen, 1989)

Western feminism is seen as a threat to what has been argued is the Samoan women's traditional seat of power (Marsh, 1999). Selina Marsh, and other Pacific scholars, highlight that what differentiates Pacific people's world view from those of the Western world is "the individual "I" is almost inseparable from the communal "we" (Marsh, 1999, p. 675; Tiatia, 2003). This echoes discussions about the 'Samoan self' as having meaning only in relationship with other people; the 'self' does not exist on its own, it exists as an inseparable part of the whole, the collective, the family, the village, the nation (Marsh, 1999; Mila-Schaaf \& Hudson, 2009a; Tamasese, Peteru, Waldegrave, \& Bush, 2005).

In the 1930's pastors' wives began to take a more formal role in organising church affairs. This brought them into public decision-making roles for the first time which strengthened their status within the village even further (Fairbairn-Dunlop, 1998). This was an important step toward the visibility of Samoan women in public leadership roles in the new Christian Samoa. Stewart-Withers (2011a) research on female-headed households (i.e. households headed by females even when a male is living in the household) in Samoa showed that having female leadership in the home is not alien to Samoan society. They do this successfully so that their capabilities as family or church or village or national leaders have never been totally dismissed as ideologically impossible by their male counterparts. In relation to Samoan woman and feminism, one can relate to Konai Thaman's words:

I was a feminist long before the movement came along, and my grandaunts were feminists before the word feminist became part of 
my vocabulary. So now when people ask, are you a feminist, if feminism is about equality, equal worth, then, yes, I am a feminist. (Wood, 2008, p. 7)

\section{SPACES FOR NEGOTIATION SOPHISTICATED MEDIATORS}

Patricia Hill Collins (1986) first coined the term 'sophisticated mediators' in which she refers to the child-rearing practices of black mothers, particularly the effectiveness of their parenting practices in dealing with or working between competing ideals of the dominant American culture and the Black value-structures (p. 183).

The theoretical concept of 'sophisticated mediators' 5 ' was identified in my Master's study highlighting the resilience of the mothers in the face of adversity (Churchward, 2011). The women were able to identify their needs as mothers before selecting appropriate solutions from the resources available to them from their Samoan cultural system and their New Zealand culture at both a social and individual level.

\section{THE VĀ}

An early definition of the word vā can be found in the 1911 Pratt's Grammar and Dictionary of the Samoan Language which describes vā as 'a space between' (LilomaiavaDoktor, 2009, p. 12). It is a concept that is used to refer to the space between two entities, usually living, as between people but could also be between people and animals, people and the environment, people and the cosmos, people and their gods or God. This space is, as Albert Wendt says, not empty but active; it is relational and holds entities together.

$V^{-}$is the space between, the betweenness, not empty space, not space that separates but space that relates, that holds separate entities and things together in the Unity-that-is-All, the space that is context, giving meaning to things. The meanings change as the relationships/the contexts change. A well-known Samoan expression is 'Ia teu le vā.' Cherish/nurse/care for the vā, the relationships. This is crucial in communal cultures that value group unity, more than individualism: who perceive the individual person/creature/thing in terms of group, in terms of vā, relationships (Wendt, 1999, p. 402).

\footnotetext{
${ }^{5}$ The redefinition of this term is specifically in relation to New Zealand-born Samoan women and the concept does not ascribe a higher value for the Samoan value-structure over the dominant culture system of New Zealand. Rather, the concept provides the women with a resilient standpoint.
} 
Samoan relationships are interdependent and 'holistic' in nature, and emerge from within an understanding of relationships as spiritual and interconnected (LilomaiavaDoktor, 2009). The vā is a 'sacred or relational space', a space that we 'feel' as opposed to 'see' (Mila-Schaaf, 2010). It explains and embodies the inextricable links Samoans draw between the 'I' and the 'we'. The và is all-encompassing of Samoan constructions of reality, of social and ethnic identity, of belonging, of all those things that bring and hold people and their environments together.

Melani Anae acknowledges the caring and nurturing aspects of the vā in her naming and theorising in her educational research model, aptly titled, 'Teu le vā' (meaning caring, nurturing the vā) (Anae, 2010; Wendt, 1999). Albert Refiti suggests that the vā is also about 'co-openness' rather than just 'betweenness', that in the vā there is an opening up of oneself to existing and pre-existing relationships, and that through this opening up, we are oriented to a collective identity that moves between and/or transcends time. He explains:

When you take a place in the ring that forms the circle of fa'amatai you are opened up to encompass the time and space of the ancestors, you belong to the time of others. The time of the world ceases to be in the ring. This conforms to the Polynesian concept of time, which suggests that we move towards a future by orienting our being to a collective opening that continues with us. (Refiti, 2013, p. 5)

This space, the active in-between space of the vā, is where 'everything is possible' but in both 'a positive and negative' way (Mila-Schaaf, 2010, p. 135). The value of the vā to this thesis is its flexibility and applicability as a descriptive term and analytical frame for understanding relationships within New Zealand-born Samoan social spaces. Suaali'iSauni describes the vā as a valuable tool even for understanding evaluation processes and relationships. She posits the reason for prioritising the vā in evaluation research is 'because we acknowledge that relationships are at the centre of any human activity' (Suaali'i-Sauni, 2014, Slide number 18).

\section{A NEGOTIATED SPACE}

The concept of a 'negotiated space' was first coined and theorised by Linda Smith and Maui Hudson (Mila-Schaaf \& Hudson, 2009b), and then introduced by Mila-Schaaf in reference to her exploration of a Pacific epistemology (2009). Negotiated space is a conceptual model describing the interface between different world views and knowledge 
systems, namely what the authors describe as Māori and Western science (Mila-Schaaf \& Hudson, 2009a). In its original context, the model relates to kaupapa Māori research whereby the authors claim that:

Research is a social project; it weaves in and out of Māori cultural beliefs and values, Western ways of knowing, Māori histories and experiences under colonialism, Western forms of education, Māori aspirations and socio-economic needs, and Western economics and global politics. Kaupapa Māori is concerned with sites and terrains. Each of these is a site of struggle. (L. T. Smith, 1999, pp. 190-191).

This resonates with Wendt's idea of the vā as 'in betweenness' (Wendt, 1999, p. 402).

In applying the negotiated space concept to Pacific epistemology and mental health, Mila-Schaaf and Hudson (2009a) illustrate the different sites that Pacific peoples have to weave in and out of when dealing with the bio-psycho-social models of Western medical science alongside their own understandings of mental health. They state that the 'negotiated space' is that space that 'provides opportunities for people to negotiate their relationship with existing and new cultural knowledge; with different systems of meaning and knowing, with culturally distinctive parties, and how individuals manage cultural choices that arise from having awareness and access to more than one culture' (Mila-Schaaf \& Hudson, 2009a, p. 117).

The most attractive aspect of the sophisticated mediation and negotiated space concepts for this study is the strength-based approach they allow for. The idea that 'Pacific peoples have the agency and ability to choose from multiple knowledge bases' to help them resolve cultural conflict, as 'opposed to being trapped between cultures' (Mila-Schaaf \& Hudson, 2009a). Mila-Schaaf and Hudson (2009a) argue the model is useful between 'paradigms' in that the negotiated space has applicability when thinking how Pacific individuals and families in New Zealand live their intercultural realities (p.117).

In telling their stories, one of the authors of 'Being 'Afakasis' described having 'two different sides' to her identity and the difficulties she faced with not having a place to really 'be with that', which consequently left her with profound feelings of 'existential loss which underpins my being' (Berking, Fatialofa, Lupe, \& Skipps-Patterson, 2007, p.

\footnotetext{
${ }^{6}$ Samoan term used to describe a person of Samoan and Papālagi (Caucasian) descent.
} 
58). These feelings of loss, of not quite belonging, of being pulled between two worlds, the risk of being faithful to one meant the relinquishing of the other appear in much of the literature around cultural identity (Anae, 2002; Southwick, 2001; Tiatia, 1998; Tupuola, 1998). Negotiating these feelings of loss and coming out of the process feeling still in control of one's senses is empowering. Indeed, as Teaiwa and Mallon (2005) argue, seeing and negotiating those complex social and cultural relationships, sometimes all encompassing, sometimes 'liminal', can be productive and a strength that provides a position of stability:

Pacific people inhabit a social and cultural space in between the tangata whenua and Pākehā and other immigrant groups in New Zealand, and they have negotiated a complex and shifting set of relationships with other groups and communities. Sometimes the space in between, some state of liminality, can be an anchoring point or a productive site for addressing the instabilities of social and cultural life. (p. 225)

\section{RESILIENCE}

Resilience involves 'struggling well' and finding the energy and fortitude to keep it together despite difficulties or feelings of suffering. Resilience is about courage to effectively work through difficulties both internally and interpersonally. In forging resilience, 'we strive to integrate the fullness of a crisis experience into the fabric of our individual and collective identity, influencing how we go on to live our lives' (F. Walsh, 2006, p. 6).

Resilience has been viewed in terms of personality traits and coping strategies, 'a biological hardiness' acquired from one's own initiative and good fortune (F. Walsh, 1996, p. 2). Resilience is both a characteristic of the individual and a quality of that individual's environment which provides the resources necessary for positive development despite adverse circumstances. A theoretical shift in focus from resilience as individually characterised to reflecting protective factors, and then to ideas of health resources and assets, now seems to be focusing on the idea of resilience as being largely about family strengths and capabilities (F. Walsh, 1996, 2006).

\section{FAMILY RESILIENCE}

The concept of family resilience extends strength-based approaches and builds on theory and research on stress, coping and adaptation (F. Walsh, 1996). Resilience is more than just getting by or coping with a challenging situation, 'resiliency is forged through 
adversity, not despite it' (F. Walsh, 1996, p. 7). An ecological perspective is required to take into account the spheres of influence in risk and resilience, and is also essential in understanding resilience per se (F. Walsh, 1996). In this ecological perspective, F. Walsh (1996) advocates in particular for family resilience: 'Family resilience seeks to identify and foster key processes that enable families to cope more effectively and emerge hardier from crises or persistent stresses, whether from within or from outside the family. In building family resilience, we strengthen the family as a functional unit and enable the family to foster resilience in all its members' (p.2).

The strength of family resilience is underpinned by viewing resilience as relationally based. This family resilience framework applies to various types of family structures as well as formal and informal kin networks. Walsh offers nine keys to resilience in three areas: family belief systems, family organisation and resources, and family communication. Consideration is given to the cultural differences that could affect these ideas for any particular family (F. Walsh, 2006).

In the area of family belief systems, resilient families:

- consider crisis as a shared challenge rather than a challenge for the 'tough, rugged individual' (F. Walsh, 2006, p. 55) to get through. Relationships are central in Pacific families, and trust is important and is strengthened by actions towards trustworthiness.

- Resilient families hold an optimistic view of life. Confidence in family strengths and potential in the midst of crisis, families encourage their members and reinforce a sense of confidence and a 'can do' spirit (F. Walsh, 2006, p. 69).

- Resilient families find meaning, purpose and connection to something beyond themselves, their members, and their immediate problems (F. Walsh, 2006). This may be defined as the family's moral and spiritual values that are their source of strength. Spirituality can be experienced either within or outside formal religious structures and many families find strength, comfort and guidance in adversity through these connections, particularly within cultural and religious traditions. Spiritual beliefs have been found to foster strong family functioning.

In the area of family organization and resources, resilient families are:

- Flexible: Resilient families have a flexible structure that can modify to fit their needs and challenges, rather than holding a rigid conception of family roles and rules. This allows the family to adapt to changes which may come about through crisis or adversity. Reference to 'bouncing back' after a crisis (F. Walsh, 2006, p. 85; 2010), a more apt metaphor for resilience might be viewed as 'bouncing 
forward' (F. Walsh, 2006, p. 85). Resilient families rebound and reorganize in the face of challenge, but do not necessarily expect things to return to the way they were before the crisis. Strong leadership with a focus on security and some sense of predictability is needed to help guide vulnerable family members through changes in the family.

- Connected and Cohesive: Resilient families function best when knowing they can count on each other during times of crisis. They maintain interdependent intergenerational relationships throughout life (F. Walsh, 2006).

- Support from social and economic resources: Resilient families have a network of people (family, friends, and neighbours) and organisations that can serve as their lifelines during challenging times. This network provides practical assistance (information, concrete services), emotional support, and connection to the larger community.

In the area of family communication, resilient families:

- Share clear, consistent messages: Communication that is direct, clear, specific, consistent and honest helps all family members understand the crisis that the family is facing and encourages them to share their feelings and opinions with one another (F. Walsh, 2006).

- Openly express their emotions: Resilient families are characterized by a climate of mutual trust and encourage their members to share a range of feelings, practice empathy, and comfort one another. Resilient families look for opportunities to enjoy humour and pleasurable interactions that can serve as respite during challenging times. Encouraging family members to laugh with one another or to enjoy a pleasurable activity together can revitalize families who are under stress.

- Use collaborative problem-solving: Resilient families identify problems and the options available to deal with them and then make decisions as a team. Resilient families focus on achievable goals and concrete steps that can be taken to achieve those goals. Families build on their success as they pursue their goals and learn from things that do not work. Through this process, families learn skills that can help them become proactive in preparing for future challenges.

These factors of family resilience draw on strengths-based, collaborative, systemic therapies. The family acting together in support can act as the glue to keeping an individual together, keeping them from falling apart. F. Walsh (2006) vision of resilience: 
Incorporating a developmental perspective on stress, coping, and adaptation, this approach links presenting symptoms with disruptive stress events, with ripple effects to all members and relationships. The family response can foster resilience for all members and their relationships. (p. xi)

The literature on resilience has been largely concerned with the individual (Ungar, 2008), yet resilience is viewed as being as much a collective attribute as it is an individual one. The origins of the resilience perspective emerged from ecology in the early 1970s through studies of interacting populations. Resilience has been an important concept in child development and mental health theory, focussing on an individual's ability to survive dysfunctional families (Ungar, 2004). Resilience is a process by which individuals show adaptive functioning in the 'face of significant adversity' (Schoon, 2006, p. 6). Resilience highlights strengths in being able to cope with adversity rather than focussing on risk factors (Churchward, 2011; Evans \& Becker, 2009). Michael Ungar's international work with youth and resilience notes there is no set explanation for what comprises resilience. Ungar's concepts of 'navigation' and 'negotiation' are helpful in understanding what is required in helping individuals and families to cope with new events; in this case, first-time motherhood (2008, p. 225). In this sense, resilience is a theme of relevance for understanding the stresses and coping mechanisms of New Zealand-born first-time Samoan mothers (Ungar et al., 2007). In terms of health, resilience is both a process of an individual's navigation towards, and the capacity of individuals to negotiate for, health resources on their own terms (Ungar, 2008) These processes are parallel to the concepts of sophisticated mediators, the vā, and negotiated spaces.

Resilience is not a concept that romanticises coping or struggling on despite adversity, and keeping one's head high. It is a concept that legitimises the perspective that, in spite of struggle and crisis, one can still succeed.

Having introduced the situation of Samoan people against the backdrop of New Zealand society, and the issues and concepts relating to who they are, the next chapter presents the methodology, including the theoretical constructs, and how the data was gathered and analysed. 


\section{CHAPTER THREE: METHODOLOGY}

In this chapter, I introduce the overall research design, methodology and methods that I chose to use for this thesis. My overall methodology integrates a number of different methodologies and methods to ensure I effectively addressed the research question. It is acknowledged that knowledge produced from qualitative Pacific research may be unique to the research participants (Sarantakos, 2005). However, the insights that can be drawn from their experiences and the way that they describe them add to the knowledge base around New Zealand-born FTSM's experiences of pregnancy, childbirth and early motherhood. There is no one 'right or pure' methodology/method. The researcher and those who are researched by them are educationally, historically and culturally influenced by their respective situations, as individuals and as members of families, neighbourhoods, communities, countries (Tuafuti, 2011). Exposure to and/or utilising multiple methodologies and methods is for those research topics involving participants who live multi-cultural, multi-dimensional lives, not only important but necessary.

This chapter explains the indigenous and Western methodologies used in this study and the epistemological concepts that inform the theoretical frameworks they operate within. These include drawing from Pacific and Western research methodologies. Each of these methodologies, models and key concepts come together in the use of the bricolage' as the umbrella methodological approach to this research. This chapter begins by describing the overall research design, then explores the epistemological and theoretical perspectives that informed the choice of overall methodological approach, which is, in turn, followed by a discussion of the methodologies and methods and how they were implemented in this study.

\section{RESEARCH DESIGN: BRICOLAGE}

To fashion their bricolage projects, bricoleurs use only the tools and materials 'at hand'...Generally speaking, when the metaphor is used within the domain of qualitative research, it denotes methodological practices explicitly based on notions of eclecticism, emergent design, flexibility and plurality. Further, it signifies approaches that examine phenomena from multiple, and sometimes competing, theoretical and methodological perspectives (Rogers, 2012, p. 1).

Indigenous approaches are based on the assumption that knowing and knowledge are not accultural, but are products of, and thus influenced by, particular culture[s], and can best be understood by way of 
research techniques that reflect that culture. (Nabobo-Baba, 2006, p.

24)

This research makes a commitment to indigenous ways of knowing by including several characteristics of a Pacific studies approach such as the 'willingness to be critical', to take indigenous approaches seriously, with an appreciation of interdisciplinarity (Teaiwa, 2010a, p. 11; Wesley-Smith, 1995). It examines literature relating to the indigenous methodological approaches such as used in Pacific studies, as well as in related disciplines, e.g. psychology, anthropology, sociology and health. The main Pacific indigenous models explored are the Fa'afaletui, Kakala and Talanoa. The main social science and health approaches explored are phenomenology, feminist methodology, reflexivity, strengths-based and the ecological methodologies. In terms of bringing all of these approaches and/or methodologies together, this thesis has adopted the bricolage' as the overall methodological frame (Asiasiga, 2007; Denzin \& Lincoln, 1994).

While FTSMs identified themselves as Samoan, they also identified with other categories. They were women, young, heterosexual and New Zealanders. All of these identities were recognised as equally important for these women. This meant a search for an overall methodology that could incorporate their multiple and multi-dimensional voices and make sense of this within their narratives. Feminist research, ecological research, phenomenological research, reflexive research and strengths-based research, therefore, informed the methodological framework of this thesis and together they form the bricolage.

Bricolage was used by Pacific researcher Lanuola Asiasiga in her doctoral dissertation which sought to identify factors that shaped research about Pacific peoples (Asiasiga, 2007). Lévi-Strauss considered the bricolage as involving 'several solutions to the same problem’ (Lévi-Strauss, 1966, p. 24).

Bricolage is a French word that is translated into English generally as 'tinkering' or 'constructing', using what is at hand. Bricolage is brought into being through the crafting of the bricoleur. Lévi-Strauss suggests that the term 'bricoleur' has no precise equivalent in English. It refers generally to someone 'who undertakes odd jobs and is a Jack of all trades or a kind of professional do-it-yourself' person (Lévi-Strauss, 1966, p. 17). Kincheloe states that 'research bricoleurs pick up the pieces of what's left and paste them together as best they can' (Kincheloe, 2001, p. 681). The greater variety of perspectives a researcher employs 'the more dimensions and consequences of a text will 
be illuminated' (Kellner, as cited in Kincheloe, 2001, p. 682). The product of a bricoleur's labour is the bricolage, something that is created or constructed from the coming together of a diverse range of things, things that are available. By utilising various theories to develop the progress of the thesis into one, this study is in itself a bricolage. Like Lanuola Asiasiga, I, as a 'Pacific researcher-as-bricoleur', draw from Western social science research and Pacific knowledge processes, to constantly gather together different parts to meet 'what is required by Western social science research' and 'the needs of Pacific peoples' (Asiasiga, 2007, p. 95).

The concept of the bricolage resonates with Wesley-Smith's (1995) insistence on combining the methods and approaches of several disciplines to advocate interdisciplinarity within Pacific studies. Wesley-Smith posits two aspects that arguably necessitate a bricolage approach: that societies, for all their connections, political, cultural, economic, social, linguistic, or spiritual features, cannot be situated under one defined discipline, and becoming interdisciplinary 'recognises the key roles of creativity, subjectivity, and poetics in the "science" of interpreting and representing the social world' (Wesley-Smith, 1995, p. 128). This allows for the bringing together into one the various expressions within the narratives and at the same time provides space for researcher reflexivity (Wesley-Smith, 1995). Roland Bathes argues that 'to do something interdisciplinary it's not enough to choose a "subject" (a theme) and gather around it two or three sciences. Interdisciplinary consists in creating a new object that belongs to no-one' (as cited in Wesley-Smith, 1995, p. 123). Patricia Donnelly, in her doctoral thesis examining the way in which migrant Samoan women gave birth in Wellington, adopted an 'eclectic' approach to gathering and making sense of her participant narratives. She drew equally from sociological, anthropological and psychological literatures to design and engage her methodological and analytical approaches (Donnelly, 1992).

\section{INSIDER-OUTSIDER RESEARCH}

This research focuses on first-time New Zealand-born Samoan mothers. I am a New Zealand-born Samoan woman, and also a mother. In this regard, I consider myself an insider (New Zealand-born Samoan, woman, mother), an insider in the sense of being on the 'inside' of that New Zealand-born Samoan mother world. As a researcher, I am also an outsider. My role as a researcher and my self-defined ethnicity as a New Zealand-born Samoan mother placed me in the unique position as insider as well as outsider. It is a position that carries both advantages and disadvantages.

The insider-outsider dilemma has been canvassed by many leading Pacific indigenous scholars, especially in relation to studies focusing on indigenous Pacific peoples. Vilsoni 
Hereniko writes that: 'Sometimes native scholars like to claim that they know their people better than foreign scholars by mere virtue of their being insiders' (Hereniko, 2000 , p. 89). 'There are certain matters, largely to do with intuition, emotion, and sensibility, that the outsider may never fully grasp, for these are things in the realm of the unseen, acquired through early socialization in the formative years' (Hereniko, 2000, p. 90). Gegeo (2001) argues this intuition when he states:

When two Pacific Islanders get together, though they may be from very different parts of the Pacific, they instantly recognize the Pacific qualities in each other, and instantly relate in particular ways in dialogue that would neither be understood by outsiders, nor be evoked by Pacific Islanders' interactions with outsiders. (p. 501)

L. T. Smith (1999) cautions, however, on the need for insider researchers to constantly be reflexive and think critically about processes, relationships and the quality and richness of data, ethics, and being respectful and humble; she also advocates for the use of support structures to address issues that may arise from insider-outsider tensions or power imbalances. She refers to a need to problematise the 'official insider voice': "she or he lives in it therefore they know" certainly validates experience but for a researcher to assume that their own experience is all that is required is arrogant'. (p. 139)

Hereniko (2000) points to the complexity of the insider/outsider concept as a distinction of 'knowing' and 'living/being'. He concedes that being native Rotuman (an insider) does not necessarily make him more knowledgeable about Rotuma's historical events 100 years ago, as opposed to a non-native anthropologist (an outsider), who has studied his culture for 30 years. Yet Hereniko, when talking about exploring 'the unseen', the cultural subjective perhaps, does seem to favour insider interpretations. Hereniko is critical about those who seek to make claims from the outside. He quotes a Fijian elder's insistence that outsider researchers do not understand 'the unseen' and suggests that there is some truth in this: '[they] do not understand the unseen, which is the reality of our lives; they do not realise its power. They look only at the seen, which is illusion' (Katz, 1993, as cited in Hereniko, 2000, p. 85). True collaboration, Hereniko points out, is a key factor in the success of the insider-outsider relationships. Much still depends on this and the type of research being carried out.

The insider-outsider status is also something that is fluid and dependent on the context (De Andrade, 2000). In many respects, it is also something that is self-defined by the participant and the researcher respectively. The FTSMs I interviewed saw me as having 
some insider status as a New Zealand-born Samoan mother myself who has been pregnant and experienced early motherhood. However, as I was an older, university student and staff member, it is quite likely that the FTSMs also saw me as an outsider. If the mothers of the FTSMs were New Zealand-born Samoan, I would also be an 'insider' for them than with their daughters. However, again, unless they worked as a university staff member, and/or were a student, I was also an outsider. Regarding the maternity healthcare professionals I spoke with, the same insider-outsider reasoning could be applied to determine my status.

None of this was taken lightly. I was very mindful of the precarious nature of the insider/outsider status. In this, I am reminded of Lanuola Asiasiga's words:

Everything is relative and no-one is wholly an outsider or insider. Relationships are constantly shifting so that even within a group where a researcher is an insider there will be some factors that create distance and others that create connection (Asiasiga, 2007, p. 91).

The idea of 'living' an experience is important to the debate. It is plausible, as Patton (2002) suggests, to have understanding of the 'lived' phenomenon under study and be enhanced by having some 'lived' experience of it. Tupuola refers to researchers 'whose national or cultural identity is mixed by virtue of migration, overseas education, or parentage' as 'halfies' and points to the challenges faced by these researchers because of their dual and/or 'in-between' positioning (Abu-Lughod as cited in Tupuola, 1998, p. 73).

In line with feminist research, it was important that I was able to minimise any power imbalances that may have arisen in perceptions of a hierarchal-type relationship between me and the participants. In line with Pacific health research guidelines, I drew on philosophies of fa'asamoa about Samoan values and relationships. I noted, in particular, the principles of respect for autonomy; nonmaleficence - causing no distress; beneficence - working for the benefit of participants; and a commitment to justice that the study was not to benefit the researchers at the detriment of others (Meara \& Schmidt, 1991). To minimise any perception of a power relationship by the participants between myself and them, I studied these guidelines and took on advice from my research mentor and my academic supervisors.

I was fully aware of the subtle, and not so subtle, differences between myself, a much older researcher, and the FTSMs. To address this, I tried to always ensure that they were 
consulted at every stage of the process and checked intuitively and explicitly that they were okay to continue participating in the study. In reflecting on the insider-outsider debate, the real difference between insiders and outsiders is that insiders have to live with the consequences' of any wrong-doing in their research as they often live on a daily basis with those research participants, whereas 'outsiders' do not (L. T. Smith, 1999).

\section{EPISTEMology AND PACIFIC RESEARCH THEORY}

The term epistemology derives from the Greek word epistēmē, meaning 'knowledge, understanding', and logo, meaning 'the study of, ... the philosophical theory of knowledge, the philosophy that deals with how we know what we know' (Crotty, 1998; Davidson \& Tolich, 2007, p. 25). Epistemology is concerned with providing a philosophical grounding for deciding what kinds of knowledge are possible and ensuring they are both adequate and legitimate (Maynard, 1994). Specifically, epistemology 'asks how do I know the world? What is the relationship between the inquirer and the known?' (Denzin \& Lincoln, 2005, p. 175).

L. T. Smith (2005) articulates that indigenous groups moving towards decolonising research need to do it in a way that honours indigenous ways of knowing "for it is not just the noisy communities of difference "out there" in the margins of society who are moving into the research domain with new methodologies, epistemological approaches, and challenges to the way research is conducted. The neighbours are misbehaving as well' (p. 85). Indigenous epistemology is concerned with the transmission of knowledge. In pre-colonial, pre-missionary oral Pacific cultures, including those of the aborigines of Australia, the transmission of knowledge has been around for as long as land has been habituated. As eloquently stated by Wendy Brady of Australia (as cited in Thaman, 2003, p. 10), the grief experienced at the loss created by 'misbehaving neighbours' on the grand colonial scale was devastating for them: 'my ancestors had in place systems of education, cultural practice and maintenance, spirituality and social cohesion which sustained them for 40,000 years. After 208 years of colonisation we are left with a legacy of grief, dispossession and struggle for survival. I believe that it is time we empowered ourselves to take back our education so that we can move with pride into our next 40,000 years'. Brady suggests a large part of reviving the ways of knowing (the epistemological concerns) of her people is to empower them to 'take back [their] education' with pride for themselves (Thaman, 2003). This spirit of indigenous empowerment lies at the heart of Linda Smith's 'decolonising methodologies' and indeed Pacific studies. 
In New Zealand, as Macfarlane, Glynn, Grace, Penetito, and Bateman (2008) point out, 'Māori did not just instantly and instinctively know about the qualities, properties of birds, plants and other natural resources' (p. 106). As with all indigenous groups 'scientific endeavours' were recorded and transmitted through everyday practices manifested through 'song, dance, symbol and story' (Macfarlane et al., 2008, p. 106). L. T. Smith (1999) states that contrary to popular belief, survival of Māori was not due to the 'beneficence of our Earth Mother', but rather from knowing how to survive, working out ways of knowing, in which Māori had to 'predict, to learn and reflect, preserve and protect' (p. 13). This strongly resonates with the arguments of Pacific scholars who point to the vast and deliberate knowledge base of generations of Pacific indigenous navigators who successfully voyaged back and forth across the Pacific Ocean, using nothing but nature, and in many cases setting up home in what is today the ancestral homelands of the Pacific migrants of New Zealand (for example see Diaz \& Kauanui, 2001; Hau'ofa, 1998; Hereniko, 2000; Jolly, 2001; Salesa, 2003). Not only did these early navigators and settlers take their navigational knowledge with them but they also passed it on to successive generations.

Pacific indigenous knowledge is a key part of contemporary Pacific epistemology. Pacific indigenous knowledge is an umbrella phrase that draws meaning from ideas or claims of 'the Pacific' (however constituted) and from the existence of 'the indigenous' in the Pacific. In the main, this refers to those peoples of Pacific Island countries, who over time established distinct languages, world views, and habits, knowledges that were and are commonly understood to be 'indigenous'. Even with contact with the outside world, many Pacific indigenous peoples have maintained their original languages and cultures in ways that find some continuity with the past. So much so that, while these indigenous knowledges are still identifiably 'Pacific', there is also evidence of 'outside' influence. This 'outside' influence is appropriated or 'indigenised' in ways that, while creating a new 'indigenous-ness' about it, is still arguably 'indigenous'. As articulated by Gegeo (1998), indigenous epistemology and indigenous knowledge are therefore part and parcel of each other. One guides, informs, shapes and produces the other. He says that:

Indigenous epistemology guides the social construction of indigenous knowledge, and indigenous knowledge is the result of the practice of indigenous epistemology. (p. 290)

Within contemporary Pacific societies, it is important to point out that indigenous epistemology and indigenous knowledge, while informing, shaping and producing each other, are also informed, shaped and produced by the world/s in which they exist, and 
these worlds, while once homogenous, are today extremely heterogeneous. The new generation of indigenous knowledge or indigenous epistemology shapers and producers live in a political, social, economic, technological environment that is so vastly different from that of their ancestors that the 'indigenous' knowledge they shape will be different. Their 'indigenous knowledge' and 'indigenous epistemology' draws not only from their past but also their present. But does that make it any less indigenous'? I would like to think not. This is not an easy question to grapple with as it has many socio-political implications. Nevertheless, it is a key issue for Pacific studies.

This idea suggested by Gegeo (1998) of indigenous epistemology guiding the social construction of indigenous knowledge and vice versa, invites and connects with the claim of Western social science ideas of social constructionism, a body of thought that has been described as providing insight into the ways in which people, as individuals, groups and/or societies, construct, make real, build, make imaginary, or re-build, their worlds. And one that is relativist in that some elements of experience or culture around mothering are dependent on that experience or culture so that comparisons are dependent on context. There are links between social constructionism and indigenous epistemology whereby both bodies of thought argue for the need to acknowledge that reality is perceived as much as it is (Sarantakos, 2005). Therefore reality, including the reality of indigenous or other epistemologies and knowledges, is as much dependent on social constructions as it is on physical, material or empirical existence (Crotty, 1998, p. $43)$.

Pregnancy, labour, childbirth and early motherhood are phenomena that take place within a social context and have meaning for Samoan families within their social worlds (Macpherson \& Macpherson, 1990; Ngan-Woo, 1985). Accessing knowledge about pregnancy from medical or health institutions and understanding the theoretical frameworks these institutions prioritise also plays an important role in how women understand and talk about what they know about and/or have experienced or will experience during these early mothering stages. Constructing knowledge in a merged, blended or hybrid way is, as discussed by Gegeo and suggested in Tupuola's use of the terms 'cultural fusion' (which she uses in her description of the blending that occurs for Pacific youth who merge their Western and Samoan worlds), is increasingly common (Tupuola, 2006, p. 298).

FTSMs' experiences are influenced by societal attitudes or cultural beliefs. Within these beliefs are epistemologies and ways of knowing that draw on both their Samoan and New Zealand contexts. Some of these knowledges may have been passed onto them by 
their own mothers and their mothers in turn. Some may have been passed onto them by the healthcare systems, whether New Zealand or traditional Samoan, and they may have accessed these by deliberate choice or inadvertently. Some may have come to know through more intuitive means, by listening to the messages of their bodies, e.g. the physical cravings, the onset of birthing contractions. Whatever the means, exploring their ways of knowing, of coming to know, and of coming to a point where they can articulate what they know, is the point where epistemology centres and where the concerns of epistemology and indigenous knowledge and the concerns of Pacific research intersect.

\section{SOCIAL CONSTRUCTIONISM}

Social constructionism has been applied within a range of different academic and professional disciplines to help illuminate the fact that reality and knowledge is socially constructed, reconstructed, and deconstructed, and that it is also open to negotiation/renegotiation.

In research terms, social constructionism challenges positivist understandings of reality. It introduces the human social element. It identifies how relative, dependent, contingent, negotiated, and thus messy, life, especially social life, can be. In understanding or making sense of social phenomena, the point raised by social constructionism that knowledge is constructed as opposed to discovered is epistemologically important (Crotty, 1998). It means that epistemologically pregnancy and the other stages of early motherhood are stages that FTSMs come to know through already existing social scripts. Therefore, the tendency of social constructionists to describe the existence of social phenomena as relativist makes sense as each society will have its own social scripts. Thus experience will be relative or dependent on the epistemological elements and logic of that script (Sarantakos, 2005).

The roots of social constructionism can be found in the larger field of postmodern epistemology. Postmodernism argues that no one true reality exists, only constructed realities (Crotty, 1998). A fundamental interest of social constructionist qualitative researchers when dealing with personal stories is identifying how they reflect the influence of dominant stories from the larger society (Ladson-Billings, 2000, p. 260). Its focus includes an analysis of 'the collective generation (and transmission) of meaning' (Crotty, 1998). Social constructionists are interested in exploring how these various accounts honour and respect the community of voices, how they tell a story that is their own, that is, in fact, the story of their culture - a story of many voices, all heard in what is said (Crotty, 1998, p. 64). 
The way of knowing, the epistemology, and the theory or explanatory model, promoted by social constructionism is that knowing comes about through being an active part of a social context. Individuals can select, modify and create many of their own social settings and experiences, depending on their own opportunities, personality characteristics and agency (Archer, 2003), but they do so in the context of the broader society and the social scripts that operate within that society. This makes people, like the FTSMs, both the 'products and producers of [their] own environment' (Vaughan \& Hogg, 2002).

\section{THEORETICAL PERSPECTIVE}

Theoretical perspective is the philosophical stance informing the methodology and thus providing a context for the process and grounding of its logic and criteria (Crotty, 1998). The theoretical perspective suggests that we bring a number of assumptions to our chosen methodology; for example, an assumption that social systems such as families exist, and that culture and social structures are real. Theoretical perspectives are important because assumptions direct our attention and provide frameworks for interpreting what we observe.

\section{PACIFIC RESEARCH THEORY}

The growing body of work in the New Zealand Pacific health research sector (Health Research Council of New Zealand, 2014), has produced several models of health and wellbeing. They provide information and evidence on the epistemological and theoretical concerns of the New Zealand Pacific health sector around what should guide health practitioners and researchers when working with or researching the health needs of Pacific peoples.

The main models of Pacific health used in the New Zealand health sector reflect the largely indigenous Polynesian origins of its Pacific population. There are four health models that I explored: the Fa'afaletui; the Soifua Mālōlōina; the Fonofale; and the Seitapu. Of these, the first and third models have been used as methodological frameworks also, although the first has been around for at least 20 years, while the third (Fonofale) is only just being proposed as a methodological framework. These four models are the more well known of the Pacific health models of New Zealand in that they have generated more institutional support than others. 
The Pacific health sector has also looked to Pacific methodologies from the related sector of education, which has produced the Kakala and the Talanoa models, for example. ${ }^{7}$ I will look into the theory behind these two research methodologies as well as the four Pacific health belief models as part of my examination of Pacific research theories relevant to understanding methodological issues pertaining to researching the experiences of FTSMs, before introducing the theoretical ideas behind Bronfenbrenner's ecological framework.

\section{Fa'afaletui}

The term Fa'afaletui is a Samoan concept that emerged during research investigating Samoan perspectives on mental health issues. Samoan elders raised the concept of Fa'afaletui as a way to explain the process of dialogue which they 'viewed themselves to be part of' (Tamasese, Peteru, \& Waldegrave, 1997, p. 23). Fa'afaletui is a term used to describe a meeting that engages different houses (or fale) and is able to weave together (or tui) the views of each of these different houses. An integral part of the Fa'afaletui model is the idea of weaving together knowledge and the suggestion that this is to happen in an appropriate cultural manner. This health research model or framework places importance on the ability to gain 'perspective' when dealing with particular issues that need to be solved. Tamasese et al. (2005) utilise the analogy of fishing provided by Tui Atua Tupua Tamasese Ta'isi Efi (who wrote the foreword to their research report) to illustrate how this involves bringing together three main perspectives, each as important the other, to inform the issue. There is the perspective of the person at the 'top of the mountain', the person at the 'top of the tree', and the person 'in the canoe'. These encompass the long, middle and closest views and together they give overall perspective to the problem (Tamasese et al., 2005, p. 1). It is suggested that while the model was developed to help encourage discussion and understanding of mental health issues from a Samoan perspective, this approach may be relevant for other Pacific Island cultures and other cultures that have a strong ethos of collectivism (Tamasese et al., 1997). The main theoretical idea in terms of health belief and research promoted by the Fa'afaletui model that Pacific health research must be 'faithful to the context of its participants' contributions, and must have as its premise a method which facilitates and delivers a construct which accurately reflects the cultural values and meanings of its research community' (Tamasese et al., 1997, p. 10).

\footnotetext{
7 Other models written about Pacific research include: Vaka (see Nelisi, 2004), Teu le Va (see Anae, 2010), Tivaevae (see Kingi-Uluave \& Olo-Whaanga, 2010)
} 


\section{Soifua Mälōtöina}

The Soifua Mālōlōina model assumes traditional Samoan values and beliefs and holistic views of health and wellbeing. Soifua Mālōlōina literally means 'life [soifua] wellness [mālōlōina]' (Lui, 2007). This model emphasises the point that, for Samoan health and wellness, it is important to recognise the inextricable connection between tagata (People), atua (God) and laufanua (Land or Environment). The relationship (or vā) between all these need to be in balance or harmony in order for a person to be in a state of mental wellness in order to enable them to meet their responsibilities and obligations to self, family, community, and God. This model draws attention specifically to Samoan views about health as holistic and spiritual and encompassing of both the physical and non-physical world (Lui, 2007, p. 70).

\section{Fonofale}

The Fonofale model was created by Fuimaono Karl Pulotu-Endemann as a Pacific Island model of health for use in the New Zealand context. While it was not originally designed to be a research methodology, it has recently been used, with some modification, by Samoan researchers for this purpose (Mauiliu, 2014).

The Fonofale model is well-known in New Zealand Pacific health circles as a health belief model (Agnew et al., 2004). It was developed in response to the Pacific health sector's call for a more culturally appropriate health service model to assist service providers to best serve Pacific consumers of mental health services. The model, like the Soifua Maloloina model, is holistic in nature, and encapsulates the inextricable link between the individual, their environment and those around them. The traditional Samoan fale (house) is used as a the main metaphor for the image that represents the Fonofale. The name Fonofale, however, is taken not from a literal interpretation of the name i.e. 'meeting house' (fono meaning meeting, fale meaning house), but as a tribute to Fuimaono's maternal grandmother whose name was Fonofale (Central PHO, n.d.).

The model identifies six dimensions of health. The foundation that the fale is built upon represents family, both nuclear and extended family (aiiga) and forms the fundamental basis of social organisation. The four pou (posts) represent four further dimensions of health, namely: physical, the wellbeing of the body, which is measured by the absence of illness and pain; spiritual, the sense of inner wellbeing, encompassing beliefs around Christianity, traditional spirits and nature or a combination of both; mental, the wellbeing of the mind which involves thinking and emotions as well as the behaviours expressed; other, encompasses variables such as finance, gender, age, education and sexual orientation. The roof symbolises the sixth dimension of culture 
representing the values, attitudes and beliefs of Pasifika culture. Some families may lean towards a Pālagi (European) orientation, practising Pālagi values and beliefs. Other families may live their lives on a continuum that ranges from a traditional Pacific cultural orientation to a Pālagi cultural orientation. These can include beliefs in traditional methods of healing as well as Western methods.

These six dimensions of health are encapsulated in the cocoon of environment, time and context. The overall influence of environment, time (inclusive of age or generation) and context on how the six dimensions operate makes the point that people and their health and wellbeing exists within these realities. These dimensions and the environment, time and context of their existence provide service providers with a starting set of markers, indicators or measures for identifying and assessing health and wellbeing within a Pacific context.

When designing Pacific evaluation frameworks, service delivery frameworks or research approaches, the Fonofale model suggests specific recognition of the epistemological values inherent in the six dimensions identified. The dimensions are interwoven and interdependent, so that altered states of wellness only occur when one or more of the dimensions are out of balance (Kingi-Uluave \& Olo-Whaanga, 2010; Pulotu-Endemann et al., 2007). Other Pacific groups have adapted this model to address the needs of their own Pacific communities (Agnew et al., 2004; Williams, McCreanor, \& Barnes, 2003). Like the Soifua Mālōlōina and Fa'afaletui models, this model has Samoan origins and draws from indigenous or traditional Samoan ideas of health and wellbeing.

Seitapu

The Seitapu model was designed as a cultural competency guide for use by mental health workers in New Zealand who work with Pacific consumers and their families (Pulotu-Endemann et al., 2007). The name 'seitapu' means a sacred object (sei means flower; tapu means sacred), i.e. a four-petal flower. The Seitapu framework places the mental health worker in the centre (stamen) of the flower as it is the health worker's competence that is the focus of the framework and essential to appropriate and successful health service delivery to Pacific peoples in New Zealand. Two of the four petals represent health worker competency in 'cultural theory' and 'cultural practice' and the other two represent competencies in 'clinical theory' and 'clinical practice'.

This model defines 'cultural' as 'ethno-cultural'. Organisations are expected as part of this model to aim for understanding of ethno-cultural health theory and practice, i.e. Pacific health theory and practice. Within this expectation, it is suggested, that 
understanding the ethno-cultural construction of family (family culture), language (culture of language, language use), ideas of tapu (culture of the sacred, ideas of the sacred), and of organisation (ideas of organisational culture) are important. It is equally important for organisations to understand the way in which family, language, tapu and an organisation are constructed within the clinical world. Given that learning about and developing actual competency is staged, the authors argue that competency levels are also staged, and thus there is need to establish core, advanced and specialist competency level requirements (Pulotu-Endemann et al., 2007). Like the others, the Seitapu model is heavily influenced by Samoan indigenous ideas of health and wellbeing. It aligns more with the Fonofale model as it was designed specifically to address organisational or service-delivery issues rather than research or health beliefs per se.

\section{Kakala}

The Kakala model developed by Tongan Professor Konai Helu Thaman focuses on describing a process for education research that could be more culturally inclusive of Pasifika motifs and epistemological assumptions and so be more relevant for Pasifika teachers and students. Thaman's Kakala framework was designed to address the need identified by Pacific scholars and researchers for more culturally nuanced Pacific research methodologies.

Taken from the Tongan metaphor of 'kakala', meaning a garland of fragrant flowers (Thaman, 2009), the Kakala model advocates for names that resonate immediately with the reality of Pacific contexts. She too draws on indigenous knowledge, language, motifs and beliefs to illustrate her model and its general principles. Thaman highlights three main principles or elements/parts to the Kakala: toli, tui, and luva. An additional two steps (teu and mafana or malie) have been subsequently added to the Kakala model by other Tongan scholars who have adopted the Kakala and sought to develop it further (Taufeulungaki, et al as cited in Thaman, 2009). However, the three stages or elements raised originally by Helu Thaman will be focussed on. In the making of the Kakala, like the final research report, researchers and Kakala garland makers must toli (select and gather) the flowers, fruit and leaves and other fragrant elements (Thaman, 2009). They choose these carefully and deliberately. There is a method and process to undertake for the selection and gathering (collating) as is the case when researchers go about selecting their participants and then collating and reviewing what they found during their fieldwork in preparation for the analysis (the tui process). Tui is thus the active process of making or weaving of the Kakala, with all the complex skills involved to ensure the garland (or the final research report) is able to, on the one hand, maximise the fragrances, colours, and textures within, and be held together strongly enough so that it 
can serve the purpose for which it was made (i.e. to address the research question/s or to be worn well and appreciated by a recipient who can then pass it on to another) (Thaman, 2009). This stage, in research terms, involves the analysis, writing up of data, checking and rechecking to ensure everything is as strong as it can be. This is when questions about project coherence, data analysis rigour, and appropriate strategies for dissemination of the results come into play. Luva is the third and last of Helu Thaman's original stages for the Kakala model. The Kakala is expected to be gifted to someone of significance to the maker of the Kakala (Thaman, 2009). This is the final process of the research, the dissemination to participants and to key stakeholders.

Kakala has been used, particularly in education, as a research framework (see Koloto, 2002 as cited in Chu, Abella, \& Paurini, 2013; Thaman, 2009). It is drawn on here because not only does it provide an example of a non-Samoan model that has influenced the New Zealand Pacific research community, but it is also the parent of the Talanoa research methodology as designed by Timote Vaioleti.

\section{Talanoa}

The Talanoa model is the most recognised Pacific research methodology in New Zealand and across Polynesia, if not the Pacific islands. Like the other Pacific models or frameworks, the Talanoa is heavily influenced by Pacific indigenous epistemology, in particular Tongan indigenous epistemology. It has received significant attention among Fijian researchers (Nabobo-Baba, 2006; Otsuka, 2006) and is used not only as a methodological framework but also as a research method (see Robinson \& Robinson, 2005; Vaioleti, 2006).

As described by Robinson and Robinson (2005) it is a methodological framework that privileges traditional Pacific processes for deliberation. They note that as a 'traditional Pacific Island deliberation process', topics are discussed at great length and several times in several ways. Talanoa is therefore, they suggest, a decision-making activity by people engaged in open-style discussions aimed at reaching a final conclusion sanctioned by the group (Robinson \& Robinson, 2005, p. 14). The Talanoa process can be arduous; it can be repetitive, slow moving and lengthy. It is underpinned by a philosophy that is based on respect, tolerance, flexibility, openness and fairness and governed by ceremonial actions, protocols, unwritten rules and etiquette (Robinson \& Robinson, 2005). The intention of Talanoa is to provide a space where it is safe to speak 'with their hearts and where there are no preconceptions' (ibid, p.17). 
The idea of open-style speaking was one of the main attractions of the methodology for Pacific peoples; however, if following traditional protocols, the process of Talanoa in some Pacific countries would not allow the participation of women or children. This meant that researchers who sought to employ the Talanoa as its research methodology would need to consider carefully how they would engage participants who would not either speak in the same space as one another (males and females or elders and young people, for example). Vaioleti argues that Talanoa is a vehicle open for people to share their stories 'issues, their realities and aspirations' with more depth and provide 'pure, real, authentic' information than data derived from other research methods (Vaioleti, 2006, p. 21). This idea of an openness to dialogue is interesting in the Pacific space because of the very hierarchical nature of their respective cultures. In the Samoan context, fa'asamoa is based on a chiefly system or fa'amatai that is very hierarchical and has associated protocols and customs of respect and deference that emphasise that hierarchy. While in the Talanoa, there is suggestion of a need to downplay those hierarchical relationships and the implicit power imbalances that sometimes come with it, the same call for horizontal open sharing is not as explicit, in fact, the suggestion is to the contrary within the Fa'afaletui model.

From the brief discussion offered above of the Fa'afaletui, Soifua Mālōlōina, Fonofale, Seitapu, Kakala and Talanoa, it is possible to see the common threads of a Polynesian, mainly Samoan-centred, approach to Pacific health research in New Zealand. Moreover, this Pacific health research approach draws heavily from traditional indigenous ideas of health and wellbeing, of sharing knowledge, and how one does or comes to know what knowledge is or what it should to be.

\section{ECOLOGICAL FRAMEWORK}

The last theoretical framework I wish to explore here is the ecological framework designed by Urie Bronfenbrenner (1977). An ecological framework facilitates organising information about people and their environment in order to understand their interconnectedness (Reifsnider, Gallagher, \& Forgione, 2005). The environment is conceived as an arrangement of structures, each contained within the next (Urie Bronfenbrenner, 1977). As part of his ecological system theory, Bronfenbrenner argues that in order to understand human development throughout the lifespan, consideration must be given to the entire ecological system in which growth occurs.

He demonstrates (Figure 1) how people move or transition from one social space and/or system to another. 'An ecological transition occurs whenever a person's position in the ecological environment is altered as the result of a change in role, setting, or 
both' (Bronfenbrenner, 1979, p26). Ecological transitions help to explain the different phases and altered roles and the different resources that are accessed during a person's experience of a social phenomenon. For example, the cluster of activities and role changes defines and gives meaning to the birth experience as a critical life event that can impact profoundly on both the new baby and parents, and family, for the remainder of their lives (Garbarino \& Benn, 2009).

This ecological model first appeared as a way to conceptualise the life span and developmental aspects in a child's life that includes their environments, and the role that each of these environments or systems play in influencing their development (Urie Bronfenbrenner, 1986; U Bronfenbrenner \& Morris, 2006). It has since been adopted to help conceptualise and explain other health and social contexts.

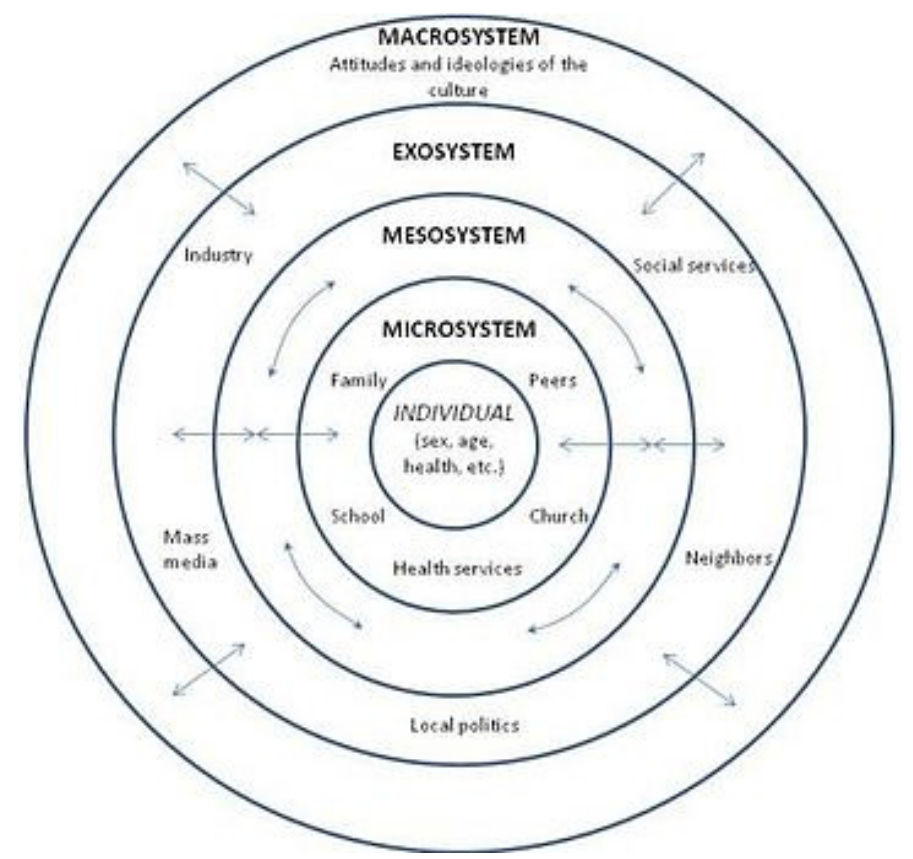

Figure 1: Ecological Model: Bronfenbrenner's Ecological Model describing the environmental influences on a child.

Source: Niederer et al. BMC Public Health 2009 9:94 doi:10.1186/1471-2458-9-94

Ecological models and theories are used in health research (McLaren \& Hawe, 2005; Reifsnider et al., 2005; Sword, 1999) to help explain the interconnectedness of people and systems. A distinct feature of the ecological model is the relevance of the four systems identified and the salience of the explanation offered for the way the four systems affect and influence each other. The attraction of the ecological framework to this study is that it is not static and each system is negotiated by those who engage in it. 
Ecological theory is a key theoretical framework, alongside the social constructionist framework, and the Pacific theories of health and research noted earlier, to examine the constructs central to pregnancy through to motherhood for this group of New Zealand-born FTSMs.

Other Samoan researchers have incorporated Western ecological models in their research (for example Cassel, 2010; Lipine, 2010; Utumapu, 1998) . As highlighted in the Pacific theoretical models of health and research discussed above, Pacific people have a holistic view of health where a person is in tune with their environment and community (Lui, 2007). Within these Pacific models the Samoan concept of 'self' defines the person as 'relational' as the Samoan person 'does not exist as an individual' (Airini. et al., 2010; Tamasese et al., 2005, pp. 29, 83). Placing emphasis on the individual Western models of the self and their environment are seen by Pacific theorists as promoting independence of self from the collective. This runs contrary to the Pacific indigenous culture or epistemological expectations of the models that place emphasis on family and interdependence between the individuals in these families.

Within these ideas of self and relationship to the collective is the idea of agency. Agency is based on the assumption that humans are not passive recipients of a predetermined life course but rather make decisions that determine the shape of their lives. Decisions are influenced by one's temporal orientations to situations, with some decisions requiring intense focus on the present and others influenced by long-term goals (Hitlin \& Elder, 2007). Personal agency, according to Bandura, operates within a broad network of sociocultural influences that he considers 'agentic transactions' where 'people are producers as well as products of social systems' (Bandura, 2001, p. 1). Bronfenbrenner's ecological framework offers this study a space to examine the social context of the maternal development of Samoan mothers, noting where they are able to exercise with increased confidence and effective agency (Archer, 2003).

\section{METHODOLOGY}

Methodology includes the strategy, plan of action, processes and/or design/s that lie behind the research approach and links the choice and use of particular methods to the desired outcomes of the research (Crotty, 1998; Maynard, 1994).

\section{Phenomenology}

Phenomenology as a methodology emerged during the $20^{\text {th }}$ century with Edmund Husserl credited as the founder (Crotty, 1998, p. 79). The operative word in phenomenological research is 'describe', to describe as accurately as possible the 
phenomenon under study, refraining from any pre-given framework, but remaining true to the facts (Davidson \& Tolich, 2007). The phenomenological approach focuses on each individual participant's subjective experiences as they encounter those events under study (Patton, 2002), and their direct, lived experiences of those events (Kvale, 1996). As Crotty states:

Phenomenological research emerges as exploration, via personal experiences, of prevailing cultural understandings. (Crotty, 1998)

Therefore, in order to really know and gain an understanding of a phenomenon, it is important to experience the phenomenon as directly as possible either through participant observation or in-depth interviewing (Patton, 2002). Participant observation is one way of observing how a participant interacts with or participates in their social world, but it does not necessarily provide a perspective on the world-view of the participant, neither can it reconstruct events or know about previous events. Moving beyond participant observation to actually 'living' the experience under study takes Patton's suggestion of experiencing a phenomenon as directly as possible that one step further. That is, not necessarily the researcher engaging in the phenomenon under study but engaging participants in discussions of their lived experiences of the phenomenon, all relevant for the current research.

\section{FEMINIST METHODOLOGY}

Feminist theory considers how women's experiences and realities are multiply constructed and shaped by society, politics, culture, economics, ethnicity and gender. The ultimate goal of feminist research is to capture women's lived experiences in a respectful manner that ensures the legitimacy of their voices as sources of knowledge. Fonow and Cook (1991) suggest that 'carefully designed research grounded in feminist theory and ethics is more useful to understanding women's experiences than an allegiance to any one particular method as more feminist than another' (p. 8).

The narratives of the FTSMs are not placed solely within a New Zealand cultural framework or that of a purely Samoan framework but within a framework that holds value in both cultural worlds. Understanding the gendered norms of these two ethnocultural worlds can benefit from a feminist perspective; in particular, the perspectives of feminist standpoint theorists.

Feminist standpoint theorists make three claims: (1) knowledge is socially situated; (2) marginalized groups are socially situated in ways that make it more possible for them to 
be aware of things and ask questions than it is for the non-marginalized; and (3) research, particularly focused on power relations, should begin with the lives of the marginalized.

Standpoint theorists generally actively engage groups on the margins of social structures in describing their experiences and perceptions (Campbell \& Wasco, 2000). Practically, feminist standpoint research utilises a variety of methodologies (both qualitative and quantitative) to engage research participants (typically members of oppressed groups) in reflection on how their gender, race, social class, and sexual orientation shape their experiences in the social world. In addition, researchers conducting feminist research are advised not only to reflect upon but also acknowledge how their own social group status influences their interpretations of their data (Allen \& Baber, 1992 as cited in Campbell \& Wasco, 2000). For example, in my own study, how would my status as an older Samoan woman affect my interpretation of the data of this young group of women? What are some of the issues that I should reflect on when analysing the data?

The use of feminist theory should not be misunderstood as 'anti-male' as this is not intended. As bell hooks (2000) proclaims, feminism is for everybody and 'feminism is a movement to end sexism, sexist exploitation and oppression' rather than to specifically exclude anyone (p.1):

Come closer. See how feminism can touch and change your life and all our lives. Come closer and know first-hand what feminist movement is all about. Come closer and you will see: feminism is for everybody (p. $\mathrm{x}$ ).

This sentiment aligns closely to the ideals of Pacific or Samoan feminism in that feminism is seen to benefit not only women but their children, families and the community rather than the individual woman. This sentiment is echoed by Safuneituuga (2005) when he states that 'the legacy of women is one of total achievement... when women succeed, their families succeed and society prospers; this is the Samoan way' (p. 3).

Feminist theory, and in particular feminist standpoint theory, makes an important contribution to understanding the gendered aspects of epistemology and methodology in the social and natural sciences, from the philosophy of science to political activism. This study is committed to feminist values and processes of research because of their ability to remind researchers working with women of the gendered inequalities that can 
sometimes be embedded in social and cultural approaches to doing and interpreting research.

\section{STRENGTHS-BASED APPROACH}

The study is positioned from a strength-based approach. It comes from a positive psychology perspective and emphasizes the strengths, capabilities and resources of a person and moves away from the deficit-based, or deviant approaches to studying a population, which many studies and research on Pacific peoples have taken in the past (Powell, Batsche, Ferro, Fox, \& Dunlap, 1997). Strength-based research builds on advances in strengths-based, collaborative, systemic therapies in the field of family therapy, especially when talking or writing about family resilience. Studies have shown that a strength-based approach that focus on the individual's and community's strengths are more empowering for the participants (Benson, Leffert, Scales, \& Blyth, 1998).

\section{METHODS}

The method used in this research is semi-structured interviews. These interviews were designed for the FTSMs using a two-phase process. Phase one included face-to-face indepth semi-structured individual interviews with first-time New Zealand-born Samoan mothers who were in the last trimester of their first pregnancy. Phase two was face-toface in-depth individual interviews with the same mothers post-birth when their babies were up to 12 months of age.

Semi-structured interviews were also carried out with their family and professional support people, namely the mothers of the first-time mothers (to include intergenerational influences of mothering), midwives and Plunket nurses. Not all the mothers of the FTSMs could be interviewed.

While the focus of this research is on New Zealand-born Samoan mothers rather than Samoan-born mothers, two first-time mothers were born outside of New Zealand but grew up in New Zealand and their formative years were spent within the New Zealand education and health systems.

\section{RATIONALE FOR INDIVIDUAL SEMI-STRUCTURED NARRATIVE INTERVIEWS}

Interviews, as Reinharz (1992) advocates, offer researchers access to people's ideas, thought, and memories in their own words rather than in the words of the researcher. Semi-structured interviews allow for some structured focus but not too much to prohibit the participant from exploring more openly an idea or line of thought. 
The mother and daughter semi-structured interviews were conducted separately. Other studies have utilised the intergenerational dyad interview (interviews with mother and daughter together) approach to try to capture knowledge passed from mother to daughter as a method for eliciting information that may otherwise be overlooked in individual or separate interviews, as well as capturing any relationship dynamics (Clendon, 2009). However, with such interviews there is an assumption that the relationship between the mother and daughter is harmonious and they are comfortable to participate with each other and hear each other's stories. In this study, there was the danger of either mother or daughter not being completely open with each other for fear of offending the other. In Samoan culture, even with New Zealand-born and/or raised mothers and daughters, there continue to exist social expectations of deference and respect to be paid by the daughter to her mother, because she is her mother and because she is older. For this reason, dyad interviews were not considered appropriate and therefore not used. Prospective grandmothers were invited to participate in the study but only with the permission of their daughter. Although most of the FTSMs described their relationship with their mothers as close, only six agreed for their mothers to be contacted for an interview. Some asked if they needed to be in the interviews with their mothers and were apprehensive about this. This confirmed that the decision to hold the interviews separately was the correct one. Of the six grandmothers that were invited, five agreed to be interviewed for this study.

Narrative interviews focus on stories that are told by the subjects (Kvale \& Brinkmann, 2009). These stories may evolve naturally throughout an interview or can be elicited or prompted by the interviewer. Such prompting allows the interviewer to introduce questions about specific episodes or happenings in an attempt to structure coherent stories (Kvale \& Brinkmann, 2009). It also allows the participants to define the themes they deem important whilst simultaneously allowing further areas of interest relevant to this study to be probed. Pacific researchers have utilized the narrative approach when addressing 'sensitive' issues within Pacific communities (Tamasese et al., 2005; Tiatia, 2003). Because the women come from an ethnic community that connects epistemologically and ontologically with other Pacific cultures, the development of Pacific research paradigms (Sanga \& Pasikale, 2002) reminds researchers of the need for cultural sensitivity and for research methodologies and methods that can better pick up on and articulate the cultural nuances of the 'talk' of participants. Pacific research theoretical ideas about cultural sensitivity together with the learning gained from feminist research allows for these sensitivities to be acknowledged as a key part of the 
methodological framework and/or approach (Asiasiga, 2007; Tamasese et al., 2005; Tiatia, 2003).

The concept of narrative interviews developed by Shutze is employed in this study. Shutze argues that narrative interviews allow for the participant to tell of their experience, using their own words to describe their situation, emotions and perceptions (Sarantakos, 2005). It is an approach that emphasises the lived experiences of individuals and this 'experience' is told through their words, as stories or narratives. While some may argue that narrative interviews are subjective and difficult to quantify, or considered a 'weakness', it is, for this thesis, considered a strength, particularly as it gives voice to the participants which helps to provide a genuine or authentic understanding of how they name and ascribe meaning to their experiences. This narrative approach draws on feminist (Harding \& Norberg, 2005; Hill Collins, 1986, 1989; L. T. Smith, 1999), phenomenological, constructionist (Crotty, 1998) and Pacific studies (Fairbairn-Dunlop, 2008a; Gegeo, 1998; Macpherson \& Macpherson, 1990; Wesley-Smith, 1995) insights.

\section{ETHICAL APPROVAL}

Ethical approval was granted from the Multi-region Ethics Committee (MREC). Ethical approval was also granted by the Royal New Zealand Plunket Society Inc. in order for me to proceed with interviews with Plunket nurses. Information sheets and consent forms were given to all the participants (see Appendices). In line with research guidelines (Health Research Council of New Zealand, 2005), the typed transcripts were kept in a locked filing cabinet accessible by the researcher only, and all recordings will be destroyed three years after the $\mathrm{PhD}$ submission date.

\section{CONFIDENTIALITY/ANONYMITY}

Confidentiality and anonymity were key ethical considerations for this research, particularly as the participants were drawn from a relatively small population. Confidentiality is when the researcher is fully aware of who the responses come from but promises not to make the connection in public. As I will continue to be a part of the Samoan community, I am researching long after the thesis has been completed, maintaining confidentiality is just as beneficial to me as an insider researcher as it is to the participants who have imparted their knowledge. As well as my own code of ethics and my duty to the community, I am informed by the ethical guidelines set out by Health Research Council of New Zealand. 
Anonymity directly relates to the participants not being able to be identified by their responses. Individual interviews with all the women were face-to-face and transcribed by me and an external transcriber who signed a confidentiality form. Individual interviews, while confidential, can never be truly anonymous (Sarantakos, 2005) as they are known to the researcher at least. The identities of the participants and their families have been anonymised by the use of pseudonyms and initials (Richards \& Schwartz, 2002; Tupuola, 1998). This minimises the likelihood of identification and is commonly used among qualitative researchers.

\section{ESTABLISHING GOOD RELATIONSHIPS AND RAPPORT}

It was important to maintain good relationships between participants and the researcher throughout the research process, particularly for the first-time mothers who were taking part in the two semi-structured interviews with me. One of the key factors in minimising the drop out of the mothers was creating good rapport and cultivating a good relationship at the first interview. If this was established, then a good relationship usually continued throughout the research process. This type of relationship also had the potential of moving beyond the research and creating a relationship of mutual trust and friendship with the women (Campbell \& Wasco, 2000). In practice, this meant being able to stay in touch via networks most utilised by the women, i.e. cell phone, telephone, internet, particularly for the first-time mothers, during the formal interviewing period and outside it.

\section{CulTural AWARENESS}

There are several current research guidelines that specifically aim to assist researchers working with Pacific peoples in New Zealand; for example, the Health Research Council Guidelines on Pacific Health Research (Health Research Council of New Zealand, 2005). There are also writings by Samoans that identify particular elements of the fa'asamoa (the Samoan way of life) that should be considered when conducting research with Samoan peoples. These elements might also be described as principles, such as the principles of ava (respect), fa'aaloalo (reverence) and alofa (love, compassion and concern) (Ngan-Woo, 1985; Tupuola, 1998).

It was important for some participants to include Samoan cultural rituals, e.g. start or finish the interview with a prayer as a couple of the grandmothers did. Equally important was the acknowledgement of those who did not live in accordance with the lifestyle and expectations of traditional Samoan cultural and social norms (Tupuola, 1998, p. 76). For example, many of the participants, particularly the first-time mothers themselves, did not ask to include any culturally specific activity. As expected, there were 
varying degrees to which the women practiced or observed fa'asamoa, and varying degrees to which they practiced or observed the New Zealand way of life. With these preferences accommodated in the research approach of this study and rapport established, open discussion with each participant was enabled.

The participants of this study were of both Samoan and non-Samoan ethnicities. Each interview started with the Samoan participants locating me in terms of a shared common ground, our ethnicity, culture, family, school, and/or other relationships. This was initiated by the participants. I had anticipated that this might occur as it had in previous research I have conducted with the Pacific and Samoan communities. In practical terms, this rapport-building exercise often meant being flexible with the interviewing time.

Getting to know each other before each interview 'officially started' was important, culturally and professionally. I was, however, concerned that if it transpired that we did share some connections that the participants may be hesitant to talk openly. There was no close connection shared with any of my Samoan participants, and I am confident that they were not hesitant to talk honestly. The way in which the interaction occurred with the Pacific participants did not occur in the same way with the non-Pacific participants. The interviews with the Pacific participants were probably a little less formal and the level of rapport was established sooner than with the non-Pacific participants. In summary, I was directed on cultural and ethical appropriateness by the guidelines for conducting research with Pacific peoples and the advice of my academic supervisors and mentors. This ensured that a level of appropriateness was observed during the entire research process.

\section{THE RESEARCH SAMPLE}

Purposeful sampling derives from a qualitative emphasis on in-depth understanding. 'Snowballing' is a recruiting technique where participants who are taking part in the study may suggest other people who might be in a similar position and interested in taking part. This was used in this study and resulted in the participation of two firsttime mothers. Mothers of the first-time mothers were recruited through the FTSMs as their participation depended on the FTSM's consent in the first place. The researcher's Pacific networks were informed about the research via private social media. In addition, a flyer with the details of the research was sent to various organisations. My contact details were noted on the flyer (see Appendix Nine). This yielded a lot of interest from prospective participants. It also attracted a number of agencies who actually sent 
through pamphlets for me to give to my participants, e.g. from an antenatal mother's group.

The selection criteria for three types of participants for this study were specific: (a) a first-time Samoan mother born in New Zealand or was in New Zealand from the start of primary school; (b) a mother of the participating first-time Samoan mother; and (c) a maternity health professional who works with first-time mothers during the ante- and post- natal periods. The first-time Samoan mother participants needed to be over the age of 16 years at the time of conception (legal age of consent to sexual intercourse).

A total of 35 face-to-face individual interviews was conducted for this study. Participants were recruited from both Wellington and Auckland to add breadth to the selection and all the participants agreed to be interviewed in English.

Individual semi-structured narrative interviews:

(a) New Zealand First-time Samoan Mothers:

Eleven New Zealand-born FTSMs took part in the study and all agreed to be interviewed twice (four women from Wellington, seven women from Auckland). The women were aged between 20 and 30 years. A pilot semi-structured interview was conducted with a Samoan first-time mother in order to check suitability of questions to be understood and generate narrative.

Phase 1: Eleven women participated in the initial face-to-face interviews. All the women were in their third trimester of pregnancy (28 weeks onwards). Topics discussed included demographic information, construction of their cultural positions, their experience of the maternity and health systems; the relationships with family, particularly mothers; expectations of childbirth; expectations of motherhood (see Appendix Four).

Phase 2: Nine women participated in the second face-to-face interviews, and had given birth to babies who, at the time of the interview, ranged in age from three months to 11 months. The second interview explored the experiences of childbirth and early motherhood; coping strategies and the impact of motherhood on their health, wellbeing and relationships (see Appendix Five). Two women did not take part in Interview two as they could not be located. Several attempts were made to contact both women via various networks, known addresses and telephone contacts, but this proved unsuccessful. 
(b) Mothers of the FTSMs

Five mothers of the FTSMs (four from Auckland, one from Wellington) took part in the research. Two of the mothers were New Zealand-born, three were Samoan-born. Topics covered with the grandmothers included their own experiences of pregnancy and motherhood, particularly within a traditional health and maternity system and/or Western health system. The level of influence the mothers' experiences had on their own daughters' expectations from their perspective was investigated (see Appendix Six).

\section{(c) Maternity Health Professionals}

Ten key informant interviews were conducted, five with registered midwives (antenatal care and early postnatal care) and five with registered Plunket Nurses (post-birth care). The key informant interviews provided a subjective observation from those who cared for women pre- and post- birth. The health professionals were not matched to the FTSMs (see Appendix Seven and Eight).

\section{RECRUITING THE MIDWIVES}

Midwives were helpful in placing flyers in their clinical offices. A couple of midwives approached me following a presentation made to a midwifery general meeting. Of the five midwives interviewed, two were of Samoan descent and three were Pālagi.

The health professionals of this study were recruited independently, i.e. there was no deliberate matching of health professionals with the FTSM. Of the midwives interviewed, only two recommended their FTSMs as potential participants. The research received good support from several midwives, who were not only willing to help with recruitment but were interested in participating themselves. But there were times where progress in recruiting midwives was very slow. One midwife voiced her concern, and surprise, that my research did not sit within the Department of Nursing and Midwifery and that I did not have a nursing or midwifery background. Reflecting on that conversation, I became concerned as this may have been an underlying issue with many of the midwives and could have contributed to a lack of interest on their part. I reflected also that, to their eyes, I was perhaps an outsider and hence their reluctance to talk with me or to participate in my research. Many of the midwives were on call 24 hours a day which may have also contributed to them not wanting to take part.

\section{RECRUITING THE WELL CHILD PROVIDERS}

One of the largest providers of Well Child services is the Royal New Zealand Plunket Society (Plunket). The process of gaining access to Plunket nurses involved several steps. An initial meeting with the research manager was needed in order to ensure that I 
fulfilled the requirements necessary for carrying out research with Plunket staff. The first step was to gain specific ethics approval from the Plunket Ethics Committee. Once approval was granted contact, was made with three area managers of the sites that had high Pacific population, i.e. Hutt Valley, Porirua, and Manukau City in Auckland. It was at the discretion of each area manager to decide which Plunket nurse would best fit the objectives of my research. Understandably, the workload of the nurses and their commitments meant the dates that I was to start and finish the interviews were determined by Plunket as was the time of day I could interview. Plunket nurses were specifically selected by the Plunket Area Managers from Wellington and Auckland, based on their caseload and experience working with Samoan women. Of the five Well Child providers interviewed, two were of Tongan descent, one Cook Islander, one Samoan, and one Pālagi.

\section{SMALL GIFT AS PART OF MY ETHICAL PRINCIPLES OF RECIPROCITY}

Reciprocity is key in sustaining and maintaining research relationships, particularly key for Pacific cultures (Health Research Council of New Zealand, 2005). Reciprocity is not restricted to monetary gifts but can be given in time spent with family members, helping with housework, and so forth (Baca Zinn, 1979; L. T. Smith, 1999).

'Meaalofa' is a Samoan term used to mean a gift, literally meaning 'a thing of love'. Meaalofa can be seen as respect, acknowledgement, a token of appreciation, and affirmation of special relationships. In New Zealand, it is synonymous with the gift giving that takes place within many of its other ethno-cultural groups. A voucher and food was provided for all the participants, regardless of where the interviews were held, as was the offer of assistance for transport, which was accepted in only one case. It is important to note that this was part of an exchange of gifts rather than an incentive to participate in the research. At the first interview, the first-time mothers were gifted with a pair of handmade woollen bootees ${ }^{8}$, as well as the food and voucher.

\section{TIME AND PLACE OF INTERVIEWS}

The interviews took between one-and-a-half and two hours. Interview locations were chosen by the participants. Most preferred to meet at neutral places such as cafés and workplaces, particularly for the health professionals and the first-time mothers, as most were still working. At Interview Two the FTSMs preferred interviews at home. This

\footnotetext{
${ }^{8}$ The handmade bootees made by my supervisor, Dr Jenny Neale, were a welcomed gift and, according to the firsttime mothers, were the first pair of bootees they had received.
} 
provided a good opportunity for me to meet with their new babies and for the FTSMs to be comfortable in familiar surroundings. With their consent, all the interviews were digitally recorded. This maintained the authenticity of the interview and enabled extraction of verbatim quotes. Consent to digitally record the interview was part of the participation criteria.

\section{TRANSCRIPTS}

All 35 interviews were transcribed verbatim ${ }^{9}$ Seven were transcribed by an external transcriber, who signed a confidentiality agreement (Davidson, 2009), while I transcribed the rest of the interviews. I listened to the seven interviews sent back by the external transcriber to check for accuracy. Reading the transcripts while listening to the recordings was very time-consuming but it provided an opportunity for me to be taken back to the time of the interview. I was able to recapture the interview itself, the surroundings, the participants' emotions, body language, tone of the voice, the facial expressions, and the interruptions (Sandelowski, 1994). The process of proofing the transcripts provided the text with a backdrop against which I could confidently represent not only what participants said but also how it was said. I had taken time away from the research so the proofing process was critical to reacquainting myself with the data.

\section{DATA ANALYSIS -THEMATIC ANALYSIS}

Thematic analyses of qualitative data such as that gathered in this research involves and acknowledges 'the active role the researcher always plays in identifying patterns and themes, selecting which are of interest, and reporting them' (Braun \& Clarke, 2006, p. 80). Themes do not purely 'emerge' or are 'discovered'. Thematic analysis, as a way of collating, analysing and reporting on the findings of the research, was appealing in that there could be some systematic linking between participant experiences as expressed individually and as groups with the broader theoretical and conceptual issues of concern or interest in this study (Braun \& Clarke, 2006).

Thematic analysis allowed for a careful read of what FTSMs were saying, how they were saying it, whether what and how they were saying what they said reflected their own

\footnotetext{
${ }^{9}$ The term 'verbatim' held different meaning for the external transcriber and me. I requested the recordings to be transcribed verbatim. The first transcript was returned with idiosyncratic elements of speech (stutters, pauses, nonverbal, involuntary vocalisations - umms, aahhs) included (Davidson, 2009). It was agreed that 'verbatim' would include the 'ums' but remove the idiosyncratic elements of speech (intelligent verbatim). This was a good lesson that illustrated an agreed understanding of terms should be addressed at the outset when contracting external transcribers.
} 
realities or a group reality and one or ones that reflected broader social 'realities' or constructions of reality, at least in relation to early motherhood. It meant I could tease out or unravel the surface of 'reality' (Braun \& Clarke, 2006).

Data from all the interviews were entered into the latest version of NVivo10, a qualitative software package that manages large amounts of qualitative data. In the first instance, the interviews were entered into the database as entire interviews. Braun and Clarke (2012) consider six phases of thematic analysis but, as the last phase is the writeup of the thesis, only five levels of analysis are referred to below.

\section{First level of analysis: Getting familiar with the data}

Transcribing my own interviews, and checking the external transcribers' work for accuracy and consistency, gave me an opportunity to absorb myself in the data. Notes were taken during this process and general ideas developed. This part of the process was very time-consuming but it gave me the opportunity to view the interviews in a collective way rather than as individual stories. I read several transcripts in one sitting and found that differences and similarities in the narratives were starting to become clear. At the research design stage, several high-level categories were set: Conception and Pregnancy, Labour and Childbirth, Early Motherhood, following the chronological course of the maternity process. When familiarising myself with the transcript data, it became clear that another high-level category 'relationships' needed to be added. These six themes formed the initial thematic collation areas for the data or participant narratives.

\section{Second level of analysis: Generating initial ideas}

The second level analysis involved the production of initial codes from the data (Braun \& Clarke, 2006). It is at this level that the systematic analysis of the data took place through coding. The qualitative software programme QSR NVivo was utilised to manage data coding. The programme was useful in that it had the ability to code large volumes of text. An extract of text was highlighted and codes generated from that

particular extract. The programme allowed the chunk of text to be coded multiple times under several codes and this was beneficial for later in the analysis. The list of codes was extensive, but at this stage I was mindful to include all the codes as the point of the next stage was to cull or merge codes.

Third, fourth and fifth levels of analysis: searching, reviewing, defining and naming themes. Searching for themes, reviewing potential themes, defining and naming themes was the last and most time-consuming part of the thematising process. Once all the data had 
been coded and collated, I was left with a very long list of codes. The codes were sorted into potential themes or ideas that identified any areas of similarity or any overlap between them. It became clear which codes were too 'thin' or 'thick', and those that were better suited to sub-themes. Reviewing the codes resulted in a refinement of the themes already identified. Defining and naming the themes was the last phase of analysis, by which time I returned to the extracts and organised them in a way that would make sense, providing a coherent and 'internally consistent account' of the theme, with the accompanying narrative (Braun \& Clarke, 2006, p. 92). It was at this point that I was ready to start the write-up.

\section{LIMITATIONS OF THE STUDY}

As with all qualitative studies, the findings are not generalisable across the current New Zealand Samoan first-time mother population. The FTSMs were also only drawn from the Wellington and Auckland region, though the bulk of the Samoan population in New Zealand live within these areas.

\section{DISSEMINATION}

This final stage of the research process is important and connects to Helu Thaman's luva stage of her Kakala research model and the Pacific health research guidelines of the New Zealand Health Research Council. Dissemination of the thesis findings will involve meeting up with the participants in person once the thesis is examined and marked, to deliver an overview or summary of the findings in a report format.

This chapter provided an outline of how the information was gathered and analysed and the underlying thinking associated with the overall bricolage methodology and methods chosen. The next chapter provides a descriptive analysis of the FTSMs' experiences of conception and pregnancy. 


\section{CHAPTER FOUR: CONCEPTION AND PREGNANCY}

'We didn't plan to get pregnant, but didn't do anything to prevent it either...'

Conception and pregnancy is considered a transitional period between not being pregnant and early motherhood. This chapter investigates how Samoan women give meaning to their experience of becoming pregnant; it explores the conception and pregnancy stage of the maternity journey. Life situations of the FTSMs were diverse. This chapter discusses the change-of-life direction at the point of confirming their pregnancy, and the impact this has on their future aspirations and that of their family.

A further focus is the discussion on the concept of personal agency and how that contributes to the way FTSMs make decisions about their bodies in terms of contraceptive use and sex. The FTSMs previous knowledge of sexual reproduction health and sexuality and how these concepts were constructed is highlighted.

The chapter explores narratives around conception stories, knowledge of sexual reproductive health, sexuality, including the use of contraceptives and planning pregnancy. Viewed from a transformative position, pregnancy results in impacting and altering the futures of the FTSMs and their families.

\section{SEXUALITY}

\section{SEX, REPRODUCTION AND SEXUALITY}

WHO offers a working definition of sexual health:

Sexual health is a state of physical, emotional, mental and social wellbeing in relation to sexuality; it is not merely the absence of disease, dysfunction or infirmity. Sexual health requires a positive and respectful approach to sexuality and sexual relationships, as well as the possibility of having pleasurable and safe sexual experiences, free of coercion, discrimination and violence. (World Health Organization, 2006)

Vanessa Griffen (1983) in writing her second manual, Caring For Ourselves: $A$ bealth handbook for Pacific women, attempted to interpret the knowledge Pacific women had at the time about their bodies and how they worked. Griffen aimed to provide comprehensive sexual health information that would be freely accessible to women, in the context of Christian circumscription and traditional cultural conservatism (in Teaiwa, 2010b), and 
to empower women to have more control over their bodies and their health (Griffen, 1983). The holistic viewpoint Griffen offers illustrated the themes associated with sexual health such as education, as well as social and economic factors, knowledge of the body in the context of the sexual reproductive system, menstrual cycles, and various other changes women experienced before becoming pregnant and during pregnancy (Churchward, 2011). All the FTSMs felt there was a lack of communication with their parents, particularly mothers, in anything to do with sexual health or about the mechanisms of how their bodies worked, e.g. menstruation.

Pacific authors have highlighted the importance of fostering open communication between parents and their children about sex education and sexuality and lifting the taboo' off such discussions (Anae, Lima, Mariner, Park, \& Suaalii-Sauni, 2000; Asiasiga, 1994; Fa'asalele Tanuvasa, 1999; Tupuola, 2000, 2004c). Tupuola advocates for Samoan women to have the bravery to 'speak out so that sexuality is defined and shaped by the individual woman' (2004c, p. 123). The development of the idea of sexuality and sexual reproductive health for Samoan women is fraught with conflicts and sexual imagery of Pacific women who have been grossly misrepresented historically (Suaali'i-Sauni, 2000) or as Jolly (1997) describes 'the sexually saturated figure of the Polynesian woman and the way in which she is represented in successive European visions' (1997, p. 99). Learning about sexuality is a cultural dilemma for young Samoan women, and the opportunity to do so is limited (Tupuola, 2000). Samoan attitudes and thoughts about sexuality have been framed within the context of Christianity, maintaining a strong influence over the way Samoan women view sexuality (Asiasiga, 1994; Tupuola, 1998). The Polynesian beauty has been personified as a sexually active, sensual, promiscuous and exotic being in direct contrast to the way in which the Samoan strict 'codes of conduct' have obstructed the development of Samoan sexuality (Suaali'i-Sauni, 2000; Tupuola, 2004c). There are several factors inhibiting young Samoan women from discussing topics considered tapu, particularly sexuality, not only in the presence of adults but also in discussion with adults, as it is viewed as violating Samoan principles of fa'aaloalo (respect) and ava (reverence) which severely inhibits any discussions on that topic between parents and children (Anae et al., 2000; Fa'asalele Tanuvasa, 1999; Tupuola, 2000).

Fa'asalele Tanuvasa (1999) in her research exploring contraception use and abortion among Samoan women living in New Zealand found that, while Samoan women were keen to openly discuss sexuality with their families, it was hindered by the cultural view that sexuality and reproduction are topics that directly relate to the "private parts of the body' which are considered sacred and therefore tapu to discuss. Tupuola (2000) argues 
that it is critical to involve young people in sexual health programmes and services, and the construction of the programmes should be from the perspectives and world views of the young people themselves. Christianity, with its conservative views, has a strong influence in the way Samoan women view sexual identity and sexuality (Asiasiga, 1994; Tupuola, 1998). Considering the high number of Samoans who affiliate with a religious denomination, it is little wonder these conservative religious teachings affect how women construct ideas about their bodies.

Discussion about sexuality between parents and children is difficult, particularly as the parents themselves are uncertain how to broach the subject or how to talk about sexuality as they do not have any model on which to base these conversations. School, either primary or secondary school, was a place where FTSMs learned about the basic mechanisms of how the body worked and sexual reproductive health. Many of them recalled the sex and health lessons being taught in their schools:

They always have the Johnson \& Johnson talk, so that answered most of that stuff and then you just pick up things... I guess what you would call the birds and the bees kind of talk. (Sita)

New Zealand's policy ${ }^{10}$ for teaching sex education is for all schools to include it as part of their curriculum. However, the delivery of the learning outcomes is up to the school and community it serves, so there is a lot of variation in how, and when, students are informed.

It was probably at intermediate, form one and two, where I learnt about the period, your body and all that. (Alma)

Sexual education at school started at fourth or fifth form, by then I was already aware of what was involved. I knew about sex before we were even taught... from watching movies or seeing it on TV. (Maria)

Many of the FTSMs discussed their menstrual cycles and sex in detail with sisters, friends and cousins who they were close to, felt comfortable with, and could confide in:

\footnotetext{
${ }^{10}$ Sexuality education is one of the key learning areas for New Zealand students from years 1-13 (primary to secondary school, i.e. five years old to approximately 18 years old). The New Zealand Curriculum is the official policy relating to teaching and learning outcomes in New Zealand schools. All schools must incorporate sexuality education as part of the school curriculum; schools must consult with their communities when developing health and sexuality education, hence there may be differences in the delivery of the learning programmes.
} 
My girl cousins introduced us to different things and I remember when she [cousin] pulled out a tampon, we were like, what the hell is that? And she showed us different things. (Maria)

Most of the FTSMs felt that discussing menstrual cycles and sexual health with their mothers was difficult to initiate and really 'awkward', but Geraldine had an open and honest relationship which made it possible:

My mum sat me down 'cause I think I must have asked her in primary school and she brought me this science book about the human body. She explained [and I thought] oh, that's how babies are born. I was traumatised and I went to school and told all my friends; they thought I was lying 'cause we all thought it came out of your belly button. When I told them the truth they thought I was sick... yeah, we always laugh about it because my mum said maybe you were a bit too young to tell you. (Geraldine)

The lack of discussions with parents about knowledge of the body in the context of the sexual reproductive system, menstrual cycles, and other hormonal or bodily changes was clear from FTSM's narratives.

The intergenerational 'silence', a term coined by Park and Morris (2004) on matters sexual in older age groups of New Zealanders is not confined to Samoans but is also prevalent in other ethnic groups. Russell et al (2013) conducted research with Māori rangatahi ${ }^{11}$ and their whanau to find ways to improve communication on sexual reproductive health within families. The research illustrated that while some kaumātua ${ }^{12}$ of the whānau ${ }^{13}$ did not openly discuss sexuality matters with their children, they perceived their relationships with their mokopuna ${ }^{14}$ to be more open and felt that they were more inclined to discuss sexuality matters with rangatahi or the younger generation. However, rangatahi indicated they did not discuss sexuality matters with any of the older generation, including their grandparents (Russell et al., 2013).

Studies have shown that a lack of knowledge and discussion about sexual reproductive health may be a contributing factor to high teenage pregnancy rates, mostly unplanned, in New Zealand, which is ranked high among the OECD (Statistics New Zealand,

\footnotetext{
${ }^{11}$ Rangatahi: youth/young people (singular or plural)

12 Kaumātua: respected elder/s

${ }^{13}$ Whānau: family/families

${ }^{14}$ Mokopuna: grandchild/ren or grandchild/ren of a whānau member in the same generation
} 
2003). Internationally, Holland has the lowest rates of teenage pregnancies and this may be attributable to societal attitudes to sexual reproductive health. Sex education is integrated into the school curriculum via various subjects and it is given a similar priority to other academic subjects (Berne \& Huberman, 1999). Furthermore, Holland holds both the community and individual responsible for the consequences of fertility. Sex is discussed in a positive light within the family setting from an early age. Rights, responsibility and respect are values that underpin the social philosophy of adolescent sexual and reproductive health (Berne \& Huberman, 1999). So as young people become sexually active, they are more likely to be prepared to make informed choices. The USA has one of the highest rates of teenage pregnancies where attitudes are influenced more by Christianity and where abstinence is taught in the schools (Kohler, Manhart, \& Lafferty, 2008).

Interestingly, the FTSMs reported that from pregnancy to post-birth their mothers became more open, some very open, with them about sexuality and sexual health. This perplexed many of the FTSMs as they felt it was 'obviously, too late'. For example, Anna spoke of how her mother quite unexpectedly started talking about how birthing 'wrecks your vagina'! And that was by way of making the suggestion of having a caesarean rather than a natural (vaginal) birth.

She [mother] goes, 'oh, it wrecks your vagina and you will never be the same', and we were like, 'what, did you just say vagina?' I was like, 'oh my gosh mum'. She's a 60-year-old Samoan lady and you don't expect that to pop out. She was like, 'oh yeah, you should have a caesarean'. It scared me a bit, I was like, 'what?' and yeah, people have said, 'it's never the same after that', but that's not really a concern. (Anna)

\section{CONTRACEPTION}

\section{CONTRACEPTIVE KNOWLEDGE AND ABORTION}

Contraception is the use of temporary, long-term or permanent methods to prevent pregnancy. Condoms are used to prevent pregnancy and protect again sexually transmitted infections (STIs). Strong connections to religious institutions/Christian beliefs, side-effects, lack of information about services, family and cultural values have been found to be underpinning the lack of contraceptive use by Samoan women (Abel et al., 2001; Donnelly, 1992). The high social and cultural value placed on children, the fear and embarrassment of attending a family planning service and a lack of discussion about sexuality and sexual reproductive health are seen as real barriers to accessing 
contraceptive services for many Pasifika people (Asiasiga, 1994; Collins, 2005; Fa'asalele Tanuvasa, 1999).

The FTSMs were asked about their historical contraceptive use, and in other relationships, rather than their knowledge about the particular types of contraceptives available. They reported they had used contraceptives in the past. If their current partner was their first sexual partner, they reported using contraceptives during the relationship. This suggested a high level of contraception literacy. Contraceptives the FTSMs mentioned were the pill, the injection and condoms.

In 2008, 2,230 Pacific women had an induced abortion registered in New Zealand. These numbers are a slight increase since $2006(2,134)$ but the numbers are lower than for European (10,499), Māori (4,250), and Asian (2,875) women (Statistics New Zealand, 2008a). However, Pacific women are overrepresented in the number of stillbirths and terminations after 20 weeks (New Zealand Ministry of Health, 2012b). Abortion is a very sensitive issue, particularly with Samoan people as it goes against their religious values where pregnancy is perceived as a 'gift from God' (Asiasiga, 1994, p. 9). However, under particular circumstances, like rape or a threat to the state of the woman's health, abortion is considered acceptable. As Asiasiga (1994) found, the cost of shaming the family with a pregnancy out of wedlock was a greater burden to bear than having an abortion.

Morality (e.g. personal or family principles and values that govern behaviour), personal choice and autonomy over one's body featured as reasons for considering abortion as a serious option. The FTSMs were divided in their attitudes towards abortion. Some were definitive in their views that abortion was wrong, it was against their religious convictions and their own beliefs, and others felt that although terminating a pregnancy was not an option for them, they were not averse to abortion being available to other women; while some considered abortion to be a choice for individuals and their situations. Only one of the FTSMs had had several previous pregnancies. During the interview she talked openly about undergoing several abortions in the past and the reasons behind those decisions ${ }^{15}$ :

When I was around 20 or so, and no one really knows this apart from [my partner] and my close friends, I did fall pregnant and did have a termination, well I had a few. Since then, I know I have been careful

\footnotetext{
${ }^{15}$ To add another layer of anonymity to protect her, her pseudonym is not included.
} 
but nothing had ever... that hadn't happened again and I kind of thought, oh, maybe something had gone wrong there... but then obviously not.

I had three [terminations] in the end. I was with a partner; it was the same partner for all three. I knew it wasn't a very healthy relationship, and I think that's why it wasn't really an option to have the baby. He was older than me as well... yeah, I wasn't wanting to go in that direction especially with him which is weird, why would I stay in a relationship with him if I knew I would never, you know, but I think I was just young.

The woman described going to the clinic on the day of her abortion and her feelings of 'shame' and concern about who she might meet in the waiting room. She described a day when, to her horror, she bumped into her mother in the foyer of the hospital on the morning of a termination:

I was walking in [to the termination clinic] and my mum was walking out, and you know, she has no idea about any of this. She was visiting my aunt who had just given birth and she said, like, 'what are you doing here', and it was just like, 'I am coming to see aunty'... it was my mum of all people.

Staying in a relationship that, by the admission of the woman herself, was unhealthy offered her no future and was why each time she fell pregnant she underwent an abortion. This complex and complicated situation ended. The woman then became very concerned about the impact that the multiple abortions may have had on her fertility:

I noticed periods were different, cramping and stuff, but I thought it could be 'cause I was getting older. I knew there was a significant change after the last termination and then I thought maybe I can't get pregnant, I know that I haven't been safe 100 percent of the time, but yes, so I did worry that something was wrong, but obviously not.

The FTSMs were open about discussing abortion or the possibility of other alternatives. A couple of the FTSMs reported they seriously considered other options if their partner was not committed to the relationship as they were not keen to be single parents: 
I think I would have thought more of a termination... I knew I was ready but, of course, no one wants the solo. You don't want your child growing up without a family. I don't know if he [partner] wasn't [prepared to stay], I don't know whether I would still be pregnant or not. (Anna)

\section{CONTRACEPTIVE PRACTICE}

Sexual health literacy was not an issue for most of the FTSMs who were aware of the contraceptive methods available and were cognisant of the consequences of engaging in unprotected sex. As FTSMs used contraceptives to prevent pregnancy, the type of contraceptives chosen was not necessarily going to protect against STIs.

The FTSMs provided multiple reasons why they did not use contraceptives. These included: opportunistic sexual encounters, a casual approach to sex, planning a pregnancy, lack of knowledge about accessing contraceptives, and doubts about their fertility:

No [I was not using contraceptives] because D was my first, we weren't going to have sex, but we ended up having sex and this and that and then fell pregnant. (Alma)

I think it was a decision that we both made that we were ready to start settling down and stuff. (Ellen)

Though infertile, they [doctors] only educated me because of my polycystic ovaries; they did tell me to still use protection because you never know, and not just because you might get pregnant, but there are other things like STDs. (Maliaga)

The school nurse played a major role for Lola:

At school they gave you boxes of condoms and pills. I used to take them, but then when I finished [them] I didn't have any more because school is finished, and I don't know where to get those from so that was what happened. I didn't know where to get some from. (Lola)

What seems to be lacking in the literature is the perspective of partners in relation to contraceptive use and unplanned pregnancies (Jackson, Karasz, \& Gold, 2011). Some FTSMs stated that their partners were part of the decision to discontinue using contraceptives, while others reported that their partners were unaware they ceased using 
contraceptives (excluding the use of condoms). It is not uncommon for older Samoan men to consider contraception as a woman's responsibility, whereas younger Samoan men view contraception use as a 'shared responsibility' (Anae et al., 2000). The majority of the partners of the FTSMs were Samoan. The point of difference between some planned and unplanned pregnancies was the partners' knowledge of contraceptive use:

He asked me if I was on anything, and he was quite a gentleman about it, he said he didn't want to force me to do anything I wasn't really ready for. I think he was just mainly scared that I might fall pregnant to him. It was like, kind of regrets that we were weren't together for a long time, but it was just him thinking about it for both of us. We talked about it and then I never actually told him that I got off it, I just randomly stopped taking the pills, and I didn't realise that I got pregnant after taking the pills, like, you know, [until] later on down the track. (Ellen)

Patricia stopped the Depo Provera Contraceptive Injection after two and half years to give her body a rest from the drug. She was also concerned what impact the long-term use of Depo Provera would have on her menstrual cycle. Her partner was keen to start a family and supported her decision. Patricia read that it could take up to two years for her menstrual cycles to regulate after being on Depo Provera. It was a year before she fell pregnant:

Yep, I was on the jab. I can't remember what it's called, I went on that for the first two to two-and-a-half years and then I stopped because I was scared. Ever since I was little, because my periods were irregular and I thought it might muck up something down there, and so I decided to stop. (Patricia)

The influence of culture and religion create the heteronormative conditions in Christian Samoan culture where it is considered the norm for a man and woman to engage in pro-creational sex:

The terms 'consciously' and 'planned' are synonymous with being in control of fertility and thus making choices that lead to becoming pregnant. Underpinning the cognitive reasons for planning or not planning pregnancy, are assumptions of heteronormativity which refers to the 'myriad ways in which heterosexuality is produced as a natural, unproblematic, taken-for-granted, ordinary phenomenon' (Kitzinger, 2005, p. 478). 
Heteronormativity, combined with religious beliefs and the high value of children in Samoan culture may further explain the lack of contraceptive use among the women. (Churchward, 2011, p. 65)

Therefore, contraception seems contrary to Samoan social and cultural norms:

Maybe it was like something that God told you, like, just maybe have him [son], who knows. He will be like a good gift or something for me, like, maybe he will change everything that happened in your life, and maybe he will be that person. So, I decided to keep him. (Lola)

After we got married we decided that we would just leave it [stop taking contraceptives] and I guess whatever blessings God had for us we would just let it be, seeing as we were married now, so under the covenant of marriage. (Sita)

Lola's and Sita's stories demonstrate the entrenched strength and faith they had in their spiritual religious beliefs. Both are practising Christians. Lola was in a long-term relationship until she found out her partner had fathered another child during this time. Three months after her relationship breakup, Lola went to the doctor but had a negative pregnancy result. It was another two months after that the pregnancy was confirmed at which time it was too late to have an abortion, something she would have seriously considered. She trusted her faith in God, and was still coming to terms with the breakup. She pinned her hopes on her unborn son being 'that person' who will transform her life, which can be seen as a retrospective benefit or secondary gain. Sita's pregnancy was intentional and planned. She considered her conception was in the hands of God. Sita's justification that her pregnancy was within her heteronormative understanding of the sanctity marriage illustrates the concept.

Within Samoan culture, constructions of pregnancy is considered a natural and normal event that is part of life, inextricably tied to religion, where children are valued as gifts from God Midwives interviewed for this study reported that many of the Pacific women they engage with have a different perspective on pregnancy:

As far as having babies or children or giving birth is concerned, a lot amongst our Pacific population groups, many of our Pacific women just see, I mean just treat, pregnancy and giving birth as normal. It's not abnormal, ah, what will be will be... if your baby is born normal that's fine, if your baby is born abnormal, to them normal and 
abnormal are synonymous... it's [baby] a gift from God... because the whole ethos, once again, around pregnancy and having a baby within a Pacific paradigm is that it's all part of the normal. (MWA5)

\section{FERTILITY ISSUES}

The narratives revealed 'suspected' or 'perceived' infertility as a reason why some FTSMs either did not use or discontinued the use of contraceptives. Some FTSMs suspected they were infertile due to not getting pregnant previously after having unprotected sex, so they convinced themselves they could not get pregnant. Maliaga was officially told by her general practitioner (GP) at a young age that she had a very slim chance of getting pregnant due to her medical condition, polycystic ovary syndrome. Maliaga was using contraceptives during her relationship, to protect against STIs rather than avoid pregnancy. When her relationship developed into a serious and stable union, she decided to stop using condoms. Her intention was to stop what she perceived to be the unnecessary use of condoms. Her pregnancy was unplanned and a surprise to both her and her partner and she did not realise until she was 13 weeks pregnant:

When it happened, the first thing I thought was wow, this is a blessing and somewhat a miracle. When I told him [partner] I was pregnant, he was like, 'are you sure?', and I said, 'I think I am'. (Maliaga)

One of the consequences of an unplanned pregnancy was not knowing early enough in the pregnancy, which poses a risk to continuing unhealthy behaviours. This was the case for some of the FTSMs, who continued to smoke and drink alcohol up to 12 weeks into a pregnancy. A few of the mothers were smokers and stopped as soon as their pregnancies were confirmed. A couple of the FTSMs were unaware of their pregnancies and continued to socialise, or smoke cigarettes:

I was very social, you know, we were, me and my friends we were out in the weekends, you know, Friday drinks and you know that kind of thing, not that I was drunk every weekend but you know we'd go out and we'd have fun and we'd dance the night away and stuff and obviously once I realised I was pregnant, that came to a grinding halt. (Anna) 


\section{PregnanCy}

\section{WHAT IT MEANS TO BE PREGNANT}

Terminology used in the literature related to conception and pregnancy include 'intentions of pregnancy' that involve ideas of 'intended-unintended', 'timed-mistimed', 'planned-unplanned', 'accident', 'mistakes', and can incorporate 'unwanted-wanted'. These binary framings often conjure negative meanings but can also cause confusion around the meaning of such terms (Cyna et al., 2006; McQuillan, Greil, \& Shreffler, 2010; Rosengard, Phipps, Adler, \& Ellen, 2004; Sable \& Libbus, 2000; Singh, Sedgh, \& Hussain, 2010; J. L. Smith, Skinner, \& Fenwick, 2013; Stevens-Simon, Beach, \& Klerman, 2001).

It is well documented that the indigenous Samoan concept of pregnancy (ma'itaga, ma'ito) is as an illness or a sickness (Kinloch, 1985; Macpherson \& Macpherson, 1990; Tui Atua, 2009). Ma'itagata, more commonly known by its shorter name as ma'itaga, essentially is to be ill (ma'i) with a new tagata (human being) (Tui Atua, 2009, p. 119). Tui Atua Tupua Tamasese Ta'isie Efi (2009) provides a snapshot of the traditional Samoan world view of conception:

The term [ma'itagata] suggests a Samoan understanding of when human life begins. It implies that human life begins as soon as conception occurs. From the moment the egg is fertilised and the mother experiences the symptoms of conception, a human life is said to exist. Here the foetus is recognised as a person. As a person the foetus gains a sacred essence. It becomes tapu. When the foetus is deliberately terminated a breach of tapu has occurred. Pardon must be sought for this breach. Promotion and protection of human life is implicit in the respect that the fa'atosaga (traditional birth attendants) give to the unborn child. Sex is respected as much for its potential to make life and continue family genealogies as for its potential to connect two living souls. Ideally, conception is the product of two souls coming together. After conception and during pregnancy expectant mothers are known to go off sex, food and husbands. Usually in the fourth month of pregnancy a noticeable calm takes over, which the fa'atosaga suggest is the time when the body of the mother and the body of the child have reached a physical, emotional and spiritual accommodation. This prepares both mother and child for the next significant phase of giving life, which is giving birth. Throughout the process from conception to birth, the main job of the fa'atosaga is to steer the mother using massage and good advice towards a successful birth. The moods of depression and abnormal 
appetite can easily put many pregnant women out of balance, mentally, spiritually and physically. The fa'atosaga's regimen of fofo and counselling is holistic. It considers the need for balancing the harmony of the mind and body of the mother paramount, ensuring that these are in balance with the growth of the unborn child. The relationship between the mother and the unborn child is sacred (p.119).

Samoan people see sickness as an inevitable, unpredictable, and as a powerful discontinuity in the flow of life, a disruption of social order. But sickness can also create. One reason the midwife in Samoa has high status is that she participates in the treatment of sickness as a creative process. Sickness events can result in a 'reorganisation of the group which is advantageous to everyone concerned' (Kinloch, 1985, p. 204).

The majority of women have their pregnancies confirmed by a GP. The idea of pregnancy as illness is suggested by 'going to the doctor.' Two other features of illness are associated with pregnancy in modern industrialised society: a pregnant woman, like other 'patients', is allowed to give up her normal work, and is 'encouraged to hand over responsibility for the management of her condition to others (the medical profession)' (Oakley, 1979, p. 46). Furthermore, the physical symptoms that pregnancy produces are also signs of illness, e.g. vomiting, changes in bowel habits, frequent urination, excessive tiredness, abdominal pain, backache. Even in pregnancy some of these require medication, something not normally associated with good health (Oakley, 1979).

\section{PlaANED AND UNPLANNED PREGNANCIES}

Bandura (2001) considers intentionality to be the core feature of personal agency (i.e. an individual behaving in a way with a specific intention) and writes that intentions and actions are different aspects of a functional relation separated in time' and it is therefore meaningful to 'speak of intentions grounded in self-motivators affecting the likelihood of actions at a future point in time' (p. 5). Questions of intent are critical to gaining a proper understanding of what 'intentions of pregnancy' means from the viewpoint of the first-time mother (Joyce, Kaestner, \& Korenman, 2002).

The intention to get pregnant is measured or assessed during pregnancy or post-birth, rather than before conception. One of the few international longitudinal studies assessing the pregnancy intentions of sexually experienced female adolescents was conducted in the USA among those who attended STD and health clinics (Rosengard et al., 2004). These adolescents, who were not pregnant at the time, were asked to report 
'any' or 'no' pregnancy intentions using different combinations of pregnancy plan types or likelihood predictions or perceptions. While the majority indicated they had no plans to become pregnant within six months, there was large variability in their assessment of a likelihood to become pregnant in that time (Rosengard et al., 2004). The FTSMs were asked about their intentions of pregnancy retrospectively when most were in their last trimester of pregnancy. Research reports show that women tend to become more accustomed to an unplanned pregnancy over time and that intention and the desire for pregnancy increase with time after conception (Joyce et al., 2002).

A study by Pulley et al (2002) examined the categories of intended, mistimed or unwanted pregnancy, and assessed associations between pregnancy mistiming and maternal characteristics such as education, marital status and age. They found that a pregnancy mistimed by a few months has few consequences for the mother, child or family; mistimed by more than a few months can have great consequences and represent a public health problem. 'Seriously mistimed' pregnancies occur more frequently with those who are poor, less-educated or black. This has implications for providing better family planning services and provides insights into women's health behaviours. It should not be assumed that 'mistimed pregnancy' is a unitary concept as it should include the extent of the mistiming. The FTSMs perceived their pregnancies to be mistimed rather than a 'mistake'. A mistake suggests an act of misjudgement or carelessness, whereas mistimed depicts an earlier than expected event that had intention. Patricia ceased using contraceptives. It was a year before she fell pregnant. Patricia's pregnancy was neither planned nor unplanned but, for her, it was seriously mistimed:

We weren't planning, but we weren't worried if I did [fall pregnant]... it was more of a relief for me, like, okay I can have a baby. Even though sometimes I think, you know, well for me - he doesn't care - I wanted another year at work because I wanted to travel. I was really wanting to travel, but he keeps telling me not to worry about it, we can travel with baby, I'm like, 'it's not the same', but he said, 'it doesn't matter.' It has hit me a lot emotionally... like, all my friends are travelling. I hear about all my friends, my friend has just gone for a big trip for two months to all these other places, China, Europe. My other friend is saving up for America and I'm thinking for the rest of my life I can't go and come back. I was thinking, oh I should be happy I'm already pregnant, I will look at the positives. (Patricia)

A planned pregnancy involves an intention and purpose to conceive, and to a certain extent, some level of organisation, i.e. ceasing to use contraception, partner agreement, 
although this may not be so, and reaching the 'right time' in terms of lifestyle, and life stage (Barrett \& Wellings, 2002). An unplanned pregnancy or an unconscious decision to become pregnant is interesting and warrants a deeper awareness of the phenomenon insofar as it helps towards a better understanding of the decision-making contexts of the FTSMs.

Women who strongly desire to avoid pregnancy select an effective contraceptive method and use it consistently, which was the case with Sita who controlled the timing of when she ceased contraceptive use. Sita meticulously planned the timing of her pregnancy by continuing to use contraceptives until she was ready to conceive:

Yeah, as soon as we got married I just stopped taking contraceptives. (Sita)

Her strong desire to avoid pregnancy previously is reflected in her consistent and reliable use of contraceptives. Her rationale for planning the pregnancy was driven by her cultural belief in the sanctity of marriage, the approval of family and economic stability to care for the child:

So, being Samoan we weren't going to have kids out of wedlock, so that was the biggest thing. I think it's mainly your parents' approval... you don't want to be the one or the child that embarrasses your family. I just wanted to make sure that we did it in the right order, and also at the same time it would help with us, once we were married and settled, to be able to support the child and that sort of stuff, so it was mainly to do with the... based on the parents as well as culture and then financially. (Sita)

Sita's motivation and intent to become pregnant was driven by her perception of what it was to be a good Samoan, behaving within cultural norms, and the beliefs and values of her parents. Her deep desire to please her parents by conforming to their beliefs ensured that her behaviour was in line with those constraints and did not jeopardise her family honour in any way. Whereas women who are undecided about pregnancy might consider the cost of contraception as higher than the cost of pregnancy (Lifflander, Gaydos, \& Hogue, 2006).

Women with unplanned pregnancies were significantly more likely to have been in situations where they stood to gain from a pregnancy (Harris \& Campbell, 1999). Evidence of potential secondary gains prior to pregnancy can imply the presence of 
unconscious motivating factors to become pregnant. Their claim would seem to support the idea that unplanned pregnancies are, at some level, planned, yet the authors are clear they are not suggesting that women deliberately become pregnant to trap partners or achieve those secondary gains. It does seem that women with something substantial to gain, from pregnancy, or those who do not care either way, are those who end up having unplanned pregnancies, further supporting the idea that situational causes play an important role in the timing of unplanned pregnancies (Harris \& Campbell, 1999). Another author suggested that women are calculating the costs and benefits of action to avoid or encourage pregnancy and when the benefits of pregnancy are high, unplanned pregnancy is a likely outcome (Luker, 1975 in Harris \& Campbell, 1999). Identifying the perceived benefits of pregnancy can appear to be judgemental and portray women as behaving in a deviant manner by intentionally 'getting pregnant' to gain social or economic capital. While this might be true, at the same time the social and economic benefits of pregnancy may be just as valid as the cultural and religious benefits that are provided by an unplanned, unexpected pregnancy even though they serve different purposes, i.e. personal gain vs collective gain.

The concept of 'secondary gain' from pregnancy helps to measure the extent a woman might have felt that a pregnancy, or motherhood in general, could change or restructure her situation for the better (Harris \& Campbell, 1999). Secondary gains of pregnancy might include autonomy from parents, escape from work, stronger emotional bonds with a partner, and if a sister or colleagues were having babies. Secondary benefits include a way to solidify a new and unstable relationship, clarify to others a real relationship, avert a threat to a key relationship, heal a rift, and alleviate financial or emotional circumstances. It should be noted 'that unconscious motivations are so deepseated as to be unobservable, and must be taken on trust' (Harris \& Campbell, 1999, p. 2). For example, unconsciously not using contraceptives might be seen as quite natural as it is the 'norm' for a man and woman to have a baby, whether planned or unplanned.

Other studies have a third category of women who were 'okay either way' about becoming pregnant or not becoming pregnant (McQuillan et al., 2010). This was the case for most of the FTSMs. Previous research found Samoan women saw that pregnancy planning is not a concept that is important in Samoan culture and if a woman is pregnant, she is pregnant' (ibid p. 156) and that each pregnancy is viewed through a 'humanistic environment' as Fa'asalele Tanuvasa (1999) argues, as children are considered part of the extension and development of the human family and are kin. The cultural and religious aspects, which have been discussed previously have a powerful influence on pregnancies, planned or unplanned. Some young Samoan women 
may deliberately get pregnant to dishonour their families and escape particular forms of punishment or adherence to a strict upbringing (Tupuola, 2000).

In New Zealand, Pacific mothers have a high rate of unplanned pregnancies with one study finding well over half (60 percent) of their mothers stating their pregnancies were unplanned and, of those, almost three quarters were not using contraception when they conceived (Paterson, Cowley, Percival, \& Williams, 2004). Paterson et al. (2004) suggest that higher education, being born in New Zealand, and living longer in New Zealand are predictive of a planned pregnancy over an unplanned pregnancy. Reasons given by mothers for not using contraception were they never thought about contraception; they did not like using contraceptives; decided to take a chance, and did not want to gain weight (Churchward, 2011). The high rate of unplanned pregnancies among Pacific mothers is supported by another large study that found 40 percent of the babies were unplanned, thus the unborn babies may be exposed to health risks by the mother's drinking, unhealthy eating and smoking before she realises she is pregnant (Morton et al., 2010). Almost a third (31 percent) of the participants in the Morton study who fell pregnant unplanned drank alcohol during the first three months of their pregnancy, compared with only 17 percent of the women whose babies were planned. This highlights the importance of informing young women and girls about healthy diet and lifestyles (Morton et al., 2010).

Unplanned pregnancies have been linked to poor infant outcomes in part because women who have unplanned pregnancies that continue to term have fewer opportunities to benefit from pre-conceptual and early antenatal care (Bouchard, 2005). Although research on unplanned pregnancies appears to be focussed on teenagers, it seems that unplanned pregnancies are on the increase among adults (Bouchard, 2005; Morton et al., 2010).

To avoid becoming pregnant requires a certain level of commitment; if the commitment is lacking, contraceptives will not be used consistently or engagement in unprotected sex is more likely (Stevens-Simon et al., 2001).

Women possessing several characteristics of an unplanned and unconscious decision to become pregnant indicate a lack of a 'firm commitment' and therefore they do not use contraceptives consistently (Stevens-Simon et al, 2001 as cited in Churchward, 2011). This seemed to fit the characteristics of decision-making about engaging in unprotected sex for many of the FTSMs: 
I guess we weren't as careful as we should have been, obviously. A bit blasé; I am not sure why because I've been so careful with everything else, you know, for the last so many years, so we were a little careless there. (Anna)

Anna was perplexed as to why she had chosen not to be as careful and use contraceptives on this occasion, even though she had made a 'firm commitment' not to become pregnant years previously. She describes her and her partner's attitude to the use of contraceptives as 'blasé' and 'careless' which led to risky behaviour and 'getting pregnant unplanned'. Importantly, she commented on the lack of contraceptive use as a 'shared responsibility' with her partner. Bandura (2001) addresses this as a functional dimension of 'intention' and writes that 'outcomes are not the characteristics of agentive acts; they are the consequences of them' and adds that actions intended to serve certain purposes can cause quite different things to happen (p. 7). Anna and her partner's intention was to have sex; the intention was not to become pregnant but to enjoy the sexual act, and the consequence was an unplanned pregnancy. Furthermore, 'most human pursuits involve other participating agents. Such joint activities require commitment to a shared intention and coordination of interdependent plans of action' (ibid. p. 7).

\section{TELLING FAMILY THE NEWS}

The FTSMs wanted to maintain full responsibility for what they had created, and coming to terms with their pregnancy was marred by the realisation that sooner or later they would have to tell others, especially their parents. FTSMs' expectations of how others would react heavily influenced how they approached the situation and how they viewed their future.

Announcing the pregnancy to family and friends now made impending motherhood a public reality for the FTSMs and highlighted the impact a child was going to have on their lives. The FTSMs soon understood the significance of preparation not only for the birth but for motherhood:

Every now and then I have the 'oh, lifetime of responsibility, oh God', reality checks, panic attacks. (Anna)

There were diverse attitudes when the time came to announce the pregnancy to family and friends, particularly if the pregnancy was unplanned and the FTSMs were unmarried. The preservation of their relationships with family was absolutely critical, 
and the news of a pregnancy had the potential to threaten those relationships and alter their connections. Disappointment, family shame, bringing the family name in disrepute may have contributed to why some of the FTSMs were hesitant to announce the pregnancy, even though they were confident their parents would support them.

Almost all of the FTSMs reported feeling anxious, 'scared' and worried about informing their parents of their pregnancies. Their underlying anxiety and fear may be attributed to the Samoan cultural view that pregnancy out of wedlock is associated with 'shame' and 'embarrassment' for the individual and their families (Churchward, 2011). This was coupled with the possibility of the negative impact their news could have on the relationships with their parents. It was a daunting prospect for many of the FTSMs and this influenced the way in which they told their parents:

My hands were shaking, and then I told them. I thought my dad would be angry but he wasn't, he just said, 'the baby is a blessing, take care of yourself'. (Alma)

Patricia and her partner were excited to tell his parents about the pregnancy and chose a novel way to reveal the pregnancy:

We got them [partner's parents] presents after we came back from their 25th anniversary and they said, 'I love my grandma' so they clicked. It was nice and happy and the dad cried, the mum was happy... and then we had to tell my parents. (Patricia)

Announcing the news to her partner's parents, whom she described as 'more New Zealand', was in direct contrast to how her parents were informed, whom she described as 'traditional strict parents'. Patricia received a text summoning her home after work. Unknown to Patricia, her partner had earlier met with her father and asked permission to marry Patricia. At the same time he revealed her pregnancy:

I got a text from my sister saying 'dad said you have to come home straight after work', and I was thinking oh, my gosh, I feel like I'm in high school again. We went back and we had a talk with my parents, I was crying... I think because out of all my brothers and sisters I'm the only one that ever finished Uni and got a job. All my sisters and brothers, they're all kind of naughtier. I think out of all of them I never got a hiding from them [parents]. I just never did anything bad to get a hiding... and this is the first time they were like, shocked. (Patricia) 
Patricia's news of her pregnancy made an immediate impact on her parents, who were shocked, but more concerned that she was unmarried. Patricia felt that she had fulfilled many of her parents' expectations when she was growing up and she felt responsible for her parents' initial deep sense of disappointment. However, Patricia would not be persuaded into marriage for the sake of the pregnancy. Parental or family expectations for the FTSMs to achieve the success that they had not achieved themselves, was often the catalyst for the perceived parental disappointment.

The worry that they would disappoint their parents was not the only reason the FTSMs were hesitant to share the news with them; the impact on their relationship with their mothers was also a concern. Henrietta's relationship with her mother was close:

The hardest part would be my family because they expected so much more from me, because they looked at me like the good girl, that was kind of hard especially telling my mum... that was really difficult. (Henrietta)

Many of the FTSMs opted to share the news with their parents without their partners present as they were uncertain of the reactions of their parents, wanting to give the opportunity for their parents to react as naturally as possible as they thought their parents may repress their real feelings if the partner was present:

We told our parents individually just because we didn't really know each other's families. I'd met his parents once and he'd met my parents once. We talked about it like do we go together or not, and I said I would rather you went and told your family on your own because then they're free to react without trying pretend and then wanting to react later with you privately. (Anna)

Anxiety about sharing their pregnancy news was unfounded, with all the FTSMs being ultimately supported by their parents and family. Telling others the news was a significant turning point in the pregnancy and the difficulty they faced with this issue should not be underestimated.

The institution of marriage was very important to the parents of the FTSMs, particularly their mothers. Often the biggest disappointment and concern articulated related to their daughters being unmarried: 
We told mum and she was in tears because she thought I would get married and then have kids that was important to her, the marriage part and telling the whole family. I think that was one of the hardest parts [of the pregnancy] and then second would have been the church. (Henrietta)

My mum thought it was a talk that we were getting married and she was all excited and happy. I was wondering why she was smiling when I came home... my dad told her about the pregnancy and she started crying, my dad was crying, we were just talking about how it was going to be done and it was just really pushing the wedding. (Patricia)

Marriage played an important (cultural) role, although the meanings that it expresses are increasingly symbolic and of diverse significance for parents and FTSMs. This may have something to do with intergenerational and social change around marriage and having children out of wedlock. Immediately after being informed of the pregnancy, most of the mothers or parents encouraged the FTSMs to get married as soon as possible. This was met with firm resistance even though some of the FTSMs and their partners had discussed marriage before the pregnancy occurred, but moving in with their partners was a certainty. The FTSMs took ownership of if and when they were going to marry and this created some tension between mothers and daughters:

They told us we had to get married in June, this was back in February. I said, 'okay we will start organising for June', and then I had to push to say I didn't want to get married, I didn't want to rush it, I would rather wait, but they [parents] wouldn't take no for an answer. (Patricia)

Patricia entertained the idea of rushing a wedding; however, decided against it and when she told her parents that the wedding plans were postponed indefinitely, they reluctantly accepted the situation. Despite her mother's disappointment that she was unmarried, Patricia described their relationship as, ironically, becoming closer since she announced her pregnancy.

\section{THE PREGNANT BODY: CORPOREALITY AND FEARS OF UNDESIRABILITY}

Ideas about the way in which the body is socially constructed are influenced by the cultural values and social structures implicit in a person's ethnicity and age (Stewart, 2004). Studies have shown that Samoan people in general have less negative attitudes about their bodies (Brewis \& McGarvey, 2000). Becoming a mother undoubtedly 
involves changes in body shape. There is perhaps no other time in a woman's life in which her body changes so dramatically and so publicly than in that transition to motherhood (Clark, Skouteris, Wertheim, Paxton, \& Milgrom, 2009). Body image was mentioned by the FTSMs as a small concern during pregnancy in relation to various experiences of physical, cognitive and emotional changes as identified in the literature (Clark et al., 2009; Nash, 2012). There are several studies related to pregnancy body image and body dissatisfaction (for example Brewis \& McGarvey, 2000; Nash, 2012; Skouteris, Carr, Wertheim, Paxton, \& Duncombe, 2005). However, many of the FTSMs, while they articulated surprise, amazement, shock and even astonishment at their changing bodies and how it impacted on the rest of their lives, did not express 'dissatisfaction', rather they accepted that their changing body provides a function:

Just being the bump, just embracing the whole thing, graciously growing. (Alma)

Pacific women were found to have both the highest pre-pregnancy Body Mass Index ${ }^{16}$ (BMI) and the highest Gestational Weight Gain ${ }^{17}$ (GWG) in pregnancy, which means they are potentially more vulnerable to weight retention problems post-partum (New Zealand Ministry of Health, 2006). There is evidence linking Pacific women who have a high BMI of over 25, when having their first baby with an increased risk of a stillbirth (PMMRC, 2014).

The FTSMs accepted, and expected, most of the changes that happened to their bodies as soon as they confirmed their pregnancies. One of the most anticipated changes was aesthetically, part of which was gaining weight. How much weight they were expecting to gain or the acceptable amount of weight to gain was often (mis)guided by their midwives, family, friends and the internet based on Western medical knowledge. Recommended guidelines for weight gain during pregnancy is based on the BMI of the women (New Zealand Ministry of Health, 2006) and many of the FTSMs took the advice from their midwives on what was considered a healthy weight gain during pregnancy.

Almost all of the FTSMs had a good balance between diet and exercise, and pregnancy was a good excuse for some women to deviate from their usual routine:

\footnotetext{
${ }^{16}$ Body Mass Index (BMI) is a ratio used to determine healthy weight ranges for humans, and has been used to define the medical standard for overweight and obesity. BMI is defined as the weight in kilograms divided by the square of the height in metres (New Zealand Ministry of Health, 2006, p. 10).

${ }^{17}$ Gestational Weight Gain (GWG) refers to the amount of weight gained from conception to delivery.
} 
I know once you are pregnant your body change(s), your boobs have all gone big to provide the milk once baby is born... I'm getting used to it, hopefully I will get back in shape. (Lola)

At first I was looking forward to it, it was like, yay, an excuse to get fat. (Geraldine)

However, the myth was soon dispelled during a visit to her midwife:

She [midwife] did talk to me at the beginning of the pregnancy saying that 10 kilos should be the allowance for how much I should gain. She based it on my BMI, and she had the chart as well, but then she was also saying she has a chart for Pacific Islanders and a chart for Europeans. I think she had put me on the European one so I was like, 'I'm having a Tongan baby!', yeah, so I've become more strict [in what I eat]. (Geraldine)

The FTSMs had variable weight gains during pregnancy:

I fell pregnant when I was $75 \mathrm{~kg}$. The first few months were fine; I didn't gain that much, my stomach was coming out but it wasn't as obvious as it is now. I went from $75.6 \mathrm{~kg}$ to $91 \mathrm{~kg}$, so about $14 \mathrm{kgs}$. Even though she [midwife] keeps telling me the normal is $12 \mathrm{kgs} . .$. my body has changed. (Patricia)

I was $63 \mathrm{~kg}$ before I fell pregnant. I am now $76 \mathrm{kgs}$, so I gained a lot ... it's all in my tummy. I thought I've still got the same size legs and arms and face, I've just gained in the tummy, and in the butt, in the thighs, in the bum, I feel fine. When I first found out I was pregnant I was still small, and then I used to look at myself and think, oh my God, how did I get so fat? (Maliaga)

The midwives consider Pacific women have a positive attitude and trust in their own bodies, and that this contributes positively to the conversations they have about the changes to their bodies. This is in line with the philosophy of midwives in which they affirm the normality of childbirth and encourage women to see that their bodies will change so as to be fit for the task of childbearing (Davis \& Walker, 2010a; New Zealand College of Midwives Incorporated, 2010). 
It's quite a big bit of me that has huge respect for women who just trust their bodies. I've heard it a few times now or I'll say it to them 'is it 'cause you just trust that your body's made to do it?' and they're like, 'yeah, it's fine. It's just a pregnancy, just having a baby'. And I kind of think actually I really love that, I love that. (MWA4)

Midwives find it a challenge promoting pregnancy and childbirth as normal to some women, particularly when it is undermined and challenged by the imperative to engage with an increasing number of antenatal obstetric monitoring procedures (Davis \& Walker, 2010a); for example, scans, measurements, weight. The perception of some non-Pacific midwives was that older Samoan women were more concerned about their bodies not being able to cope during pregnancy due to their age. The worry for one of the midwives was not the age of the woman, but whether she was overweight and therefore at a higher risk of developing diabetes. This midwife was concerned about BMI, a generic measurement used to determine an acceptable bodyweight that is considered to be within a healthy range according to medical science.

There are differences in beliefs about what is overweight. Pacific adults are more at risk of obesity than the overall New Zealand population (New Zealand Ministry of Health, 2008). Most of the midwives provided guidance around the recommended weight gain during pregnancy and the impact this would have not only for her current pregnancy and health but also for any future pregnancies. Broaching the subject of obesity and weight gain during pregnancy can at times be a challenge for the midwives and requires diplomacy and trust in the relationship:

A [Pacific] woman recently [came in to the clinic] who was in her forties and pregnant and said to me, 'I've never thought of myself as obese before', and of course, you know, our focus is very much on this. (MWA4)

Perceptions of acceptable weight are clearly, which is evident in the woman's belief that she was not, contrary to what her midwife perceived, obese. The FTSMs accepted the weight gain as part of their pregnancy and were pragmatic that not only was it short term weight gain, but it was beyond their control:

To me, I'm not fat, I'm pregnant. The way I look has never really bothered me even before I was pregnant. I never cared how I looked, didn't care about how other people think, so I'm happy. (Maliaga) 
Being overweight has connotations of being out of control with eating and socially unacceptable, but pregnancy weight gain is acceptable.

The value of slimness in the typical image of a sexually attractive, desirable woman is common to the 'social construction of femininity' particularly within modern Western culture: 'obesity is often seen to be a physical disability' for which the person is responsible (Oakley, 1980, p. 211).

There was a sense of curiosity and fascination among the FTSMs around the weight gain distribution on their changed bodies. Although many of them took a pragmatic approach to the physical weight gain, the impact was felt in other areas of their lives, e.g. changes to their eating habits and making healthier choices was something most of the FTSMs took on board, and for some that meant taking extra supplements:

She (sister-in-law) said, 'you know when people say to you oh, she's eating for two' it was like, 'don't believe it, because you're not eating for two', and so I think I've kept that in mind as well. (Maria)

Being healthy, I'm not the healthiest, but during this pregnancy... the Island food that my parents would make, I would just go and dish it out or make a salad or something and it's like, filling because I'm already bloated anyway. If I wasn't pregnant it would be nowhere near satisfying, but just healthy food, drinking heaps of water because I never used to drink any water. Just [a] fizzy drink person, I still do drink fizzy but not as much, probably these iron pills ... yeah ... I'm also taking, I forgot what it's called, it's for baby's brain development. (Alma)

She's [mother] always asking... always making sure I'm eating healthy, and if I eat my chocolate she says 'it's not about you'... that's probably about it, just food, make sure I'm eating right. (Mele)

Changes to the breasts was something that two FTSMs articulated as being the most unexpected of the bodily changes and something that was not talked about among their friends and family:

The change in my breasts, has been quite a big change. If anything in my body, you know the way the nipple changes colour, and it gets bigger, I was like 'oh my God, what is this?'. People don't talk about this, you know, and obviously the size, they just went up and up, and I 
was buying bras, and having a breakdown... you know, and in the changing room, it was like, 'oh my God an F [size bra]'. (Anna)

I always used to be small up here, my breasts used to be really small, they never used to be that big. You know how your areola gets big and everything like that, so that was different, that was different, that was probably the biggest change for me. (Patricia)

Physical changes, including hormonal modifications and social changes, can have a major impact on the pregnant women's physical well-being, relationship and sexuality (Trutnovsky, Haas, Lang, \& Petru, 2006). Cultural images of sexuality and maternity contradict one another: a woman who is 'sexy' or desirable is not a mother and mothers are not 'sexy' people (Oakley, 1980). Female sexuality, feelings of being sexy, and wanting to feel desired is not something that is freely articulated within Samoan culture (Tupuola, 2000).

The physical changes to their bodies and their attractiveness to their partners was something many of FTSMs mentioned as important. They embraced their changing bodies but at the same time they were worried about how their partners would react to the changes. Feelings of attractiveness, intimacy, desirability and revealing their changing bodies to their partners or others, were factors that emerged:

I had like, big hips anyway; it wasn't until recently that I really felt that I was real big and my skin was getting darker, but I still didn't feel unattractive. (Alma)

Ever since I became pregnant I started to get rashes or pimples on my face and my midwife said, 'that's normal because of your hormone changes and they just don't go away'. So I became nervous, I don't want to wear a dress that shows my back or anything so I always cover up. (Patricia)

Anna grappled with contradictory emotions:

I think it's hard because being excited about the pregnancy and then the body changes, they excite you because it's happening and I'm like, oh yes, this is happening, and that's what it says is going to happen but I've got to admit I felt insecure and unattractive, you know... with insecurities and feeling unattractive. It was more about him or me and him, our relationship than anything else, but you know, sometimes I 
think is it just the hormones. I would have these spells of crying and oh no I am so fat... it's just stupid stuff like that which I know is silly. (Anna)

Anna articulated her excitement in that her body changes publicly declared her pregnancy status. She realised that her insecurity over her relationship was unfounded but still found it difficult to shake those feelings. Often during the first two trimesters there tends to be a decrease in pregnant women's sexual interest which may be due to several contributing factors including tiredness, nausea and lack of desire (Trutnovsky et al., 2006). Anna's sexual desires diminished during the early period of her pregnancy partly due to the 'visual' aspect of her changing body:

We [Anna and partner] talked about it a lot... well, I always felt that I needed to talk about it because I felt like I was letting him down, you know, I didn't want him to feel that he was unattractive (to me) and things like that. We did talk about it and he was really reassuring saying that's fine whereas when I did get that urge back, I don't think he was as willing as he was, well he wasn't as willing as he was, and I think that was because... we did talk about it a lot and he's like, 'now there's this (pointing to her pregnant stomach) in front of us'. He felt quite uncomfortable with that and I guess I did too, so it's been a bit hard that way, or earlier maybe near the end of the second trimester. Now we both understand, everything just kind of comes as a shock, but yeah, I only talk about it because it was a big change in our relationship and it was a big insecurity for me; it's worked itself out. (Anna)

Anna was honest about discussing with her partner the intimacy issues in their relationship but for many women sexuality during pregnancy is not often discussed with anyone let alone partners or health professionals (Trutnovsky et al., 2006). The decline of sexual urges did not diminish the need to be desired by their partners, in fact the need to be desired increased and was related to the feelings of attractiveness:

With my partner, I don't like getting naked around him... just since I'm pregnant, yeah, before I didn't care but ever since being pregnant I just feel uncomfortable, he doesn't make me feel uncomfortable, it's in my head, and he keeps telling me it's in my head, you know what I mean, I said just wait when I lose this next year. (Patricia)

I kept asking him [partner] do you still love me the way I look and he said, 'of course I do' and I would say 'don't lie to me, you're just saying 
that', he goes 'oh if I didn't I wouldn't be here', and I thought that's true. (Henrietta)

The pregnant body performs an important function in pregnancy as it operates an important function of physical ability pre-pregnancy. Before pregnancy, most of the FTSMs were keen sportswomen and participated in at least one sports activity, and many were involved in several. During early pregnancy, they continued to participate in their sports. Lola continued playing sports at five months as she was unaware that she was pregnant. Many of the FTSMs articulated their disappointment at having to stop involvement in their sports but some were happy to take up other sports activities that were more conducive to their physical and energy abilities:

It felt weird not being active, not playing sports, but then there were also other options like aqua jogging and going for walks and all that, which was okay. I ended up doing a lot of walking which was good for me. Body changes, I kind of knew what was going to happen because of my friends being pregnant, they were saying 'you're going to get swollen feet', so I kind of knew what was coming, but I really wasn't used to it when my body changed and everything, but I'm used to it now. (Henrietta)

I was definitely active before, well more active. I played netball right up to until five months, and it was sort of changing the type of exercise that I [did] beforehand... I did do some running right up until five months until I felt a bit too heavy and now it's sort of changed to aquajogging and yoga. (Maria)

The change in physical mobility definitely had an impact on the women and their emotional wellbeing. They were forced to temporarily change their chosen sport, which many of the women did, in order to keep active and busy.

The changing body was confronting for some of the FTSMs and many compared their physical bodies to others who were, or had been, pregnant. Anna was pleasantly surprised when her expectation did not match her experience of stretchmarks:

I know I'm bigger and I've got a few stretchmarks here, but in comparison to what I expected, 'cause my sister she had quite a lot of stretchmarks, and so did my mum. When I had seen that, I was expecting the same. (Anna) 
Receiving reassurance from her husband allowed Sita to relax about her changing body:

He's pretty good, which is good. It's helpful 'cause it makes you feel like you don't have to, sort of, I guess, live up to any image or something and it's been really good just enjoying pregnancy. (Sita)

The image media portray of what constitutes the ideal body of a pregnant woman is unrealistic and often based on celebrity bodies from the entertainment industry of Western society. Once women realise this image is unattainable and unrealistic, they focus more on the pregnancy, although it is not always possible to shift away from these media images of the so-called ideal body.

\section{PREPARING FOR BIRTH}

In their research exploring the experience of first-time mothers, Dahlen, Barclay, and Homer (2008) found that preparation for birth consisted of finding a child birth setting and setting up birth expectations. These categories were mediated by beliefs, convenience, finances, reputation, imagination, education and knowledge, birth stories, and previous life experiences. Pregnancy confirmation is often the time when women start to prepare for the birth. Maternity care for women in New Zealand is accessible for those who fit an eligibility criteria (New Zealand Ministry of Health, 2014a).

It is not a legal requirement to register with a Lead Maternity Carer (LMC) but it is strongly recommended by the health practitioners. There are two ways to locate and register with an LMC - a recommendation from others, or independently finding one (New Zealand Ministry of Health, 2014b). One of the most common ways to find an LMC is from a list of midwife names given to expectant women by either their GP or other health professional; this way of engaging with an LMC has been found to be unsuitable (Churchward, 2011). Given the time period spent with an LMC, as well as the close physical relationship shared between a midwife and expectant mother, this adhoc manner was perceived as totally unsatisfactory (also see Relationships):

That part was probably the difficult part, finding a midwife, because someone gave me a number for one midwife that they preferred, but that one was booked up, and then someone else gave me another number to my midwife now, but it took ages for her to get back to me because she had other patients as well, but she came through and said she could take me on board, so that was good... that took almost a month and a half. (Henrietta) 
Other than the partner and significant family members, the midwife plays a prominent role in the preparation for the impending birth. Once the pregnancy was confirmed, usually within the first and second trimesters, all the FTSMs were registered with an independent midwife or LMC. However, registering with an LMC was not without its difficulties and this is supported by other research which found that one in five women in New Zealand (19 percent) had problems securing an LMC to provide care (New Zealand Ministry of Health, 2007).

The FTSMs spoke of the daunting prospect of getting a list of midwives' names and contact numbers to 'cold call', adding that they found this process 'disempowering'. Supposedly, getting a list gave the mothers choice but for many the situation was simply 'overwhelming' and isolating and in some instances resulted in women compromising in their choice of midwife.

Securing a midwife by chance rather than by choice was unsatisfactory, but not uncommon (New Zealand Ministry of Health, 2007). This ad hoc process experienced by most of the FTSMs interviewed was not ideal and left many in limbo:

We went to the Family Planning for a confirmation in town and she gave me a list of midwives, [gave me] all these pamphlets and sent me off. We weren't too sure how far along I was or anything, and I kind of felt left in the lurch. (Anna)

That part was probably the difficult part, finding a midwife, which took almost a month and a half. The last week of my first trimester I was relieved because I thought I wouldn't find one before my second trimester. (Henrietta)

Most of the FTSMs preferred the recommendation of a midwife from family and friends. Meeting with the midwife and discovering common social connections provided a way to reduce the formality of the situation:

It took me a while to actually have a midwife. My doctor suggested all these midwives and I said, 'oh, okay' ... he said, 'well we've got midwives here at (Medical Centre)' and so I said, yes to them. I didn't realise that my sister-in-law, people from church all had the same midwife so it was kind of funny talking to a midwife saying 'oh I know this person' and 'I know that person' and 'I was at the birth of this person'... I was like, 'oh cool, what a small world'. (Ellen) 
A referral of a named midwife from family or friends came as a great relief for many of the participants, who trusted the advice of those closest to them. Geraldine's aunt called the midwife direct and advocated on behalf of Geraldine. The midwife agreed to take her on despite her full case load:

Yeah, my aunty actually rang her and told her I was pregnant... she was saying she wasn't able to take me on because she was quite busy but then she did it as a favour to my aunty. (Geraldine)

My partner's cousin is a nurse at [hospital name] and she gave us a list of her top midwives she said, so she told me who to contact and then I contacted her. (Patricia)

FTSMs placed a lot of trust in these personal recommendations and this was often the most preferred way of engaging with a midwife.

Previous research found that women preferred midwives of a different ethnicity to themselves as they were less likely to share social networks and thus confidentiality was more likely to be maintained (Churchward, 2011). Ethnicity of the midwife was not the first concern for the FTSMs:

As it was somebody that made me feel comfortable, but they'd actually referred her so I thought I would just give her a go and she's turned out to be really good, she's got a good balance between the Western and as well as the traditional Samoan myths or... or remedies. I have a habit of googling, I googled her to make sure [she was okay]. I checked and she's like, 30 years, she's a senior consultant, a lactation consultant... after reading the Herald and the midwife mucked up this lady, this hospital gave a miscarriage tablet and I'm thinking, 'oh what?'. (Patricia)

The FTSMs articulated cultural and traditional beliefs about pregnancy and postbirth behaviours passed down to them by family members, particularly the older female members of their families. Similar to the findings in Churchward (2011), some of the FTSMs were uncertain if the advice related specifically to Samoan culture. Some FTSMs described their parents as traditional and active in the church but not superstitious when considering traditional pregnancy beliefs, which is how many of the FTSMs viewed these beliefs. Similar scepticism was noted by another New Zealand study on infant care practices in New Zealand (Abel et al., 2001). Interestingly, many of 
the FTSMs were happy to indulge traditional beliefs 'just in case' something did happen or to keep 'mum happy':

I don't really abide to any of it... my mum kind of believes in it and stuff, I respect it, like, I respect it and stuff, but personally I don't believe in it. (Maliaga)

No, my parents haven't really offered anything like that, not that I've really approached them and it hasn't really come up as a topic. (Maria)

Traditional Samoan beliefs included: do not wear scarves, necklaces, or do not reach for anything higher than your head as these actions may cause the baby to choke on the umbilical cord; do not wear long big earrings or the baby will be born with big ears; do not wear watches or bracelets as the baby will be born with damage to its wrist; do not cook in front of the oven; avoid eating spicy food as it will cause the baby eczema; do not be left alone or go out at night or drive because of 'bad spirits'; do not put anything hot against your stomach as it will make baby's skin rough; do not clean as that involves bending down and that might hurt the baby, and do not cut your hair during pregnancy as it is bad luck.

There was a lot of discussion around fofo (traditional massage). While many of the women were happy to have light massage around the body, not the stomach, most did not take up the opportunity to seek a fofo, nor were their parents encouraging them to do so. A couple of the women had heard horror stories about fofo:

With massages, I always heard about getting fofos, but my mum knew and she said, 'no, never get one during pregnancy'. My partner's mum said, 'don't get a fofo', because her cousin in Samoa that was having twins, just this year, both twins died, passed away because the fofo, they were quite hard, they're rough massaging them and pushed on the babies, apparently something happened in the massages. I knew not to get any massages. (Patricia)

There were mixed reactions as to what would happen to the placenta post-birth, with some women indicating nothing would happen, or thought the parents would decide with the partner's family:

[I said to my parents], 'you know, do you guys want the placenta or do we bury it in the backyard and put a tree on it?' and dad said, 'well, it's completely up to you'. (Maria) 
I definitely know that we have to bury it, where I'm not sure but I know that's one thing we definitely have to do. I just have to figure out where, we will probably get the advice from our parents in terms of what their thoughts are of what they've done. (Sita)

Historically, Pacific women have a low rate of attendance at mainstream antenatal groups, such as Childbirth Preparation, Education and Antenatal classes (Fa'asalele Tanuvasa, Cumming, Churchward, Neale, \& Tavila, 2013; Low et al., 2005). Most of the FTSMs were aware of antenatal classes; many booked to attend classes, but did not attend or attended only one or two. Of the 11 women interviewed, five FTSMs did not attend antenatal classes for reasons such as 'doesn't seem appropriate', 'too busy', 'confident about birth from sister's experience', and 'no time, no transport'. There were mixed reactions to the necessity or the benefits of antenatal classes. Those FTSMs who went to antenatal classes were specific about what they wanted to get out of them:

We went to two of them [antenatal classes]; mainly I wanted to go and find out about the pain relief, the labour and the pain. I just felt like I didn't know enough about the options, but it [antenatal classes] didn't clarify things. J [partner] and my mum share the same opinion where, you know, we're not stupid we don't need to go to those things. (Anna)

Family members often gave advice about antenatal classes based on their own experiences or stories from others. The FTSMs took their advice into account but made their own decisions to attend antenatal classes based on their own needs, expectations and abilities. This was typically expressed by Geraldine:

My mum told me, you know, to do those classes. I was quite surprised too 'cause my friends that do have kids none of them do these classes and I found that quite interesting. I always knew in my head that I would do those sorts of classes 'cause I'm one of those people that need to know everything 'cause I'm a freak like that, I want to be extra prepared. (Geraldine)

Some felt that they were well informed and confident to deal with birth and motherhood from personal experiences they already had:

I have family and friends with babies; it feels natural, it feels like I've had a kid before, even though it's my first kid, but it feels normal ... you know, breastfeeding and stuff feels normal. (Ellen) 
Ellen's normalisation of childbirth clearly influenced her belief that she did not need antenatal classes, and that it would not have prepared her any better than the knowledge passed on from family members and friends.

The lack of uptake of antenatal or education classes by Pacific women was frustrating for some midwives as they were concerned that the women who did not attend would be unprepared at the birth. Other midwives believe that Samoan women see birth as normal and therefore do not see the need to attend antenatal classes.

In preparing for the actual birth, the FTSMs, along with their partners, were in charge of orchestrating and organising who would attend the birth, e.g. having family members and friends. The birthplan, which is a formal written record of a woman's wishes of how she wants her birth to proceed, is also used by maternity professionals involved in her care to dictate who can and cannot be at the birth (Families, 2010). All the FTSMs, except one, had either completed, or were in the process of completing, their birthplan and were doing so at their antenatal appointment. The birthplan was beneficial as it gave most of the FTSMs a sense of control over their birth, and they felt organised. In addition, as is commonly found, none of them were concerned if their labour did not progress according to the birthplan (Whitford \& Hillan, 1998). The birthplan is considered important and is designed to be able to be changed at any time. However, a birthplan was not for everyone. Alma was reluctant to fill out a birthplan as she felt it would be restricting and would conjure up feelings of anxiety for her:

I always just think just do it, just get there and get this baby out... you know, like, I might panic. I have a fair idea of what's to be expected. (Alma)

Having a comprehensive birthplan ensured that everything that needed to be covered was covered. Having complete trust to hand over the decision-making to the health professionals made Anna feel secure. In trusting the 'experts' and the advice they gave, she opted for a completely natural birth yet was open to intervention if necessary:

I would rather be safe than sorry and whatever they [health professionals] feel is necessary in the way of drugs and pain relief or whatever... and that's okay with me. I feel very trusting... as natural as possible but if help is needed that's fine. (Anna) 
Being prepared for the unexpected gave the FTSMs a sense of control that engendered a pragmatism that supported the need for the birthplan to be adaptable. Whatever happened in actuality, the FTSMs acknowledged the possibility of several outcomes occurring and were willing to adapt their birthplan as circumstances dictated.

At the time of the first interview, some of the women had not filled in their birthplan; for example, Geraldine contemplated a water birth, but this proved to be complicated as the hospital she planned to give birth at did not have the required facilities. She feared it was too risky to be anywhere other than a medical hospital and her midwife was not experienced with water births and would need to refer Geraldine to another midwife if she went ahead with this which was not an option:

I was thinking of having a water birth... the only thing that freaked me out [was] if there were any complications. I didn't want to have that risk. [Home birth is] something for us to think about when we have another kid, 'cause I'd know what the birth is like. Because this is my first-time I'll just stick to a normal birth just to be on the safe side. (Geraldine)

A hospital birth was considered 'normal' and 'safe' by the FTSMs. The birth setting was important to them in their preparation for the birth, and their decisions of where to give birth are mediated by beliefs, convenience, education and knowledge, birth stories and life experiences (Dahlen et al., 2008). The FTSMs chose to have their babies in hospitals close to their homes. Other than a couple of mothers who fleetingly considered a home birth, all were adamant in their choice of birth setting.

\section{EXPECTATIONS OF PAIN DURING CHILDBIRTH}

The expectations of what a good childbirth experience was influenced by many factors, including books, media, health professional advice, what was heard at antenatal classes or from other women's experiences. The FTSMs' notion of what constituted a natural childbirth was articulated as the safe delivery of a live baby and emphasised little or no drug intervention. The preference for a non-intervention childbirth may appear as 'romantic' (Crouch \& Manderson, 1993), but the FTSMs articulated that if something went wrong during the natural non-intervention birth, that intervention would be 'okay'.

Understandably, one of the biggest fears the FTSMs articulated in their expectations of birth was pain, or the unknown level of pain, and whether or not they would be able to tolerate the pain before making a decision for intervention. Often they were looking for 
comparable experiences of pain they could relate to. One FTSM asked her midwife if it was like being 'tackled' on the rugby field:

The pain, but I will always ask my midwife if the pain is like the same as getting tackled in rugby and stuff, 'cause I played rugby. Hopefully it's not a really long painful birth, I said to L [partner], 'if it's painful, if it's pains that I never ever want to go through again, that's it, it will be only one [baby]'. (Ellen)

Another FTSM commented that the fear of the unknown was so intense that the anxiety manifested itself in dreams:

Just scared that something might go wrong... like, I had a dream last week that I gave birth at 30 weeks. (Geraldine)

\section{SUPPORT SYSTEMS}

Support systems are a crucial part of the transition to motherhood. It is not only the mother, and consequently the child, who benefits when she is well supported, it is an advantage for the whole family. There are strong links between reliable levels of social support and positive wellbeing during the entire maternity period (Oakley, 1992; Small, Taft, \& Brown, 2011).

Support is considered a multidimensional concept that includes different types of support (Robertson, Celasun, \& Stewart, 2003). Sources of support can be a partner, family, friends, work colleagues; types of support include advice and guidance that is given; instrumental support by way of practical assistance such as financial or help with tasks; and emotional support, the expression of caring and nurturing. Other studies have found that a link between perceived social isolation, or a lack of support during pregnancy, was a strong risk factor for depressive symptoms (Churchward, 2011).

Family, friends, community and the church are considered to be important sources of support within Pacific families, yet at times they can be viewed as a hindrance, as the existence of a social network does not necessarily equate to support (Churchward, 2011; Fairbairn-Dunlop \& Makisi, 2003; Tiatia, 2003). There are a variety of reasons, support may be accessed outside of the family and personal social networks (Donnelly, 1992; Tiatia, 2003; Tupuola, 1998). For example, the internet and social media sites may provide confidential medical advice; or inter-generational tensions might exist between Island-raised parents, who hold firmly to traditional beliefs and practices, and their New 
Zealand-raised children, who have begun to challenge the traditional beliefs (Meleisea \& Schoeffel 1998; Tiatia, 1998 as cited in Abel et al., 2001; Tupuola, 2000).

It was no surprise to find that families, partners and friends closely associated with the FTSMs were mentioned as the main sources of social, emotional and practical (including financial) support. They played a significant role in supporting the FTSMs throughout their pregnancy. This was a precursor to the support they were to receive post-birth. The FTSMs were confident they could rely on the support from their families regardless of whether their families were happy with the news of their pregnancy or not. This was very reassuring, particularly for those who were living in the family home at the time:

My parents will always be there for us kids, they've always said it... so I just always knew, even though they're angry that I'm not married, they could never, ever kick me out or not support me because they've always supported me. (Patricia)

The family have been really, really good, they've been very overprotective, but the support from the family is never-ending. (Maria)

Support from the wider family network, including grandparents, aunts, cousins and those unrelated family members, were central during the pregnancy period. Advice and showing concern was seen as caring support. Mothers were considered a vital part of the support system. All the FTSMs were adamant that mothers played a key role during their entire maternity experience (see Relationship chapter also):

My mum will always be who I listen to, if everyone else is in my ear I will be like, oh yeah, yeah, but whatever mum and A [midwife] say is what I go by. A 'cause she's the professional, and my mum 'cause she knows what's best for me... my mum knows what's best for me. (Geraldine)

Partner support was very important. The practical support offered by partners came in many forms. They, more often than not, acted as confidante, cook, chauffer or masseuse, they made sure the FTSMs ate healthy food and rested well. The partners were credited by some with being the reason for a healthy pregnancy: 
I think he is the reason why my pregnancy has been so strong up to this point, every little pain I go through he was like, okay, let's go get you checked out and stuff. (Ellen)

While most FTSMs' partners' commitment to the pregnancy and the woman was unspoken, it was an important part of a woman's wellbeing that she felt cared for, loved and part of a secure relationship with her partner. This meant ensuring the partner became an integral part of the pregnancy.

However, not all partners were as giving of their support or commitment and this was a harsh reality for one FTSM. Lola separated from her partner of three years soon after she found out he fathered another child four months before she confirmed her own pregnancy:

It was hard for me to confront him because he wasn't raised in $\mathrm{Sa}[\mathrm{moa}] . .$. it will be a different story, to him he can just have that kid and then just dump that kid. I wish he would actually man up and be like, be there for me and baby, but he is a New Zealand-born and he doesn't actually know the traditional way... I feel like I really need his support. (Lola)

Aside from Lola's perception that her partner, a New Zealand-born himself, can just have a 'kid' and 'dump' him, Lola felt abandoned by her partner and was disappointed at the lack of commitment and support from him in carrying out his duties and responsibilities as a father to their child. Her resentment that he chose the 'other' family over hers was evident throughout her narratives, as when she articulated she did not need him, she equally expressed her need for his support. Her contradictory comments illustrate her difficulty coping with his absence and lack of interest in her child.

Almost all the FTSMs expected to have their partners present at the birth as well as significant family members:

Yep, I told her [mother] and she said, 'I don't want to be in the room' and I said, 'you're going to be in the room, I'm forcing you to be in the room', so she's coming along. (Henrietta)

I want him [father] there... it's his first grandchild and he's so excited, I'm his only daughter... I just think it would be really cool. (Maliaga) 
She is my mum, if she wasn't there it would feel wrong. I know she would want to be there and if I took that away from her it would actually crush her, and it would crush me that I would crush her. (Patricia)

Yep, she [mother] already made plans she was coming in, she already nominated herself. (Mele)

Mele's mother expected to be at the birth and told Mele that it was wrong to be unmarried and have her partner in the room. Mele was the only woman to exclude her partner from the birth as she felt her focus on birthing would be compromised by his presence. It is uncertain how much influence, if any, her mother had in that decision.

Other informal sources of support, especially during pregnancy, included work colleagues. Most of the FTSMs were working, and continued to do so up until their last trimester of pregnancy. The support from work colleagues was overwhelming for them. Practical advice, emotional support and conversations about their welfare encouraged the FTSMs:

A work mate of mine who was a really good friend, she is two months ahead of me, and she's had her baby and so she's been a major support. Actually, she's probably played a really big supportive role in terms of advice and going through it together. She's been really, really awesome. (Anna)

My team leader at work, she is a mother of five and she is always asking how my pregnancy is going, and she actually wanted me to take leave earlier because she was concerned about my emotional wellbeing. (Geraldine)

Gaining unconditional support from their respective workplaces helped Geraldine and Anna feel comfortable to share their pregnancy experience with other colleagues. It provided an opportunity for new friendships to develop that may not have otherwise.

FTSMs had mixed feelings about the support received from church members or 'church family'. Both Patricia and Henrietta were unmarried, yet the response to their news of pregnancy by their respective church communities was quite different:

When my church found out I was pregnant, most of the ladies said, 'about time', you know, one lady came over and said, 'you know we are 
all happy' because I've looked after all my nieces and nephews and it's about time I look after my own. (Patricia)

There was a lot of talk at church that discouraged me a little bit [by] saying that 'you should have got married before you got pregnant' and stuff like... I was saying [to my mum] 'don't worry about what they say', and all that, and so my mum just held her head up. I was close to most of the church family it was okay, but then still at the back of your head you're thinking they're still going to backstab, so I still went to church doing my own thing. (Henrietta)

Henrietta's narrative illustrates the tension that some FTSMs have to deal with. Her example showed personal resilience as Henrietta was not only being unfairly judged by her church community behind her back, but she also had to deal with judgemental comments made directly to her. Henrietta not only decided to continue to attend church activities, she did so knowing full well that her church community would continue to be critical and gossip about her and her family. Henrietta considered this both a challenge and a crisis that her family had to deal with together. It is a working example of personal and family resilience (F. Walsh, 2010). Henrietta was more concerned for her mother as the fact of her pregnancy out of wedlock greatly affected her and her mother's relationship with their church community.

Maria's partner was immediately 'descholarshipped ${ }^{18}$ ' from his congregation due to her unplanned pregnancy; this placed an enormous amount of strain on the couple's relationship. Maria felt responsible for her partner's demise and was very upset at the public humiliation he faced:

When we got pregnant it was like, okay that just changed everything. He [partner] got descholarshipped from the church so he's no longer allowed there. After a few meetings he had to go to meetings and he had to confess his sins, confess his sins being he has been seeing a worldly girl, and he's been having sex, pretty much that was what it was. So he had to go through all of that and then after a few weeks after that meeting, they announced to his congregation which is their church, and other congregations that 'JM [full name of partner] has been descholarshipped'; they announce it, they don't say why but they

\footnotetext{
18 'Descholarship' as described by Maria was her partner being asked to leave his religious congregation. The term 'excommunication' in which an institutional act of religious censure is used to deprive, suspend or limit membership to a religious community, is more common than use of the term of 'descholarship'.
} 
just announce it. Like, if we're to go to the mall or go out in public, and he sees them they're not allowed to talk, not allowed to look at each other because it's like,... he's like infecting the congregation, so he has to stay away. (Maria)

The excommunication of her partner from his congregation had an enormous impact not only on Maria and her partner, but also their families. Maria's family were concerned about the effect this would have on her health and rallied around providing her with moral and emotional support.

In terms of formal support, most of the FTSMs felt the midwives were a great source of support in offering them professional advice, information and emotional support during pregnancy. The midwives encouraged the FTSMs to trust their own knowledge and abilities and offered continuity of care that motivated them to seek help from them when and where necessary.

She's [midwife] been good like that, she's just made it as normal as possible, where it's a normal condition and not a sickness. She's always said, 'it's a natural process of life, you know, your mum did it, I've done it, your mum's mum has done it, unless something is wrong then we will address it but other than that you will be fine', so she's been really good. (Patricia)

The encouragement given to Patricia by her midwife not only reassured her that birth is a normal, everyday event but empowered her to feel confident that she could achieve the goal of safely delivering her baby. The importance and benefit of professional support in antenatal care is discussed in much of the literature.

The link between well-being and social support during pregnancy has been widely investigated (Oakley, 1992). Oakley provides an operational definition of social support: 'Provision of a non-judgemental listening ear, discussing with women their pregnancy needs, giving information when asked to, and carrying out referrals when appropriate to other health and welfare professionals and voluntary and statutory agencies' (Oakley 1994 as cited by Finfgeld-Connett, 2005). This was available to the FTSMs from both their personal and professional supporters.

Access to technology was salient during pregnancy, including internet, personal cell phones and landlines available in most homes with most people having access to at least one of these. The various options open up a social as well as a world in which support 
is available 24 hours a day, seven days a week. The internet option is particularly accessible for women at home in the early days of motherhood. Healthline ${ }^{19}$ and Plunket $^{20}$ Line are two of the largest telephone-based advice services in New Zealand. Telephone-based or computer-based interventions, while lacking the physical presence of a person, provide social support, personal solace and promoting (Finfgeld-Connett). Internet and cell phone usage were incorporated in the lives of the FTSMs, who grew up in a world of technological advances. A variety of support systems available to the FTSMs encompassed the technology age in which cell phone and the internet feature significantly in the way in which women maintain contact with friends and family, and access health information that helps with their decision-making in pregnancy (Lagan, Sinclair, \& George Kernohan, 2010).

Statistics show that households with Pacific people were less likely (23 percent) to have internet access (Statistics New Zealand, 2004). However, all the FSTMs had cell phones and internet access at home or work. The advantage of utilising the internet for information is participating in interactive discussions, the instant and open accessibility, speed of feedback (if you are part of an internet support group), and anonymity. The 'virtual' social support can increase the FTSMs ability to cope with the transition to motherhood, particularly as they are new expectant mothers (Nystrom \& Ohrling, 2006; Henrietta O'Connor \& Clare Madge, 2004). Most of the FTSMs belonged to wellknown pregnancy and baby centre websites or social media websites:

I'm always forever reading online about stuff, have a look at different blurbs about it just to find out if there is anything else that I should be looking out for. It has been helpful and then when there's things I'm unsure about, I will just go and Google it... it's actually helped. (Sita)

I just text my friends and talk about what is happening... I know calling them is the easiest way but it depends on credit, you know, the phone is a little bit expensive right now so it's just texting, easier and free. Sometimes [I] go on Facebook and chat with others. (Lola)

\footnotetext{
${ }^{19}$ Healthline is a national telephone health service provided by the Ministry of Health and delivered through a contracted service provider. All calls are answered by registered nurses with telenursing training who assess the caller's health needs and provide information and advice as to the best level of care (New Zealand Ministry of Health, 2010b). Healthline also offers an additional service of an interpreter for callers whose English is their second language.

20 Plunket provides free services to New Zealand families for children aged from birth to five years old. One such service is PlunketLine, a free telephone advice service available to all families, whānau and caregivers. Calls are answered by a Plunket nurse, who can give advice and information on parenting issues and children's health and wellbeing (Plunket, 2010). Both services are toll-free, 24 hours a day, seven days a week.
} 
Statistics show that ownership and use of mobile phones for 15-29 year-olds in New Zealand is very high (90 percent). The mobile phone was a very useful tool used by the FTSMs for keeping in contact with others, including midwives. It gave them a sense of security knowing they could make contact with their social support when necessary or when they wanted (S. P. Walsh, White, \& Young, 2008).

The availability of support systems varied and some support mechanisms were more readily available and practical than others. However, as some of the FTSMs' quotes show, strategies that helped them to cope under stress were simple tasks such as undertaking household duties, talking to others or praying. One FTSM described herself as an 'active relaxer' - a term taken from a New Zealand campaign fronted by a sports celebrity run by the Ministry of Health ${ }^{21}$, promoting a self-help programme for depression sufferers:

I'm an active relaxer... actually that's come from John Kirwan's ads, I always have to be doing something, and, to my husband, he always says 'can you just sit down and relax', and I'm like, 'well this is not stressing me out at all, this is actually something I love to do', I do, you know, washing and wash the dishes and cook at this stage [of pregnancy], and my husband is like, 'I will do it'. I don't look at it as a chore, it actually gets my blood flowing and my brain. (Maria)

Best to talk to someone and let it all out... just so I can let it all out. (Mele)

Prayer, I just continually prayed through that whole day. I thought there must be some sort of way out of this, but it was good because then the next day it was almost like nothing had happened and it was just back to normal. (Sita)

The FTSMs talked openly and honestly about their experiences of feeling down and how they managed under these situations. The coping mechanisms were varied and personal.

\footnotetext{
${ }^{21}$ The National Depression Initiative (NDI) is made up of many components, including television, radio and online advertising, health resources, guidelines and workforce development for primary care, phone, online and text-based support services, two websites and research (New Zealand Ministry of Health, 2012a).
} 


\section{Single PARENTING}

Stewart-Withers (2011a) argues that, on the whole, fa'asamoa values provide Samoan women with an 'expected degree of security and certainty' from the family to provide to the single mother full and total support to ensure her own wellbeing as well as that of her children (p. 59). The varying degrees to which fa'asamoa is recognised by each family will have an impact on the support given, indicating that single mothers are not stigmatised and not isolated as individuals or as a social group (ibid.).

Although most of the FTSMs felt secure in relationships with their partners, a few of the FTSMs actively sought from their partners their commitment to the relationship and the child. This seemed common in unplanned pregnancies as FTSMs were faced with having to decide on other options if the relationship did not work out.

Intergenerational single motherhood was a concern. Geraldine's mother and grandmother were both solo parents:

She [grandmother] goes 'it's alright hun, you're old enough now, you're in a relationship'. They knew my partner and that was one thing that my mum was really happy about because she didn't want me to be a single parent. (Geraldine)

Mele's mum went with her to confirm the pregnancy and was vocal that the pregnancy was going to proceed:

My mum actually decided, yeah, cos we were at the doctors and the doctor was talking about like, termination and my mum straight away said, 'no, we don't believe in that, she's going to keep the baby'. So yeah... I knew, I knew that she was going to decide that because of our beliefs. (Mele)

Mele revealed that her intention to continue with the pregnancy was not based on her mother's decision but rather centred heavily on whether her partner remained in the relationship:

I don't think I would have... growing up with no dad, I wouldn't want my child to grow up without a dad, I knew what that felt like. (Mele)

Anna had a supportive and loving extended family, she was 29, with an established career and financial independence, yet the thought of single parenthood and not 
providing the child with the 'nuclear' family status was a motivating factor for her entertaining the idea of an abortion. Lola and her partner were not together by the time she found out she was five-months pregnant:

Having an abortion would have been easier for me, but I found out that baby has already been formed, it was like, halfway. (Lola)

\section{SORTING OUT FINANCES}

At the time of the interviews, all the FTSMs were in permanent full-time work. Research has shown an increasing trend in fathers getting more 'involved' in the primary care of children while the mothers returned to work (Schmidt, 2014). The financial implications of having a baby, particularly as almost all of the pregnancies were unplanned, was a sharp reminder for many of the FTSMs, their partners and families of the realities of having a baby. All the FTSMs were financially independent before their pregnancies and they also contributed to the household expenses 22 if they lived with their partners, their families, or independently. The pregnancy, for some families, signalled a loss of financial contribution towards the household, particularly if the FTSM planned to leave home to move in with her partner earlier than expected.

The personal circumstances of the FTSMs meant that their financial autonomy or independence was no longer possible. A few of the FTSMs were in stable financial positions either through their own economic position or family status. The inevitable shift from financial independence to dependence on partners or families was difficult for them, but they came to accept the prospect of relying on others for monetary support, and had to deal with their feelings of not 'contributing' (in a financial sense) in constructive ways, as Anna expressed:

I have fears, you know, these daunting fears that I won't have a job, I won't have money, like the financial thing is a big scary fear at the moment. We've just brought a new vehicle, because I was in a little two-door run-around and even buying that, it was like, I said [to my partner], 'I can't afford it, I can trade my car in and I've probably got a thousand though', so he's fine with it. He's prepared to pay all the bills and he's done the budget. I think I'm just struggling to come to terms

\footnotetext{
${ }^{22}$ As is fairly common for many Samoan families, extended families live in one house and contribute to the expenses of that household (Statistics New Zealand, 2010b) and therefore the pregnancy affects the economic situation of the extended family.
} 
with it, that it's not 50/50 ... I don't know, I feel like it's not okay, so that's a bit of an issue, the idea of not working, I don't know, it just doesn't seem realistic. (Anna)

Preparing for the financial costs of birth and motherhood required some long-term planning which, for some FTSMs, involved them as a couple disclosing financial status to each other (which is difficult for new couples). It sometimes also meant redirecting their financial focus, cutbacks, maternity leave ${ }^{23}$ from their employers, and budgeting skills. As some FTSMs found, the future of surviving on one income highlighted their need for cutbacks to their spending and careful management of funds:

We were always thinking about saving for our marriage and our house and now I can't do that, you know, we have to save for baby, and that's probably hit me the most. I wished I just had one year, I kept telling him and he's always telling me to shush, you know, I just needed one year, we could have got married, I would have saved this whole year. We've just been saving for baby whereas it could have been for the wedding and our travelling. (Patricia)

Uncertainty around financial security was reflected in one FTSM's hesitation to commit to the full length of her maternity leave:

Initially, I applied for the three months and then I asked to extend it to six months, and then keep it open in case I change my mind... at the moment it's six months but I'm intended for three. (Sita)

When possible, financial help also came from family in the form of free or subsidised accommodation, the purchase of big items (bassinette, cot, pram), child care or cash:

I kind of felt a bit bad because she [mother] had come, she wasn't working straight away but my step dad was sending money to help us out. (Geraldine)

The FTSMs and their partners were serious about taking responsibility for supporting their child as demonstrated by their actions to plan, budget and focus on the long-term

\footnotetext{
${ }^{23}$ The Parental Leave and Employment Protection Act 1987 (New Zealand Government, 2008) prescribes parental leave entitlements for female and male employees and protects the rights of employees during pregnancy and parental leave. The Parental Leave and Employment Protection (Paid Parental leave) Amendment Act 2002 and the 2004 amendment provide eligible employees with some parental leave payments of up to 14 weeks, available through the Inland Revenue Department.
} 
financial commitments. The FTSMs also accepted that, while their financial intentions were not always going to run to plan, they were willing to accept financial help from family.

Cultural and intergenerational differences or tensions between the young FTSMs and their parents were evident throughout their narratives. The difficulty with parents' inability to communicate around topics of sexuality and sexual reproductive health was discussed, as was the preference of the FTSMs to learn about these sensitive issues through education systems and same-age cousins and peers. Knowledge of, and use of, contraceptives does not necessarily protect against pregnancy, as intentionality and fertility issues were also related to FTSMs' unplanned pregnancies. The FTSMs constructed their unplanned pregnancy from a positive position and articulated it as being a 'gift from God', or a mistimed pregnancy rather than a mistake or unwanted. And although religion played a major part in the lives, and futures of the FTSMs, it also had the potential to divide families. The experience of change in relationships, future, body, self-image, status, their coping mechanisms and planning for the birth were discussed in this chapter. The next chapter discusses the experiences of labour and childbirth, beginning from the first signs of labour. 


\title{
CHAPTER FIVE: LABOUR AND CHILDBIRTH
}

\author{
'There is no backing out now, birth was amazing, and crazy'
}

Labour and childbirth are both biological and social events. They take place within a cultural context that is shaped by the perceptions, beliefs and practices of society (Liamputtong, 2007). Giving birth is a key life event and gives rise to changes, losses and gains for any woman who goes through it (Oakley, 1980). Childbirth is a phenomenon that involves birthing through the physical feelings of labour and birthing without labour, e.g. a caesarean birth. Labour and childbirth also overlap with early motherhood. For the purpose of this thesis, motherhood begins once the child is born, which for all the FTSMs was in the hospital. This chapter describes the labour and immediate childbirth experiences of the FTSMs, and discusses some of the Samoan beliefs surrounding these.

\section{LABOUR}

The first signs of labour can be a frightening time, particularly for first-time mothers uncertain of what to expect. The first call is to the midwife and usually this is to ensure that things are unfolding as they should be. Generally, midwives offer reassurance and encouragement. The trust that is placed in the midwife at that time should not be underestimated and is a key factor in the FTSM's birth experiences. Belief in the professionals' expertise influences the type of birth relationship that occurs between FTSMs and midwives. Research has identified a need for a flexible relationship between women in labour and their midwives (Bluff \& Holloway, 1994).

The timing of admission to the labour ward is an important decision; when to go to hospital appeared to be a three-way decision between the FTSM, midwife and maternity ward. Women maintained their trust and belief in their midwife and her professional assessment of their situation as they were seen as experts who 'know best' (Eri, Blystad, Gjengedal, \& Blaaka, 2011).

Midwives use a variety of emotional, psychological and physical cues to assess and diagnose labour onset, including physical movements (if the midwife is with the woman), breathing levels, conversation and emotional states, changes in voice tone if the contractions are strong or have changed. Often the first telephone conversation between midwife and expectant mother finds that the women are at the very early stages of their labour, as was the case in this, and previous studies (Churchward, 2011; Winter, 2002). 
All the FTSMs, with the exception of two, went over their expected due date for delivery. One woman was on time with her delivery, while another gave birth earlier than her estimated date.

The strength of pain felt by the women was one of several factors that influenced their labour experience. Other factors recalled included the support they received from family members, health professionals, their involvement in decision-making, the labour setting, access to pain relief (if necessary), being fully informed during the entire process and their sense of control. It is acknowledged that 'control' in labour and childbirth is highly subjective. It is a concept that, for the purposes of this thesis, is as described by O'Hare and Fallon (2011):

Control has been conceptualized as the woman having internal control (control of her own behaviour and coping mechanisms), external control (feeling in control of the environment, what staff did and in decision-making) or relinquishing control (being content to relinquish control and decision-making to the midwife or obstetrician). (p. 169)

Labour is, therefore, about the stage in childbirth when mothers start to feel the pain of contractions, through to the time they give birth. Labour ends as soon as the baby is born, either a vaginal birth or a caesarean.

\section{THE ONSET OF LABOUR}

With the exception of Mele who had an elective caesarean, labour signs varied between the FTSMs. Some women were induced while others experienced symptoms more common of labour, i.e. waters breaking or a 'bloody show'24. FTSMs or their partners alerted family members when labour pains became more intense. Anna recalled feelings of frustration at not being able to contact family members, concerned they would not make it to the hospital, and her birth, in time:

Me and $\mathrm{J}$ and then my sister arrived [to hospital]... well, I rang everyone about 8 in the morning and no one was answering any phones and I was like really? I am overdue and nobody answers their phone, and then finally (they) started ringing and saying 'oh my God, we'll be there soon'. (Anna)

\footnotetext{
${ }^{24} \mathrm{~A}$ small discharge of blood mixed with mucus from the vagina is usually a clue that labour is about to start. This 'bloody show' may appear as early as 72 hours before contractions start (Merck, Sharp, \& Dohme Corporation, 2010).
} 
Anna was overdue and was booked in to be induced. Before her induction date, Anna decided to have acupuncture to help speed up the process, but when that did not work she went to hospital as planned and was induced.

The unexpectedness of how labour unfolds was disconcerting for some FTSMs, particularly where the labour happened quite fast and both the FTSM and the health professionals were unprepared for it. Geraldine's labour and birth, for example, was very quick from the time she was admitted to the hospital until birth:

So I rang S [partner] and said, 'the [hospital is] going to induce me, but I had started already getting contractions, and probably nothing will happen so you can stay at work.' He said, 'I'm coming home straight away'. And just as well because half an hour later I was like screaming... [I called the midwife and] she was like 'come into Middlemore' and I will have a look, I will check you out. I was getting contractions, it felt like every 2 minutes but they were only lasting about 30 seconds, and then she checked me and she's like okay you're two centimetres dilated and I wanted to die. It was like 'is that all?', and then she got me to move to a different ward and then I just started vomiting out of nowhere. She needed to check me and his heart rate had just dropped real fast so they needed to do an emergency caesarean, they had to put me to sleep because it was that fast, I was really scared. We got to the hospital about 4pm [and then] 4.30pm I think it was, he was out, so yeah, it was all real fast. (Geraldine)

Five of the FTSMs had induced labours and were admitted to hospital to carry out the procedure, so they laboured in the hospital. The four FTSMs who laboured at home were instructed by their midwives to stay home as long as possible. None of the midwives visited the FTSMs in their homes from the time they reported their contractions to hospital admission. Rather the midwives assessed the state of their labours over the telephone, which was not always an appropriate, let alone accurate, method.

Patricia experienced contractions and laboured at home with her partner, mother and sisters. Her midwife suggested that she stay at home for as long as possible, which suited Patricia as she was comfortable in her own home. Patricia was pre-booked for an induction at $7 \mathrm{pm}$, but when the midwife called Patricia at home in the afternoon, she was in terrible pain and ended up taking herself to the hospital straight away, against the advice of her midwife: 
She [midwife] thought I hadn't dilated or anything so by the time I went to hospital I was $6 \mathrm{cms}$, so she was like I was lucky because if I had stayed home until $7 \mathrm{pm}$ I would have had the baby at home. (Patricia)

The midwife assessed Patricia's state over the phone, believed that she had not dilated enough. Fortunately Patricia, who was adamant the pain and discomfort she was experiencing was a more real indication of labour, made it to the hospital with time to consider options for pain relief.

Similarly, Lola's midwife had assessed her condition wrongly. She judged that by Lola's tone of voice she was not yet in labour:

I just stayed home and just [did] what she [midwife] said. I kept calling her, but she just said it will be a waste of time if I just go there [maternity unit] and it's not time. But with me I [knew] it was time. (Lola)

Like Patricia, the advice to stay home did not sit well with Lola and, after several subsequent phone calls to her midwife, Lola listened to her body and decided to go to the hospital. The car journey was intense as she was fearful she would give birth to her baby in the car. Lola gave birth 15 minutes after arriving at the labour ward. Her midwife later apologised for her mistiming of the situation. Overriding the trust she placed in her midwife to trust herself enabled Lola to take control of her situation and make her own decision about when to go to the hospital:

She [midwife] said she could tell from my voice, because I was talking to her normal, I don't know why I was like that... she said sorry for letting me hold back at home. (Lola)

Research show that women want to take an active part in their labour, which translates into feelings of being in control (Bluff \& Holloway, 1994; Gibbins \& Thomson, 2001). If women are to be empowered by making choices for labour and childbirth and feeling in control', then it is 'important for midwives to explore and discover the wishes and feelings of women in their care so that realistic expectations can be promoted and then hopefully fulfilled' (Gibbins \& Thomson, 2001). Both Patricia and Lola reclaimed the trust they had had in their midwife back to themselves and their bodies. These examples highlight the ability of the women to take back control of the situation after listening to their own bodies. These actions suggest a level of self-belief the women possess and can 
give them the confidence to persevere with how they want their birth situation to be managed. It gives them the necessary feeling of being in control.

The FTSMs placed an enormous amount of trust in their midwives because of their midwifery experience, but also as they were aware that this was a time where they would be feeling vulnerable, tired and anxious.

One of the biggest fears the FTSMs had was around the unknown intensity of the labour pain and their ability to deal with it. In reality, all of the FTSMs expressed complete surprise at the strength of pain and feelings of exhaustion during labour. Henrietta's experience of labour was much worse than she expected:

For those who already gave birth they said that it feels like... the contractions feel like period pains but that is totally the opposite, it is way worse than that, it was like you are kidding me right, it's the worst, it's the worst pain ever. (Henrietta)

Only one participant described her labour pains as bearable:

It wasn't that painful because it was really fast. (Lola)

The rest of the FTSMs were completely taken by surprise at how they could not cope:

The contractions, sheesh, it was the worst pain I could have ever felt, I couldn't even move. (Patricia)

Just literally went like, 'oh my gosh, I need some pain relief', so they gave me heat packs and I said, 'no this is not working', and then they gave me gas and I was like, 'I don't even think this is working', you know, and then I had an epidural... it was crazy. (Anna)

And then they induced me at 2 o'clock; they broke my waters at 10 o'clock that night. They broke it themselves 'cause I was three centimetres dilated, so they broke it, that was the most painful experience of my life, that traumatised me that. Yeah, that traumatised me. Made it worse the only people in the room were my partner and my father. (Maliaga) 
The exhaustion that often accompanies labour was especially difficult to deal with and was a frightening experience, particularly for some of the FTSMs who laboured through the night or over a long period of time:

Yeah, yeah, really, really exhausted, I think that was one of the things that I didn't expect was the fact that... not just that it was painful but it was exhausting, it was really tiring and I think with the gas, I'm not sure but I'm guessing that you should limit your intake cos she [midwife] never said anything about the sort of push... I was actually falling asleep half the time. (Sita)

Maliaga's feelings of anxiety was also exacerbated by fatigue and caused her to visualise the unimaginable of actually missing the birth:

I felt like I was gonna fall asleep and I was scared if I was gonna fall asleep I wasn't gonna wake up... I was scared I wasn't gonna wake up. That's how tired I was 'cause I hadn't slept that whole time I was in labour, had like mini naps here and there, but nothing good. (Maliaga)

\section{SIGNIFICANT ROLES PLAYED BY FAMILY DURING LABOUR}

The FTSMs felt that inviting people to be part of a very intimate event in their lives, was a serious matter. During the planning phase, the question of who should be at the birth required negotiation and many conversations with their partners, which involved working out family dynamics. This was all part of preparing for who would be in attendance in the birthing room. Partners and family members were considered by FTSMs as incredibly important during the labour process. They provided physical, moral and/or emotional support. The family members who were invited to the labour and birth were able to be present. But there were some unexpected attendees.

There is an expectation within Samoan society for mothers to attend their grandchild's birth. However, for Maria's mum, the invitation was not expected as she had not thought she would be present:

I think my mum was quite surprised that I asked her to be in the room, I don't think she wanted to push the subject as much, because my mum is sort of, she is a bit iffy with blood. I wasn't so sure that she would last in the room, but she was fine and having mum in there I was really glad... before that, I don't know if she's going to stress me out, or if she's going to start panicking or make me panic but she was just 
someone else really, yeah, so I was so glad that I had her in there. (Maria)

Maria initially had concerns about having her mother at the birth but she was pleasantly surprised. It is interesting to note how Maria saw another side to her mother 'she was just "someone else" really', a person who could cope well despite a fear of blood and tendency to panic. This was a side of Maria's mother that was unexpected and contributed to Maria's overall labour experience.

Physical closeness and emotional support from family members was a significant part of the FTSMs' labour and birth experience. It provides and maintains a closeness and intimacy between them and their families, offering practical support and making the family member feel involved. For example, Henrietta's mother and partner took turns to massage her:

He was just telling me it was going to be alright and just rubbing my back because I had the baddest back pain... my mum was around and kept massaging me when P (partner) wasn't there, when he went for a smoke because he couldn't handle it sometimes which is understandable. (Henrietta)

The presence of other members, either in the hospital or in the birth room itself, reflects that these FTSMs viewed labour and childbirth as a family affair that went beyond that of the nuclear family. Whether labouring at home or in the hospital, the comfort of the FTSM was most important, as labour was a vulnerable time for them, therefore trust in those members present was crucial. This sense of trust helped with the labour process. The attendants who often had the biggest role during labour were mostly those the FTSMs held in high regard or to whom they were personally very close.

Of this group of FTSMs' families and support people, only one grandfather was at the birth of his grandchild as planned:

So, I was wanting people to massage me and stuff. That's what my dad did, he massaged me the whole time. My dad was really good and he was helping me control my breathing. He was like, every time I'd get upset and start panting and stuff he'll be like, 'Maliaga you're breathing', like really staunch, like just tell me... there was no fluffing with my dad. He just told me straight and I knew just to listen. I knew just to listen. (Maliaga) 
It was natural for Maliaga to have her father present at the birth; the bond they shared is evident in Maliaga's description of the support her father provided. Her father's presence helped to decrease her fear of the labour pains and childbirth. Their closeness appeared to supersede the Samoan tapu of males (except the husband or partner) being at the birth. Traditionally, childbirth in a Samoan context is more commonly attended by only the women of the family. It was very unusual for males to be present (Barclay, Aiavao, Fenwick, \& Papua, 2005). Maliaga was not concerned that her father might witness her at different stages of vulnerability and exposure during the birth, i.e. being physically exposed or having her private body parts displayed; nor was she concerned that her mother was aware of her preference for her father to be at the birth. Maliaga's father's presence at the birth strengthened their relationship further.

\section{CHILDBIRTH}

\section{BIRTHING AND BIRTHING SPACES}

In traditional Samoan birthing, the birth always takes place in the house, where privacy is very important. The birthing space is considered most important with the environment being as conducive to the women's needs as possible. The midwife will be 'closest to the mother' but also several other women, usually female family members including the mother of the birthing woman, 'will also be included in the house' with the sole purpose of supporting the birthing mother through prayers, massage and words of encouragement (Barclay et al., 2005, p. 23).

Davis and Walker (2010b) refer to a 'space for birthing' that, although not always achievable, attempts to challenge the 'obstetric constructions of childbirth and woman' in ways that can create opportunities for women that are less constraining and more enabling of an enjoyable and successful birth. In reference to the FTSMs, space for birthing is about the physical space and who is present, and what happens in the space. Often this is negotiated, defined and controlled by both the FTSMs and the health professionals. The social interactions that occur within the realms of the birthing space are important in the lead-up to the birth. The room in the maternity unit can be seen as the birth setting regardless of the clinical and surveillance aspect of this. It was perceived by the women as their place. They invited family members and friends to share the space and it became a place of family gatherings, a place where the status of people change, i.e. the FTSMs are seen as mothers, or as part of a couple in a nuclear family, or as an addition to the extended family. 
The birthplace or birthing spaces during labour and childbirth were very important on so many different levels for the FTSMs and, for some, what happened in their birthing spaces united and linked people; it solidified relationships, warring families stood side by side, while for others it was a space where private moments could be shared and emotions freely expressed. Unresolved issues between Maliaga and her partner's family created spaces of unspoken tensions in the birthing room between her parents and her partner's parents:

His mother actually showed up when I was in labour - for the first time they met my parents in the hospital room. I was happy because he [my partner] was happy. I was a bit sad for my parents and stuff. With our culture I knew that was rude and that was wrong; you're aware of the Samoan tradition. How when the guy gets a girl pregnant, the guy's parents, it's tradition they go over, it's respect they go over and stuff and apologise to the parents for their son getting their daughter pregnant. They're Samoan, but they don't do culture... yeah religion comes first. So it was weird, but my parents know that that's not the time to bring it up, you know, just let it happen, handle it later. I'm lying there drugged up, looking tragic and they're meeting for the first time. (Maliaga)

Healing the rift between the two families needed to happen within a cultural framework but perhaps not in the hospital unit. Maliaga felt caught in the middle but understood what having a baby meant for both families:

It was very awkward for my family. I could tell that they were somewhat unhappy, but for my sake and for J's sake, because we were having a baby, my parents and my family actually bit their tongues and just left it. Just said, 'Hello', welcomed her, were polite and she actually left because I actually... like lying in the bed I had the perfect view of everybody, 'cause they were all looking at me so I could look at all of them. (Maliaga)

Maliaga was a strong woman who was forthright and honest, and felt poised during what was a tense situation when the estranged parents of her partner came to the hospital room. She stayed focussed and did not let the situation get her down. It was clear to Maliaga that she was in control of keeping the situation calm. Maliaga's parents decided against raising any issues with her partner's parents as they were mindful of Maliaga's position. In turn, they were polite and decided the issue was ongoing so chose not to address it at that particular time. Maliaga revealed that she suspected her partner called his mum in to support him, oblivious to the trauma it would cause her family: 
I actually think he texted his mother to come because he needed her there. But he wouldn't tell me that because he'll protect his mother. Because he knew I would have said, 'Why did she come, that's not the place.' And you know him as a son, he loves his mum; he's a mummy's boy; he protected his mother and he lied to me. But I know when he's lying. But to me it didn't matter. I was like, 'Okay it happened; it's not worth arguing over.' It was bound to happen sometime, whether it be a good way or a bad way, it had happened; couldn't do anything about it. (Maliaga)

Irrespective of all this, Maliaga was aware of the importance of the support that her partner and family provided her, and in turn accepted that her partner needed his family's support as well, regardless of how she felt about them. She overcame her disappointment at what she suggested was her partner's dishonesty, taking the pragmatic approach to the situation and not causing a scene, thus avoiding any further friction between the families. Maliaga's situation emphasises the different dynamics and tensions the FTSMs sometimes had to mediate.

Being able to be in the birthing room was special. Being able to control who could be present in the room at the time of birth was important to the FTSMs. Knowing they had some control made it special for those who were invited to be present:

I think it was more intimate and it was more special for them [the mother and husband]; that they got to witness and see A first before everybody else started running through the room and I think it was good because it wasn't so stressed. I could imagine [what] it could have been if there were more people in the room... anybody that knocked at the door we had to send my mum out to tell them to stay out. (Maria)

The FTSMs saw childbirth as precariously balanced between the best and worst experiences of their lives. In the process of producing a healthy live baby, the experience was one that moved between the two extremes. The words used to describe their childbirth experience included: chaotic, panic, uncertainty, unknown, frustration, tension, mess, prayer, whispers, no choice, shock, neonatal, worry, waiting game, tests, emotional, intimate, amazing.

The FTSMs also experienced births with and without complications. A few got to hospital just in time to give birth while others spent lengthy periods of time waiting. As planned, all the FTSMs had family members and their midwives present at the birth, and 
all had their babies in the maternity unit of their chosen hospital. What all the FTSMs expected of childbirth did not match their actual experience. While many were 'disappointed', this was for them merely a fleeting thought, quickly surpassed by the pleasure of having a live healthy baby.

A 'natural birth' for many of the women meant low or no intervention, no epidural, but a vaginal birth. With the exception of Lola, all the FTSMs received gas or drugs to help them with their labour and birthing. They were under no illusion that childbirth was going to be physically easy and many could articulate quite vividly some of the difficulties. However, none were prepared for the emotional intensity and elation that followed:

The biggest thing that I didn't expect was how amazing and that it happens all the time; it's just kind of like, oh you're giving birth, oh you're having a baby, cool... but not until you are in it, very emotional... it's just amazing. I can't believe people do it, you know, it just happens all the time. (Anna)

Regardless of how well organised or planned the labour and childbirth was, there was always the risk of an adverse event happening during this time that could generate a lot of negativity in the birthing space. This included tensions caused by not being informed about what was happening during childbirth. Many of the FTSMs felt a lack of control and believed they were poorly informed, particularly about what was expected to happen during, or what could lead to, an emergency situation, especially with difficult births. Anna, Geraldine and Henrietta had difficult births:

She came out floppy, that's what they call it, floppy, it was horrific... but then they took her over and sorted her all out but then she was over with me within minutes but I just felt like, oh my God. She just wasn't breathing, I'm not sure, like no one really explained. (Anna)

It was really fast, she [midwife] just checked his [baby's] blood pressure and then she just pressed a button and heaps of people started rushing in and started putting an IV in, and they said I might have been a little dehydrated, and then she just explained to me that they needed to do it, the emergency caesarean, and then they rushed him out. (Geraldine)

We had to wait for half an hour for the nurses to come because my midwife had called them twice telling them there is something wrong, baby is not coming out... they [nurses] finally came... probably about five 
or six nurses that came in, all came in at once; telling me to get emergency C-section done... when he came out he wasn't breathing, yeah, so he had to be in ICU for about two to three weeks because there was no blood going through his organs through to his brain so he had a difficult birth. (Henrietta)

Communication was a salient feature in the experience of the childbirth and stay in hospital. Many of the FTSMs highlighted that communication from the medical staff was seriously lacking. Geraldine and Henrietta had complicated births that resulted in emergency caesareans. Immediately after the births, the women felt they were not well informed about what was happening or the reasons why the emergency occurred. The waiting and not knowing was frightening. Geraldine was not permitted to see her baby until the next day which scared her. Geraldine's anxiety forced her to discount the severity of the pain she was enduring:

I couldn't see him until the next morning because I had a C-section; they wouldn't let me go down because I had to stay in bed. I woke up and I was in so much pain but they were like, 'what's your pain scale', and I just wanted to see him [baby] so I was just lying saying it wasn't even that bad, just so they would let me go and see him. I think they knew I was lying because they still wouldn't let me go. (Geraldine)

Henrietta made a shocking discovery when she overheard her midwife being told by the hospital 'doctors' to withhold the information about her baby's condition from her:

I could hear the doctors whispering to $\mathrm{N}$ [midwife], don't say anything, so $\mathrm{N}$ had to come and hold my hand; I think she wanted to tell me but I think she couldn't... I knew straight away something was wrong because I saw his [partner's] face and then I could hear the doctors talking to N; they were saying 'don't mention anything at the moment just wait until she gets back to her room and stuff like that. (Henrietta)

The knowledge that the doctors were withholding information about her baby seriously betrayed Henrietta's trust and confidence in the way the hospital staff were dealing with her and the situation. Their lack of transparency and honesty, coupled with the endless waiting for information, frustrated her:

That whole waiting was just... I was getting annoyed, yeah. They were telling me we had to wait, we couldn't see baby until we saw the nurses 
first and so we were just playing a waiting game that whole time I was in hospital. (Henrietta)

When Henrietta was finally given the news that her baby was very ill, not only was she still dealing with the powerful drugs given to her for pain relief but she was told the news when she was alone in her room, and she had no family support. The news heightened her anxieties and vulnerability. Her partner was with their baby in the neonatal ward as was her midwife, and her family were in the waiting room:

The morphine helped alot, it was like, oh, my gosh where am I... I had about four or five nurses come into my room and I was like, 'what is going on?'... they came into the room and told me that he wasn't breathing when he came out and that he could have brain injuries, permanently. They said that they had to warm him up for three days and all that, and then they had to cool him down and all that. (Henrietta)

The retelling of her experience was still raw for Henrietta and she was very upset throughout this part of the interview. The nurses were strangers to Henrietta; she did not know them prior to her admission to hospital and they were not going to be part of her life when she left. She was in an incredible state of vulnerability, yet they gave her devastating news about her baby when she was alone, and, due to her drugged condition, was less likely to properly absorb the information. The hospital staff did not seem to care. As the nurses left the room, together, they reassured Henrietta they would do all they could to support her yet they left her on her own:

I was crying and then luckily my mum came through and she... sorry [participant starts to cry]. But then mum came through, oh gosh, finally I could see a face that I know, $\mathrm{N}$ came through and she was worried as well but she was saying that she would do everything that she could do for baby. (Henrietta)

The communication between Henrietta and the nurses did not get any better:

It was still the same thing on the first day, we had to wait and wait and wait. I kind of got annoyed and frustrated especially for a first-time mother, it was like what's going on. (Henrietta)

Henrietta's experience demonstrates how the actions and attitudes of the medical professionals can easily lose the focus of 'woman centeredness' childbirth, and perceived by them to be in the best interests of the woman, they often are not, unintentionally 
having the opposite effect and removing any form of control or empowerment for the woman. The birthing space is, in this context, no longer a place of privacy, warmth and calm but just a cold, impersonal hospital room. Henrietta's rights as a health consumer had been breached on several levels (The Health and Disability Commissioner, 2009). Henrietta felt that she did not have the time or energy to go through with the process of making a formal complaint to the District Health Board, and was just glad to have her baby home.

Anna's experience in the hospital with the hospital midwives was, as she described, 'horrific'. It was not until Anna was informed that she had to stay an extra night in hospital, due to possible health issues her daughter might suffer, that Anna realised she may not have been told the full story about her daughter's condition at the time of birth:

She [nurse] was like, her test results from the placenta or something was not that good, hopefully there shouldn't be any long term... and I'm like, I was kind of listening but I was kind of like, oh yeah, but then I said, 'what? hopefully there shouldn't be long-term, like what happened?'. And then all of a sudden I was thinking what actually happened, no one has explained to me any kind of ordeal of the birth. (Anna)

The results from the tests performed on her daughter turned out to be fine, but the communication and the way in which the news was delivered completely stunned Anna:

And then anything that she [the nurse] said after that I couldn't even like concentrate, I was just 'what the hell?' and I started crying. In my mind I was like, 'oh my God', you know, it just freaked me out the way she said it, I didn't quite understand it and I couldn't quite get an explanation really, because after she said long-term effects I was just like... brain damage? She's not going to walk? I was a bit of a mess. (Anna)

These FTSMs felt isolated and in some cases needed help with the baby, particularly those who were dealing with the effects of drugs or who had major complications with their birth. The uncertainty of events and the lack of communication led some FTSMs to describe the childbirth experience as a 'rollercoaster' of emotions.

\section{CHILDBIRTH IS A FAMILY AFFAIR - FOR GOOD OR BAD}

FTSMs' mothers were a great asset during the actual labour and childbirth process. They described their mothers as comforting and nurturing, and while some of the FTSMs' 
mothers found it difficult to cope, it was usually in relation to seeing their daughters go through the pain, an experience they knew so well, or seeing them be mistreated if they perceived their daughters were not receiving the treatment they needed. Maria's mum witnessed her daughter giving birth which brought back her own memories:

My mum was very calm, and then when it came time to pushing and giving birth, mum was very teary and quite emotional. I think it was because mum was looking at it as: my daughter is going through this, delivering her grandchild. I said to mum, 'are you okay?', and mum said, 'yeah', it just flashbacked to when she had me; her mum wasn't there so it was quite emotional for mum. (Maria)

When the support person is not coping, it can be very distracting and diverts the mother's attention away from concentrating on the task at hand:

My mum was actually a bit of a mess, she was in and out of the room as well, she couldn't really... she didn't like seeing me in pain, she's a strong Christian so she was coming in and praying and stuff and I was like: 'mum, it's really not the time and she was just in and out and all over the show, she wasn't dealing with it well... I think I like pushed her away and I was like oh my God, I'm going to strangle her. (Anna)

Anna's mother found it difficult to cope with Anna's labour and birth. Praying may have been a suitable coping mechanism for her comfort but annoyed Anna. Fortunately for Anna, her sisters also attended the birth and could, to some degree, take care of their mother.

Henrietta's mother was present when Henrietta gave birth, during which time she conversed in either Samoan or English. Henrietta's mother was not happy with the nursing staff but, instead of directing her frustration at them, she expressed this in the Samoan language so only Henrietta could understand. While this added extra pressure and stress to Henrietta, she felt better that her mother's concerns and reactions were directed to her rather than the hospital staff:

I think it was okay for me because I think I knew what she was going through when she was giving birth to us kids. I was probably all drugged up by the time she was saying it but it was good she released her frustrations out at the time instead of taking it out on nurses and all that. (Henrietta) 
The FTSMs applied different coping mechanisms to deal with the distractions or interruptions during the labour. Maria and her mum were comfortable and secure conversing in Samoan:

Mum spoke Samoan because it was more comfortable speaking Samoan; it's her first language, it's natural for us so I didn't see that there was anything wrong with her speaking Samoan. She was just saying to 'keep strong, stay strong, stay focussed', and I could just tell by her voice that she was breaking into tears because it was getting a bit croaky, but I was so focused on breathing. (Maria)

While Maria opted to concentrate her total attention on her son:

I just block everything, like my personal life. The things that are surrounding me, like all the dramas, I just block it all out and just focus on getting my son out, because I have been waiting, everything is waiting, everyone is waiting, it's just him that's taking his time, so I just wanted to get him out. (Lola)

\section{FTSMS REFLECTIONS ON THEIR EXPECTATIONS AND REALITY}

The FTSMs reflected post-birth on their expectations of childbirth compared with the reality. Geraldine expected a natural vaginal birth and to be in a lot of pain. She hoped she would not need an epidural but, as with most of the FTSMs, if the need arose she was happy to receive one. She ended up feeling disappointed at having an emergency caesarean:

I kind of felt like a failure, like I couldn't give birth properly or that I had done something wrong and that's why I had such a difficult birth, but then I got over that eventually, yeah. But, yeah, I did feel like that at first... I know if I got pregnant again I've got nothing to prove to anyone, like I would do what's best for me and the baby, yeah, I think at first I was just trying to act like I was just tough [to give birth without an epidural]. (Geraldine)

Some of the FTSMs watched television programmes such as 'One Born Every Minute' and felt they were prepared for their births. What they expected from the television programme was quite different to their experiences: 
I thought [childbirth] would be so much worse; the pain and everything and I'm not trying to sound... but I watched, you know that programme 'One Born Every Minute'? I was like oh my gosh, is it really that bad?, and then I got to experience it. I was like it's actually not that bad. (Maliaga)

You just see what's on TV and what you hear from other people, and so I expected to feel excruciating pain the second the waters broke. I was expecting that I would be down on all fours crawling to the hospital, but none of that happened and it was such a calm day that day that my waters broke. I was quite surprised about how calm I was and so was my husband, he said he thought I was going to break all his fingers and scream the house down but it was just... I don't think I screamed once. (Maria)

Many of the FTSMs articulated their elation at the fact that they had given birth - some experiences had lived up to their expectations while many did not. Maria summed up the immediate post-birth space:

I have got to say it was awesome afterwards. It was like an achievement like you've just conquered something, like you're standing on $\mathrm{Mt}$ Everest shouting out look I can do this... there is so much pain, you go through so many emotions and feelings and you are on a rollercoaster pretty much. You're up and down and you've got all these needles in you; you've got all these people who are encouraging you and you've got all these breathing exercises. You've got a million things going through your head and on top of that you're connected to this baby that's inside you and you're trying to keep your baby alive and focus on your baby; it was quite a good feeling, a very good feeling. (Maria)

This chapter presented the narratives of the FTSMs, from the onset of labour, or in some cases from the time the FTSMs were preparing to go to the hospital for a caesarean, to the actual birth of their new baby. It argued that the 'birthing space' was significant for the FTSMs as it was both a space for transformation and for control. The FTSMs could control the space by dictating who could be there for them. It was a space in which she could share with those around her the wonderment of birth. It was a time that transformed them, their relationships with each other, that contributed to the overall experience and construction of what motherhood means for them. 


\title{
CHAPTER SIX: EARLY MOTHERHOOD
}

\author{
'We know he's ours, but it's just weird knowing we're parents'
}

What is the meaning of early motherhood? I ponder my own understandings of early motherhood and always come up with ideas about the sense of pure love, of a new identity, of a new life within that identity, of a 'new' self that is built upon an 'old' self. I think of my own mother, my daughter, my grandmother, my sisters, my sisters-in-law, my aunts, my nieces, of all the women in my life. These meanings of motherhood for me and of how it has changed my own sense of self, my role within family relationships, with friends, community, society, are not fixed, They are constantly negotiated as I age and move through life, and engage with different people in different spaces.

While this chapter focuses on the specific stage of early motherhood (rather than motherhood more generally), it is worth noting that motherhood is a concept that carries with it socially constructed ideals about womanhood and about what roles and responsibilities women should play in society. This social construction takes into account biological facts as well as social, cultural, political and economic values.

With FTSMs, the issue of motherhood is defined, read and experienced through multiple lenses. Two lenses of particular importance to them are the Western cultural lens of the New Zealand society they reside in and the traditional ethnic Samoan lens of their Samoan parents, extended family, church and community. This chapter explores how early motherhood is perceived and discussed by the different participants of this study, but, in particular, the FTSMs. It explores the first few days and weeks following the birth, as well as FTSMs' feelings and perceptions about their 'post-birth' body, their new status as a mum and how that affected the way they saw and related to others.

\section{INDIGENOUS NOTE ON MOTHERING}

Embedded within historical and anthropological scholarship are Pacific women's maternity experiences, recorded mainly by early missionaries (Jolly, 2002b) and academics visiting the islands (Mead, 1928, p. 152). Early accounts explained ancestral beliefs and practices about mothering within a particular area or island (e.g. Vanuatu), although practices differed between different islands and cultures throughout the group (Jolly, 2002b; Macpherson \& Macpherson, 1990). The influence of missionaries, colonial policies and the introduction of Western medicine and biomedical birthing methods, and the challenges and consequences around the definitions of 'traditional' 
versus 'modern' in terms of motherhood are salient in terms of understanding of indigenous birthing practices and mothering (Barclay et al., 2005; Jolly, 2002a, 2002b). The differences between 'traditional' and 'modern or Western' practices of mothering are often constructed as non-intervention versus intervention practices (Jolly, 2002a).

Traditional midwives are mediating agents between their indigenous knowledge, which has been handed down through generations, and the colonial or modern health system that has an impact on their work (Barclay et al., 2005; Hattori, 2006; Macpherson \& Macpherson, 1990). The Samoan fa'atosaga ${ }^{25}$, similar to the indigenous midwives of Guam, dealt with the derogatory attitudes towards their traditional midwifery methods and practices (Hattori, 2006, p. 10). Tensions that occur in many countries, including Samoa, between the Western paradigm that is highly medicalised; and that of the traditional framework of healing and spiritual notions of health and illness (Barclay et al., 2005). In Guam, replacing the traditional knowledge with Western based-knowledge failed and the graduated nurses 'did not simply replace traditional methods with navy teachings, but instead syncretised newfound knowledge and techniques to create a hybridised practice of maternal care' (Hattori, 2006, p. 18). This is an example of sophisticated mediation at play in the world of maternal healthcare. There is a need within these different mothering spaces for sophisticated negotiation and mediation.

\section{FEMINISM AND MOTHERHOOD}

Adrienne Rich (1977) investigated the phenomenon of motherhood as both an experience and an institution. She argues that there is a potential relationship of power between being a woman and being able to have children. However, that power in patriarchal societies is controlled by men, who seek to ensure that that potential is defined in such a way as to normalise and reproduce the status quo of male control. While Rich's writing might be read as reflective of white middle-class mothers (of the 1970s) there is relevance for this study in that contemporary New Zealand and Samoan societies continue to privilege patriarchal models in their institutions of family, church, work and government.

Rich (1977) wrote about her experiences with deep emotion. She shares the conflict she experienced of becoming a mother and being a daughter. Rich points to the 'doublerole' of working mothers, i.e. mothers today are producers and nurturers of children

\footnotetext{
${ }^{25} \mathrm{Fa}^{\prime}$ atosaga is a person who is regarded as a specialist (midwife) and a professional by herself and her community. TBA (traditional birth attendants) is the term used to refer to midwives and other women who have attended the Department of Health training course (Barclay et al., 2005).
} 
and paid workers in the market place. In the 1970s, this was a relatively new concept, but in 2014 this is the norm for many women. Rich writes that patriarchal socialism in the 1970s, finds the institution of motherhood 'revised' and 'reformed', but in ways which 'permit women to serve' to reproduce the status quo of male domination (p. 54). She suggests that despite the key role that mothers play as the main carers of children, male and female, many of whom later become leaders of society, the persistence of a patriarchal socialism whereby women are deliberately prevented from taking on positions of power over men in contemporary Western society continues (ibid.).

Patricia Hill Collins (1997), an Afro-American feminist, cautioned against the Eurocentrism of white feminism. She argues that there exists within feminism (like many other intellectual activist movements) competing perspectives on motherhood. This cautionary note resonates for many Pacific female activists and intellectuals (see Teaiwa, 1999; Tupuola, 2002, 2004a). Collins explains that for traditionalists (a category many Samoans might fit within), differentiating between the experience of motherhood, which for them has been quite satisfying, and motherhood as an institution central in producing gender inequality, has proved difficult.

There exist, as Hill Collins (1997) says, difficulties in applying wholesale feminist arguments about patriarchal socialism without proper thought to the 'on-the-ground' workings of the group that such arguments are applied to. In the Samoan case, there are competing emotional alliances to one's ethnic (i.e. Samoan) identity over gender (i.e. female) identity on the one hand and to the inextricable ties between Christian patriarchal ideas of womanhood implicit in church doctrine and ethnic values on the other (Griffen, 1989; Stewart-Withers, 2007).

Both the Samoan and New Zealand cultural systems of mothering are major influences in the lives of the FTSMs. Traditional Samoan values and beliefs surrounding motherhood sometimes conflict with New Zealand aspects of motherhood. Often these conflicts reflect identity and cultural differences (e.g. infant feeding and cosleeping issues as discussed later). Such differences in beliefs and values must be taken into consideration when thinking through how to interpret or make sense of the FTSMs' descriptions of their experiences of motherhood: how to read their specific constructions of conception, pregnancy, labour, childbirth and early motherhood.

Early feminist assumptions that mothering happens within the boundaries of a private, nuclear family household in which the mother has almost total responsibility for childrearing does not apply universally. Collins, for example, argued this assumption is 
not applicable to Black or Afro-American families for the reason that boundaries distinguishing biological mothers of children from other women who care for children are often fluid and changing'(1997, p. 329). Mothers, in that case, include both biological and non-biological mothers, with the latter often including women related to the biological mother such as grandmothers, sisters, aunts, cousins, but also close friends or paid help (such as nannies, governesses or 'house girls'). This is similarly true for Samoan families. Within the Samoan traditional culture the family is understood as the extended family and includes both biological and non-biological kin, i.e. kin by marriage or by close friendships that were enabled through people sharing the same village or household and, by extension, sharing of childcare and/or early mothering responsibilities.

Moreover, Collins notes that the Western feminist assumption of strict sex-role 'segregation defining male and female spheres of influence within the family' (1997, p. 327) must be contextualised. She argues that the traditional Western African way of mothering was retained a lot more among African-Americans than first thought. Thus Western feminist critiques of ideas of a 'good' mother as one that must stay at home, making motherhood a full-time occupation, was problematic because it was uncharacteristic of African-American families (Hill Collins, 1997, p. 328). Her point is taken when reflecting on how best to interpret the context of FTSMs experiencing motherhood for the first time in New Zealand.

\section{HOSPITAL EXPERIENCE}

Most of the first-time mothers view maternity professionals as experts and consider hospitals as a place of safety. Some of the FTSMs found that making sense of the hospital setting post-birth and negotiating new relationships with the hospital professionals was difficult; they had not anticipated having to adapt so much to the hospital setting. Women's perceptions of their care and treatment contributed to their birth experiences. It is well documented that personal, caring and cooperative relationships with all maternity care professionals are crucial to mothers feeling good about their birth experience (Howarth, Swain, \& Treharne, 2011, 2012). The importance of maintaining a good relationship with first-time mothers cannot be stressed enough and the impact of a 'bad' experience can have far-reaching implications. The hospital maternity professionals-FTSM relationship is often a stressful time as they are brought together during a highly energetic, highly emotional time, often with family members present, and only for a very short period. Almost half of the FTSMs were highly critical of their hospital stay and were appalled at their treatment, which heightened their feelings of vulnerability and helplessness, particularly as, this being their first maternity 
experience, they were uncertain of what to expect, or what was expected of them. The FTSMs felt frustrated at the lack of communication from the hospital nurses as illustrated by Patricia:

I wasn't sure what to do and I wasn't sure how to change his nappy, I didn't know how to breastfeed... it was weird that I had a baby.

The majority of FTSMs were over their due date by the time they gave birth. Mele had an earlier-than-due-date elective caesarean as her condition was identified as high risk early in her pregnancy. The length of time spent in hospital varied for the FSTMs, shown in the table below. Lola and Maliaga spend the least amount of time in hospital following the birth of their babies. Both FTSMs were very keen to return home. Lola had a vaginal birth and was up and walking about within an hour of the birth, while Maliaga underwent an emergency caesarean and, while strongly advised by the medical staff to stay in hospital, discharged herself less than 24 hours after the birth. Mele spent the most time in hospital; again, this was related to her high-risk pregnancy, earlier birth and caesarean section. Geraldine, at her own request, was the only FTSM to move to a birthing unit for an extra two nights.

Table 1: FTSMs length of time spent in hospital before returning home

\begin{tabular}{|l|l|l|l|l|l|l|l|}
\hline \multicolumn{2}{|l|}{ FTSM } & $\begin{array}{l}\text { Length of time } \\
\text { in the hospital } \\
\text { or birthing unit }\end{array}$ & Overdue & Induced & Vaginal & $\begin{array}{l}\text { C } \\
\text { section }\end{array}$ & Complications \\
\hline$(31)$ & Anna & 2 nights & Yes & Yes & Yes & - & Yes \\
\hline$(25)$ & Geraldine & $\begin{array}{l}\text { 3 nights/2 } \\
\text { nights }\end{array}$ & Yes & - & - & Emerg & Yes \\
\hline$(28)$ & Henrietta & 5 nights & Yes & - & - & Emerg & Yes \\
\hline$(22)$ & Lola & $<$ One night & Yes & - & Yes & - & No \\
\hline$(24)$ & Maliaga & $<$ One night & Yes & Yes & - & Emerg & No \\
\hline$(30)$ & Maria & One night & Yes & Yes & Yes & - & No \\
\hline$(21)$ & Mele & 7 nights & Early & - & - & Elect & Yes \\
\hline$(26)$ & Patricia & One night & On time & Yes & Yes & - & No \\
\hline$(28)$ & Sita & 2 nights & Yes & Yes & Yes & - & No \\
\hline
\end{tabular}

\section{RETURNING HOME}

Women who thought that they would be organised and controlled during their early motherhood days were soon faced with unpredictability, utter physical exhaustion and altered family dynamics. Recalling the first days back at home with their baby conjured up many feelings for them. The emotions they expressed ranged from negative 
(nervousness, being scared, frustrated, worried), to positive (being excited, having the normalcy of routine, being happy) to a mix of both.

Returning home with their baby was an interesting experience for the women when a new sense of identity, that of being a mother, emerged. The FTSMs and their partners were transformed from being a couple or two individuals, into being a family, parents with a child. These FTSMs faced the reality that they were now embarking on a new journey one of discovery, not only in terms of learning about themselves, especially their new bodies and emotions, but also about their families, friends and the new people they were meeting and the relationships they were forming.

FTSMs noted that no amount of planning or having 'realistic' expectations could have prepared them for the days following actually giving birth, or the amount of support they needed in order to cope immediately post-birth. The support they received from family members was significant, and much appreciated by the FTSMs:

We were like swamped with our family, our immediate families. Actually, even that was exhausting, it was like we never had a break. They were there to help which actually it was good because a lot of the time my husband and I actually got to have a sleep at night time because someone would come over and watch baby while we had a sleep. It was really nice... the first couple of weeks especially the first one, they were doing night and day shifts sort of thing, so we'd always have someone over. (Sita)

My grandma just, just made me more confident as a mum because then I knew that I didn't have to overreact with a lot of things. Sometimes when he would cry, my mum would be holding him, and she's like just give him to Nan, and she will start singing some Samoan songs and he will fall asleep. She [grandma] still comes over every weekend. (Geraldine)

It was like I'm coming out [to my parent's house] every weekend, it was just like really luxurious not being the only person doing everything... but yeah, having my mum and my sisters... it was like a break, just phew, I thought I totally get it now. I think why didn't we have my mum [come and stay], but I guess like if I had my mum come and stay then I wouldn't have felt like I could have done it... but it's not like anything went wrong anyway... I just realised I needed to go 
and stay with my parents ... I thought, oh my goodness, no wonder peoples' mothers come and stay. (Anna)

Indeed for some FTSMs, knowing that there were family members on hand to help out, especially their own mothers, meant that they were able to develop somewhat of a blasé attitude or approach to dealing with the care of their newborn:

I will just go with the flow and I will have my mum there to help out. She always told me that I should look after my own child and don't get other people to look after my child, yeah, so just around staying home, I want to be at home for at least the first two years and then go back to work. (Geraldine)

However, having a constant stream of visitors proved too much for some FTSMs:

I remember the first two weeks people are always coming over, and so that whole thing... we were like oh, my gosh, it's so exhausting. So, I think now we know if anyone else has a baby we will give them some time. (Sita)

I think we finally got her down at about 10am in the morning and we thought, ahhh, finally, and then we decided to tuck ourselves into bed, and then we had visitors at $11.30 \mathrm{am}$. I was like 'oh, I just need to go to sleep', so they came in and they probably stayed for about half an hour until my husband said, 'look, just to be honest, we haven't had much sleep and we're not being rude or anything but...'. I think that first week with A was a true reflection of what was to come. (Maria)

Most of the FTSMs expected, and were confident, that their families would be their main source of support. They were certain that their partners would be there to help them out full-time, or at least for the first couple of weeks. The FTSMs expected that once their partners returned to work that their families would step in and pick up the slack. Some of them had even planned for their mothers to stay at home with them for the first couple of weeks post-birth. How this all worked was negotiated by the FTSMs with their family members and partners. Anna, for example, had planned that not only would her family be around to help in the first few days post-birth, but that she would have the first few days at home with just her partner, herself and their baby. She felt her ability to cope was due to her age: 
We just want to have those first few days, or that week, where it's just us, and I feel like I'm capable enough... you know, to be able to do that and if I needed help I would call my mum, I mean I am 30, not that that should make a difference in what we're capable of, but I feel confident in that I will be okay. (Anna)

During the initial days of returning home, the FTSMs described their new life as busy, juggling sleep deprivation with the usual household chores and 'getting used' to having a new person in the house. Alterations to sleep patterns are common during pregnancy and early motherhood. This is related to a number of different changes the FTM undergoes: physiological changes (hormones), physical changes (e.g. discomfort after a caesarean), and/or coping with the newness of looking after and being the primary caregiver of a newborn baby. Patricia realised: 'I had to take care of myself because he [baby] depends on me; I am sick, he is sick.'

Lack of sleep has health implications (i.e. fatigue) for the mothers' wellness, and sleep disruption has been associated with mood disturbance in anything from baby blues to feelings of postnatal depression (Matthey, White, \& Rice, 2010). Some of the FTSMs envisaged that their baby would sleep a regular set of four hours at a time and were quite surprised when reality set in:

No one told me it was every half hour, every hour or every two hours, sheesh when I came home I thought [babies] sleep for four hours, wake up for a feed, then go back to sleep and then every four hours, so not this time. So my sleeping pattern changed a lot, so from the six, seven, or eight hours sleep I got, I think I managed, if I get a good two-three hours' sleep that's the best sleep, I think I've adjusted to that, sometimes I have a 20-minute nap and I feel really, really good whereas my partner will have a 10-hour sleep. (Patricia)

It was a really good morning that morning just because we had a big sleep. (Anna)

The FTSMs did expect a certain amount of stress, 'sleepless nights' and feelings of 'tiredness' when they returned home with their newborn. This expectation was based largely on observations of what other family members went through:

I'm expecting a lot of stress, I'm expecting the works... I'm expecting a lot, the whole sleepless nights... there's just a lot, it's overwhelming but no, I'm excited for it, I'm not scared because the way I see it, it's 
normal, I mean, this is what happens every day, women have babies every day, they pop them out every day. (Maliaga)

How they dealt with this stress, lack of sleep and tiredness was drawn from observations of how other family members managed. One FTSM spoke of how her mother helped her brother out during their early parenthood stage and how not only was that a great help to them, but it also seemed to her to be a very Samoan way of helping out:

His [her brother's] kids are very, very close to our family and my mum. Every weekend [she] takes them regardless of what's happened in her life. Samoans, we come in numbers, so we're always around babies and kids and looking after each other. (Maria)

Coping with tiredness and complete exhaustion was a significant struggle not only for the FTSMs but also for their partners. In fact, most of the FTSMs did not expect the high levels of fatigue and sleep disturbance that they experienced going into early motherhood, nor the possibility of limited mobility as an after-effect of a caesarean or epidural. The high level of emotional stress within their relationships with their partners and families was a surprise. The FTSMs believed that there would be obvious changes by having a baby, and that the transition would mean changes in their relationship. Their partners, and their families, they assumed would, in the end, be 'okay', that it would not be as difficult as it sometimes was; for example, Anna's living situation changed dramatically within the first three months of having her baby. Her partner was away for long periods of time and she developed feelings of isolation and loneliness:

The first three months I really struggled to do stuff like clean the house, so I would have these days when everything would work out great, she would go back to sleep, I could shower, you know, get her dressed, clean the house and do everything...but her napping, I don't know, sometimes I would have these bursts, but generally I was a bit of a mess. Then our relationship wasn't the best and he [partner] wasn't around and we were in between [houses] and we were living out of a bag because we would come out here [to sisters' home] and stay all the time. Yeah, I don't know, I guess I've kind of struggled with it. (Anna)

A key struggle in Maliaga's experience of early motherhood was her temporary physical immobility as a result of her caesarean. Her first week at home, she could not help with the care of her baby which was left to her mother and partner. She stated that she felt 
'stink' that she could not help with her baby's needs but that did not mean, as she was quick to point out, that she did not have any control or influence over how the baby was looked after. Her struggle was perhaps more in terms of reconciling or dealing with her own feelings of uselessness, something she took care of by ensuring that her voice was definitely taken into consideration in the decision-making process. She states:

My mum had two weeks off so she was at home with me and J (partner) for the first two weeks, which was good. J gave baby the first feed, the first bath, the first change; the first everything J got to do, I didn't get to do it. But some people think that's a mother's job; a mother should be able to do that for her own baby. I didn't care, as long as it was done and that he was okay, I was fine. But it did make me feel stink, you know, like I couldn't help; I couldn't get up when he was crying, couldn't hold him. But I had a say of what he would wear. I was like, 'what are you putting on, that's ugly, change it.' And they were like, 'oh Maliaga, still the same, just go to sleep.' I was like, 'no, don't dress my son in that, it's ugly'. (Maliaga)

The FTSMs raised their fear of becoming bored during early motherhood, especially those who were building their careers, and were active in sports and community events. Patricia spoke about the issue more directly and in more depth. The unexpected pregnancy, together with having her baby before she could consolidate her career or travel overseas as she hoped to do in the future, created a situation where she became less enthusiastic and somewhat ambivalent about becoming, and then being, a mother. Patricia ensured that I understood that she was in no way blaming the birth of her baby as the reason for her feelings of regret. The timing of his arrival and the emotions that came with it, did contribute to, and so should be read as, part of the context of what she was coping with. Her comments, while somewhat contradictory, reflect her struggle with the unplanned timing of her pregnancy:

I know very well that I hate just being home because ever since I was little we were always only allowed to be at home so I was stuck at home for 18 or 19 years. Even when I turned 18, I didn't drink, I wasn't allowed to ... I got told 19 or 20 ... so I've only had about five or six years of freedom and now I'm back. You know, while I will love being a mother, but now I'm back to just staying at home, even though I can't experience a lot of things. I think in the first few weeks when I did have him [baby], I did have some low times when I used to wish that I had travelled. This year was my travel year, my third year of teaching, and I was supposed to be registered. I think I was just down, 
my partner was always telling me, 'who cares, we can do that when we're older, we can take him with us.' It was always about travelling, I always got down about it, because I've always wanted to travel. I was meant to go to Japan to go and teach because I had been looking forward to it for a long time and I was telling my partner, 'now I can't do it.' I think that was about the only time that I was getting down, it was always about travelling, and now I always look at him [baby] and think I'm so sorry, just having a little down moment. I just started this semester to do my post-grad to have something to do. (Patricia)

\section{POST-BIRTH BODY}

Weight gain and the changes, both physically and visually, that accompanies pregnancy were raised as concerns for some of the FTSMs during pregnancy and were raised again in relation to their post-birth body. Mass media portrayals of celebrities losing the 'pregnancy' weight so soon after giving birth gives women unrealistic views of what is attainable for post-pregnancy weight loss. The expectations of how their bodies would cope post-birth and the reality of what they actually experienced surprised some of the FTSMs. They believed that their bodies would go back to their pre-pregnancy state soon after birth, but found it took longer than anticipated, as articulated by Maria:

After doing all of that [giving birth], you don't realise how much your body goes through. It was like that first week, I was in pain, I was slow at moving around, I felt like I was still pregnant, first stages of pregnancy; your tummy is still out, you kind of expected it to just to deflate and go back in. I still had my tummy out, my breasts were hard and were solid, rock hard. I didn't expect any of that, I didn't know that that was what would happen afterwards. My whole body was like, oh, my gosh, on top of that with all the bleeding and everything, everything was just all [out of] whack for me. I was like, oh my God, not only are my boobs sore, but I'm bleeding and I'm really slow, so it was quite weird afterwards. I just didn't expect any of that... I thought you would just jump out of bed and that's it, you've done the hard bit.

\section{ENGORGED BREASTS AND BREASTFEEDING: NO ONE TOLD ME! NO ONE SHOWED ME!}

A key change to the post-birth body was the changes to the FTSMs' breasts. Some experienced, as is normal during pregnancy, tender and enlarged breasts. However, they noted this was nothing compared to what they went through post-birth. Most of the FTSMs were surprised at just how difficult breastfeeding was; the pain, the engorged 
breasts, and the length of time it took for the baby to feed or for her and baby to get the rhythm of breastfeeding right:

The one thing that I always remember now, because no one ever mentioned much about it to me, was the breastfeeding... no one ever mentioned it, I think maybe if someone warned me earlier that breastfeeding would have been this difficult then maybe I would have been a little more prepared. (Sita)

They [midwives] told us that breastfeeding is not meant to hurt, but then they say that you will be sore after the next few days. I was never told that part until in the hospital. (Geraldine)

Both these FTSMs indicated that dealing with these changes was something they were not really made aware of pre-birth or even immediately after birth. FTSMs highly recommended that new mothers should be told this explicitly:

I never heard much feedback about it, it was never a topic that people say, when you are a first-time mum breastfeeding is really difficult... yeah, I wasn't really told, it was through experience. What I would recommend [to other mothers]: it's good for them to have an idea about what is the worst of it... so there were a couple of things in there, like that, and the worst of things that I wasn't aware of... I would have liked to have someone give me a heads-up. (Sita)

I had a lady come and she was really good. She was a Samoan lady, and she was telling me how to breastfeed. She actually told me, like, when your breasts get really heavy and really sore, lucky she told me; I wouldn't have expected anything. (Geraldine)

The initial physical introduction to breastfeeding occurs immediately after birth and for most of the FTSMs it was a struggle. They worried about their ability to produce enough milk to continue to feed their baby; they found the experience painful and really difficult.

On top of dealing with the engorged breasts, the FTSMs also had to deal with societal attitudes towards breastfeeding, as well as expectations of their own mothers' and family members, and most notably, that of their health professionals. The World Health Organisation recommends exclusive breastfeeding for the first six months. After six months, it recommends other solid foods be added to a baby's diet alongside the breast 
milk which would ideally continue until the child reaches at least two years (World Health Organization, 2014).

Exclusive breastfeeding rates in New Zealand have nearly reached a 20-year high as figures released by Plunket show an increase in women breastfeeding their children. However, for Pacific women in New Zealand the rates of breastfeeding have either decreased or remained constant (Royal New Zealand Plunket Society Inc., 2010) and remain short of the World Health Organisation recommendations (National Breastfeeding Advisory Committee of New Zealand, 2008). Breastfeeding is promoted in New Zealand as the preferred method of feeding for babies for the health and wellbeing benefits for both mother and baby, and economic benefits (i.e. saving money) for the family (Butler, Williams, Tukuitonga, \& Paterson, 2004; New Zealand Ministry of Health, 2009, 2010a).

A New Zealand study exploring the breastfeeding experiences of Pacific women found that, while breastfeeding has been the norm in Pacific cultures in the island countries and in New Zealand, patterns are changing in both settings (Abel et al., 2001). While Pacific women value breastfeeding for the health benefits it provides, transitioning to milk formula and solids earlier than recommended by health professionals was considered more economical and/or less emotionally stressful. Women either had to return to work early and/or felt the baby was not getting enough milk from their breasts (either because they were not producing enough milk or the baby could not latch on properly). As well, problems with the breasts including cracked nipples and infections, are central to why mothers discontinue breastfeeding. (Schluter, Carter, \& Percival, 2006).

In New Zealand, breastfeeding is promoted by midwives during both the antenatal and postnatal period. Well Child providers support the 'breast is best' promotion. An FTSM's decision whether to breastfeed or not was heavily influenced by family members, friends and their own attitudes.

The FTSMs were aware of community-based breastfeeding and antenatal classes to support mothers in their preparation for breastfeeding, such as antenatal breastfeeding classes, breastfeeding peer support groups, parent centres, lactation consultants and La Leche League breastfeeding support groups. Many of these offered classes specifically targeting Pacific women in a direct attempt to address the low breastfeeding statistics among Pacific New Zealand mothers. 
At the first interview, all 11 FTSMs expressed their intentions to breastfeed. They did not envisage any barriers to realising this goal, though some voiced their concern about not being able to breastfeed. At the time of the second interview, the nine FTSMs interviewed had babies aged between three and 11 months and were at various stages of feeding. Breastfeeding was something the FTSMs wanted to do for at least six months. However, for some this was not possible or proved too difficult. Table 2 provides information on the FTSMs' breastfeeding.

Table 2: FTSMs and their babies ages; and length of time breastfeeding

\begin{tabular}{|l|l|l|l|}
\hline \multicolumn{2}{|l|}{ FTSM } & $\begin{array}{l}\text { Age of baby at post- } \\
\text { birth interview }\end{array}$ & Breastfeeding \\
\hline$(31)$ & Anna & 8 months (G) & Yes \\
\hline$(25)$ & Geraldine & 4 months (B) & Yes, will continue to 6 months at least \\
\hline$(28)$ & Henrietta & 6 months (B) & No, stopped at 3 months \\
\hline$(22)$ & Lola & 11 months (B) & No, stopped at 2 weeks \\
\hline$(24)$ & Maliaga & 4 months (B) & No, stopped at 1 week \\
\hline$(30)$ & Maria & 8 months (G) & Yes \\
\hline$(21)$ & Mele & 3 months (G) & Yes \\
\hline$(26)$ & Patricia & 5 months (B) & Yes \\
\hline$(28)$ & Sita & 10 months (G) & No, stopped at 4-5 months \\
\hline
\end{tabular}

It is of interest to compare how FTSMs spoke about breastfeeding pre-birth and then post-birth. During her pregnancy, Lola planned when she would discontinue breastfeeding, almost to the week, so that she could continue studying. During the first interview she explained:

Yes I am [going to breastfeed], but once I go back to school we are going to feed him by bottle so that he will have milk at home... [He will be] two months [old]. (Lola)

Lola had decided and accepted that her baby will eventually be given formula milk. Lola's mother, who breastfed her brother and advocated for breastfeeding, tried to support Lola to continue breastfeeding, but Lola felt that she 'didn't have enough milk for [baby]'. The breastfeeding interrupted sleeping patterns for both Lola and her son and she reasoned that without sufficient rest it would be really bad for both of them, and so it was better to give formula, as she recalls: 
Yeah, for like two weeks and then it's just not enough milk. I felt sorry for him because he cries every night and I just don't know what to do, I didn't have enough milk for him... I breastfed for two weeks and then my midwife came for another check-up and I told her that I will put him on the bottle because I will be going back to school soon.

To breastfeed or not, or to breastfeed alongside giving formula and solids, was largely a pragmatic decision for these FTSMs. While their own economic and family context shaped this pragmatism, their relationships with the health system, and in particular with health professionals (such as their midwives or Plunket) and their advice on breastfeeding and how to cope with breastfeeding, also had an influence.

While in hospital or a maternity unit, some of the FTSMs were given a DVD to watch to help them with breastfeeding techniques. For most of them, the DVD only frustrated them more as it did not show them exactly how to master the techniques, or even show what could be suitable for them and their particular babies. One of the most common concerns the women expressed was the 'how' to breastfeed, namely the 'latching on' properly technique and how to deal with the pain sometimes associated with initiating breastfeeding during those first few weeks, especially when the breasts become infected. The emotional trauma of it all caused some FTSMs to break down in tears, leaving them tired and extremely frustrated:

I had watched the [how to breastfeed] DVD and all that kind of stuff, and I thought, oh, I guess it's not that hard, you know. Then, when it just wasn't working, I was like but I've watched the DVD, I've followed the instructions, and then it was hurting. Oh, for the next few weeks it was just, or maybe two weeks... like horrific, the pain and there was blood. In the first few weeks I cried a lot because of the breastfeeding. (Anna)

At first until I got the hang of it, breastfeeding was quite difficult at first ... just latching her on, yeah. (Mele)

I didn't realise it was going to be that demanding and painful. I think that was one thing, at one point I was just so... I got a little bit sick mastitis, so there was a couple of, maybe two days, I got a bit sick where I was really, really sore and I think that at that point I was at my lowest. I felt drained, oh my gosh, and I've never been through something like this before. With the breastfeeding and being tired and exhausted and at the same time we were trying to work between both 
families. I was really lucky to have the support that we had at the time. (Sita)

Sometimes advice from well-meaning family members added to the FTSMs' frustrations and breastfeeding difficulties. Anna, for example, found the advice offered by her mother and mother-in-law unhelpful, and the more advice she was offered the more she retreated:

Just the pressure with all these people around... but when it was me and her [daughter] at home together, like I didn't mind her crying because I knew eventually, even if it take (sic) 20 turns, she eventually will get it right, it's just everyone watching and they're like do it like this, do it like this, you know. (Anna)

Interestingly, Anna was also encouraged by her mother-in-law to discontinue breastfeeding, as this would allow the mother-in-law to spend more time with her granddaughter. Anna tried to appease her mother-in-law by expressing milk and managed to build up a few bottles for storage:

Now that I think about stuff, it was like, 'oh why don't you get her on the bottle?', like there was this constant pressure to, like, get her on the bottle and stuff; to try and put her on the bottle just so that she could have her, you know, and I was like that was a bit annoying. I was like, 'oh I will just express', it was like: 'oh well I'm expressing now', so I just fluffed it up like that. [I would say] 'I've got a few bottles stored if you want to take her'. (Anna)

The decision to end breastfeeding is not easy for most mothers (Manhire, Hagan, \& Floyd, 2007). There are a variety of reasons why women chose to breastfeed or bottle feed. While all the FTSMs considered breast milk was best, there were some who did not continue breastfeeding, as noted in Table 2 above, to the recommended age of six months.

I stopped breastfeeding when he was two months old; he wasn't full so he went on the formula straight away and just took it, so that was okay. Usually what happened is I would breastfeed him and he would have two bottles after that... so all up he would have eight bottles, and me in one day, yep, that's how big he was, yeah. (Henrietta) 
He doesn't get enough milk from me, so I just thought I would just put him on formula so he would have enough for him. (Lola)

I did breastfeed for a week, but I wasn't producing enough for him. So he was still hungry and I know I had other options but I tried him on formula and he was fine, so that was it. [My mum] was telling me, 'oh, you don't need to breastfeed. Don't listen to all these Plunket this and that.' But you know I listened to them and I hear what they have to say and to me they have a point, you know breastfeeding is good. But then I look at my mum and listen to her and then I look at me and my brothers and I'm like, 'we turned out fine.' My mum's like, 'oh no, who cares. No, no it's fine'. (Maliaga)

My midwife told me to promise her not to start [the baby on solid food] until six months. [But, my mother-in-law] at first she said wait until six months, she read the book as well, but she said he is getting a bit hungry, and I said, 'oh, maybe he is, but I still want to breastfeed as it's cheaper and better for him, because I really want to wait for his stomach, you know, like before six months their digestive system isn't perfect, but I have a feeling that I have no choice because he's getting hungry these days. (Patricia)

However, even when Maria wished to transition to 'the bottle', the baby had other ideas:

She absolutely hates bottles, refuses bottles, I think we've spent a good $\$ 600$ on bottles so we've built up a good collection at home, so she doesn't take the bottle, during the day she just eats and drinks on her sippy cup. (Maria)

Patricia, who was desperate to have time with her partner, wanted to wean her baby off the breast to create more opportunity for this, but she did not want to stop breastfeeding until at least six months:

We can't do nothing until I wean him to a bottle. We're going to go on a family trip and his parents said they were going to come along, so we've got to somehow figure that out for them to stay so we have some time alone. I have to say, me and my partner, I cannot wait for us to have a night [on our own], you know, not saying we want to get rid of them. (Patricia) 


\section{BED-SHARE OR CO-SLEEP}

The issue of bed-sharing and/or co-sleeping (not sleeping in the same bed but sleeping in the same room as the baby) was discussed by the FTSMs. Most of the babies were both bed-sharing and co-sleeping during the first six months. McKenna and McDade (2005) state that the terms co-sleeping and bed-sharing should not be used interchangeably as the different sleeping arrangements have different outcomes. The term co-sleeping refers to infants who may sleep in a different bed/cot/space to the mother but in the same room and within arms-reach; the term bed sharing is different as the infants share the bed with the mother. The implication is that there exists in the latter the risk of the mother unintentionally smothering the child during sleep.

Bed-sharing is considered the norm in many cultures particularly in Asia and Hong Kong where Sudden Infant Death Syndrome (SIDS) is amongst the lowest in the world (McKenna \& McDade, 2005). McKenna and McDade provide a compelling argument promoting co-sleeping arrangements, particularly for breastfeeding mothers, when they argue that mothers who co-sleep are more likely to breastfeed longer than those who promote separate sleeping arrangements (ibid.). Ball et al (1999) found a relationship between breastfeeding and co-sleeping, in which new mothers discovered the ease with which they could nurse at night when co-sleeping, indicating breastfeeding for much longer periods of time. Where an infant actually sleeps is not necessarily a medical issue but mostly socially relational based on economics (McKenna \& McDade, 2005). Others see bed-sharing as an important time for bonding between parents and baby, and may help with the baby's breathing techniques, even overcoming pauses in breathing (Fa'alau, Finau, Parks, \& Abel, 2003). The New Zealand Cot Death Study identified several factors that focussed on 'modifiable' risk factors which were incorporated into a SIDS national prevention programme resulting in the decrease of national SIDS cases and rates, but being less effective for Pacific infants than non-Pacific infants (Fa'alau et al., 2003). The recommendations were criticised as being 'monocultural' and led to the development of a Pacific-specific SIDS prevention programme resulting in the 'rising trend of SIDS among Pacificans... have been curbed' (Finau, Finau, Fuamatu, \& Tukuitonga, 2003, p. 191).

Abel et al (2001), in their study of infant-care practices in New Zealand in relation to sleeping arrangements, found that Pacific mothers modified their behaviour to negotiate between traditional practices and Western beliefs. Co-sleeping or bed-sharing is one of the key factors related to SIDS, especially for those babies younger than three months. Mitchell and Blair (2012), particularly, emphasise that mothers should never share a bed 
with baby after smoking cigarettes. Some FTSMs did smoke before becoming pregnant, but all stated that they stopped smoking before they gave birth and never took it up again post-birth. Some of their partners were smokers, however.

An international study that asked parents about sleeping arrangements with their new baby indicated that co-sleeping was a relatively common practice, particularly with firsttime parents who, when interviewed during their last trimester, had no intention of cosleeping with their babies (Ball et al., 1999). The FTSMs tried the co-sleeping rather than the bed-sharing arrangement as recommended by the health professionals, but would end up having the babies sometimes sleep with them, either because they felt this was 'an island thing', or the baby outgrew their bassinette, or because their partner was away and they felt alone and bed-sharing with baby made them feel less alone:

We tried two different bassinettes because we thought he didn't like it, but I thought he doesn't have a clue what it looks like. On the first night he slept in a bassinette it didn't work, so he slept in the bed with me. A lot of people said it was bad, but it was fine, we took turns, my partner slept on the floor and I slept on the bed with him... my partner's brother and his wife are doctors so they kept saying, they go by research, they were saying it was bad to co-sleep and all this stuff, and I was thinking I have seen so many of my family co-sleeping, it's such an island thing... even my partner's mum said that even she coslept, and I thought if no one knows we will just do it and it worked. (Patricia)

$\mathrm{S}$ [partner] kept saying he's [baby] going to sleep in the cot, and I was like no, he's fine, so S would sleep in the spare bed while baby would be in bed with me. Eventually we put up the cot because he [partner] was throwing a sooky around, he didn't like that because sometimes he would come in the room and say, 'can I sleep with you' and I will be like, 'no, because you might squash baby.' It's funny because now we have put the cot in the spare room, we've still got the double bed in there but we both sleep in there, just so we can watch him. (Geraldine)

She [baby] was in a bassinette next to our bed and she was in there until about three months, and then she got too big for that... she had a cot in her room but then J started going away. So she's just been sleeping with me which is really bad, like, she'd start in the cot and then I'd bring her into bed and then after a while its like, we'll just go to bed together, it's just you and me at home. Now, I'm trying to get her back into the cot... she starts in the cot but then she pretty much 
ends up in bed, we kind of pretty much all end up in bed, hence the reason why we're buying a bigger bed, we're getting a super king. (Anna)

All the FTSMs had their babies in their rooms with their own bassinettes or cots. They were acutely aware of the differing beliefs around bed-sharing, particularly the beliefs held by their health professionals, which led some of the FTSMs to choose not to tell their midwives or Plunket nurse that this was what they sometimes did. Geraldine, for example, hid from her midwife the fact that she was bed-sharing with her baby for fear that her midwife would disapprove. In Patricia's case, even though she noted that her inlaws were doctors and advised her against bed-sharing, she and her partner continued with the practice. Co-sleeping and bed-sharing transpired in different situations. Patricia and her partner lived with her family. When they visited her in-laws, they stayed in a bedroom which had a double bed and a portacot. The baby bed-shared with Patricia often as he did not settle into the portacot:

Yep, yep, they [in-laws] brought a portacot, he really doesn't go down properly so I sleep with [baby] on the bed, and my partner sleeps in the sitting room. Sometimes during the night I stress out because if he cries a little bit they will come, $2 \mathrm{am}$ in the morning and they will come, whereas here [at her parent's home] I like that I can soothe him myself; they [in-laws] will come in and say what's wrong, what's wrong and I'm like he's fine, he's fine. (Patricia)

Sleeping arrangements with infants or babies vary significantly from culture to culture. Western philosophies around co-sleeping are often based on getting rid of sleep-related crying known as 'crying it out' by enforcing no touching and/or verbal attempts to calm the baby so that the baby sleeps on their own and learns to soothe themself. The view that babies should sleep on their own to teach them right from the outset about independence, is opposite to views that babies need close physical contact at all times including when sleeping so that co-sleeping (not bed-sharing) is considered a key part of nurturing a secure parent-child attachment (Ramos \& Youngclarke, 2006). The experiences of the FTSMs not only seem to support the latter more, but also the strongly disapproved practice of bed-sharing.

\section{TRADITIONAL SAMOAN MASSAGE (FOFO)}

The question of whether to take baby to a fofo or not was a question that gave rise to a mixture of beliefs. Geraldine reluctantly took her son to a fofo because of her sense of obligation to her partner's family, who wanted him to go to a Tongan fofo. Both her 
Samoan grandmother and her midwife advised against this but, if she were to take him, the midwife advised that she ensured that the fofo did not touch or put oil on the baby's 'belly button'. However, when they got to the fofo this was exactly what the fofo did, and Geraldine felt unable to tell the fofo to stop for fear of causing conflict between herself, her partner and her in-laws. When she saw that her son seemed to be enjoying the fofo, she relaxed. She was nonetheless still unsure about whether it was something she should allow her son to be a part of or not:

When we went to the fofo they did oil straight on his belly button, and I was like, 'oh my God', and you know, you've got to be really sensitive with the baby's head, and it was his aunty that was saying that the head is not together or something. So she's [fofo] like massaging his head saying all babies have to be like this, all his nieces and nephews all went through. The first time he [son] cried and he cried, and I wanted to cry, I wanted to pull him off her, and be like, don't do that to my child, but I couldn't because S's mum was there. I didn't want to go back because we had to do it for five consecutive days and you couldn't bath him during that time, but then the next day he was fine, he loved it and he would be like smiling at her while she was massaging. I would be like crying on our way there because I was scared for him, but because it was something new, it was just like what the hell is going on, but after that he [son] loved it. (Geraldine)

Patricia shared her experience of a similar situation where she also felt that she had 'no choice' but to abide by her in-laws suggestion for her son to get a fofo to heal his illness, even though she had flatly refused her mother's request to get one only days earlier. Patricia discussed treatment for her son's illness, taking on board what the medical professionals advised her, and the advice from her in-laws. Patricia was not totally against fofo; it was how it was presented to her, i.e. as the mother, she was not given the opportunity to make the decision. Unbeknown to Patricia her mother-in-law organised for a Samoan fofo to come to her home. Patricia felt blindsided and shared her disappointment with her partner but decided not to confront her in-laws at that time, as she explains:

She [mother-in-law] got a fofo, I didn't want it but I thought I have no choice I might as well just try it; it did stop [the infection] and she [mother-in-law] was saying that it was the fofo, and I'm like, oh yeah, maybe. I think it was just time and it would have gone away anyway. I wasn't very happy that they had gone forward without me, and saying to get it [fofo] because I kept saying it was my son; I said it to my 
partner I wouldn't say it to them, that's disrespectful to say it [to the inlaws]. My mum keeps saying to get fofo, but I said I don't want to, and no. She's gone to Samoa, and when she gets back [she will know] that he got a fofo and I have been the one saying no to her, she might be a bit sad.[The doctors] told me to just give this medicine but they [inlaws] had a big input about what medicine to give him. I wanted to give him Pamol but they said, 'no, no', so I sometimes just secretly [gave him medicine, because] he needed electrolytes, but they said no try and feed him, but I did it secretly because I was scared that he would get dehydrated. Yeah they do get quite upset if I don't do as they say. It's a bit tricky, with my partner's parents you can't say no, they're very pushy. (Patricia)

\section{TECHNOLOGY AS A KEY SUPPORT}

In New Zealand, recent initiatives to support Pacific women during pregnancy and post-birth have established technological advances by way of smartphone applications and websites to specifically cater to their identified needs (TAHA, 2014). The Smartphone App is a way of providing access to maternal information and knowledge. While the FTSMs did not specifically mention the Smartphone App, they did talk about the important role of technology in supporting them.

All FTSMs had access to the internet and used it often, in conjunction with their cell phones, particularly texting, to communicate with friends, family and health professionals.

Use of technology as a basis for communication during pregnancy and post-birth as a key support option for FTSMs has been supported by other studies (Bae \& Heitkemper, 2006; Churchward, 2011; Statistics New Zealand, 2010a). This is also in line with UK research that found one in five mothers would access their GP as their first port of call, 29 percent would first ask their own mother for advice, and 26 percent said they would rely on the internet for information (for example, see Baum, 2004; Berland et al., 2001; Blackburn, Read, \& Hughes, 2005; Boston, Ruwe, Duggins, \& Willging, 2005; Brodie et al., 2000; Daneback \& Plantin, 2008; Kildea, Barclay, \& Brodie, 2006; Lagan et al., 2010; Lamp \& Howard, 1999; H O'Connor \& C Madge, 2004).

Telephone or online support networks such as Facebook or the search engine Google as well as Plunketline also cited. Often the women would access these support services to avoid bothering family members, or if they felt that their concerns were only minor: 
The internet... at the same time it was a great help because of what I read in the internet, and then I would call Plunket Helpline. Plunket helped and said, 'if you need any more reassurance, just go to your GP', and because from under six they are free, we just take her to the GP. But yeah, I have been an internet mother that searches everything and all the websites. (Maria)

I joined a Mummy Matters page on Facebook - my friend put me through to it. It's where you can ask questions to New Zealand mums, and all the NEW ZEALAND mums put in their responses which is really nice rather than going to a doctor who has probably never had a kid, you can ask the mums who are at home. One time he [baby]wasn't feeding and I put it in[to the webpage]; I put in all the signs and some of the mothers told me, 'go get this teething spray', 'he's teething', 'don't get Bonjella, get the spray, it's homeopathic'. So I went and grabbed it, and sprayed it, and he seemed to like it and it worked fine. (Patricia)

It depends. If I'm in a position where I can get in touch with her [grandmother] straight away, then I'll ask her first, but if it's late at night, I will Google it. (Geraldine)

We'll just check on Google, but we've found it's been very helpful because a lot of the time when we've ended up going to the doctor, a lot of the time the doctor actually says what was on Google. So, I know it's not the right place to go for a diagnosis, but it does give us some idea of what certain symptoms might lead towards, and that sort of thing, so that's been really helpful, that's one thing. If there's ever a situation, or even with pregnancy or any time something comes up and I'm worried, I would just Google it and see what comes up. (Sita)

Many of the FTSMs would weigh up the advice from different sources and then decide for themselves what worked, as articulated by Geraldine:

I use the Island ways mixed with what I'm also told by the Plunket nurse, and what I've read, the European way I guess; I bring that into what I've grown up with, yeah, and I don't really listen to all the Island ways. To be honest, I always ask my grandma because my grandma would just tell me. My mum would be like, 'you have to kind of figure it out, so it's whatever suits you best', and I like that advice too because that's how I make my decisions as well because I always Google it, yeah. 


\section{FINDING TIME FOR SELF}

The first few months after childbirth are a whirlwind time for first-time mothers. The energy required to tend to the needs of a newborn and maintain relationships can sometimes test the mother's ability to cope. Sleep deprivation and lack of time for self can produce feelings of incompetence. Taking time out for oneself can be fraught with time constraints, guilt, changes to friendships, or work demands. Yet finding a time to themselves, and/or their partners, was considered by the FTSMs to be an important part of being able to cope and manage as a new mother with the transition process they were experiencing of early motherhood.

When they were able to find time for themselves, the kind of activities the FTSMs got involved in ranged from 'helping out with making dinner' to more personal upkeep or 'maintenance' such as 'waxing, pedicures, and manicures'. A time for self was not always planned. Anna's intention to have an hour to herself turned into having a late night with a friend:

I thought I'm going to have a bath and do all these fabulous things and I'm going to paint my nails. [With my friend] D we had some wines, and those wines went to three in the morning, but the whole point was to get some sleep, but I felt like it was myself again or just me. I felt really weird just me but then I thought, no, I'm allowed. I was just going crazy. (Anna)

However, many of the FTSMs found that even when they did have some time to themself that they missed their baby and wanted to 'hurry' back home:

Before my graduation my mum and my grandma both watched [baby] and I went and got a pedicure and a manicure; I got my eyebrows waxed, got my legs waxed, yeah, and looking for something to wear on my graduation. But that was so tiring because then I had to pump milk for him and, yeah, and then during the graduation I just missed him, and I just wanted it to hurry up and finish, yeah, so I always make sure that I go and do my eyebrows. (Geraldine)

The transition into being a mother took a bit of getting used to for most of the FTSMs. During this early motherhood stage, they often felt that they were putting their lives on hold or that their baby consumed their worlds. However, Lola, was not really interested 
in time to herself and taking up a social life, unless she could take her son along with her:

Ever since I had this one [baby], I just lost that buzz of going out, hanging with friends. I just thought I would grow up and be more mature. My friends, they just text me and they are, 'come out let's go and watch a movie', but to me it's different; for them, they can just get out and go or whatever, but to me if I want to go, what about this one [pointing to her baby]? I just have to think about what is good for him and then I can make a move. (Lola)

Resuming activities like playing sport again, having 'alone' time with their partners, returning to work, were all part of slowing moving into a new routine whereby they were not only able to find some part of their old selves again, but also to reshape themselves in ways that made them feel comfortable as mothers:

I have got to say that A [baby] has consumed my world now, even when I do go out shopping; I do look at baby stuff as well. (Maria)

For myself, I feel like I've kind of put things on hold. I feel like, in general, my life has been on hold for a good six months, and now I feel like I'm just starting to feel that I can start doing things again. (Anna)

Sport. I am back into rugby training so I've started playing rugby... we started training about a month ago. I did more exercise before I started training anyway; I started going for walks. When he [baby] is asleep, I try and relax; they say when baby is asleep you should sleep as well but you just can't sleep, I just relax and watch TV or my friends come over. (Henrietta)

They're [parents] always pushing for us to go on dates, or go to the movies, or even just to go grocery shopping by ourselves. I think for both of us, because it's our first child, we go [out] and sort of feel a little bit guilty. We sort of think, oh, my gosh, we're enjoying this moment without her. But yeah, we do go out and spend time together, even just a car ride in to work together is more than enough for us to just talk and laugh and joke around. (Maria) 
Most of the FTSMs reported finding babysitters was not difficult as family members, particularly grandparents, made themselves available. This made it easier for the FTSMs to actually have this time to self:

My job is flexible so I can always catch up with friends during the day, maybe for coffee or something, so it's really good in terms of we've always got babysitters on hand, so it's really nice, it's a luxury that not many people have but at the same time we try not to abuse it. (Sita)

A time for self was thus a time to de-stress, especially when there were relationship problems on top of mothering challenges. Trying to schedule time for themselves as a couple was also conceived interestingly as part of some of the FTSM's idea of 'time to self'. But this was not easy when the partner works two jobs as was the case for Henrietta:

We try to [get out together] because he [partner] does 40 hours a week, and sometimes during that week he does DJing for gigs as well, so it's kind of hard, not hard but like it does get to a point where we just need to have time to ourselves. We haven't had couple time lately because he's been busy. I've been busy as well.

The arrival of a baby filled these FTSMs' lives in ways they had never thought possible. But, for most, it was still thought important to have some time to themselves, either entirely with themselves or with their friends or partners.

\section{RETURNING TO THE WORKFORCE}

Returning to work was a financial necessity for most of the FTSMs, albeit a very difficult one to make. One FTSM returned to her job three months post the birth of her baby. A couple of the FTSMs decided to resign from their jobs after the birth, while a couple extended their maternity leave or decided to change their hours from full-time to part-time. The loss of financial independence was difficult for some to come to terms with, but they were able to reason and accept that their change of lifestyle and financial dependence was a function of being a family and a newly formed family. The support from their extended families was essential in their ability to return to work as many of the women were hesitant to leave the care of their babies to strangers.

During their maternity leave, Anna and Maliaga decided to resign from their respective jobs. They were both in, what they considered to be, comfortable financial situations. Anna applied for maternity leave for one year with the expectation that she would 
return to her job at the beginning of the following year. At the time, her partner was at the beginning of a financially lucrative sporting career. Anna spoke openly of her difficulty in accepting her financial dependence on her partner, but soon understood this to be part of the bigger plan for their family:

If I go back to work, it's kind of a bit difficult for us. She's [daughter] a bit young, we can afford it, he's financially supporting us 100 percent and it's quite comfortable, so it was like, well, we will never get this opportunity again. We're quite lucky to be in a situation where I can stay home and look after her and still we can do everything that we want to do. I was talking to another friend, because she ended up resigning, and her husband, he's a lawyer, but they can live quite comfortably and they're looking at having more children. She's like, 'oh look Anna, who is the best person to look after her at the end of the day; who would he trust the most?', and I'm like, 'oh yeah, exactly'. (Anna)

Anna, who was fiercely independent, sought and appreciated the reassurance from her friends about her new role of a stay-at-home mother even though she knew rationally that it was the best decision for her and her partner at the time.

Maliaga, on the other hand, was blasé about returning to work. She lived with her parents rent free and was financially supporting herself and her son with income from child support (and possibly from maternity leave) and from her own savings. These living arrangements, which she felt secure with, and the fact that she had options, may have contributed to her relaxed attitude to returning to work:

I probably won't go back [to work] 'cause like at the time when I only took a certain time off, things were different and I thought they would have gotten better. But it kind of took a U-turn and just went the other way. So, like, now I just have to go with it. I mean, if I can't go back to work, then I won't go back to work. Financially I'm okay, I've still got money coming in and savings and everything. But there's not much money [that I need] to spend, it's just his formula, his nappies. Yeah and I don't pay board, my parents won't take board from me. I've even said, 'Let me pay at least $\$ 200$ a fortnight or something small?' But no. (Maliaga)

Maria, on the other hand, worked throughout her maternity leave from her job in one of the major banks, to earn extra money to top up the household income: 
Yes I do, yep, still do it and when I was on maternity leave I was pretty much doing it as a job on the side, just in my garage, yeah. (Maria)

When she returned to her job at the bank after maternity leave, she found it a refreshing change, not just for herself but also for her daughter:

It was hard at first, really hard. I think my manager asked me how I was going and I said, 'in the first five minutes that I've been here, I've looked at her photo about four or five times'. But then again, it's a good break, you know, it's sad that work is a break but it is. I think she's [daughter] at the stage where she needs to socialise with others as well, because towards the end of my maternity leave she was getting a bit bored and it was like the same thing. I think it was time to pass the parcel. (Maria)

Many of the FTSMs did not have a choice about returning to work as they needed two incomes to financially support themselves, particularly those who were living independently (i.e. not living with other family members who could contribute financially). Geraldine's mother stayed with her and her partner during Geraldine's pregnancy and for three months after birth. Her mother contributed to the household expenses which ceased when she returned home. Living on one income meant Geraldine had to balance their finances carefully:

After my mum left and my maternity leave stopped, that was a big thing, financially, like, having to shift everything around and really budget, but we've got the hang of it now. We don't starve so we're all good, we've still got a roof over our head, but just little things like the car registration, flat tyres, warrant of fitness, school uniforms. It was a bit tough at first because I hated not having my own income and always having to ask S, but now I'm used to it. (Geraldine)

Patricia and her partner lived in her family home and, similar to Maliaga, this allowed Patricia to extend her maternity leave slightly longer until she felt comfortable leaving her baby with others. The pressure to earn money not only to live but also to do some of the things they had planned to do pre-pregnancy versus being with their baby at home for as long as possible was a tension for many of the FTSMs and their partners:

I can take up to four terms but I took three because I thought me and my partner need the money, but then I saw my nephew who is nearly 
one and he is still crawling and stuff and I said [to my partner], 'I can't go back to work' and he said to take an extra term off. So, I will go back in Term 4, and my partner is going to take another month off work because we don't want to put him in day-care because he's so little. I need to get back to work to earn some money because we plan on doing one big trip to the US; that is our big trip but not until he is about 2 or 3. (Patricia)

Thus returning to work was bittersweet for some of the FTSMs:

We need the money, and no I don't want to leave him. (Henrietta)

For the FTSMs who returned, or were returning, to their jobs post maternity leave, child care was the most pressing concern. Family was the obvious and sometimes only choice when considering childcare options:

We're trying to find someone to look after him so it might be my sister or his mum, and I asked his mum but she said she can't take the time off so I said okay that's fine. (Patricia)

I know I have to go back to work. Yeah, that's the downfall going back to work, I don't have a choice. I think it will be either my sister [to look after baby], it depends on the days I work as well. P's [partner] mum doesn't work on Friday so if I work on Friday, I can give him to P's mum. (Henrietta)

When faced with a choice as to which family members to use for babysitting or childcare when returning to work, the FTSM had to make sure they were being fair in giving equal opportunity to both sides of the family, both her family and the family of her partner - to ensure no unnecessary conflict arose. This was the case for Sita:

I didn't think that could happen but it does, so we had to make sure that everything was even and time is divided, oh man, but yeah. Even now my mum takes baby for two days a week, and my mum-in-law takes her for the other two while I am at work. I am back at work for four days. Up until a month ago, I was only part-time, two days a week, and now I have her one day a week. If we didn't have our parents, I wouldn't be able to work, part-time or full-time or whatever. We would still have to look for childcare and that sort of thing and, in that case, we would have to weigh up the options. So, I think if it wasn't for them, I wouldn't have gone back to work, but the fact that 
they've been there, and they've offered to look after her and we've been able to say okay, you know. (Sita)

FTSMs were also advised to be careful about not leaving their baby with one particular family member or person too long for fear of the baby getting 'closer to them' than to their mother:

She's staying with my sister-in-law, and my mother-in-law was saying, 'don't get upset when you pick her up and she's closer to them; it may seem that way but it will take her about five minutes before she realises you're her mum'. Mum said that to me before I started work [as] mum used to look after my brother's kids, and mum said she saw that my sister-in-law would get a little bit upset when she saw the kids would cry for mum rather than their actual mum. (Maria)

One of the challenges of returning to work during the early motherhood stage was that some FTSMs, who were also still breastfeeding their babies and wanted to breastfeed for as long as possible, had to find a compromise. Sita decided the compromise was to ultimately go with formula rather than breast milk, while, for Maria, it was to ensure that breast milk was given at regular times of the day:

It got a bit difficult for me to express milk while I went back to work, then we sort of tried to do both, but then it got to the point that she started liking one and not the other. She started liking the formula and not the breast milk, and then she started coming off altogether. But, had I had it my way, I would have liked to have kept breastfeeding exclusively even if I had to express and leave it, it would have been fine. But it just got to that point that it was quite difficult on me to do so. (Sita)

Two weeks before starting back at work, I would breastfeed her in the morning, 6.30am [the time] from when we would wake up to get ready for work, and then I wouldn't breastfeed her for the rest of the day until about $5.30 \mathrm{pm}$ so that she got used to the routine. (Maria)

\section{A NEW NORM}

After the FTSMs had developed their ability to cope with their new baby, a new norm set in. The enormity of the changes to their lives in their transition from being a woman to being a mother for the first time was underestimated by many of the FTSMs. They expected their lives to be different but had not anticipated just how much it would 
change. The intense focus they had to give to the baby, to decisions around the needs of the baby, coupled with the intense changes they experienced within themselves, within their relationships with their partners, with their parents, wider family members and friends, were such that they often found little time for self-reflection. The adjustment to the new norm was understandably more difficult for some than others. With this in mind, there was a general acceptance among the FTSMs that from pregnancy through to having the baby, they now lived a very different life; they had a new reality:

It's way different. To me, having a baby is different in a whole new way because I didn't really expect this: me going from working nine to five, five days a week, come home and then go training after work. I didn't expect to have a baby, yeah, come home and just stay home all day with baby, and all that. It's the total opposite, the total opposite from my normal everyday life, staying home, yep. (Henrietta)

To me, being a teenager has gone to a new lifestyle now. (Lola)

In every relationship it's all the same; it doesn't matter what ethnicity or age, your relationship does take its toll. Once you have the baby, everything changes, it's so different. (Sita)

These FTSMs spoke of how they have now come to appreciate their own mothers and what they must have had to go through raising them:

I was like, it's hard work but I love staying home. I think I realise now what my mum went through, you know, having four kids; coming from Samoa was even worse. Bring them up [and] letting them have good jobs, I am more aware of what it was like to be a mum, big change. (Patricia)

Many of the women were definite that they would have more children and with their current partners. Most planned for another baby in the next couple of years. By the second interview, Sita was pregnant again and due to give birth just before her first child turned one. She commented that her second pregnancy was a surprise:

At one point, I was actually under the impression that it's 100 percent [safe] with breastfeeding [to not get pregnant] and I was always fulltime breastfeeding. We were just like shocked and we were, like, 'what are we going to tell our families?', but they were good. My mum was 
worried can I handle [another pregnancy] with my body, and that sort of stuff but other than that... yep, got another one coming along. (Sita)

The motherhood literature states that conflict may arise if there is a mismatch between expectations of childbirth and early motherhood, and the actual experience. Early research with first-time mothers found they were disappointed if their experience of what they imagined about giving birth and being a mother was less than what they experienced (Choi, Henshaw, Baker, \& Tree, 2005; Forster et al., 2008; Gibbins \& Thomson, 2001; Knight \& Thirkettle, 1987). The workload of caring for a new family, being responsible for another person, the physical exhaustion and the emotional turmoil that is associated with early motherhood was a surprise and unexpected for many mothers.

The reality of early motherhood for each of the FTSMs at times matched with their expectations pre-birth, while at other times it was at polar opposite. The emotional extremes the women faced (excitement, happiness, worry, sadness), the changing dynamics, adapting to a different routine were articulated and accepted by the women, and acknowledged as just something they had to go through. Although the women imagined they would be tired, the reality of complete physical exhaustion was a surprise. Having family always on hand was for the FTSMs during this early motherhood stage, as well as during the earlier stages, both the saving grace and the frequent source of emotional frustration. However, their families, while challenging, were spoken of by these women as more their source of strength than their source of frustration. The following chapter explores the relationships. 


\title{
CHAPTER SEVEN: RELATIONSHIPS - INTERPERSONAL AND MATERNITY PROFESSIONALS
}

\author{
It was a relationship that we both had to build with each other'
}

The arrival of a new generation affects existing configurations of interpersonal and professional relationships. Existing relationships are disrupted or forced to change to allow for the development of new roles between key people (mother, father, grandparents, uncles, aunts) within the family and the establishment of new relationships between the new mothers and the professional maternal health providers they come into close contact with. First-time motherhood therefore invokes new forms of sociability and forges new bonds or strengthens old ones. Mothering as a phenomenon characterised by the 'challenges of synchronisation', in which if not everyone is on the same page when it comes to the maternity journey, can lead to conflict (Thomson, Kehily, Hadfield, \& Sharpe, 2008, p. 92).

This chapter explores the nature and evolution of key relationships during the stages of pregnancy, labour, childbirth and early motherhood for the FTSMs. The starting point of any relationship that leads to having a child is being a couple, even if just for the act of copulation. It should be noted that what constitutes a couple can vary.

Samoan people are almost always a part of an extended family from birth through to death (Ngan-Woo, 1985). A first-time mother continues to be part of her extended family, part of her birth nuclear family. While she does take on a new status within her own family, extended and nuclear, as someone who now has a 'partner' or has matured in terms of sexual relations, the idea of her being part of the family does not change. When she becomes pregnant, the Samoan woman, whether married or not, continues to be viewed in terms of her status as sister or daughter or aunt within her family. Moreover, her new role as a mother merely adds to these statuses and reconfigures her relationships with her partner, the father of her baby, or husband, with her own parents, the parents of the father of her baby, and their respective extended family members. As a couple, they not only become a nuclear family in themselves but also a new extension to their respective extended families.

All the FTSMs were in heterosexual relationships at the time of conception and generally their partners were slightly younger than them. The duration of these relationships ranged from two months to nine years. Some were married, while one FTSM was on the brink of a break-up. A couple of women introduced their partners to 
their unsuspecting families for the first time when they announced their pregnancy, while the partners of others were already considered part of their families.

This chapter describes the relationships both personal and professional that FTSMs had with the people whom they saw as critical to the experiences of pregnancy, labour, childbirth and early motherhood.

\section{Personal Relationships}

\section{FTSMS, THEIR MOTHERS \& GRANDMOTHERS}

Previous studies have highlighted the significance of the mother of the FTSMs in terms of their influence, their own knowledge about motherhood and the support they can provide their daughters. Exploring this relationship offers an insight into its significance in the ability of FTSMs to negotiate their relational spaces and develop the kind of sophisticated mediation and resilience necessary to come out of the early motherhood experience with a level of success, despite the struggles.

Developing or fostering a close connection with their own mothers or with a significant mother figure (e.g. aunt, sister, in-laws) was something that the FTSMs spoke about a lot, as did the mothers of the FTSMs. This need for a close relationship with their mothers was tempered by the FTSMs' simultaneous desire for independence, the ability to make decisions about their own bodies or their babies and/or about their relationships with their partners without unnecessary interference. The FTSMs wanted space to be independent when they wanted, on the one hand, and their mothers always available when they needed support, emotional or otherwise, on the other. This created a natural tension in this relationship. Whatever the nature, state or stability of the relationship between FTSMs and their mothers before the pregnancy and even after the birth, the FTSMs did rely heavily on them for support.

The FTSMs talked about being quite surprised about how open their mothers became talking about sex once they accepted that they were going to have a baby. Before pregnancy, especially for the unmarried FTSMs, the subject, and any related subject, such as boyfriends and menstruation, was somewhat taboo and not talked about. The FTSMs attributed this to the strict upbringing that their mothers had experienced growing up in Samoa, with its associated firm boundaries and expectations based on religious beliefs about abstinence from sexual activity until marriage. Anna recalls that while growing up she was not comfortable sharing her personal issues with her mother, 
particularly in relation to boyfriends and periods, something that was similar for the other FTSMs:

I just remember it was really awkward for me to tell my mum that I had my period; I think I just kind of said I've got my period and just ran off into the room. (Anna)

My mother wouldn't speak to me [about sex education]. It was just not the norm, you know; if they did it, would be uncomfortable ... now we can talk about it. (Patricia)

Many of the FTSMs kept the relationship with their boyfriends or partners a secret from their families and felt it was easier to sneak around rather than face the awkwardness and likely punitive consequences of introducing or announcing to their parents that they were in a relationship:

I never told my parents that he was my boyfriend, they just clicked onto it. I couldn't say it because it's not normal to say to my family this is my boyfriend. I couldn't say those words, that's how weird it was. (Patricia)

Another FTSM, who was adopted out to her paternal uncle and his wife from the age of five, grew up in a family environment where it was expected not to consider, let alone to actually have, a boyfriend before marriage. At 23-years-old she had been living with her partner for eight months when she became pregnant. Ellen viewed the lack of open mother-daughter discussions on the topics of sex and boyfriends as a cultural belief that such topics should not be raised until the daughter 'came of age':

It wasn't until I got to mid-20, that's when my mum actually talked to me about boyfriends. I just thought it was this, like, a really FOBything (Fresh Off the Boat - FOB), you know, they were going to keep me down on lock-down until I was like, you know, this old widow.

Sometimes Ellen felt that her mother gave her a lot of mixed messages which confused her and made her feel like her mother was testing her:

She was like, you know, if you have a boyfriend bring him home. I always found that funny when my mum says that because she's this really strict woman that sticks to her fa'asamoa hard out... like with chores and stuff like that, going to church, doing this for church, 
doing that for the church. It really surprised me, I was like thinking, oh okay, you know, is she testing me, that's how I saw it like she was testing me to see if I had a boyfriend. (Ellen)

Ellen had two mothers, her biological and adopted mothers, which added a further complication to her mother-daughter relationship. She had not communicated much with either mother over the past year. Instead, she had built up a strong bond with her partner's parents and came to treat them as her 'own parents'. Ellen was estranged from both mothers, opening an opportunity to form a relationship with her mother-in-law in ways that perhaps may not have been possible if her relationships with her two mothers was stronger.

While sex education is something that was closed for discussion in many of the motherdaughter relationships, that was not the case for Geraldine. She was 24-years-old at the time of her pregnancy, working full-time and living with her partner of three years and his daughter from a previous relationship. Geraldine described her relationship with her mother as 'really comfortable' and 'real close' and felt their closeness was partly due to her mother and grandmother being solo parents themselves. She believed this situation lent itself to them having more time for each other. The approach taken by Geraldine's mother was the expectation of 'no sex in high school' but that after high school it was more a matter of 'safe sex':

She'd just talk about, you know, not having sex in high school, and after high school was more along the lines of contraception, making sure I was safe.

Henrietta's mother was of the same view:

My mum just told me if I was to have a boyfriend just to be careful; don't get pregnant too early is pretty much all that she said to me, just watch yourself. (Henrietta)

However, it was different for Patricia:

I knew nothing from my parents, they didn't inform me, I learnt nothing. I found out through my friends and my sisters, I always saw them using tampons and pads and I never knew what it was... because I'm the youngest. I have two older sisters but we don't talk about things like that; my parents were traditional strict parents. I am Catholic, they're very strict, they're all in their church groups, Samoan 
church groups. We never had conversations at home about any of that stuff. My mother wouldn't speak to me [about sexual health]. It was just not the norm, you know; if they did it would be uncomfortable, you know, even if I spoke to my sisters back then it would be uncomfortable. Now we can talk about it. (Patricia)

When discussing relationships with their mothers and vice versa, some of the FTSMs' mothers preferred their daughters to be in relationships:

I told them to look for a good man, a good man who loves the parents and loves you. The main point is love. The guy that loves the parents, your parents, and loves you very much. You know, respect the parents, that kind of man. (SitaMum)

Sita's mother considered finding a man a priority, especially for a pregnant woman. SitaMum was prescriptive that a 'good man' must align with the values and beliefs that underpin Samoan culture, respecting the parents. Sita's mother articulated marriage should precede starting a family to avoid the social stigma of being a single mother. Interestingly, the literature identifies Samoan cultural beliefs about gender boundaries and/or sexual taboos that hinder any type of discussion about sex, sexuality and sexual health (Anae et al., 2000) and underline social stigma associated with single motherhood. While a lot of these beliefs and the social stigma still prevail, many of the FTSMs described this as being the 'norm' in relation to their family and friends who were also Samoan or Pacific. Some insight is gained into these cultural beliefs and ideas of what is 'normal' through an analysis of what the mothers of the FTSMs talked about in terms of their relationships with their daughters and their reflections on their own journeys as first-time mothers.

The change from a mother-daughter relationship to a grandmother-mother relationship presented new and interesting emotional and practical issues for the FTSMs and the grandmothers (most of who were grandmothers for the first time) about how to relate to one another in these new roles. Generally, both parties welcomed this new stage in their lives and saw it as a natural part of life while being aware that the new situation was not without complexities or complications. However, for all FTSMs, there was the overwhelming and deep sense of security engendered by the knowledge that their mothers and families (extended and nuclear) would always be there to support them regardless of the circumstances. 
At the time of the first interview, the FTSMs were confident that they would receive unconditional support from their mothers regardless of whether they had a close bond or not. All believed strongly that their mother would be there in person for them if they needed them, especially because it was the first time they were pregnant and were to give birth. Even those who may have had cause to doubt having their mothers present because of age or the fact that she lived in another country, still believed she would be there. This applied to all the FTSMs regardless of whether they were married or not, or whether they were living independently with their partner or in the family home:

Growing up around my parents and around my family, all the dramas and stuff that happened it always came down to family support. You have to be there for one another, you love one another and all that sort of stuff. I just knew even if my parents were going to be angry and stuff [about the pregnancy]... I would have their support and that I would be okay. (Maliaga)

Alongside their innate confidence was a strong concern that their unplanned pregnancies would or did cause deep disappointment. Some were able to overcome that obstacle; others were still working on it and saw it as ongoing. Lola was five months pregnant before telling her parents and by then a social worker had become involved:

I had no idea I was pregnant, and then she told me I was five months pregnant. I was like oh, my gosh. I was planning to tell them [parents] on the first day that I found out, but then I waited for all of my family and my sisters to have, like, a little gathering and that, so I can tell them face to face but... a social worker showed up and she told them; it actually killed the buzz. I was planning to tell them myself and she showed up.

Some events signalling possible 'disconnects' that were raised by the FTSMs included differences or divisions that existed between the families of the couple (the first-time mother and father of the baby) prior to the birth of the baby being exacerbated after the birth. An example of this is offered by Maliaga who at 23-years of age lived at home with her parents and was financially independent up until she started her paid maternity leave. Her partner's family are devout Jehovah's Witnesses and this caused an enormous amount of friction between them and Maliaga. They totally rejected the partnership and the pregnancy as it was against their religious beliefs.

Maliaga and her partner were living together when she conceived and, although they are still a couple, they no longer live together. Shortly after the birth, it was decided by 
Maliaga, her partner and her family that her partner would move out of her family home. Maliaga's mother had not quite forgiven Maliaga's partner's family for the way they treated her during her pregnancy, even though they had apologised to her for their behaviour (although only because they wanted to know their grandchild she felt), and there were still lingering tensions between the two families. Maliaga's mother's dislike for her daughter's partner's family was so intense that at one point she suggested it might be best for Maliaga and her grandson to move out of their family home in order to preserve their relationship as mother and daughter:

It's just sometimes, to me, they overreact and they go a bit too far, but out of respect, I won't say anything, I'll just shush. She [mum] told me it might be best that me and [baby] go out and live with my [partner]... and she said, like, it will probably save our relationship too as mother and daughter. (Maliaga)

Clearly, both mother and daughter had to adapt and negotiate how to get along with each other. Patricia described the time with her mum during labour and how this changed her perception of her mother. The impact raised their relationship to another level:

Before I went to hospital, I was in her [my mum's] room and every time I woke up she just sat there. My partner said she just literally just sat next to me and watched me the entire time. I was so grateful because I would look up and she was there, putting flannels on my head. Sometimes, when my sisters would have arguments with my mum, I used to always go against her, sometimes she was always wrong, now I don't know, I feel like more on my mum's side, especially with birthdays. I never used to buy my mum presents, we used to just say happy birthday, presents isn't much, we don't do presents only for the kids. Last year, I actually went out and brought her a \$140 Puletasi from Otahuhu... I told my partner I wanted to buy my mum something nice. I think it [the birth] has done something... it made me realise that it's a hard job being a mum and, if I ever had this answering back to me, I realise that it does hurt. It's weird now that I'm a mum. I know how much my mum feels for us even though we have had so many arguments in the past and we were always close to our dad. I was always my dad's little girl and now it's sort of, like, I'm with my mum now; it's weird but I would always want my mum there. (Patricia) 
By the time the FTSMs had their babies and during the first six months post-birth, most described their relationship with their mothers as 'very close'. Often it was their own mothers who were vocal about the way in which they were parenting or mothering, or who actively influenced the FTSMs about which parenting values they should adopt. The FTSMs who supported Plunket's philosophy often did so because their own mothers had experienced and supported Plunket's services:

My mum would always say, 'maybe you should check with Plunket and see', or mum would say, 'how did the Plunket visit go?' and I would say what Plunket would say and mum would say, 'oh I remember that, yeah, that's a good idea'. (Maria)

In contrast, there were mothers of FTSMs who opposed Plunket's ideals:

So she [my mum] was telling me, 'oh you don't need to breastfeed. Don't listen to all these Plunket this and that'. Yeah, so just little things like that. And it's pretty much everything Plunket tells me, my mum's like 'oh no, who cares. No, no it's fine'. (Maliaga)

Because of this close relationship, and without any reason not to, FTSMs took the advice of their mothers seriously. The relationship between FTSMs and their mothers became more meaningful as the daughters gained a heightened understanding of their own mother's motherhood experiences which led to goodwill and a deeper respect. These kinds of insights also affected the FTSMs' relationships with their own grandmothers and produced an inter-generational bond that moved between three as well as two generations:

My grandma actually came and stayed for his [baby] first two weeks. She came and stayed here and she was such a huge help. My mum came and told me that she was going to stay for the weekend, and then I wanted her to stay longer after that. (Geraldine)

The FTSMs told stories of how their mothers and/or grandmothers took long periods of time off work to help with the baby post-birth and/or moved in for the first few weeks post-birth, were birth partners where the partner was not available, or even if they were also present, helped with childcare duties, and/or offered practical financial help and emotional support: 
I just wanted him [my baby] to be with me. But then my mum was like, I will take the day off, and I was like yes please. I appreciated it way more once I had him, because her and my grandma, were so much help. She [my mum] was really good with baby and she wouldn't panic. My mum, she cooked all the time, she cleaned the house. I didn't have to touch the toilet and bathroom or anything the entire time she was here. (Geraldine)

The mother-daughter-granddaughter relationships are an integral part in the overarching meaning of motherhood. Mothers and daughters rely on each other to help bridge that transition to motherhood and draw on each other's experiences in positive ways to forge forward. That connection might produce intense moments of identification and the recognition of a shared inheritance, as well as moments of disconnection marked by a felt need to break with the past' (Thomson et al., 2008, p. 122).

Most of the mothers described the relationship with their daughters as very close, honest and open, explaining that they deliberately nurtured this aspect. It was an important part of their own parenting and something they thought about carefully about because it was something that was often missing in the relationship they had had with their own mothers:

I'm quite open [with Mele], where my mother and I didn't have much of an open relationship because it goes through one ear and it comes out the other, whereas, I like to listen to Mele and give her my input. (MeleMum)

But while great significance was placed on maintaining a strong and open relationship with their daughters, the mothers of these FTSMs also believed it was important to uphold clear boundaries within the mother-daughter relationship:

I always made it clear to Geraldine that I'm not your friend, I am your mother first and foremost... making sure there was a lot of physical contact like things that me and my mum stopped doing such as hugging, kissing, and just sitting and talking and being able to come and share if she was upset. (GeraldineMum)

The need for clarity between parent and friend-type relationships was also talked about by Mele and her mother. Because there was not a large age gap between them, sometimes they treated each other more like sisters than mother-daughter. However, 
implicit in MeleMum's quote below is the perception that there is still a line, even if blurry at times, between herself as mother and herself as friend:

Sometimes we act like sisters, yeah, 'cause she had me when she was young, she had me when she was my age, so quite young, yeah, so she's been more like a sisterly figure. (Mele)

I have learnt that being a single parent, yes, I have to teach Mele and tell her these things. If you make a wrong decision, well, figure it out, how am I going to fix it? I can help you, but I can't give you the answers to every single thing, you have to do it yourself. I'm trying to instil in her that you need to make decisions [about childcare] now because we're already coming towards the end of March. She gets frustrated when I keep reminding her, but I'm just doing it out of love because she needs to do it. And if she thinks she's going to get [her boyfriend] to come and look after her at my house - no deal. Oh no, no, no, no, no. (MeleMum)

The mothers of the FTSMs saw that the impending status of motherhood for their daughters brought with it a high level of maturity and independence. In many ways, the FTSMs' mothers saw their daughters entering into roles and responsibilities that were now the same as them in terms of being parents:

She is having a family. Sita is thinking like me, the same as me and my husband and my children. I'm thinking about Sita [being] independent now, so it's different than before; we are not forcing or doing anything because she has a family and a child. It's different for us; we're not counting her in as a family because she has a family, she is independent. (SitaMum)

The way in which some FTSMs may perceive this new stage of independence, responsibility or maturity and its impact on how they relate to their parents, was illustrated by Alma, who stated that it gave her licence to change from asking to telling:

I don't ask them [parents] if I can stay [at my boyfriend's house]. If I really do need to stay, I just tell them and not ask them... if I ask them, then it will just open the questions, but if I just tell them, then I can do whatever. (Alma)

Some of the FTSMs grew up in households with other extended family members or in a household where three generations of women lived. This raised complicated family 
dynamics, particularly around negotiating the different parenting styles of the three generations and doing so in ways that maintained good relations:

I had to say to my mother 'you didn't spend much time with me; I don't want to do the same things to Mele, so I'm going to change my wheel around to accommodate Mele as well as you. You know it's not all about you and what you want, Mele's another person as well'. (MeleMum)

The opportunity to gain insight into the story of Samoan motherhood from an intergenerational perspective adds richness. The stories of the five grandmothers that I spoke with are outlined as follows, highlighting how they saw their relationship with their daughter, and how they understood and/or experienced pregnancy, childbirth and early motherhood within their own Samoan and/or family contexts. The five grandmothers who shared their story at the time of the interviews were: AnnaMum, GeraldineMum, LolaMum, MeleMum, and SitaMum.

\section{ANNAMUM STORY}

First-time motherhood for AnnaMum was associated with reluctant independence, loss and isolation. Moving to New Zealand for the first time from Samoa, exacerbated what AnnaMum perceived as a problematic situation. At 21-years-old, AnnaMum left Samoa for New Zealand soon after finding out she was pregnant to a much older married man with whom she was not in a stable relationship. She described herself as 'confused' and 'scared' about whether to stay in Samoa, particularly due to possible retribution from the man's wife when she found out about the pregnancy. AnnaMum decided that she would leave Samoa. She did not tell her parents she was leaving or that she was pregnant for fear of 'upsetting' them. However, after arriving in New Zealand with hopes and dreams of creating a new life for her and trying to settle, she soon realised after her baby was born that she did not have what she considered 'training' to look after a baby. Her confidence as a new mother was further reduced by the constant disapproval and lack of support from her extended family in New Zealand. She struggled to maintain care of her new baby and missed the support she believed she may have received if living in Samoa. In a state of desperation, she contacted her parents soon after the birth of her baby. AnnaMum's mother came to New Zealand and returned to Samoa with the three-month-old baby:

That was very hard because, you know, how your parents have those high expectations of you, and they hear you are having a baby without a father. You know, because I'm sure every parent expects the 
daughter to get married first and have a good husband, but it didn't work out that way. My mum took her [my daughter] to Samoa and looked after her. (AnnaMum)

AnnaMum worked long hours at her paid employment in New Zealand at the time and, although she received good support from the Home of Compassion, there was no encouragement or help from the extended family she lived with. This was not an easy time for her and she recalls her home life was riddled with problems, especially difficult family dynamics. Not long afterwards AnnaMum fell pregnant for the second time, and again, to a man she was not in a steady relationship with, and she made the agonising decision to send her second daughter to her parents in Samoa. She was and still is grateful to her own mother for taking her two children:

My mum was waiting for them [my children]. Two of them. So I am so thankful that my parents stood by them. (AnnaMum)

AnnaMum's conceiving a child while not being in a stable relationship whereby the father could help raise the child, the lack of finances, and lack of confidence in her ability to parent, were reasons that led her to conclude that her daughters would be better off with her parents in Samoa than with her. This was at the emotional cost of not being able to develop a close relationship with her two daughters. Both daughters stayed in Samoa for at least 19 years, with the occasional visits to New Zealand to see AnnaMum when finances permitted.

AnnaMum regretted disappointing her parents, and will always remember, with a deep sense of gratitude, their support of herself and her two daughters at that time of early motherhood. AnnaMum drew on that experience when raising her subsequent daughters to her current husband:

I said 'you are not going to do anything to that baby, because I am here to look after that baby. I can sit home and look after our baby but you are not going to do anything about that baby'. That baby is going to be my grandchild, there is nothing wrong with having a baby before you get married or study or whatever. (AnnaMum)

AnnaMum was a lot more open with the daughters she raised and has close relationships with them. This was reflected in the way in which Anna announced her pregnancy to her mother, openly and casually, a far cry from the way in which AnnaMum informed her own parents of her pregnancy: 
Anna just walked in and said 'I'm pregnant, I'm pregnant'... She was just so excited for herself that she forgets all about us parents or anybody else but she said 'oh, I'm pregnant', walking around the house 'I'm pregnant'. (AnnaMum)

\section{GERALDINEMUM}

GeraldineMum was 20-years-old when she conceived Geraldine, her only child, but it was her second pregnancy. GeraldineMum's first pregnancy was terminated, at Geraldine's father's suggestion. She described how, after she had the termination, she slumped into a depression. Her depression, she surmised, due to the frustration at not having the tools or skills to express her feelings about her situation, i.e. being pregnant out of wedlock, and so she would 'beat up on herself':

I came from a background where there was not a lot of expression around our feelings and so that was really hard. It was really just basically suppressing the pain, and the hurt, and the anger, and the disappointment. So, one thing I was really good at, was beating up on myself. (GeraldineMum)

When GeraldineMum got pregnant for the second time, she believed the pregnancy would help to improve her relationship with her partner, as well as help to alleviate the negative feelings she felt were stemming from the termination. The second pregnancy did not, however, mend the relationship, quite the opposite, but it cemented GeraldineMum's decision to return to New Zealand. This renewed her confidence in her ability to look after herself and her baby and avoided the prospect of remaining in an unhealthy relationship or her baby being born on 'foreign soil' (in Canada). Her return to New Zealand pregnant and single concerned her as she was aware that it might reignite the 'stigma' and 'shame' that her own mother and family experienced with her mother:

We stayed with an aunty that probably had her own mental health issues. With mum being a single parent and two kids from two different partners, culturally, that's so unacceptable especially back in those days, it's just unheard of and there was a lot of stigma and shame. I think mum was ridiculed a lot and belittled because of it. (GeraldineMum) 
GeraldineMum recalled that her mother's reaction was 'really good' when she told her about her situation and this helped to strengthen her resolve to move and scope out a future for herself and Geraldine in New Zealand:

I came home [pregnant] with Geraldine, told mum and mum was really good. I think I was more afraid of mum's reaction, but when she said it was okay, there was like a big relief for me, a big sigh of relief for me, yeah. (GeraldineMum)

GeraldineMum's experience of mild depression soon after the termination of her first pregnancy directly impacted on how she felt about Geraldine's pregnancy. She stated that her concern for Geraldine was for her emotional state and that of the stability of her relationship with her partner, rather than her ability to cope with impending motherhood. She implied that that would not be a problem because she was there to help. GeraldineMum credits avoiding symptoms of postnatal depression to her own mother who provided social support and intervention at times when things were desperate. The point was that she would be there for her daughter like her mother was for her:

I don't think I did [have postnatal depression]. I think the reason why I think, it was such a relief to have mum, and something as simple as don't do the big meals. Just rest, sleep and look after baby and I was thinking, oh my gosh, I can't believe it, I'm in heaven. (GeraldineMum)

GeraldineMum was returning to her homeland, New Zealand, rather than migrating as her mother had done years before. Pregnant and single, GeraldineMum had a vast network of family and friends in New Zealand who supported her. Her mother lived close by and she had reliable assistance from extended family and friends, access to good healthcare and social benefit support. This allowed her access to financial assistance and choices for maternity care, an option not afforded to AnnaMum during her first pregnancy.

\section{LOLAMUM}

LolaMum's story differs yet again from the other two 'FTSMs mother' stories already told in that her story of motherhood originated in the USA, where she had her first child, before migrating to Samoa where she had more children and then to New Zealand where she had her last child. She gave birth to Lola, who is her fifth of six children, in Samoa. Lola's baby is her first grandchild. 
LolaMum fell pregnant with her first child when she was 17-years-old. She married the father and went on to have more children with him. Her last child, only a few years older than Lola's baby, was born in New Zealand. LolaMum's own mother stayed in Samoa for an extended length of time during LolaMum's pregnancies as she was worried about LolaMum's welfare, particularly as she was very young.

LolaMum left Samoa, leaving her five children (Lola was the youngest and three years old at the time) with her husband, to re-educate herself and look for employment in the USA. The long periods away from her family deeply affected her children, not only because they desperately missed their mother, but because their father's new partner moved into the marital home not long after LolaMum's departure. Against her family's wishes, LolaMum returned to her husband, partly due to her faith in the institution of marriage and her love for him, but mainly because she missed her children and was concerned she would lose custody of them if they separated. The couple reconciled, which was the catalyst for their move to New Zealand to start a new life.

Reflecting on her own upbringing, LolaMum described her life with her parents as secure and she had felt well loved:

I have a free life with my parents and my family; I open the fridge eat the apple, eat the orange, whatever I want I do... they make food from the Samoan kitchen, they light the fire and cook food. (LolaMum)

LolaMum was under no illusions regarding her family's opposition to her ever returning to live with her husband, yet their unconditional support allowed her to make her own decisions, regardless of the intense family disapproval. It is on this basis that LolaMum wanted to, in turn, provide similar unconditional support to Lola when she became pregnant to her boyfriend (who had another pregnant girlfriend due at the same time as Lola!).

\section{MELEMUM}

Like the other grandmothers' stories already discussed above, MeleMum's story places a lot of emphasis on the importance of having a close relationship between a first-time mother and her own mother. MeleMum's own experience of her relationship with her mother was, like the others, enmeshed in an experience of trying to negotiate between the social stigma of having a child out of wedlock. 
MeleMum was separated from her partner when she was pregnant with Mele, an only child, and she and Mele lived with her parents in the family home at the time. Now that her mother has passed away and her father is in a retirement home, MeleMum and Mele live in the family home on their own. Although technically an only child from her mother's second marriage, MeleMum had a full sibling, a sister adopted to her aunt in Samoa in the 1960s, although the two are estranged. She also had older half-siblings from her father's first marriage. MeleMum was close to her cousins and their relationship was more like that of sisters:

She [MeleMum's mother] was there but I had my cousins' support also, 'cause they were like my sisters 'cause being an only child. (MeleMum)

MeleMum was not present at the birth of Mele's baby which caused her deep regret and she referred to it as her 'biggest disappointment'. Giving birth was an event she would have liked to have shared with her own mother:

Mum wasn't there, my mum came to me when I was pregnant with Mele and (again) my mum came after the birth. (MeleMum)

When MeleMum found out she was pregnant she was quite distraught and felt that she had 'disappointed' her parents. She confided in her father, who reassured her things would be fine; however, her mother insisted she marry Mele's father who was living overseas at the time. MeleMum considered that the difference in responses from her parents were due to cultural differences. Her father was Pālagi and her mother Samoan:

See the difference, one says it's okay no worries, but where you've got one culture that says 'okay you got to marry the fella' and I was pushed to try and marry him. But I was fairly uncomfortable and my dad would say to me 'you've got to make decisions; it's not your mother'. (MeleMum)

MeleMum described her relationship with her mother as 'good' but it changed over time when MeleMum started to voice her own opinions:

She didn't really like it, because she thought her input was law. (MeleMum) 
Melemum was keen to create a relationship with her own daughter containing the important relationship hallmarks which she perceived were missing from her relationship with her own mother.

\section{SITAMUM}

The final grandmother story is that of SitaMum. Her story makes similar points to the other grandmother stories in that her relationship with her mother during her early motherhood stages informed the basis of her own relationship with her daughter Sita during these early stages of her own first-time motherhood. Like MeleMum, SitaMum was unable to attend the actual birth of her grandchild by Sita.

SitaMum has been in New Zealand for over 27 years, arriving with her two small children and her husband. She had a very supportive extended family. SitaMum chose to stay at home with her children until the youngest went to school. She talked about the reliable support she received from her own mother after her first child was born and attributes her mother's influence to her own positive child rearing skills:

My mother is a good mum. That's why I [am] like this because of my mother. All of our children and my sisters, when they give birth, oh she's the one [who] takes care of them from three months. We went to work, she looks after them, baths them. (SitaMum)

SitaMum did not attend Sita's child's birth and, similar to MeleMum, she was extremely disappointed. Both mothers believed their daughter's partners were primarily responsible for excluding them, either intentionally or otherwise. While this did not have any lingering effects on how they perceived the quality of their mother-daughter relationships, it bothered both mothers enough for them to express their disappointment during their interviews.

It was made very clear by the FTSMs and their mothers that they strived to build and maintain a good relationship with each other, regardless of whether the FTSMs' motherhood decisions were not attuned to their own beliefs and values system. They were keen not to impose the same barriers and difficulties on their daughters that they themselves had been subjected to by their mothers. Experiences of migration (i.e. growing up in Samoa and then migrating to New Zealand) and the impact that had on the FTSMs' mothers' experience of motherhood was a significant factor in terms of different mothering advice compared to the mothers of those FTSMs who were born and raised in New Zealand (DeSouza, 2010; Rumbold et al., 2011). 
All the FTSMs' mothers reported having good relationships with their daughters prebirth and the birth of a child further strengthened this relationship, regardless of whether it was their first grandchild or not. The FTSMs and their mothers all felt that the nature of their relationships would be very different to that between a mother and son who is having a child for the first time.

Another key relationship for a FTSM is that between herself and the men in her life she considered important, namely her father, and her partner. Because of the focus on mothering in this thesis, the discussion on these cross-gender relationships is limited either because there was no father or male partner present, or because discussion about the relationship was either too difficult, or not important to the FTSM.

\section{FTSMS AND THEIR FATHERS}

Changes within societal attitudes to parenting have seen a marked increase in the involvement of grandfathers in the care of children, including babies, and with assisting their daughters with various aspects of childbirth and early motherhood.

While absent and disengaged fathers may impact negatively on their daughters' lives, they also have the potential to impact on the mother-daughter relationship as well. For example, daughters may not want to have contact with their absent fathers for fear of alienating their mothers or creating tension in their relationship with their mothers, particularly if the parents' relationship is acrimonious. Two FTSMs had never physically met their biological fathers, nor had they developed any type of relationship with them (both of whom lived overseas). Mele did foster a relationship with her paternal grandfather and was satisfied with that as the male father figure in her life. Geraldine did not really think about her father until she faced impending parenthood:

I've only been thinking about it [contacting my dad] recently, now, that I am having a baby. I've never really thought much about him. I remember looking at a photo and everyone says I look like him but it used to make me feel uncomfortable... but now I'm trying to look for it. (Geraldine)

To date, neither had placed any great urgency on contacting their biological fathers, nor did their biological fathers attempt to forge a relationship with them. The absence of her biological father in her life made Mele evaluate the importance of a father figure for 
her own child. Deciding to follow through with her pregnancy was, in part, because her partner made the commitment to stay:

Growing up with no dad, I wouldn't want my child to grow up without a dad. I knew what that felt like... he left when my mum was pregnant. (Mele)

FTSMs whose fathers were present during their upbringing had on-going relationships with them and saw that they were delighted at becoming a grandparent. Fathers were at times a source of solace for the FTSMs, enjoyed a close connection with their daughter, and generally preferred to give support from the background. Maria, whose relationship with her father was very close, commented on how her father broached the subject of safe sex:

I introduced him to a boyfriend at the time, and that's when dad sort of approached the subject because he knew that it's come of age. He started off with talking about protection... dad was actually quite good about it. (Maria)

The fathers of some FTSMs were able to moderate the somewhat unforgiving responses of their mothers after disclosing their pregnancies to them. Anna was unsure how to respond to her mother's emotional outpouring on learning of her pregnancy, but the relaxed attitude from her father helped:

He [dad] just turned to the cat and said: 'oh, [name of cat], there's going to be another baby', so I could tell he was really supportive and really excited. (Anna)

Maliaga's father's response to the pregnancy arose out of concern for her wellbeing rather than the social stigma of how he would look having a daughter who got pregnant out of wedlock:

My dad is open, my dad, actually he was the one that was more concerned than my mother because I am his princess... I am very honest with them. (Maliaga)

It was Maliaga's father and partner who were present when she gave birth. Her mother went out for a cigarette and missed it: 
When I got the epidural, I was getting pins and needles. He [dad] massaged me the whole time; my dad was really good and he was helping me control my breathing. He was like, every time I'd get upset and start panting, he'll be like 'Maliaga, you're breathing', like really staunch, there was no fluffing with my dad... he just told me straight and I knew just to listen, I knew just to listen. (Maliaga)

Alma's father, on the other hand, was more stereotypical as the patriarchal Samoan father who had and was given the final say in their family:

My dad's [rule is final]. Until I get married, it's always going to be my dad's. (Alma)

\section{FTSMS AND THEIR PARTNERS}

A pivotal relationship for FTSMs from the early stages of becoming pregnant to caring for the newborn baby was with the father of their baby. While this was the first pregnancy to result in childbirth for all the FTSMs, for two of the partners it was their second child.

Just over half of the FTSMs were living with their partners at the time of pregnancy. By the time of the second interview at up to 12 months post-birth, all but one of the FTSMs were still with their partners. The one FTSM who was separated from her child's biological father was with a new partner. Another two FTSMs were still in their relationships but the relationships were not stable. They were trying to work through issues and were not living together. The remaining six were in more stable relationships and living together.

While most of the FTSMs described their relationships as solid and stable, they were also open that they required constant work and re-evaluating. Most of the FTSMs and their partners had access to advice from others (friends, family, health professionals) about what to expect post-birth and what they needed to do to ensure that they made time for themselves as a couple, such as going on date nights or just keeping the lines of communication open.

Most of the FTSMs' accounts of their partner's reaction to the unplanned pregnancies were, on the whole, positive. The partners were serious about their future role and responsibility as a parent, articulating their commitment not only to the child but to their relationship with the FTSM. Henrietta's confidence that her partner would not 
leave her after finding out about her pregnancy may have been an expression of relief but it also served as confirmation that her relationship was stable:

At the time, I knew he wouldn't leave me. (Henrietta)

Alma was more direct about the state of her relationship before she became pregnant and was very matter-of-fact about how she conceived:

Before I got pregnant there was, like, two months of unstableness... I just went out and had sex and then became pregnant. (Alma)

A commitment by the partner to the relationship was vital to most of the FTSMs, as they needed the support and help from them. However, a few of the FTSMs reported that their partner's initial response to the news of the pregnancy did not deter them from continuing with the pregnancy as they saw a future with their baby, with or without their partners:

\begin{abstract}
Abortion was never an option, adoption was never an option. I was like, no, this is my baby, this is my baby that's it... like, I did think that maybe J would back off and maybe he won't want a part of it but that never stopped me from wanting to keep it. I knew that I would be okay... I had the support I needed and my baby would have me. (Maliaga)
\end{abstract}

Ellen articulated an unsettled time before she met her partner as she had just reunited with her biological family but still lived with her adopted family. Ellen discussed unresolved historical family issues and felt a sense of divided loyalty between her parents after meeting her birth family. She discussed her resentment of aspects of her upbringing, framed by Samoan culture:

I was like a slave to them [aunty and uncle], like, before I go to school, you know, like, typical Island life like, chores before going to school, after school do some more chores. The difference between me and my brothers, or me and my cousins, was the fact that I did everything ... it's a girl thing, it's a Samoan thing. (Ellen)

Not long after that, Ellen met and moved in with her boyfriend and his family. She became pregnant about eight months after: 
I didn't even think about that, I just stopped [taking the contraceptive pill] because I knew he was the one and that was the only thing that crossed my mind. I never thought about the reasons why I would stop and the reasons after that. I just knew that I could trust, you know, that he was the one that I could trust myself with and I actually told him that and yeah, like, he wasn't... like, he didn't back out or anything. He was like, 'well, if you're happy, then that's the main thing'. He just really cared about it; I never actually thought anything of it afterwards. (Ellen)

Moving in with her partner and his family gave Ellen a different perspective on Samoan family life and stability and she resented aspects of her own upbringing as they were 'very Samoan', yet she described her partner's family as 'strict like in fa'asamoa'. Ellen's fragmented relationship with her parents opened an opportunity to forge close bonds with her partner's family 'I treat them like my own parents and we have this really strong connection with each other'. When Ellen found out about her pregnancy, she was keen to reignite her 'fa'asamoa' ways and increased her proficiency in the Samoan language.

A common issue for the FTSMs was losing their financial independence. All were financially independent before pregnancy and it was very difficult for some of them to accept that at post-birth they would be financially dependent on their partners for the time they would not be working:

I've never had to depend on anyone financially. I hated not having my own income and always having to ask [partner]. He was, like, I will pay for it; sometimes I feel bad as well because I know he pays the rent and everything else. (Geraldine)

Anna's partner was a high-profile sportsman. Before Anna fell pregnant the focus on his career had been intense. He was an elite sportsman when Anna met him, but it was not until he was elevated to the top New Zealand team that things began to unravel in their relationship. Long periods of time overseas and unrealistic expectations on his return home put a strain on their relationship. Throughout her pregnancy and postbirth, she fully supported his career, not only for his benefit but also for their growing family, but she found it increasingly difficult when, as she puts it, his ego expanded:

We just wanted J [partner] to come home. Then he'd come home and it was almost like he was antsy, you know, we kind of felt like we're not fun anymore... I pretty much said [to J] look, we're moving out 
because your ego has moved in, and it was like there was not enough space for us here. (Anna)

Anna kept the decline of her relationship and her unhappiness to herself for fear of jeopardising what was a 'dream come true' in his career. But without the support she needed from him to cope with having and raising their baby, Anna finally confided in her family. With full help from her family, friends and their commitment to salvage their relationship, both Anna and her partner have been able, for a time, to work through their issues constructively. It was not until the relationship hit rock bottom that Anna felt she had very little option but to try to save it.

Without the support of family, it is very difficult to overcome differences or work on strengthening couple relationships. The outcome can be detrimental to not only the FTSM but also the child. Three FTSMs struggled with their relationships due to issues with their partners and their families' opposition to the relationships continuing, despite the birth of a child.

Mele suffered the miscarriage of one of her twin's in-utero early in the pregnancy. This was an emotional and devastating blow for both her and her partner. During her pregnancy, her relationship was stable and her partner was well liked by her mother. However, after the baby was born, Mele's mother did not approve of her partner's lifestyle and that of his family as she believed the family was not a 'good Christian family', and the partner was 'lazy' and did not set goals for the future. Although her partner could visit Mele and their baby at their home where they lived with her mother, he was no longer permitted to stay longer than two-three nights. This put an enormous amount of strain on Mele, who felt she was in the middle of a rift between her mother and her partner which, she believed, had caused her relationship with her partner to weaken. She felt 'angry' and 'stuck in the middle' of their disagreement, and that resolving it was out of her control. Mele was also grieving for the lost twin and felt her partner could support her and so should be able to stay with her. Mele wanted to develop the relationship with her partner further and have him move into her family home but she did not broach the subject with her mother, not because she was concerned her mother would reject her request but because she felt raising the subject would cause too much stress for her and her baby:

I have to keep the peace right now... I know my mum, and she overacts and plus baby is still young so I don't want her to be affected. (Mele) 
When it came to having a baby, regardless of the reasons behind conception, all the couples, especially those in shorter-term relationships, believed that the prospect of having a baby and becoming parents advanced their relationship to a new level. Compulsory parenthood forced the couples to have discussions about living arrangements, about their commitment to each other as a couple and as parents, about the practicalities of maternity leave and financial dependence, and about future goals.

\section{FTSMS AND THEIR FAMILIES}

The last of the more personal relationships for FTSMs were those with wider family members. Mediating between partners and their parents caused some FTSMs, like Mele, to withdraw from socialising with other family members when they came over to their home. When her mother was home, Mele would retreat to her bedroom so as not to cause any further arguments.

Religion is an important part of Samoan culture and life. Maliaga's family had very different religious beliefs and this caused an enormous division between the families of Maliaga and her partner. When Maliaga became pregnant, her partner was 'descholarshipped' or excommunicated from his congregation and his parents would not see him for a period of time. During the time between pregnancy and birth, Maliaga invited his parents to events to do with the pregnancy (e.g. scans, baby showers) but their lack of attendance only exacerbated the tension between her family and them.

Maliaga built a very strong resentment against her partner's family's rejection to the invitations as a personal attack on herself and her family. Maliaga attributed the family rift to the built-up tension in her own relationship with her partner. She felt she was often unsupported when he defended his parents' decisions and took their side over hers. When Maliaga was in labour, her partner's mother attended the birth and, when the baby was born, his parents extended a formal apology to Maliaga, to her parents and her grandparents who were present. Unfortunately, the relationship between Maliaga and her partner deteriorated to the point that she asked him to move out of their family home. He visits every day after work and, although they are not living together, they still consider themselves a couple:

We're still together, but right now, with the differences in religion and everything, it's just hard to be together. (Maliaga) 
The social climate in Samoa at the time that most of the FTSMs' mothers had their first child was not conducive to openly supporting single mothers and many struggled. When they migrated to New Zealand, it was considered a place of hope and solace. That is not to say that they did not see challenges, but they felt that it offered necessary distance and time to rebuild their lives. The same was the case for relationships. Many were fraught with difficulties at times - there were aspects of these relationships that just needed time to adjust. This was especially evident in the accounts about the older generations who were more likely to follow 'traditional' ways of parenting (i.e. mothers and grandmothers of the FTSMs) and wanted mothering to happen in a certain way.

\section{PARTNERS' FAMILY/IN-LAWS}

Family in-laws are an integral part of the lives of the FTSMs and, like kin, family members can hinder or support the women during their maternity journey. In Samoan society, the birth of children and the links that are formed can be complicated depending on the descent link, i.e. matrilineal and patrilineal (Shore, 1981). The 'power' that a husband has over his wife is not of the same quality as that which a sister has over her brother, a key relationship in Samoan society (ibid.). As articulated by the FTSMs throughout their interviews, family played an integral part in their lives with the support they provided, but family were also difficult to deal with at times and this had the potential to unravel any progress or advancement by the FTSM in their new role as mothers. Anna found the 'dominant personalities' of some of her partner's family members to be 'intimidating' and she grappled with how she could deal with them, particularly as they were the senior members:

J's (partner) aunties, who are quite dominant personalities, they're quite strong personalities, I felt like they all had an idea of what to do and how to do it and I remember thinking, well, I know best. (Anna)

Anna confided in her sister and midwife about the aunt situation and drew confidence from their reassurance that she was the mother and she knew her baby well. Although most of the FTSMs felt they were lucky to have good relationships with their in-laws, whether they lived close by or not, at times tensions between in-laws also created tensions between them and their partners' particularly if the partner was in agreement with the ideals of his family.

As with most of the FTSMs, Patricia stated that her in-laws have been a great support: 
The only thing I get irritated at, which is with every mother-in-law, is when she just says her advice which, like I will do something and she will say something which means I shouldn't be doing it and I know she's trying to tell me to stop doing it. (Patricia)

Many of the FTSMs felt more inclined to voice their opinions openly and freely to their own families while opting to stay silent with their in-laws, leaving it to their partners to inform their families if there was a conflict of beliefs:

She (mother-in-law) would always text and J (partner) would be saying no, just leave them alone and stuff like that, they're sleeping or you know... he kind of sheltered us from a lot of it. (Anna)

Dealing with family in-laws can be, at times, as Patricia put it, very 'tricky'. Confronting in-laws can be fraught with complications and can create a whole host of other problems or conflicts. Difficulty in being upfront or speaking up or putting forward their opinions could often be taken as a sign of disrespect. The nature of respect is deeply rooted within the Samoan culture, a belief that most of the FTSMs were fully engaged with. The FTSMs appreciated their in-laws and their support and felt their inlaws were a vital part of their network, particularly as grandparents to their children, and their support and the help they gave was perceived as coming from an honest and well-meaning position, even if the FTSMs did not always agree with them.

\section{SUPPORT NETWORKS}

Support from family members came in different forms; financial, childcare, emotional, and practical, such as buying groceries and cooking food. Geraldine's mother and grandmother helped with the housework and did all the cooking and cleaning so Geraldine could sleep and rest:

My mum, she cooked all the time, she cleaned the house, I didn't have to touch the toilet and bathroom or anything the entire time she was here... that was so much help because I felt I could sleep more properly during the day than at night. (Geraldine)

The strength of the support from partners who gave emotional, physical and financial support cannot be underestimated. Just the mere presence of partners was sufficient to help the FTSMs gain confidence in their ability to care for the baby: 
As long as my partner was there, for some reason if my partner is not here, it is a lot harder, I like him because he supports me, it's really nice him here even though he can't put him to sleep... he does the laundry, he does the rubbish, if I'm changing, he will go and grab the nappy, you know all those little things, it really does all add up. Once he's at work, then I've got to put him down. (Patricia)

Yep, we try and support each other. I try and support him and he supports me; it's him mainly supporting me. (Henrietta)

Helping after baby, he does what I tell him to do, he's good, always listens to me, yeah, and then he just reassures me that everything is going to be okay. (Mele)

The absence of a partner was felt by Lola who was the only FTSM to separate from her partner during her pregnancy. Her situation and emotional attachment to her ex-partner was complicated. Her parents were adamant he should not have any rights to see the baby, and she fluctuated between wanting and not wanting her ex-partner in their lives. Lola remained unwavering in that she did not seek financial support from her expartner as this would open up the possibility of custody issues in the future, yet she wanted emotional support, particularly in relation to her son getting know his father and his family:

With all the dramas with his daddy, I just want to deal with it my way. He [ex-partner] will be close to A [my son] so when A is older he will know who he is. Mum and dad want to shut him out for good, but to me I just don't want him [my son] to grow up and ask me the hard question of who his dad is. I still have that soft side in wanting him [my ex-partner] to visit baby so I don't have that hard time when he is older... it's sad for my son growing up not having a dad. I just can't do much about it while living under this roof because it's under my mum and dad's house so I can't really do much about it so I just let go. (Lola)

Confiding in someone close, be it family member, friend or colleague, was important for many of the FTSMs. Often friends who had children were a great source of support:

I have a friend that is like my go-to person and whenever I need advice about anything ... she's a great help and I like talking to her as well because she never tells me what to do; she's like, well, I did this. (Geraldine) 
My cousin, yeah, she's had a baby too... so we talk to each other (ever since) we were young when we were growing up... we share everything. (Mele)

There is no doubt that changes in the relationship between a FTSM and her mother, her father, her partner, her wider family members and friends continued to occur during the course from pregnancy to post-birth. The transitions might enhance the relationship i.e. a daughter might become more interested in her own mother's experience or the mother may now view her daughter as an adult and relate to her in a different way. The relationship may be strengthened between a FTSM and her parents and/or grandparents now that the FTSM is going through the responsibilities of a mother/parent/'wife', married or defacto. These relationships might at times be challenged as differences in preferred child-rearing approaches become apparent.

The complexities that emerged within each of the relationships discussed so far were not major. Some issues were related to differences in religious or traditional cultural beliefs about sexual relationships or motherhood. Elements of mothering that were considered both 'traditional' and 'modern' were passed from the FTSMs' mothers to the FTSMs and often embraced by them. This reflected the degree of trust in the relationship.

The term 'pivot-generation' or 'sandwich generation' is referred to in the literature as the generation of people in their 50s and 60s who may be combining paid work with caregiving, either for young grandchildren while their parents work, or for elderly parents and relatives who require care, so they have a multiplicity of roles (Mooney, Statham, \& Simon, 2002). The term can also be conceptualised as mid-life adults who simultaneously support dependent children or independent children and care for frail elderly parents (Grundy \& Henretta, 2006). Grundy and Henretta (2006) describe how people in the pivotal position may have to cope with demands from adult children and from elderly parents that may compete, i.e. providing help to one may decrease the resources or help given to the other. Hollway's (2010, p. 142) description of new mothers as 'generational pivots - positioned in the middle of three generations - are powerful transmitters of culture transgenerationally' is an adaptation of the concept where there is transfer of knowledge within the relationship of motherhood, or being the woman in the position of daughter as well as the position of a mother. 
In the present study experience, knowledge or practical advice that is transferred between generations and the impact this has on the parenting skills of the FTSMs rests largely on what advice and knowledge the FTSMs accept and apply. Drawing from the dominant culture, her personal beliefs and those of her partner also heavily influence the FTSMs' decision-making and parenting style. The family structure of the FTSMs included parents, siblings and extended families, and the influence of each of these impacted on the FTSMs' experience of pregnancy, childbirth and early motherhood.

Running parallel to becoming a mother for the first time, is becoming a grandmother - a significant event for both the new mother and new grandmother. Pregnancy creates a future role for both. While this new identity was welcomed by all of the mothers/grandmothers, it did not come without challenges. Over time, the difficulties of the relationship were either overcome or worked through. Although some of the grandmothers' narratives described experiences of hardship, isolation, lack of support, terminations, rape, single parenthood, infidelities, barriers to maternity care, separation, teen pregnancy and difficulty assimilating in a new country, there were also stories of consistent love and support from their mothers and, in most cases, their extended families. Two of the grandmothers felt that leaving countries they resided in to come to New Zealand seemed a far better option than the prospective lives they would have faced raising a baby under difficult personal and social situations. While stories highlight similar reasons for coming to New Zealand (i.e. better lives for themselves and their babies), it eventuated in different outcomes. The relationships they forged with their own mothers were interspersed with overcoming major obstacles, self-growth and learning. These experiences had a direct impact on the relationships they shared with their daughters.

For the FTSMs, regardless of age, marital status, living situation or the closeness of their mother-daughter relationships, gaining their mothers' approval of their pregnancies was imperative, and often set the tone for future relationships not just between them but also between them and their partners, their fathers and wider family. While the initial response may not have been positive, their mothers' approval was always given and this helped to boost the new mothers' confidence knowing they had that support.

\section{MATERNITY HEALTHCARE PROVIDER RELATIONSHIPS WITH FTSMS}

Health professionals such as midwives, Well Child health providers, breastfeeding or lactation specialists contribute enormously to the maternal experience of FTSMs. Timing of access to the services provided by the health professionals are dictated by the 
natural sequence of the maternal experience, pregnancy, childbirth and early motherhood. Often the services may, for a very brief time, overlap, e.g. during the midwife handover to a Well Child provider. Sometimes the services of the health professionals may conflict with those offered by the families of FTSMs.

\section{LMCS AND THE NEW ZEALAND MIDWIFERY SYSTEM}

The history of the midwifery establishment in New Zealand is interesting and complex. The Midwives Act 1904 was passed to prevent further decline in the European birth rate so that white New Zealanders were not 'outbred by the non-white races' and thus could maintain power over New Zealand (Donley, 1986, p. 32). One way this could be achieved was by making improvements to maternity care for the 'deserving [white] poor' whose infant mortality rate was particularly high (ibid.). Regulation for the practice of midwifery, the Midwives Act 1904, was passed to establish 'state control' (Stojanovic, 2010, p. 54). This is aptly articulated by DeSouza (2011) in her discussion about 'governmentality' as a way of maintaining control over women's health:

Roles of nurses and midwives extend to defining norms of good/normal mothering and they are in a position to determine the criteria for interventions on behalf of the state and the kinds of discourses that can be made available. (p. 43)

Midwives and consumers campaigned throughout the 1980s for midwifery autonomy and the right to practice independently of the medical profession (see New Zealand College of Midwives 1990). The Nurses Amendment Act 1990 reintroduced autonomous midwifery practice. The act separated midwifery and nursing, which were established as separate and distinct professions. Educational institutes could offer direct-entry midwifery training and a nursing qualification was no longer necessary (Kirkman, 2012).

Currently, midwives in New Zealand form two distinct groups. The first group are core midwives, employed in maternity units, facilities and hospitals and are assigned to distinct areas of maternity care, in line with the institutional division that separates care into pre- and post-natal wards, and labour and delivery suite. The second, known as Lead Maternity Carers (LMCs) or case-load midwives, are based in the community, either as employees of midwifery services (e.g. Domino midwives or Nga Tapuhi Whakawhanau) or are self-employed. The latter group is often referred to as independent midwives. Either way, they provide continuity of care for clients, an important tenet of midwifery philosophy in this country (New Zealand College of 
Midwives Incorporated, 2010). The midwives interviewed for my study were all caseloading independent midwives with one exception, a midwife who was based within the hospital setting.

\section{Case-load midwifery versus core midwifery care}

Tinkler and Quinney (1998) explored the effectiveness of involving a team of midwives for mothers compared to having only one dedicated midwife for each expectant mother. The authors found that women who were with a team of midwives reported greater satisfaction with their care than did women who were registered with one midwife. The study highlights the importance of quality midwife-woman centred relationships.

Others have argued that case-load midwifery offers greater relationship continuity, by ensuring that mothers receive their antenatal to postnatal care from one midwife or her colleague. Studies in the UK found that one-to-one midwife-woman relationships and the continuity of the woman's preferred carer improved the mother's satisfaction. It also lead to greater job satisfaction for the midwives, increased their autonomy and reduced intervention rates (Lesley Page, 2003; L Page, McCourt, Beake, Vail, \& Hewison, 1999). This was supported by McCourt et al (1998) who found that women receiving one-toone care had higher levels of continuity of caregiver and midwife-led care than those in conventional midwife team care. Women in their study expressed a preference for continuity of caregiver, and most preferred that care to be provided by midwives in a community setting. The confirmation of a pregnancy by a health professional is often the catalyst for women in New Zealand to engage the services of an LMC whose role is to provide and coordinate their maternity care from pregnancy, childbirth and up to four weeks post-birth. While most LMCs are midwives, doctors and obstetricians can also be LMCs (New Zealand Ministry of Health, 2014b).

There are several ways in which FTSM's engagement with LMCs can take place. Usually if the pregnancy is confirmed by a health professional (i.e. GP, Family Planning), they provide a list of midwives available in or around the local area. The women can also access midwives through a recommendation from family, friends or colleagues, or by searching the internet. The development of a genuine and caring relationship with health professionals can help mothers become confident and secure to make informed choices which directly affect their own and their baby's safety.

Midwives enter the relationship with the woman and her family based on trust, shared decision-making, responsibility, negotiation and shared understanding (New Zealand College of Midwives Incorporated, 2010). There is a real drive to provide women- 
centred maternity services that privilege women's views and address their need for choice, control and continuity of care, framed under a quality care-giver relationship.

Midwives clearly have the potential and power to enhance or spoil women's experiences of pregnancy, childbirth and/or early motherhood. However, it is less clear which aspects of the midwives' care are the most significant. Professional midwives are given status within society, both in New Zealand and Samoa. First-time mothers, on the other hand, are in an emotionally and physically vulnerable state and come to rely from the outset on the expertise and professionalism of the midwife to ensure that their and their baby's health needs are met. There is an imbalance of power in the relationship which midwives must be aware of.

The world view and background of all mothers should be fully understood by the midwife in a way that is non-judgemental, inclusive and practical, especially given the fact that the LMC has access to intimate information about the private lives of these women and has the power to make decisions that could affect the wellbeing of mother and baby. The FTSMs were keen to enter into a relationship with their LMCs based on trust and mutual respect, at the very least. While the FTSMs were aware of the necessity and importance of maintaining a strong relationship with their LMC, the time available was by definition short and, therefore, it was imperative that relationship-building was nurtured quickly.

The FTSMs spoke about their relationships with their midwives as one of a midwifeclient type relationship. It was strictly professional. Sometimes the FTSMs' family members would also be brought in to support the FTSM with negotiations with her midwife.

\section{Choosing a midwife}

The argument about ethnically matching service providers and professionals to patients or clients is very much present in midwifery care in New Zealand. In a New Zealand study exploring Samoan women's attitudes towards antenatal and midwifery care, Fa'asalele Tanuvasa et al. (2013) found that midwives supported the view that Pacific women preferred their midwives to be of the same ethnicity as themselves as they shared the same 'language' and background and so 'understood their experiences' ( $p$. 719). This is supported to some extent by DeSouza's (2006) study investigating the health information needs of Asian mothers living in New Zealand, where she found that new migrant mothers prioritised the ability to communicate in their mother tongue over the midwife's perceived skills (p. 200). 
The main influences for FTSMs in engaging a midwife was her locality and availability. The FTSMs reported that the key feature of a 'good' midwife was (perceived) competency rather than ethnicity (despite the fact that they had no experience to evaluate whether or not a midwife had that quality, other than what they had read and heard from others). Alma, who had a Pālagi midwife, implied this expectation when she stated:

I don't really mind... just as long as this [points to pregnant stomach] was taken care of... it's all good. (Alma)

While ethnicity was not a priority for these FTSMs, if by chance the midwife was of the same ethnicity, then that was viewed as particularly helpful in terms of the midwife 'knowing' the culture and being able to communicate in Samoan, if necessary, to their family members who had limited English:

As long as it was somebody that made me feel comfortable. They [cousins] had actually referred me [to a Samoan midwife], so I thought I would just give her a go and she's turned out to be really good. She's got a good balance between the Western as well as the traditional Samoan myths or remedies... she understands exactly what my parents mean by certain things... she is an older woman, she's probably in her 50s or 60s but she's got a really good balance of both the Western culture and the Samoan culture which is really nice and she's like a motherly figure. (Sita)

Some of the midwives interviewed believed that shared ethnicity, culture and language was an advantage to working with ethnic minorities. Some said that it enhanced the relationship due to a shared background and allowed the midwife to communicate fully not only with the mother but her wider family, particularly with older members such as the grandmother, who may prefer communicating in her mother tongue. One of the Samoan midwives interviewed argued that this would also be helpful within a hospital setting as it negated the need to employ auxiliary staff as translators, a highly inappropriate practice she suggested, which compromises the patient's privacy and safety as medical terms may be translated inaccurately by a non-medically aware translator:

If they [Samoan speaking mothers] can't speak good English, they can speak to me in Samoan. I can understand what they're saying and 
translate, yeah, and again another goal for me is I really want to be able to speak fluently. So, if they [Samoan speaking mothers] come that I can actually talk to them back in Samoan, especially if there's an emergency happening. I know what's going on and no other people there do, I mean there's lots of people at the hospital but they're not midwives, they're cleaners... and it's not appropriate to use them in that situation. (MWW2)

There are many advantages engaging with a Pacific midwife, and there can also be disadvantages. Earlier studies (see Churchward, 2011; Ekeroma \& Harillal, 2003) found that Pacific women did not prefer a doctor of the same ethnicity due to confidentiality and privacy concerns. MWA4, a non-Pacific midwife, had lived in Samoa for years and worked as a midwife there. Yet, despite this experience, she could never fully understand the complexities of working with Samoan families, some Samoan mothers pointed out to her. Pacific mothers were mostly recommended to her, but she was acutely aware that she did not share the cultural intricacies or unspoken cultural nuances that a Pacific midwife may have been privy to. However, MWA4 was also aware that many of her mothers engaged with her precisely because she was non-Pacific:

They [mothers] look at me and go 'you wouldn't understand', you know, and that's fine. I'm okay with that... it's not that simple... it's really interesting for the Pālagi people who think that Samoans have a really simple kind of existence. They're so wrong; it's way more complicated, the family obligations, I will never, ever fully understand it. (MWA4)

\section{FTSMs and their midwives}

The initial meetings between the FTSMs and their midwife centred around establishing the midwife's availability, setting the location of meetings, establishing trust, getting to know one another, and focussing on the growth and development of the baby. FTSMs and their families gaining the approval of the midwives about how the FTSMs were coping and managing their pregnancies was also a factor in the initial stages of the relationship.

Research has identified that Pacific mothers generally engaged with antenatal care either very late in their pregnancies or in hospital when they presented for birth (Low et al., 2005). However, engaging the services of a midwife as soon as possible, for some in their first trimester, was important for these FTSMs as this gave them more time to develop and establish a relationship. 
Most of the FTSMs registered with a midwife as early as eight weeks into their pregnancy, the majority engaging with a case-loading independent midwife. Only one mother utilised the services of a team of midwives attached to a maternity unit within a hospital due to the high risk of complications in the pregnancy and birth.

\section{Trust, Confidentiality and Continuity of Care}

Trust, confidentiality and continuity of care were key factors in maintaining a good relationship between FTSMs and their midwives. Trust comes in many forms. Trusting a midwife for many women is more than just ensuring they can do the job, or are reliable in turning up to appointments, or are well-informed. Important to all the FTSMs was an inherent belief, a trust, in the midwife's ability to maintain confidentiality, particularly if the woman is in a dire situation and needs to conceal her pregnancy. While there is a lack of statistics on concealed pregnancies other than media reported incidents, there is substantial anecdotal evidence that this occurs.

It is salient when working with Samoan women and their families for the cultural beliefs of Samoans to be understood. One of the Samoan midwives interviewed felt that Samoans did not view postnatal depression as separate from the normal event of pregnancy and felt social stressors impacted on their coping abilities rather than it being a separate, depressive episode brought on by the birth of a baby.

MWA5 referred to the term 'ma'i Samoa' which is quite separate from postnatal depression or general mental health. She shared her experience of working with a pregnant woman and her family, whom she felt were affected by ma'i Samoa. During the time she spent with this younger mother, MWA5 informed her colleagues that she gave her the 'heebie geebies' - the feelings were not due to one particular incident but over several meetings, during one of which the young mother told her that she and her sons saw 'visions' of people from her past. The midwife described her behaviour as odd and found her 'really cool, very cold stare' unsettling. MWA5 was so concerned she invited her colleagues to meet the young woman and her family, after which her colleagues supported MWA5 in her concerns that this case appeared to be different from a mental-health issue. 
MWA5 believed that if this woman were to be diagnosed using Western mental-health criteria, then health professionals might incorrectly diagnose her illness as schizophrenia; however, to MWA5 this was definitely a case of ma'i Samoa ${ }^{26}$ :

The long and short of it is, within our Pacific nations there are things beyond our own meagre understanding that we cannot even begin to make sense of. I know that, prior to Christianity, we walked alongside others. I have never, ever, ever, come across this phenomenon before [with the young mother]. When we speak about depression, I would have to say that within the Samoan context, yeah, sure depression may very well exist, but I think a lot of our depression stems from the social competencies that impact on our daily lives. (MWA5)

MWA5 grappled with her strong cultural beliefs against the conflicting professional Western view as she tried to figure out how to deal with the young mother and how she could access help and support for her that was culturally and socially appropriate. In understanding Samoan illness beliefs, MWA5's insight into the contrasts between the Western models of diagnosis and traditional beliefs, caused her to challenge the health system from which this family would have received care and treatment (Macpherson \& Macpherson, 1990). Eventually MWA5, referred her to the Pacific Mental Health Team where she felt confident the young mother would be treated in a culturally appropriate manner.

Confidentiality is critical to all midwives. An example comes from another midwife who was able to gain and keep the implicit trust of one of her Pacific teenage mothers, through the way she demonstrated her support of that mother's express wish not involve a social worker, something that went against usual practice, by actively advocating on the Pacific teenager's behalf against her obstetrician. The midwife used this case to illustrate her belief that sometimes Pacific women may deliberately choose her, a non-Pacific midwife precisely because she is non-Pacific, because they feel that their situations would be more easily kept confidential.

Acquiring a reputation as a midwife who can respect patient confidentiality is very important for midwives, whether of Samoan or non-Samoan ethnicity. Most midwives

\footnotetext{
26 * Ma'i Samoa - Samoan sickness, spirit caused. Symptoms caused by aitu, or aitu is impeding the healing process.

**Aitu - spirit of dead person, or general spirit.

reference (University of Hawaii: ADAP Project, 2001)
} 
who work closely with Pacific peoples are aware that the Pacific community is very small and there is a view that 'everybody seems to know everybody':

Samoan people are very private; they don't want their business out there and sometimes it's why they use Pālagi because they don't want their business elsewhere. Sometimes they choose us because they know that they can confide in you and it's okay, you understand, you don't have to explain yourself and why you do certain things. (MWW2)

Something that our Pacific families are very, very, you know, they're quite suspicious about is whether or not they trust you enough to ensure their confidentiality is maintained. (MWA5)

During the labour and birth itself, the FTSMs saw the midwives as an integral part of the process and relied heavily on their advice. By this time, most of the FTSMs viewed their midwife as the link to the maternity hospital. The FTSMs did not want to challenge the midwife but also wanted to remain composed. While the FTSMs got annoyed and frustrated with some of the midwives' instructions, it was a fine line between listening to the midwives implicitly against trusting themselves and listening to their own bodies. (see earlier Chapters)

In their relationships with their midwives, the FTSMs were conscious not only of weighing up the advice they gave vis-a-vis the advice of family and their own sense of what was right or wrong, but were clear that their midwives needed to deliver reliable and continuous care. FTSMs were able to form a close relationship with a midwife (maybe even a team of midwives if necessary) and the relationship was ongoing from the time they first met pre-birth to the time they had to change to the services of a Well Child provider. Continuity of care was so important to Maliaga that she was confident enough to end the relationship with her first midwife. Maliaga stressed that she accepted and expected there would be times her midwife would not be available but she had to balance the midwife's absences with her own expectations of what she considered proper maternity care. The breaking point came when Maliaga missed out on the first two weeks of her maternity-leave pay due to her midwife forgetting to send the appropriate paperwork to her workplace:

With the midwife, it's not so much the support for myself, it's me putting my baby first. I know that while I am pregnant, the midwife is 
a very key person. I've gone to seek more support for my son. With me, personally, I am quite stubborn. (Maliaga)

For two months during the transition between midwives, Maliaga was left not seeing anyone.

During her pregnancy, Sita developed a good relationship with her midwife, describing her as nurturing and very reassuring in her approach. Although her midwife was Samoan, her ethnicity was not the key factor as to why Sita engaged with her so well. The midwife being Samoan was a bonus as she had a deep understanding of the Samoan culture which helped her communicate with Sita's parents:

She gives us all the info we need but she doesn't give us anything [that might] unnecessarily stress us out... she's just made it as normal as possible, where it's a normal condition and not a sickness, so she's always said that it's [birth] a natural process of life. (Sita)

Unfortunately for Sita, the characteristics of her midwife that worked so well during pregnancy did not work during childbirth. Sita felt her midwife became 'passive' during her birth and did not provide the full attention and care she needed and deserved. She felt so disappointed and became so dissatisfied with the care she was receiving that she and her partner made a brave call and requested another midwife. This required confidence from the couple to dismiss their midwife at such a critical time. They took a significant risk but in the end it paid off:

Our midwife at the time, she'd been fine up until then but then the actual birth it was kind of... I don't know if she was really passive... things like I had to initiate the gas, the pain relief, and ask for it... I don't know if that was what made the experience... at times she would be on her phone texting, you don't want them to be there all the time, but it just seemed so passive sometimes and we had the student midwife, she was really good. In the end, it was one of the nurses that delivered me, not the midwife... in the middle of the birth my husband went out and asked if there is another midwife, someone that could come, it was just the time. (Sita)

It is a woman's right to leave or dismiss her midwife if she is not happy with the level of care and treatment she is receiving. Women who know this can be empowered. Many midwives stated it was important to tell their new clients at the outset that changing midwives is always an option which can be exercised at any time. Both Sita and Maliaga 
did not believe their expectations of their care and treatment were unrealistic and in both cases their decision to change midwives was not made lightly and came after every other option had been exhausted.

Some of the midwives interviewed were fully supportive of the principle that women should always have choices and if that meant, for whatever reason, engaging with another midwife, then that is a woman's right:

So babies are not in a routine, they're not on a schedule, and that's a huge shock for them and missing out appointments, you know. If I have to ring and tell them look, I can't make it, they get upset but I said well, it's just the nature of the business. I can't predict when a woman is going to have a baby and I have to cancel you, as long as I'm courteous and ring you in advance and say listen I can't come and some of them say, well I'm not happy with that, I will find someone else. I say, well that's fine but they'll have the same problem as everybody else... and that doesn't bother me. (MWW2)

Our philosophy is that it is their birth and it is their baby and they have the right to say no. We do that for all of our girls; we never say go and do this test, we will say this is what this test is for, would you like to do this. (MWA3)

First-time mothers generally place an enormous amount of trust in their midwives, especially those who could give them a sense of security and reassurance (Howarth et al., 2011). Engaging with a midwife brought a sense of control over a situation and independence from personal problems associated with that situation. The midwives often became allies when FTSMs were faced with well-meaning but authoritative family members.

One of the most important and testing times between the midwife and expectant mother relationship occurs during the early stages of labour and just after childbirth when the mother is recovering and trying to learn how to breastfeed for the first-time. Here, the midwife's professional knowledge, past experiences and perception of the first-time mother gained over the previous few months is put to the test. This is particularly so for midwives or maternity nurses who care for the women in hospital. 


\section{Hospital midwives}

The relationship between FTSMs and hospital midwives was less close because they had less time to get to know each other and there are a lot more mothers and new babies for the hospital midwife to contend with. When her new-born son was sick in hospital and required tube feeding, Geraldine had to learn to express breast milk. She was taken aback by the nurse's highly inappropriate and forceful approach to showing her how to do this. She explained:

I had to, like, express in those little syringes and, instead of explaining how to do it [express], she [the nurse] just comes in and grabs my boob and then just puts it in the syringe and I was like really overwhelmed and I was just um, okay... I was scared to leave hospital just because of how he was sick. (Geraldine)

Describing their hospital experience was very emotional for some of the FTSMs, and emotions were still raw months after the event, conjuring up feelings of anger and even reducing some women to tears during their interviews. In contrast, there were some FTSMs whose hospital experiences were the opposite. Mele, for example, found her treatment by the hospital midwives to be very good. She felt that the staff was reassuring and communicated with her and her family really well. There were difficulties with Mele's pregnancy from the start and, having miscarried previously, she was enrolled under the high-risk medical care team and established relationships with several health professionals. She liked her midwife whom she got to know well, and talked about how her midwife's humour added something which was very comforting:

She's pretty good, she's talkative, she goes through all the options, she makes me laugh, she's a comedian, yeah she's good. (Mele)

Women who have a team of midwives, rather than having their own dedicated midwife, may be more likely to adapt to the different styles and approaches of several midwives. Therefore, their expectations of care and treatment, while not less, are different. Anna described her experience with the hospital nurses and midwives as 'horrific'. She believed the midwives were abrupt and 'screamed at' her, which intensified her emotional state and left her in tears. These events made Anna feel isolated and lonely, like she was 'on another planet', and spoiled the 'amazing experience' of her baby's birth, just hours earlier. 
Anna felt the midwives assumed she knew what to do. Anna's negative descriptions relate to the night-shift staff only, as she had the opposite experience with day staff, whom she liked:

I was like, do you have to be such a bitch, it's the middle of the night and she's [baby] crying and I don't know what to do and I thought, are you kidding me... I just had this most amazing experience and you're wrecking it. She [the midwife] was just really mean and I pretty much cried all night. The [hospital] midwife was just so mean, I was, like, I don't want to be here another night because she was just so horrible. (Anna)

Anna relied on the nursing staff to help and support her after her partner and family left. This lack of caring impacted greatly on Anna's hospital experience and made her believe the only option was for her to leave the hospital and go home, regardless of whether this was best for her and her baby. Anna was disappointed that her treatment almost overshadowed her positive birth experience.

Geraldine's time in hospital was difficult. Her son was born unwell and spent time in the neonatal ward. During this time, hospital staff asked Geraldine to leave hospital due to bed shortages, which upset her because her son was still not well and she was not confident enough to care for him on her own at home. Geraldine articulated to the hospital nurses her hesitation about leaving but the hospital nurses not only downplayed her concerns but misrepresented them to her midwife and caused her to become more distressed:

They rang my midwife and said that I wanted to leave and then A [midwife] rang me and asked if this was true. I told her everything and she was really angry, she rang them back and she must have blew them up. She made a complaint on behalf of me and said I don't have to leave if I don't want [to]. (Geraldine)

Soon after her midwife's intervention, Geraldine was told she could stay longer in hospital. However, by that stage the relationship between Geraldine and the hospital staff had already reached a point where she no longer felt welcomed or comfortable to stay on. She transferred instead to a birthing care unit.

The FTSMs' relationship with their midwives affects how they will respond or interact with the maternity healthcare system and its professionals, especially midwives, in 
future. Understanding how FTSMs choose a midwife or midwives helps towards better understanding of what maternity care policies work, why and why not.

\section{The advice of midwives}

The midwives interviewed worked with diplomacy and were firm in their intent to create a safe environment for the women, helping them to realise their needs and wants and acting as an advocate particularly with families. Ensuring that the FTSM was comfortable and safe and that her relationship with her family remained intact, involved midwives advising her on a range of matters, including, where necessary, speaking for her when the FTSM asked for their intervention in family relationships:

They're often very shy about their bodies, and it's actually a time when they don't want their bodies being exposed to anybody else. We've had these older relatives who have not been very happy with us for contradicting their advice. I've felt that they [the mothers] have been quite relieved because they've got quite upset when they're being bullied, basically by their own family members who are taking on a role that is not theirs to have. I think that we've built a trusting relationship already, you know, these are women that we've known for quite a few months now, and they trust our judgement. I think they trust it over their own relatives... respectful, respectful, always respectful to the older relative, always acknowledging them, always, always including them in conversation. But if we're getting to the point where you know they're actually taking it too far, then it's our job to actually keep that woman safe. (MWA4)

From the perspectives of the FTSMs, midwives were described as advocates, particularly in relation to dealing with hospital staff and families. The midwife as advocate provided the FTSMs with a voice, especially in the hospital environment where power was clearly with the health professionals. FTSMs often felt powerless in hospital and so the midwives were also to act as go-between and help preserve relationships between FTSMs, their families and hospital staff. For example, Patricia and her midwife discussed the issue of Patricia feeling uncomfortable and embarrassed about her mother-in-law being present at the birth, but neither Patricia nor her partner wanted to tell her. When it came time for Patricia to push, the midwife asked both the mothers to leave the room. Neither mother was perturbed at the request, mainly because it came from the midwife, and it helped Patricia a lot:

My mum and his mum had to leave the room because I think the midwife clicked that I was embarrassed about pushing while his mum 
was there. So, instead of telling just his mum to go, she told both of them to go. I spoke to her [midwife] beforehand and she said if she sees any sign of me feeling uncomfortable, she will send them out. We organised it beforehand so I wouldn't have to say it. (Patricia)

Maria had a similar experience where her midwife instructed family members when it was appropriate to come into the room, relieving Maria of the responsibility. Both FTSMs had immense faith in their midwives' ability to neutralise potential conflict and therefore provide a safe birthing place for them.

Midwives, especially the Pacific or Samoan midwives, found value in understanding the perspectives of the grandmothers or mothers of their Pacific first-time mothers. They generally encouraged intergenerational links between mothers and the elders in their families. When it came to negotiating and advising on who can participate in the birthing or other parts of the pre and post-birth care, they welcomed and encouraged the grandmothers and aunts to accompany the first-time mothers. One of the New Zealand born-Samoan midwives interviewed saw great potential for herself, as a professional, in terms of learning more about the Samoan context. MWA5 described communication with the grandmothers as 'invaluable':

When I meet these lovely grandmothers and older aunts, oh I get so hungry for their knowledge because I want that. Although we have New Zealand-born, we still have our Samoan-born and for me it's about merging the two together. Because the two together, I think, and truly believe, helps strengthen who I am as a service provider, you know, as a professional. (MWA5)

The cultural exchange of learning was articulated by all the midwives who were open to, and appreciative of, the reciprocal nature of the families of mothers they worked alongside. The midwives were clear about their role as midwives, their guiding philosophy being to support the mother and her family. The birth belongs to the mother and midwives are present as 'guardians for safety'.

There was a level of reliance on the family to be part of the labouring and birthing process and a belief that the extended family are 'equally as gifted' in their skills, whether it was providing comfort to a labouring mother or advising on a crying baby. Midwives saw this as aligned with the reciprocal nature of the relationship of Pacific or Samoan culture. MWA3 stated her position strongly in that she is a 'protector' of the women to upkeep their increased status by becoming a mother. MWA3 believed her role 
is to ensure the women maintain their empowerment afforded by their family support and her role is as guardian, a guardian against depression (among other things). She explained:

That's my job basically. I see myself as a guardian of safety, but that's midwifery, my vehicle for actually helping these women feel much greater self-esteem. If you've got good self-esteem and a good support system, depression is not something you're going to see very often. And the women don't get tired because they're never, as a rule for the first six to eight weeks, left alone in a family without another adult or two adults around. Usually an auntie, a mother, a sister, there is someone, and sometimes it might mean they've kept an older child home from school, but that mother is never left alone. So if the baby needs nurturing, it needs cuddling, it needs whatever while the mother gets some sleep, that's what happens - she sleeps. So, you know the sleep deprivation? So if you don't have sleep deprivation you don't have a trigger; what I believe is a major trigger for depression. (MWA3)

It was important for midwives to maintain a good relationship with both the propective mother and her family. The FTSMs did not always want to involve their family in their pre- and post-birth experiences, but felt unable to convey this to their families for fear of upsetting them. So, it was useful that the midwife was able to express the FTSMs' wishes to the family in a manner that did not result in any negative consequences. When the relationship was good, the FTSMs did not need to spell things out for their midwives; where it was not, the FTSMs were able to change their midwives, even during birthing.

\section{Saying Goodbye}

Studies have found that some women reported feelings of sadness, and midwives a sense of 'grief', after the end of the relationship with their mothers postnatally (for example, see Hunter, 2001; Kennedy, Shannon, Chuahorm, \& Kravetz, 2004; D. Walsh, 1999). Saying goodbye or dismissing their midwife was hard or difficult for the FTSMs.

To many midwives, depending on the level and intensity of their relationship, saying goodbye to the women they have cared for over many months was also difficult at times. Midwives talked about professional boundaries, which are a constant and taken seriously, and that some maternity relationships were more enjoyable than others: 
You've had a lot of time with the women. Ten months is a long time and, with some particular clients you are quite happy to say goodbye, but some you don't want to say goodbye to. But you have to have a boundary point to say, you know, I need to say goodbye now so they can move on. There are some women who are very clingy and quite needy and obviously you will see them for quite a bit longer if they require those services. There are some who want to take your relationship beyond the professional and that doesn't work. I think a lot of the time you just want to say it's lovely having met you for that period of time but it's time to move on. (MWW2)

The time to say goodbye occurs either at the time of the changeover in maternal health provider (at the transfer from midwifery services to a Well Child provider at any time up to four-six weeks post-birth) or just when the mother herself decides it is time. Some midwives are happy for women to maintain contact with them. One midwife reported that 'my door still remains open' and she continues to see some of her patients intermittently. In this case, the midwife recognises that the relationship they build with the mothers are relationships of trust that can sometimes go beyond the work space to the more general human space so that they become friends that mothers can confide in if they have any concerns or even if they just want to have a talk.

\section{FTSMS AND WELL CHILD PROVIDERS}

Well Child providers are health providers who give mothers support to help look after themselves and their babies when they return home. These include Plunket, Southseas Healthcare, and Tamariki-Ora which are the three Well Child providers mentioned and accessed by the FTSMs. Well Child Tamariki-Ora providers include, but are not limited to, Māori health providers, Pacific Island health providers, Public Health Services which include, for example, public health nurses, community nurses, community health workers, social workers, home visitors and Plunket (Well Child, 2011). Of the nine FTSMs who participated in a second interview, seven had registered with the Royal New Zealand Plunket Society, one with SouthSeas in Auckland and one with TamarikiOra in Wellington.

The FTSMs' decision as to which of the Well Child providers to register with was influenced by midwives, family tradition, or friends. The midwives provided the FTSMs with information about the Well Child providers available. A few of the women preferred home-based care rather than clinic-based care such as Plunket. Studies have shown that home visiting was key to the success of the nurse-mother relationship, particularly in establishing and maintaining ties between the mother and her family 
(Wilson, 2001). This sentiment was echoed by some of the FTSMs. One FTSM was particularly thankful that there was a provider who did home visits in the first couple of weeks of returning home with baby. Henrietta's son was unwell when he was born and spent his first two weeks in the neonatal ward. When they returned home from the hospital, Henrietta was concerned about his fragile health and did not want to put her baby at any unnecessary risk of getting ill or hurt by taking him out of the house. This was why she chose a Well Child provider that would do home visits:

It was kind of difficult for me [to travel] because, if it was a cold day and I had to go and see them, I had to catch a cab or catch a bus and I just don't want to get him sick. The other Well Child care people, they said they would do home visit. I don't mind Plunket but I just couldn't. I don't want to risk anything especially after what he had to go through when I gave birth. (Henrietta)

The relationship between a Well Child provider and a first-time mother was different to that of her other relationships. While the FTSMs did not go into any great detail about their relationships with these providers, most did note not being 'fussed' which Well Child provider they were transferred to or whether the provider was a Pacific provider or not. As a professional body that is responsible for providing post-birth support to first-time mothers, these providers are an important group for FTSMs and their families to be aware of. The most well-known Well Child provider among the FTSMs was Plunket.

\section{FTSMs and Plunket}

Plunket is the largest provider of Well Child services in New Zealand, with just under 55,000 newborns and their families enrolling with the organisation in 2012-2013. This accounts for 91.8 percent of births for the same period, of which 10 percent were Pacific women enrolled (The Royal New Zealand Plunket Society Inc., 2012). The first two visits by Plunket are home visits; the first occurring around two-five weeks and the second around six-nine weeks of the mother and baby's return home. The majority of transfers from midwife to a Well Child provider, at least to Plunket, occur before six weeks (67 percent) (Dwyer, 2009). The Plunket visits thereafter require the mothers to travel to the Plunket clinic closest to their homes.

The FTSMs registered with Plunket for various reasons, including family or personal history of being with Plunket, convenience of the clinics, or on recommendation from a trusted source. Geraldine's first meeting with the Plunket nurse (PN) became fairly formal quite quickly with the tone set by the PN: 
She was getting a little bit of information and I started going on and on about my birth and stuff like that, and she kind of stopped me and was like, 'I don't need to know all the details', and I was like, okay. So it's very formal with her and it's kind of just come and weigh him and do all that sort of stuff and talk about anything I have on my mind and then that's it ... yeah she's Pālagi. (Geraldine)

Geraldine, uncertain about what to expect at her first visit, started the relationship with the PN from a personal position and was initially taken back by the PN's response and level of formality. She was used to a more open relationship with her midwife in whom she felt quite free to initiate the topics for discussion and to discuss issues frankly and widely. However, she was quick to learn that her PN was different and she had to adapt accordingly. What became clear was that, unlike the relationship between mother and midwife where the focus was on her and her baby, the focus for the PN seemed primarily on the baby. Geraldine's desire to share with her PN is interesting as it illustrates a desire by women to continue to share their birth stories with others and, particularly, with those who are coming into their homes and trying to establish a relationship that is relatively long-term - at least four years.

The FTSMs had to negotiate between the health services' philosophies of professionals, such as those on child nutrition for example, and those held by their families (DeSouza, 2011). Plunket's advice to FTSMs was to put baby on solids no earlier than six months and up to a year. This differed from the advice given by some mothers of FTSMs. This conflict occurred for Geraldine:

I used the Island ways mixed with what I'm also told by the Plunket nurse and what I've read, the European ways I guess. I bring that into what I've grown up with, yeah, and I don't really listen to all the Island ways. Grandma told me to start feeding him now; he's old enough now you can start giving him some solids, she said 'just smash up a potato' you know, she's like telling me what to do but my mum is actually saying no, wait until he's six months, listen to the Plunket nurse.

Some of the FTSMs confided in their PN that they followed their mother's advice more to preserve their relationship rather than because they supported her view. Wilson (2001) suggests issues relating to 'dishonesty' are significant as they bring to the surface the power relations implicit in the nurse-mother-grandmother relationship. First-time mothers were found to lie to PN to avoid possible confrontation and questions about 
their baby's milestones. While PN do realise the diversity in childrearing practices and the complexities that surround them, and are quick to point out that their main aim is to support mothers, babies and their families, rather than to judge, they are nevertheless perceived by the mothers as being judgemental at times. This was the case for some of the FTSMs. As DeSouza $(2006,2010)$ points out there is a lot of social pressure on the mothers to do the right things. However, FTSMs reported that they did feel judged on their abilities as a mother and therefore were not as forthcoming about some of their practices as perhaps they would have been had there not been the fear of disapproval.

This chapter explored key factors that contributed to healthy, well-connected relationships: Reliability, trust, honesty, understanding and the ability to inform or transfer knowledge. The relationships were not without struggles or conflict. There were different forms of sociability, new bonds were formed, current relationships strengthened, and seeking of new social networks, i.e. seeking out others with children.

Members of the extended family had new roles and new identities created by the birth of the baby. New family connections were forged, i.e. with in-laws, the father of the baby's family, and, while cultural and religious values may clash and tensions become heightened, these conflicts needed to be worked through and each of the parties involved needed to acknowledge the existence of a relationship and its importance. In the course of the FTSMs' journey through the pre- and post-birth stages of becoming a new mother, some relationships were sacrificed; some strengthened; some just fell by the wayside.

The mother-daughter dichotomy was pivotal for many of the FTSMs, who found their mothers, regardless of the nature of the relationship pre-pregnancy, their greatest support during this significant transition in both their lives.

This chapter considered ways in which family relationships changed in the face of new motherhood. The experiences shared by the FTSMs and their mothers revealed an insight into an intergenerational experience of early motherhood and the social contexts surrounding that across two generations. It noted how FTSMs expressed difficulties growing up with an absent father and how that impacted on their decisions about how to involve the father of their baby in their upbringing. It explored the character of the relationships fostered between the FTSMs and their various healthcare professionals.

The first-time mother and maternal healthcare professional relationship happens over a relatively short period of time and, while it remains a professional one, it happens 
within an extremely sensitive and delicate space. The narratives of the midwives highlighted the differences even within the professional midwifery and nursing sectors, much of which seems dependent on the pregnancy or childbirth philosophies of the different providers.

Each of the relationships, personal and professional, discussed within this chapter centre, for their longevity and meaning, on notions of trust, respect and partnership. The FTSMs stated it was imperative that their families were incorporated in these relationships. The FTSMs and their babies were first and foremost the ones the midwives and the Well Child provider nurses were accountable for and their first line of concern, yet they had to ensure the FTSMs and their family were also acknowledged as important to any effective maternity care they offered.

On the birth of the baby, mothers become grandmothers, daughters become mothers. Their status is neither one nor the other but is in addition to their previous identities. Intergenerational transmission of knowledge: knowledge of motherhood issues (Dohmen, Falk, Huffman, \& Sunde, 2012), of young motherhood (Stanfors \& Scott, 2013), parenting; tensions between Island-born parents and their New Zealand-born children (Abel et al., 2001); and intergenerational relationship in a migrant context all play a part in understanding the maintenance and preservation of those relationships which were key to the success of a FTSM's experiences of pregnancy through to early motherhood. 


\section{CHAPTER EIGHT: DISCUSSION AND CONCLUSIONS}

First-time early motherhood for Samoan women living in New Zealand is a process of constant negotiation between two different cultural frameworks, Samoan and New Zealand. Mothers are faced with challenges in managing their transition to early motherhood. From the findings of this thesis, the transition to motherhood for FTSMs could perhaps be understood as a process of 'successful struggling' which involves understanding concepts such as resilience, negotiated spaces and the Samoan concept of the vāa, reciprocal spaces where there are expectations; there are rights and responsibilities that are constantly shifting between negotiated entities, through an ecological lens. Some of the changes and negotiations that influenced the FTSMs' maternity experiences are between themselves and their bodies, between themselves and their families and social networks, and with their health professionals, maternity institutions, and technology and social media. The process of negotiation is positioned against the stability and reliability of family and relationships.

The initial intention of my study was to build and extend on previous research on the maternity experiences of Samoan mothers living in New Zealand, not only to gain a deeper understanding of the influences that contribute to their overall experience but of how this was constructed and portrayed by the FTSMs themselves. In addition, I was interested in the coping strategies used by FTSMs to deal with the pressures or challenges they faced during this time. The thesis starting point of a strengths-based position (Powell et al., 1997) emphasizes the strengths, capabilities and resources of the FTSMs and her family and social networks.

It was clear the issue of new motherhood for these women was both simple and complex. Issues that arose from the narratives tell of a group of women who were influenced by two social systems, at times contradictory, at times competing, but most times amenable. The most significant theme to emerge from the narratives of the FTSMs' was the importance of reliable relationships during their journey through early motherhood, of preserving the relationships that exist between them and key family members, along with the professional healthcare system. The discussion in this chapter begins by retracing the three stages of early motherhood explored in this thesis: conception, pregnancy, labour and childbirth, including relationships. It ends with some thoughts on sophisticated mediators and their mediation, negotiated space, and the vā, in relation to the intricacies of how these play out within relationships and in markers 
of resilience that seemed prevalent from the narratives of the FTSMs. The chapter ends with some reflections and suggestions for ways forward of the study.

\section{Conception And PREgnancy}

I have argued that the family is an important source of support, information and learning for the FTSMs, and has a strong influence in their decision-making and behaviour in relation to their maternity journey. The input of the FTSMs' was salient, particularly the mothers of FTSMs. Culture and religion influenced the strict upbringing of many of the FTSMs, so much so that socialising outside of family events and with boyfriends were not permitted. Most of the FTSMs learnt about sex, sexual health and sexual reproductive health through family members, sisters, cousins, peers, and through school education classes. Learning about sex, sexual health, sexuality and sexual health was important for the first time mothers as they felt they were not as knowledgeable about sexual health issues compared to how they perceived their mainstream New Zealand non-Samoan peers to be. It was unimaginable to the FTSMs that talk around sex, sexual health or contraceptive use would be brought up as a topic for discussion with their parents. It would seem highly inappropriate and unfathomable to discuss these topics with parents, not least for the embarrassment and shame it would cause to them and their parents, particularly as discussion around naked bodies is considered culturally taboo.

The FTSMs' mothers talked more openly about sex and sexual health matters after the FTSMs confirmed their pregnancy. Parents faced their own roadblocks to discussing sensitive topics with their children. In this environment, the FTSMs were unsure how to initiate such conversations; some were afraid to find out about sexuality, some were ambivalent, others did not want to seem disrespectful or inappropriate to their parents, and others were just accepting that it was a no-go zone. The strong religious and cultural beliefs that advocate abstinence from sex before marriage negates the parents' need to talk openly about the issue at hand. As the narratives illustrated, these strong convictions were linked to family status and honour, and the 'embarrassment' caused by a pregnancy out of wedlock. Educational status, age, and/or high sexual health literacy, as well as knowledge of the implications of practising unsafe sex, did not seem to matter when it came to protecting against an unplanned pregnancy for the FTSMs. This has interesting implications for further research.

\section{BODY CHANGE AND SEXUAL DESIRABILITY}

Desirability and the need to be desired by their partners was a theme that emerged, particularly in relation to the FTSMs' pregnant bodies. Most of the FTSMs, through 
observation of family members or friends, expected to gain weight and saw it as part of being pregnant. There were contradictory emotions during pregnancy about their changing physical body, and some FTSMs had not expected their bodies to change much.

The relationship between body image, body changes and partner desirability emerged from the narratives as directly impacting on the self-esteem and confidence of the FTSMs. This was particularly salient during pregnancy when the body went through the most dramatic change. Desirability was not only the FTSMs wanting to be desired by their partners but also them being mindful of how their partners were feeling. This was particularly important for the FTSMs who were in fairly new relationships.

Preserving the intimate relationship with their partners was vital for the FTSMs. A perceived lack of physical attractiveness was considered a threat to the stability of the relationship - real or imagined. Open communication between the FTSMs and their partners, along with positive affirmations of attractiveness from their partners' was key to enabling the FTSMs to feel wanted, and, by and large, this helped them move through the phase with confidence and emotional security, contributing to the building of their competence and resilience in coping with the struggles of pregnancy.

\section{ECONOMIC WELLBEING VS EMOTIONAL WELLBEING}

Before pregnancy, all the FTSMs were either in paid employment or studying and working. There were varying degrees of financial struggles. All the FTSMs considered themselves to be financially independent, and for some this was made possible by living with their parents and families. The FTSMs were unprepared for the impact the pregnancy had on their financial position. Financial planning, disclosure of finances to partners, and monitoring their 'spending' was something new for many of the women. Paid parental leave was a great help and maintained the family income, and helped the FTSMs to feel that they were actively contributing towards their economic wellbeing, rather than relying on their parents and extended family members.

However, while not all the FTSMs reported financial struggles, all did comment that their financial dependence on their partners was akin to a loss of independence. This sometimes added pressure on the relationship with their partners. Over time, maintaining the household on one income became difficult and resulted in some of the FTSMs moving in with parents or family and/or for some returning to work early. This was an agonising decision for some of the FTSMs, who preferred to spend more time investing in their child, and being able to witness first-hand the developmental 
milestones rather than hearing about it from those who were taking care of their baby while they returned to the workforce. Sometimes incomes were boosted by other sources of funds, e.g. financial assistance from parents, paid parental leave, working for families. It should be noted that the FTSMs' desire to stay at home was not linked to the idea of how a 'good' mother is meant to function; rather it was about their belief that they had to be with their child. Nevertheless, while it was difficult for the FTSMs to either 'ask for money' from their partners, or parents, or even to go back to work, they accepted, eventually, that they had to make a decision and that, if they did not return to work, their contribution to the household, while not monetary, was equally important. This reflected a level of acceptance of the transition to a 'new norm' for them.

\section{PREGNANCY PLANNING AND ABORTION}

A very interesting theme that emerged from this study is that of an ambivalence towards unplanned pregnancies. Most of the FTSMs' pregnancies were unplanned. Not planning to become pregnant but not planning to avoid pregnancy seemed an oxymoron. The casual use of contraceptives meant FTSMs ran the risk of becoming pregnant, thus their surprise was interesting. The FTSMs described their becoming pregnant as a situation of 'mistiming' rather than a mistake or anything else. To describe it as a mistake was considered too negative and they were clear that they did not think it was something bad. The FTSMs were adamant they did intend to become pregnant in the future, but not quite at that moment. Similarly, unplanned was often perceived by the FTSMs as unwanted, whereas for them, babies were welcomed and wanted. This distinction needs to be considered when discussing the issue. The FTSMs discussed the desire for more children in the future, but vowed their next pregnancy would be well planned, contrary to their first. Abortions were discounted from the outset by some of the FTSMs, while for others it was a serious option.

Religion was an important part of life for most of the FTSMs. They all commented on the religious aspect of their upbringing, and that this influenced the way in which some of them discounted abortion as an option for the unplanned pregnancy. Other FTSMs said they had seriously considered abortion as a viable solution to their unplanned pregnancy if their partners did not commit to parenting with them, as they did not want to become single mothers.

\section{LABOUR AND CHILDBIRTH}

The FTSMs understood labour and childbirth through their own expectations of what was to come based on stories from others' experiences, including their own mothers, aunts, cousins, friends, in-laws, siblings, and from what they were told by the maternal 
healthcare system and picked up from their own research. The FTSMs' narratives revealed that being in control during labour and childbirth was important. Control was conceptualised as the women having internal control, that is of her own behaviour and coping mechanisms, and external control, which was feeling in control of the birthing environment and of the decision-making processes associated with the birth rather than relinquishing this to the midwife or obstetrician.

The FTSMs were cognisant of the fact that when they went into labour they wanted to be in control of the whole process, but that sometimes that may not be possible, or appropriate. There is a level of personal confidence that the FTSM must have in order to take full charge of the situation, even in the most straightforward of cases. Within the phenomenon of labour, there is always the risk of complications and the mother, who is undergoing significant trauma to her body, will, at the best of times, find it extremely challenging to always stay in control throughout the process. It is not surprising, therefore, that the FTSMs trusted their health professionals implicitly, particularly their midwives. The knowledge and advice given by the midwife was valued by the FTSMs. At times, there were clashes between the beliefs of the FTSMs and their midwives about when they were actually in labour. This was to be expected and, even if the midwife's error during labour was hard to take for a FTSM, after the birth the FTSM was usually able to restore the relationship, restore the vā between them.

\section{EARLY MOTHERHOOD}

\section{NEW SUPPORT SYSTEMS AND TECHNOLOGIES}

There is a need to provide or look for innovative ways to help Pacific mothers increase their communication with health professionals and keep them updated with resources to ensure their health and wellbeing during pregnancy, childbirth and early motherhood. Technology in the way of the internet and cell phones was part of the FTSMs' support system. Recent initiatives by the health sector to increase Pacific mothers' antenatal engagement have included social media technology to reach and entice Samoan women to attend. Smartphone Apps have been specially tailored and marketed for Pacific mothers. The App provides information leading up to, during and after the pregnancy with features that include information about how to search for a midwife, find advice on their pregnancy, and tips for caring for their baby.

Other initiatives, such as the Taha Well Pacific Mother website, aim to improve health outcomes for Pacific women during pregnancy, childbirth and early motherhood. In future, it would be interesting to evaluate what impact these technological advances in communications have had on the maternity experiences of Samoan women. 
The utilisation of social media for Samoan first-time mothers has huge potential. FTSMs were more likely to consult with Google before they sought help from their GPs or other health professionals. There are various reasons for this, including cost, convenience, accessibility, and because they did not want to appear as over-anxious mothers.

While technology initiatives are a new form of resource that is becoming popular and preferred by many women, it is not a substitute for human or physical contact. Samoan people are dependent on physical, human contact which is critical in maintaining relationships. When developing maternity educational services, there is an emphasis on face-to-face contact or at least in-person by telephone contact. Making decisions on the appropriateness of approach to Samoan mothers needs to take into account age, Islandborn or New Zealand-born status, education, employment and household income.

\section{DEALING WITH UNMET EXPECTATIONS (EXPECTATIONS VS ACTUAL EXPERIENCE)}

The impact of unrealised expectations may be manifested as postnatal depression. Research (for example, see Darrah, 2011; Forster et al., 2008; Gibbins \& Thomson, 2001; Knight \& Thirkettle, 1987) suggests that the mismatch between the woman's prenatal expectations and the postnatal experience can result in postnatal distress (PND). PND can be debilitating and have devastating effects for the woman, child and her family. Experiences and expectations, while separate cognitive entities, are themselves related. There are areas of overlap in what Darrah (2011) argues is an area of intersect between a women's prenatal expectations and their subsequent postnatal experiences. The overlap represents events which have been realistically considered by the women and, therefore, the postnatal experience is predicted and is likely to result in a positive transition to motherhood that is merely a positive adjustment. Postnatal distress occurs if there are large areas where the expectations and experience do not overlie. However, as Darrah concedes, one cannot accurately foresee how a person is going to react to an event. Many of the FTSMs commented on either knowing someone who had depression or of reading about it in books or seeing it on television. They discussed feelings of being down but related this to 'normal' relationship issues and physical exhaustion which they felt was part of the birth. In the main, while they suggested that their expectations did not match their birth or early motherhood experiences, the FTSMs accepted that their early expectations may have been unrealistic and did not dwell on whether they matched their experiences or not. 


\section{NEW NORM}

The FTSMs identified themselves as New Zealand-born Samoan; most were second generation, some were third generation. All viewed their homebase as New Zealand but they had a strong affinity with the Samoa homeland of their parents. The FTSMs talked about finding a balance between the two cultures which was 'sometimes difficult'. Their narratives illustrated an awareness of their identities as New Zealand-born Samoans. The indigenous epistemology of the FTSMs was constructed from the world view (or position) of those who had influence on their lives, i.e. family (mother, aunt, grandmother), school, friends, work, and the public and maternity health system. The indigenous knowledge of pregnancy and motherhood may be a combination of both traditional knowledge and knowledge they gained growing up in a Western society, thus perhaps a new way of 'being Samoan'.

Samoan people's world view is inspired by their surroundings and cultural belonging, and their relationships with others. Traditional and cultural influences (for example, cultural customs, church, family members) had a place in the lives of the FTSMs, and their construction of what pregnancy, childbirth and early motherhood was, was influenced by these. Reconstructing their world and themselves following childbirth was a process. It was a process of trial and error as the FTSMs attempted to cope with their new role and responsibilities of motherhood.

Following childbirth, the status of the women changed, instantly she became a mother, and expected to be responsible, if not for herself, then for her new baby. Motherhood is now the new norm. 'Time for self' was a past concept for the single person. However, in the narratives of the FTSMs, they talked about the importance of having time to themselves as mothers to do the things they used to enjoy before they became pregnant, to catch up with friends or family or to rest, so as to ensure that they kept themselves well. Ensuring they had time to themselves featured significantly as part of their 'selfcare' regime. Having this time away from their baby meant they were able to be better mothers, partners and daughters.

\section{SOPHISTICATED MEDIATION, NEGOTIATED SPACE AND THE VĀ}

The maternity journey for the FTSMs was viewed through the theoretical concepts of sophisticated mediation, negotiated space and the vā. The negotiated space is powerridden and, where there is power, there is a need for checks and balances against the unequal distribution of that power. This is something strongly advocated for by feminist and indigenous scholars. 
Indigenous scholars, such as Albert Wendt (1999) and Karlo Mila-Schaaf and Maui Hudson (2009a), suggest that the spaces that first-time Samoan mothers journey through in their first early motherhood experience are spaces that are constantly negotiated, but in ways shaped explicitly and implicitly by Samoan epistemological values and ideologies and New Zealand society in all their various manifestations over time. The most central of these values and ideologies is the value and ideology of family.

Social constructions of family are made sense of and practiced by first-time New Zealand-born Samoan mothers in terms of their understandings of family, their responsibilities to family, and the responsibilities of their families to them. Family was a significant influence in the lives of FTSMs and impacted, as expected, on their perceptions of Samoan and New Zealand approaches to, and on their own sense of self, as a new mother. In all of this, the FTSMs, as Patricia Hill Collins (1986) describes, mediate and negotiate in sophisticated ways the active spaces or vā implicit in the relationships they must care for, from those involving the maternal healthcare system, to those within their wider and immediate family circles, to that between themselves and their newborn baby and their changing body.

The many varied and competing relationships that operate within the vā are constantly being negotiated by these FTSMs and in ways that, as their experiences attest, are not straight-forward, i.e. it is a struggle. However, at the same time, the women succeed through their struggle by tapping into a resilience that seems rooted in their family support and which may also help temper a susceptibility to depression. Recognition that the vā is a concept and space that is embedded in Samoan family epistemology is a necessary starting point. It is a space occupied by relational ideals that draw from the way families relate to each other, the way they prioritise roles and responsibilities, the way they resolve disputes, the way they practice spirituality, religion, and culture. In tracing how first-time mothers experience this early stage of motherhood, this study gives insight into 'the how' of how these FTSMs coped, using their own voices to tell of 'successfully' negotiating these relational spaces immediately before and after having their babies.

The notion of sophisticated mediators thus refers to individuals mediating between the inherited Samoan value and belief system and the New Zealand value and belief system. The way in which the women used 'space', their space, performed their interactions in the vā, was largely by selecting the most appropriate and fitting offerings 
from both cultural systems that would enable them to develop into independent, confident, successful, and capable women and mothers. This was not to say they were not faced with difficulties and barriers, or were not tested throughout their maternity journey, quite the opposite. Many struggles were faced by the women, whether relational, emotional, financial, psychological, or cultural. But they 'struggled well', that is, they experienced suffering but had the courage and worked effectively through difficulties, both internally within themselves and interpersonally, in their relationships with others (F. Walsh, 2006, p. 6).

Sophisticated mediation is closely linked with resilience, which is the capacity to adapt successfully in the face of adversity. The terms 'merged knowledge' and 'cultural fusion' articulated the blending by the women of their Western and Samoan worlds. These are particularly relevant for the FTSMs who, I would argue, synthesise knowledge from two separate systems but mediate between the two to construct their own understanding and knowledge of pregnancy, childbirth and motherhood. Becoming pregnant and developing into a mother for the first time is, therefore, an experience of constant negotiation and mediation, regardless of whether the pregnancy was planned or unplanned.

Sophisticated mediation is a behaviour that requires the 'agent' or the individual to have the ability to operate with deliberation and tact in order to meet their purposes and/or needs. This thesis supports Tupuola's (2004b) articulation of the presence of resilience in young people who 'walk' between cultures and often on the edges of those cultures. Tupuola argues that 'edge-walkers' learn to develop coping mechanisms that promote 'cultural shifting' as a positive, character-building, strength-building, rather than negative risk-based, exercise.

\section{RELATIONSHIPS}

The research generated a strong case for the importance of relationships, of knowing how they worked, how they strengthened the participants within those relationships, of how they might have been unhealthy, but mostly about how they were core to the FTSMs' 'struggling successfully' and being resilient as first-time mothers. What is clear is that mothering for the FTSMs was done with others. As such, the relationships they formed with these others were important. Relationships with significant others, whether biological or not, and with health professionals were pivotal in their maternity experiences. Relationships were typified by trust, reliability, honesty and compromise. 
The most prominent relationship for the FTSMs was that between them and their families followed by those within their wider environments. The meaning of family was not restricted to immediate family, but immediate family was important, especially parents and, within that, especially mothers. In the Samoan context for these FTSMs, family relationships included those with partners, with their partner's family (in-laws), with their own birth parents, with cousins and aunts. These familial relationships were always mediated by assumptions of caring for the vā. In practice, these often translated into caring for another's feelings or wellbeing; being sensitive to their idiosyncrasies; and caring for the needs of the collective over the individual.

The vā can be a vague entity but, fundamentally, it relates to the idea that there exists between two distinct entities a space that connects, as Albert Wendt posits. There is a ripple effect in the way in which the vā works. If there is a perceived breach in one space, all other related spaces are also bound to be affected. These tensions can be resolved by the different parties being open to dialogue, to mediating and negotiating their respective positions, to compromising for the sake of collective peace. Connectedness and cohesion are important characteristics in family resilience. Families function best when they know they can rely on each other in times of crisis.

\section{FAMILY}

Female members of the family, such as mothers, sisters, aunts, were instrumental in assisting the FTSMs to build their knowledge base and to make sense of their first-time experiences of being a mother. These female supporters were important mentors to the women, particularly if they had experienced motherhood themselves, e.g. women are more likely to consider breastfeeding their babies if that was what their mothers or grandmothers or great-grandmothers did, and did successfully. These intergenerational relationships were important, especially where the older generation shared their specific maternity knowledge with the younger generation. As the FTSMs became more competent and confident, the type of support and knowledge they were given altered to suit their changed situations. While they did not always access all the family networks available, the fact they were available gave the women confidence to seek help. All FTSMs were part of a larger family network that included extended family, friends and work colleagues, even going so far as 'cyber' friends via specific websites aimed at supporting new parents. Friends were considered cousins; cousins were considered friends. The social networks were very important and, for many, it meant that they were not alone, as there was always someone they could confide in or a place to go to. 
The power of family and friendship ties was an important aspect in the experience of the maternity journeys of the FTSMs. Their everyday lives were governed by the needs of their families and, to some extent, this influenced the way in which the women made decisions about how exactly they should mother or carry out a specific task associated with mothering.

The relationships of the FTSMs were relationships of strength. This was most evident when, despite not having or feeling like there was a close relationship with their mothers pre-pregnancy or pre-birth, new relationships with their mothers were founded postbirth, one based on a new admiration for what the FTSMs perceived their mothers went through themselves in childrearing. The deeply held beliefs of some parents that conceiving children should be within the sanctity of marriage compelled them to convince their daughters to marry and, for a short period of time, this created stress in their relationships. However, families were willing to work out a solution together, illustrating family resilience as they dealt with the intergenerational and cultural differences in beliefs, attitudes and values.

All the FTSMs shared a profound desire to maintain their parents' love and approval. The narratives of the mothers of the FTSMs were equally revealing in their aspiration to provide the love, care and resources to support their daughter during their transition to first-time motherhood. Interestingly, the mothers of the FTSMs marvelled at the level of closeness they shared with their daughters, which was so different to the relationships they shared with their own mothers. Stories told by the mothers of the FTSMs were framed by sadness, lack of support, isolation and barriers to good maternity care. Their experiences modified the way in which they related and supported their daughters, as they did not want their daughters to experience similar difficulties and barriers. However, at times the support given by the mothers of the FTSMs was allconsuming, and at times perceived by the FTSMs as overwhelming. The narratives of the FTSMs and their mothers about their relationships highlighted intergenerational shifts and continuities.

Grandparenting is an intrinsic part of Samoan culture and grandparents are revered within the Samoan family. The phenomenon of grandparents raising grandchildren is not new within Pacific culture and is comparable to an informal adoption, more often than not driven by single parenthood and/or economic reasons (see Ofahengaue Vakalahi, 2011; Yancura \& Greenwood, 2013). The adoption or sole care of the grandchild by the extended family or grandparents is based on the high value placed on children in Samoa (see Churchward, 2011; Stewart-Withers, 2011b). Grandparents share 
in the development and growth of the grandchildren and this is linked to their cultural belief that grandparents have a wealth of knowledge that can link grandchildren with their past (Ngan-Woo, 1985). It is believed to be beneficial for not only the child but also the parents and grandparents. All the FTSMs were on good terms with the parents and most times with their in-laws, and these grandparents were instrumental in the lives of the new grandchildren.

\section{PARTNERS}

All the FTSMs, except for one, were in a relationship with the father of their baby and had been from the time they confirmed the pregnancy until their last interview postbirth. The relationships varied in stability, i.e. some FTSMs were no longer cohabitating with the partners but still considered themselves a couple. The partners featured significantly throughout the FTSMs' narratives as a salient part of their experiences in the transition to motherhood. The FTSMs talked openly about difficult times with their partners. FTSMs in relatively new relationships had the additional pressure of having to get to know their partners quite quickly after finding out they were pregnant. Some who had not lived with their partners beforehand found learning to be a couple, in addition to learning to be parents, was not easy.

The FTSMs articulated the importance of their baby's father being present in their lives; not only as their partners, but also as the co-parent to their child. While their partners' financial and practical support was appreciated, it was, more importantly, the emotional support and reassurance that they were doing a good job as mothers that the FTSMs spoke a lot about.

\section{HEALTH PROFESSIONALS}

LMCs and Well Child providers played a major, albeit short-term and intensive, role in the maternity experiences of the FTSMs. Engaging with the right midwife was an important, if not major, factor in developing a sense of capability and control in the FTSMs' transition from pregnancy to impending motherhood. It was vital to maintain trust and respect in the relationship between the FTSMs and their health professional, and, if either of these were compromised or were not present, the relationship broke down and the FTSMs replaced the health professional with someone else. It was essential that the health professionals maintained a key role in the maternity experiences of first-time mothers, which could involve mediating between the FTSMs and their families. 


\section{RESILIENCE}

Resilience, both individual and collective, was an important component within this thesis as I argue that the FTSMs illustrated individual resilience as well as being part of families who characterised collective resilience. Resilience is considered a characteristic of both the individual and the quality of the environment from which resources are drawn. Maintaining a support system through nurturing important relationships helped FTSMs and their families develop resilience.

Conflict and change are a part of life, as is tradition and continuity. Resilience was not about facing adversity and getting over it; it was about how the mothers and their families coped with adversity. Pregnancy, childbirth and early motherhood were events that were met with happiness, disappointment, joy, confusion and overwhelming stress as families juggled expectations and experiences. The maternity journey tested the resilience of the FTSMs and their families, but they managed to struggle successfully together and achieve a positive outlook.

A key component of this research drew from previous research (Churchward, 2011) that found first-time Samoan mothers' positioning firmly placed between what was considered 'traditional' and what was considered 'Western ways' of thinking. AnneMarie Tupuola (2004) writes about the maturation of Samoan young women and argues that the Western notion of 'human development' as defined in popular psychology texts challenged how Samoans viewed adolescence. She found that many of her participants seemed to 'associate their maturation process with cultural and familial expectations and had some difficulty identifying with a concept that seemed age-defined and progressive in nature' (ibid. p. 162). Some of the behaviours the FTSMs exhibited in terms of planning their pregnancies (or not) mimicked some characteristics of unplanned teen pregnancy, in that they were mostly unmarried, attended only a few, if any antenatal classes, and were inconsistent with contraceptive use. The similarities between Tupuola's findings and mine are worth exploring further. 


\section{Resilience in context: an ecological perspective}

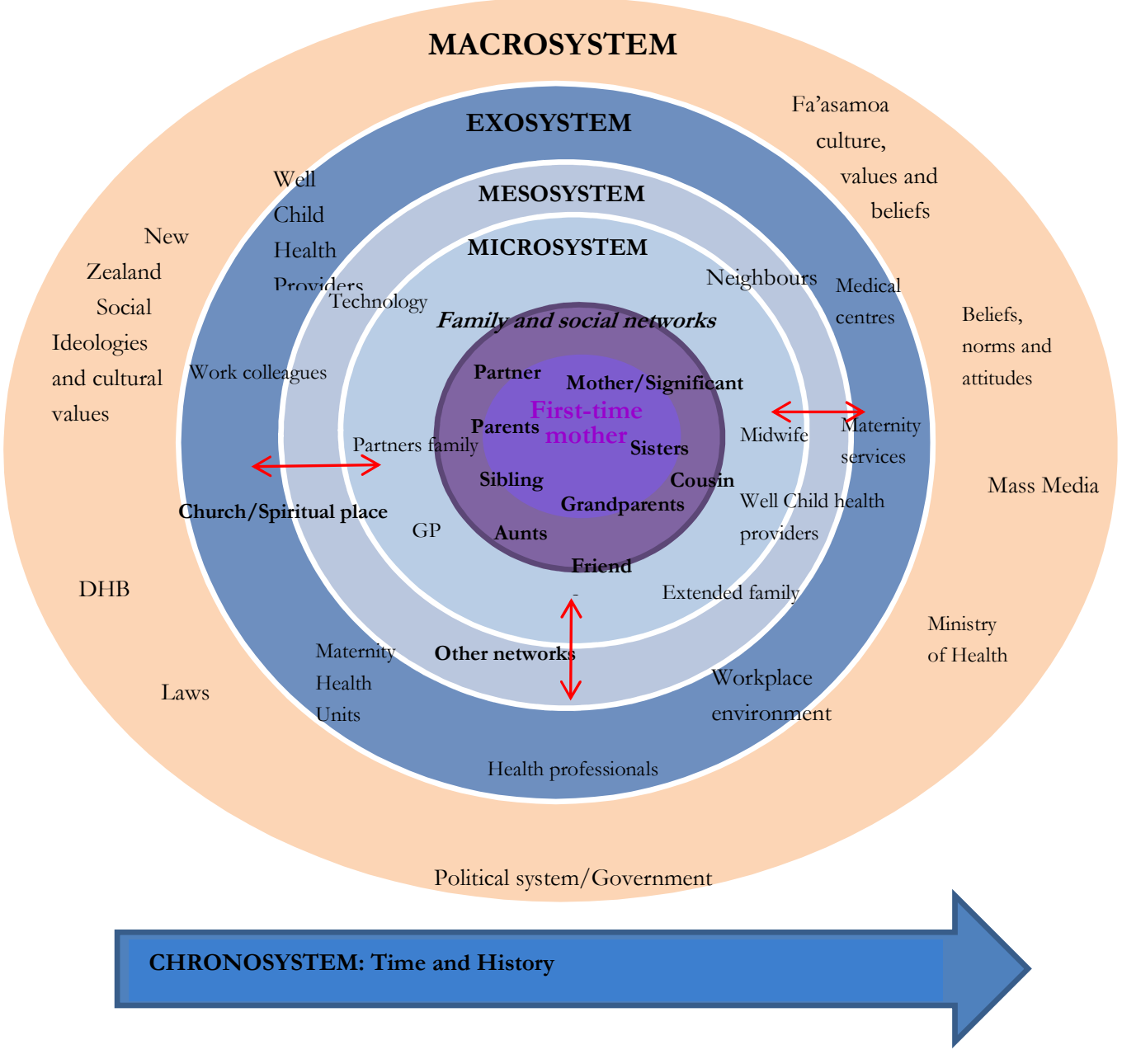

Figure 2: A social ecological model for Samoan women's experiences during first-time motherhood

Relationships between the first-time Samoan mothers and others were key features throughout the thesis. Ecologically, as depicted in the figure above, relationships within the microsystem were crucial to the women. Within the concept of mothering and of being a mother, when the FTSM became a mother the balance changed within the mother-daughter connection. The grandmother was concerned about her daughter (now a mother herself) and wanted to advise and protect her in her new experience. Most of the time, the advice and protection was welcomed by the FTSM, or at least tolerated in order to preserve the mother-daughter relationship.

The adapted ecological model (Figure 2), or circle of influence, was used to explore and make sense of a range of potential factors that were perceived as influencing the women's maternity knowledge, health and wellbeing; and transition to motherhood. The 
microsystem clarified that maternity experiences of the mothers (pregnancy, childbirth and motherhood) are influenced through multiple levels including the: (1) Microsystem; (2) Mesosystem; (3) Exosystem and (4) Macrosystem underpinned by the (5) Chronosystem (Urie Bronfenbrenner, 1994).

At the microsystem level, the FTSMs feature at the centre of the model. The inner circle is shaded rather than specifically bordered to illustrate the intricate and close relationships the FTSMs shared with their mothers, or significant other, and family during their maternity journey. The family members were reliable and saw the new family member (the newborn baby) as much their responsibility as a family as were the parents. The grandmothers or significant other featured prominently from the time the FTSMs confirmed their pregnancy, and maintained a strong influence throughout the maternity journey.

The centre of the ecological model for Samoan women experiencing the birth of their first child is family. Family members, in particular grandmothers and significant others were core in the developmental transition from women to mothers. Further, the interaction with family and the quality of these relationships had the greatest influence on the mother's own resilience. The family support that surrounded the FTSMs promoted not only individual resilience, but also family resilience. The relationships are bi-directional; that is, family and grandmothers affect FTSM's behaviour and the FTSM's characteristics, personalities and capacities also affect family and the mother's behaviour. A theoretical model to explain the ecological world of the first-time mothers was used here to illustrate the way in which each system that the FTSM was a part of worked in relation to each other.

Each domain contributes significantly to the experience of FTSMs. During particular stages of the maternity process, the significance of different people changed, e.g. in the health professional space, during the pregnancy, childbirth and early weeks of postbirth, the LMC plays a major role in the lives of the FTSM; after those first few weeks, the care is then transferred to the Well Child health provider. The narratives suggest that the maternal transition begins at the point where the pregnancy is confirmed. The woman's relationship with her partner changes after pregnancy is announced and then again at the birth of the baby. From that stage on, they go from being a couple to being a family.

It was evident there were multiple influences in the women's lives that were contributing to their maternity experiences. Different stages of their maternity journey involved 
several people, and various services, at different times. It was important to highlight these in diagrammatic form, as it enables a visual representation of the different relationships and environments involved as well as how they interact with each other or not. During the stage of pregnancy, for example, one can see how maternity services were first accessed, when and where midwives were appointed, how certain relationships were more core than others and when they might change.

\section{SUGGESTIONS FOR WAYS FORWARD}

This research provided insights into the experiences of first-time mothers which can be drawn on to inform guidelines, programmes and policies not only for Samoan families but also for first-time mothers in general. The theories and models utilised can also be used in future research investigating experiences of motherhood, especially with other groups that have similar values, beliefs and world views.

Recommendations from this research and the way in which it could improve areas of the maternity system follow:

- Online websites mothers can join should include a chat area where they can ask questions, share stories or read articles. Antenatal groups, as they are currently structured, do not work. The FTSMs were not interested in getting together with a group for various reasons - time of the classes, they were uninterested in being with strangers, or the women had large accessible networks of family and friends.

- A system needs to be developed for choosing an LMC that is acceptable to all prospective parents. Providing a list to first-time mothers with the names and numbers of midwives where the mothers need to systematically go through to choose an available midwife, as is currently the case, is not acceptable.

- First-time fatherhood is often overlooked. The FTSMs articulated the importance of the presence of the father in not only their child's life but also in their lives. Seven of the 11 FTSMs had partners who were also of Samoan descent. It would be interesting to explore the experiences of first-time fathers, an often neglected viewpoint.

- The economic wellbeing of the FTSMs and their families was important, and was the point of difference for some women in having to return to work earlier than anticipated. Increasing income in some way, particularly for first-time parents, can create opportunities and choices for families.

- Serious gaps in communication between maternity hospital staff and first-time Samoan mothers need to be addressed. Communication is salient in all aspects 
of the first-time mothers' lives, particularly in unfamiliar environments such as the hospital. Lack of communication left mothers feeling unsafe, vulnerable and tainted the positive experience of childbirth. The manner in which they were treated was highly unethical and totally avoidable. The problem may lie in the organisation, with systemic issues such as a lack of staff rostered on shifts or lack of knowledge of the needs of first-time mothers; therefore, this serious issue must be addressed at the policy level. The ability of health professionals to make mothers feel supported and safe is of utmost importance, and building relationships is vital.

- Co-sleeping and bed-sharing is happening. Some of the FTSMs talked openly about bed-sharing with their babies for its convenience, particularly if they were breastfeeding, or as part of bonding with their new baby. However, when the mothers were asked by the health professionals if they bed-shared, the practice was denied for fear of being shamed or being told to discontinue. The differences in bed-sharing may be cultural and environmental and these factors need to be taken into account when providing postnatal education. Currently, health professionals do not promote bed-sharing and provide the first-time mothers with oral and written advice. Advice on co-sleeping/bed-sharing needs to include different strategies or options for the mothers to try, reassurance to the mothers that children are safe, secure and happy in their own beds, or promoting the use of Moses beds.

- Further research around the intention to become or avoid getting pregnant is required. My study illustrated that contraceptive use and knowledge does not necessarily mean women will plan their pregnancies. Pregnancies that are unplanned but not unwanted happen. Most of the FTSMs were well educated, independent, and confident users of various contraceptives as their preferred method of birth control, yet the majority of pregnancies were unplanned. 


\section{REFLECTIONS}

Throughout the research, I felt a sense of responsibility to present the stories of the women in a way that was not only genuine and sensitive, but made their voices become visible and transparent. The information they shared with me was not only very personal but at times complex; there were times of long pauses when participants needed moments of silence as they recalled events that were particularly upsetting, other times where there were roars of laughter! Most of the FTSMs and their mothers commented that sharing and expressing their experiences felt 'therapeutic' and they could not imagine why anyone else would be interested in their stories. The FTSMs and their mothers felt especially appreciative of being able to share everything and anything in a safe space, but, more importantly, all the participants were pleased to know that their information had the possibility of helping other first-time mothers cope with the transition to motherhood. Reflecting back on the process, I feel privileged to have been part of this journey with the respondents.

\section{Motherhood is a natural process.}

Motherhood is a family affair.

Motherhood is a struggle.

Motherhood is a strength. 


\section{APPENDICES APPENDix ONE: PARTICIPANT INFORMATION SHEET}

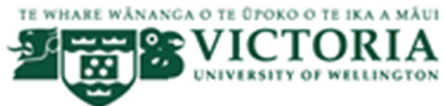

Title: An investigation of the intersection between resilience and risk factors for firsttime Samoan mothers living in New Zealand during pregnancy, childbirth and early motherhood.

I am a PhD candidate with Pacific studies at Victoria University of Wellington. As part of this degree, I am undertaking a research project leading to a thesis. This research project has obtained ethics approval from the Multi-Region Ethics Committee, Wellington. The research project I am undertaking involves exploring factors that may affect the health and wellbeing of first-time Samoan mothers living in New Zealand during late pregnancy and post-birth (up to 12 months after the birth of their baby), the impact of childbirth on the emotional wellbeing of women, and also the strategies these women utilize to cope with motherhood. I am interested in maternal knowledge that is passed down from mother to daughter, and the influence of 'others' during the antenatal and postnatal period, e.g. midwives, Plunket nurses. I am also interested in the range of support systems that Samoan women may utilize and their decision-making around accessing these systems. This research will give us an in-depth understanding of the experiences of first-time Samoan mothers. The research will be conducted with Samoan women living in New Zealand.

The research will give us a chance to discuss ways to help other Samoan first-time mothers cope through pregnancy and early motherhood. The information provided will also give us a better understanding of what services or support will help other women and their families and may lead to services that are culturally appropriate and safe.

The individual interviews will take between one and one-and-a-half hours and will be arranged at a time and place of the participants' choice. Participants are welcome to bring/have a support person(s) with them during the interview. For first-time mothers, there will be two interviews - (1) in their last trimester of pregnancy; and (2) up to 12 months post-birth. For mothers of the first-time mothers, midwives and Plunket nurses, there will be one interview only. All participants will receive a voucher of their choice as a token of appreciation.

The information provided will be kept confidential that means participants; will not be able to be identified, and the information will be securely stored. All results will be presented in an aggregated form and every attempt will be taken to maintain confidentiality of participants' identity. However, as participants are drawn from a small community, there is always a very slight chance they may be recognized by someone who knows them well. Participation in this research is voluntary and participant's can withdraw from this research up to two weeks after the interview.

About the researcher: My name is Marianna Churchward, I was born in New Zealand, both my parents are of Samoan descent, I identify as New Zealand Samoan and I am the mother of three children. My contact details are: 


\section{APPENDIX TwO: CONSENT FORM FOR FTSM, AND THEIR MOTHERS}

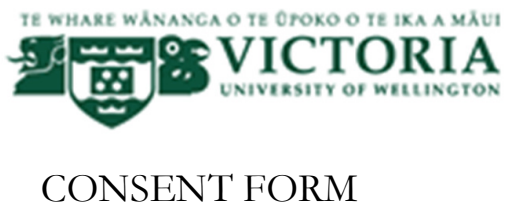

Title: An investigation of the intersection between resilience and risk factors for first-time Samoan mothers living in New Zealand during pregnancy, childbirth and early motherhood.

I have read the information sheet and have been given the opportunity to ask any questions I may have and these questions have been answered to my satisfaction.

I agree to be interviewed twice by Marianna Churchward. My interview will be recorded and stored in a password folder on a secure hard-drive, and destroyed 3 years after the completion of the PhD thesis.

I understand that you may want to speak to my mother to get her perspective which I am happy for you to do so.

Her contact details are: Name:

Address:

Phone/Email:

I understand that the recordings will be heard and transcribed will be read only by Marianna Churchward. I can withdraw information from the study up to two weeks after the interview without any future consequences.

I understand that all the information I provide will be kept confidential. The de-identified data I provide will only be used by Marianna for her thesis and related publications. If at any time during the interview I am feeling uncomfortable or distressed I will let Marianna know immediately and we can stop the interview and continue at a later time or date. I understand I will be given a list of agencies I can call if I feel distressed after the interview.

PHOTOS: I agree to photos of myself and my baby being taken and possibly included in the final thesis. I understand the photos might form a part of a montage.

PLEASE SIGN HERE:

Signed: Interview $1 / 2$ (please circle)

Name: Date:

Baby's name and DOB: Cell phone number 


\section{APPENDIX THREE: CONSENT FORM FOR KEY INFORMANTS}

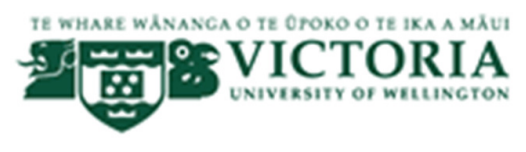

\section{CONSENT FORM}

Key Informants

Title: An investigation of the intersection between resilience and risk factors for firsttime Samoan mothers living in New Zealand during pregnancy, childbirth and early motherhood.

I have read the information sheet and been given the opportunity to ask any questions I may have and these questions have been answered to my satisfaction.

I agree to the digital recording of the interview and understand that copies of the recordings will be kept in a password folder in a secure hard-drive, and destroyed three years after the completion of the $\mathrm{PhD}$ thesis. These recordings will be heard and transcribed only by Marianna Churchward or a transcriber. I may withdraw information from the study up to two weeks after the interview without any future consequences. I understand that all the information I provide will be kept confidential. The deidentified data I provide will only be used by Marianna for her thesis and related publications.

If at any time during the interview I feel distressed I will ask Marianna to stop the interview and continue at a later time or a later date.

PLEASE SIGN HERE:

Signed:

Name: Date: 


\section{APPENDIX FOUR: INTERVIEW CHECKLIST: FIRST-TIME MOTHERS ANTENATAL}

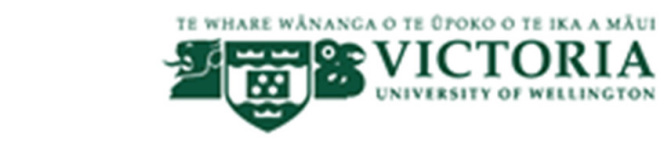

Interview Checklist First-time mothers ante-natal

Title: An investigation of the intersection between resilience and risk factors for first-time Samoan mothers living in New Zealand during pregnancy, childbirth and early motherhood.

Phase 1: Last trimester of pregnancy

\begin{tabular}{|c|c|}
\hline Theme & \\
\hline 1. Self & $\begin{array}{l}\text { Tell me a little about yourself: } \\
\text { Prompts: Hobbies, family, friends; Identity; Language; } \\
\text { Relationships }\end{array}$ \\
\hline Knowledge of your body & $\begin{array}{l}\text { Tell me about what you know about how your body } \\
\text { works? } \\
\text { Prompts: Knowledge; Changing bodies/Periods; Sex } \\
\text { education }\end{array}$ \\
\hline $\begin{array}{l}\text { 2. Decision to have a } \\
\text { baby }\end{array}$ & $\begin{array}{l}\text { Most pregnancies among Pacific women are } \\
\text { unplanned ...I would like to talk about the decision or } \\
\text { reasons behind having a baby: } \\
\text { Prompts: Relationships; First pregnancy/child?; Planned } \\
\text { with partner; Contraception; Lifestyle }\end{array}$ \\
\hline 3. Getting pregnant & $\begin{array}{l}\text { Samoan women have very high fertility rates, however for } \\
\text { some not getting pregnant can be an emotional } \\
\text { experience. } \\
\text { Prompts: Conceiving - any problems?; Medical } \\
\text { intervention? }\end{array}$ \\
\hline 4. Pregnancy & $\begin{array}{l}\text { Some women feel ambivalent about their pregnancies, } \\
\text { while others are certain about what they will do once their } \\
\text { pregnancies are confirmed. } \\
\text { Prompts: Feelings about pregnancy, yours, others; Impact } \\
\text { on you; Telling others; Doubt about the pregnancy? } \\
\text { Options? }\end{array}$ \\
\hline 5. Physical & $\begin{array}{l}\text { Women's bodies are different in how they respond to } \\
\text { pregnancy, how did you feel about the changes; how did } \\
\text { they impact on your lifestyle }\end{array}$ \\
\hline
\end{tabular}




\begin{tabular}{|c|c|}
\hline & $\begin{array}{l}\text { Prompts: perceived body change; health and wellbeing in } \\
\text { terms of food and physical exercise; work }\end{array}$ \\
\hline 6. Experience & $\begin{array}{l}\text { Let's talk about your pregnancy experience. Can you } \\
\text { describe what it has been like physically, emotionally, } \\
\text { spiritually and socially? Explore the experience. } \\
\text { e.g. a difficult pregnancy - what do you think made it a } \\
\text { difficult pregnancy, and what strategies did you adopt to } \\
\text { get you through?; an easy pregnancy - what do you think } \\
\text { contributed to your 'easy' pregnancy? }\end{array}$ \\
\hline 7. LMC & Tell me about your experience finding a midwife/LMC? \\
\hline $\begin{array}{l}\text { 8. Cultural/traditional } \\
\text { beliefs }\end{array}$ & $\begin{array}{l}\text { There are some women who think some beliefs about } \\
\text { pregnancy are specific to the Samoan culture, what do you } \\
\text { think? } \\
\text { e.g. Placenta (knowledge: beliefs); Fofo/Traditional } \\
\text { Samoan massage (knowledge: beliefs); Others }\end{array}$ \\
\hline 9. Support systems & $\begin{array}{l}\text { Support systems vary for each woman, for some it may be } \\
\text { family, for others work colleagues. There are two types of } \\
\text { support systems I would like to explore - formal and } \\
\text { informal. Formal support might include your midwife, } \\
\text { informal may be your mother-in-law,or social forums } \\
\text { including chat groups on the internet. }\end{array}$ \\
\hline 10. Resilience & $\begin{array}{l}\text { Resilience is described as someone who has the ability to } \\
\text { succeed or prosper after facing setbacks and hardships. } \\
\text { e.g. Facing challenges; Coping under stress }\end{array}$ \\
\hline 11. Expectations of labour & $\begin{array}{l}\text { Expectations of birth? What are your expectations of } \\
\text { your birth }\end{array}$ \\
\hline 12. Feelings of sadness & $\begin{array}{l}\text { - } \text { previous history of depression } \\
\text { - postnatal depression }\end{array}$ \\
\hline 13. Mothers' birth stories & $\begin{array}{l}\text { Do you know about your mother's birth or can you tell me } \\
\text { any birth stories in your family? How much influence does } \\
\text { your mother have regarding your pregnancy? }\end{array}$ \\
\hline $\begin{array}{l}\text { 14. Expectations of } \\
\text { motherhood }\end{array}$ & $\begin{array}{l}\text { What are your expectations of motherhood? I would like } \\
\text { to talk about your expectations of motherhood? }\end{array}$ \\
\hline 15. Other Comments & \\
\hline
\end{tabular}




\section{APPENDIX FIVE: INTERVIEW CHECKLIST: FIRST-TIME MOTHERS POSTNATAL}

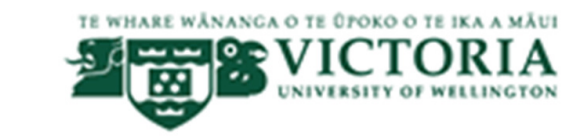

Interview Checklist

First-time mothers post-natal

\section{Title: An investigation of the intersection between resilience and risk factors for first-time Samoan mothers living in New Zealand during pregnancy, childbirth and early motherhood.}

Interviews are semi-structured. Themes and the questions with prompts are guidelines only. Participants may talk about themes or issues they see as important that may not be included in these guides.

Phase 2: upto 12 months after birth

\begin{tabular}{|c|c|}
\hline Broad Questions & Prompts \\
\hline Self & - How have you been since we last met? \\
\hline Experience of labour & $\begin{array}{l}\text { I am interested to hear about your experience during labour and childbirth. } \\
\text { Some women become disappointed when their expectations don't quite match } \\
\text { their experiences. Some women feel they had just the right amount of people } \\
\text { (or sometimes too many) to support them. } \\
\text { - What was it like for you? } \\
\text { - Expectations vs experiences }\end{array}$ \\
\hline $\begin{array}{l}\text { Experience of motherhood } \\
\text { At home (First week) }\end{array}$ & $\begin{array}{l}\text { Some mothers feel quite nervous about the responsibility that lies ahead with a } \\
\text { new baby whereas others feel quite confident. Talk me through your } \\
\text { experience } \\
\text { - } \quad \text { Leaving hospital } \\
\text { - } \quad \text { Being at home } \\
\text { - } \quad \text { Expectations vs experiences }\end{array}$ \\
\hline UPTO 6 months & $\begin{array}{l}\text { Some mothers have described the first } 6 \text { months post baby as 'busy, hectic and } \\
\text { life changing'. } \\
\text { - } \quad \text { Talk me through your experience }\end{array}$ \\
\hline & $\begin{array}{l}\text { Thinking about the first interview we had when you were in your last } \\
\text { trimester of pregnancy, you shared your expectations of motherhood, how } \\
\text { different/similar is this experience to your expectations (might need to prompt } \\
\text { with responses from first interview) }\end{array}$ \\
\hline EMPLOYMENT & $\begin{array}{l}\text { Maternity leave for you and your partner? } \\
\text { Did your partner take maternity leave from work? How long? }\end{array}$ \\
\hline \multicolumn{2}{|l|}{ At home (6-12 months) } \\
\hline SELF-CARE & $\begin{array}{l}\text { With a new baby it can be difficult to find time for yourself. Tell me how you } \\
\text { are looking after yourself? }\end{array}$ \\
\hline Cultural/traditional beliefs & - $\quad$ Samoan beliefs \\
\hline
\end{tabular}




\begin{tabular}{|c|c|}
\hline & - $\quad$ Advice from others \\
\hline Support systems & $\begin{array}{l}\text { FORMAL AND INFORMAL SUPPORT SYSTEMS: } \\
\text { PRACTICAL: e.g. housework, preparing meals, helping with the baby } \\
\text { SOCIAL AND EMOTIONAL: } \\
\text { INFORMATION OR ADVICE - helping with breastfeeding, answering } \\
\text { questions } \\
\text { What or who are your support systems? (explore) } \\
\text { Specific support needs - who helped? What helped? } \\
\text { Specific support needs - who hindered? What hindered? } \\
\text { Did you seek help? What were some of the barriers? } \\
\text { PARTNER SUPPORT: How }\end{array}$ \\
\hline Partner support & $\begin{array}{l}\text { Has your partner been supportive? } \\
\text { Some men find it difficult to cope when a new baby comes into the household } \\
\text { particularly as it takes the attention of the mother ... (Fam viol) } \\
\text { Has that been the case with your partner? } \\
\text { How has your partner supported you? } \\
\text { Have you felt unsupported? In what ways? How have you managed this? }\end{array}$ \\
\hline $\begin{array}{l}\text { Telephone helplines/Internet } \\
\text { Some women have found } \\
\text { telephone helplines and chat } \\
\text { forums on the internet has } \\
\text { helped. }\end{array}$ & $\begin{array}{l}\text { (a) Have you accessed these types of support? } \\
\text { (b) How have they helped you? }\end{array}$ \\
\hline Advice & $\begin{array}{l}\text { If you had the opportunity to talk with other first-time Samoan mothers, what } \\
\text { are some of the things that you were told? What kind of things did you find } \\
\text { valuable enough to pass on? What kind of things were not so valuable to pass } \\
\text { on? } \\
\text { What are some of the things you experienced that you think other first-time } \\
\text { mothers would benefit from knowing? } \\
\text { What are some not so good things that you experienced? } \\
\text { What are some of the things you were told that first-time mothers should } \\
\text { know but after your experience should not worry about? (explore) }\end{array}$ \\
\hline
\end{tabular}




\section{APPENDIX SIX: INTERVIEW CHECKLIST: MOTHERS OF THE FIRST-TIME MOTHERS}

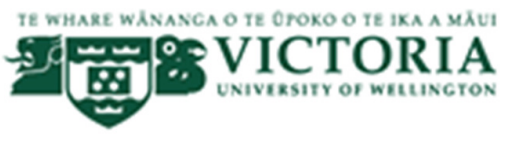

Interview Checklist

MOTHERS of the First-time mothers

Title: An investigation of the intersection between resilience and risk factors for first-time Samoan mothers living in New Zealand during pregnancy, childbirth and early motherhood.

Interviews are semi-structured. Themes and the questions with prompts are guidelines only. Participants may talk about themes or issues they see as important that may not be included in these guides.

\begin{tabular}{|c|c|}
\hline Broad Questions & Prompts \\
\hline Self & $\begin{array}{l}\text { Tell me a little about yourself? } \\
\text { - } \quad \text { Family; How long in NEW ZEALAND? }\end{array}$ \\
\hline Relationship & $\begin{array}{l}\text { How would you describe your relationship with your daughter? } \\
\text { - } \quad \text { Pre-pregnancy/pregnancy/early motherhood } \\
\text { - } \quad \text { Experience with your relationship with your own mother? }\end{array}$ \\
\hline Pregnancy & $\begin{array}{l}\text { How did you feel about your daughters' pregnancy? } \\
\text { - } \quad \text { Compare with your own experience of first pregnancy? }\end{array}$ \\
\hline Antenatal & $\begin{array}{l}\text { Were you part of the antenatal process with your daughter? } \\
-\quad \text { Clinic/classes } \\
\text { - } \quad \text { Comparison with your own experience during the antenatal period? }\end{array}$ \\
\hline Labour & $\begin{array}{l}\text { During labour (i.e. contractions) I am interested to know how you felt about } \\
\text { the experience of your daughter? } \\
\text { - Who was present } \\
\text { - Communication with midwife } \\
\text { - Comparison with your own experience of labour? }\end{array}$ \\
\hline Birth & $\begin{array}{l}\text { In the last stages of labour, when your daughter was ready to give birth, talk } \\
\text { me through the process. } \\
\text { - Who was present at the birth } \\
\text { - Comparison with your own experience of your own birth? } \\
\text { - Was it important to be at the birth? }\end{array}$ \\
\hline Postnatal & $\begin{array}{l}\text { Tell me about when your daughter returned home? Do you think it was how } \\
\text { she expected it to be? } \\
\text { - Comparison with your own experience of returning home? }\end{array}$ \\
\hline $\begin{array}{l}\text { Experience of motherhood } \\
\text { At home (first few weeks) }\end{array}$ & $\begin{array}{l}\text { Thinking back to the first few weeks your daughter was at home with her } \\
\text { newborn, how do you think she was coping? } \\
\text { - Comparison with your own experience of early motherhood }\end{array}$ \\
\hline At home (6-12 months) & $\begin{array}{l}\text { In comparison with your own experiences of motherhood, how do you think } \\
\text { your daughter is doing? } \\
\quad-\quad \text { Comparison with your own experiences of motherhood }\end{array}$ \\
\hline
\end{tabular}




\begin{tabular}{|l|l|}
\hline EMPLOYMENT & What are your thoughts about your daughter returning/not returning to work? \\
\hline Cultural/traditional beliefs & $\begin{array}{l}\text { What are some things about motherhood you consider traditional for } \\
\text { Samoans? Did you discuss some of these things with your daughter? }\end{array}$ \\
\hline Support systems & $\begin{array}{l}\text { What are support systems does your daughter have access to? } \\
\text { Family, friends, work colleagues }\end{array}$ \\
\hline Telephone helplines/Internet & $\begin{array}{l}\text { In terms of parenting, can you think of an example where you and your } \\
\text { daughter differ in terms of bringing up your grandchild? It might be to do with } \\
\text { breastfeeding, food choices, choosing a crèche, discipline? } \\
\text { If so, how do you compromise? } \\
\text { Is your 'way' of doing things more important, less important or the same } \\
\text { importance as they 'way' in which your daughter would like things done? }\end{array}$ \\
\hline Advice & $\begin{array}{l}\text { Some women have found telephone helplines and chat forums on the internet } \\
\text { has helped. Do you know if your daughter has accessed any of these support } \\
\text { systems? What do you think accessing these systems? }\end{array}$ \\
\hline Other comments? & $\begin{array}{l}\text { Did your daughter seek your advice during her pregnancy or early } \\
\text { motherhood? Can you think of some of the advice you gave your daughter? }\end{array}$ \\
\hline
\end{tabular}




\section{APPENDIX SEVEN: INTERVIEW CHECKLIST: MIDWIVES}

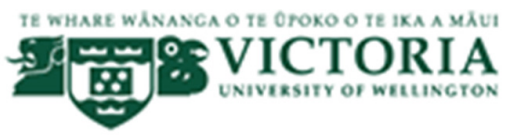

Interview Checklist

KEY PEOPLE: Midwives

Title: An investigation of the intersection between resilience and risk factors for first-time Samoan mothers living in New Zealand during pregnancy, childbirth and early motherhood.

\begin{tabular}{|c|c|}
\hline Themes & Questions \\
\hline Background & $\begin{array}{l}\text { Tell me a little bit about your background: } \\
\text { - Family }\end{array}$ \\
\hline Training and Experience & $\begin{array}{l}\text { Tell me a little bit about your background and interest in midwifery. Why you } \\
\text { trained as a midwife? } \\
\text { - } \quad \text { Training } \\
\text { - } \quad \text { Experience } \\
\text { - } \quad \text { Current employment }\end{array}$ \\
\hline Philosophy & $\begin{aligned} & \text { I am interested to know more about your philosophy of midwifery. } \\
&- \text { Natural } \\
&- \text { Feeding methods } \\
&- \text { Home and hospital birth } \\
&- \text { Communication with clients }\end{aligned}$ \\
\hline $\begin{array}{l}\text { Antenatal care } \\
\text { Social } \\
\text { Emotional } \\
\text { Physical }\end{array}$ & $\begin{aligned} & \text { Talk me } \text { through your antenatal care process: } \\
& \text { - } \text { Samoan clients } \\
& \text { - } \text { How do Samoan clients differ from others (explore) } \\
& \text { - } \text { Process; Registration of women - how do they find you } \\
& \text { - } \text { Participation of family members } \\
& \text { - } \text { Birthplans } \\
& \text { - } \text { Antenatal class e.g. parenting/feeding classes } \\
&\end{aligned}$ \\
\hline Labour & $\begin{array}{l}\text { Often midwives have quite different views of how laboring (i.e. the } \\
\text { contractions period) should progress, I am interested in your perspective of the } \\
\text { laboring process: } \\
\text { - } \quad \text { Samoan clients } \\
\text { - } \quad \text { How do Samoan clients differ from others (explore) } \\
\text { - } \quad \text { Duration of labour; Place of labour; Communication; Plan if you are } \\
\text { - } \quad \text { Bnavailable } \\
\text { Birthplan; Complications }\end{array}$ \\
\hline Birth & $\begin{array}{l}\text { The birthing process (i.e. the last stages of labour just before birth): } \\
\text { - } \quad \text { Samoan clients } \\
\text { - } \\
\text { - } \\
\text { - } \\
\text { - }\end{array}$ \\
\hline Postcare & $\begin{array}{l}\text { - Handover to Plunket? } \\
\text { e some of the challenges you face working with Samoan women and their } \\
\text { families? }\end{array}$ \\
\hline $\begin{array}{l}\text { Communication and } \\
\text { Technology }\end{array}$ & $\begin{array}{ll} & \text { Internet e.g. social media websites } \\
\text { - } & \text { Mobile phone } \\
\text { - } & \text { Landline; Post } \\
\end{array}$ \\
\hline Any other comments & \\
\hline
\end{tabular}




\section{APPENDIX EIgHT: INTERVIEW CHECKLIST: PlunKET NURSES}

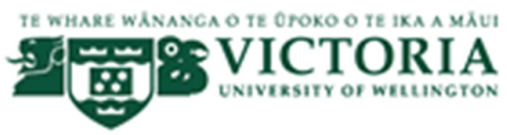

Interview Checklist

KEY PEOPLE: Plunket nurses

Title: An investigation of the intersection between resilience and risk factors for first-time Samoan mothers living in New Zealand during pregnancy, childbirth and early motherhood.

Interviews are semi-structured. Themes and the questions with prompts are guidelines only. Participants may talk about themes or issues they see as important that may not be included in these guides.

\begin{tabular}{|c|c|}
\hline Themes & Questions \\
\hline Background & Tell me a little bit about yourself \\
\hline Training and Experience & $\begin{array}{l}\text { Tell me a little bit about your background and interest in nursing. } \\
\text { Why you trained as a plunket nurse? } \\
\text { - } \text { Training } \\
\text { - } \quad \text { Experience } \\
\text { - }\end{array}$ \\
\hline Philosophy & $\begin{array}{l}\text { I am interested to know more about your philosophy and the role of the } \\
\text { Plunket Nurse e.g. } \\
\begin{array}{l}\text { - } \quad \text { Feeding methods } \\
\text { - Communication with clients; Well Child }\end{array}\end{array}$ \\
\hline Postnatal care & $\begin{array}{l}\text { Talk me through the postnatal care process: } \\
\text { - } \quad \text { Handover from LMCs } \\
\text { - } \quad \text { Well Child } \\
\text { - } \quad \text { Registration of women - how do they find you } \\
\text { Samoan clients } \\
\text { - } \quad \text { How do Samoan clients differ from others (explore) } \\
\text { - } \quad \text { Is there a high level of participation by family members } \\
\text { - } \quad \text { What are some of the challenges you face working with Samoan } \\
\text { - } \quad \text { Women and their families? } \\
\text { - } \quad \text { Pomen and their families? } \\
\text { Postnatal classes e.g. parent groups. Do Samoan women take } \\
\text { - }\end{array}$ \\
\hline Communication and Technology & $\begin{array}{l}\text { How do you stay in touch with your Samoan clients in between } \\
\text { meetings/appointments? } \\
\text { - Internet e.g. social media websites } \\
\text { - Mobile phone } \\
\text { - Landline } \\
\text { - Post } \\
\text { What is the best way to communicate with your clients? }\end{array}$ \\
\hline Any other comments & \\
\hline
\end{tabular}




\section{APPENDIX NINE: FIRST-TIME MOTHERS RECRUITMENT FLYER}

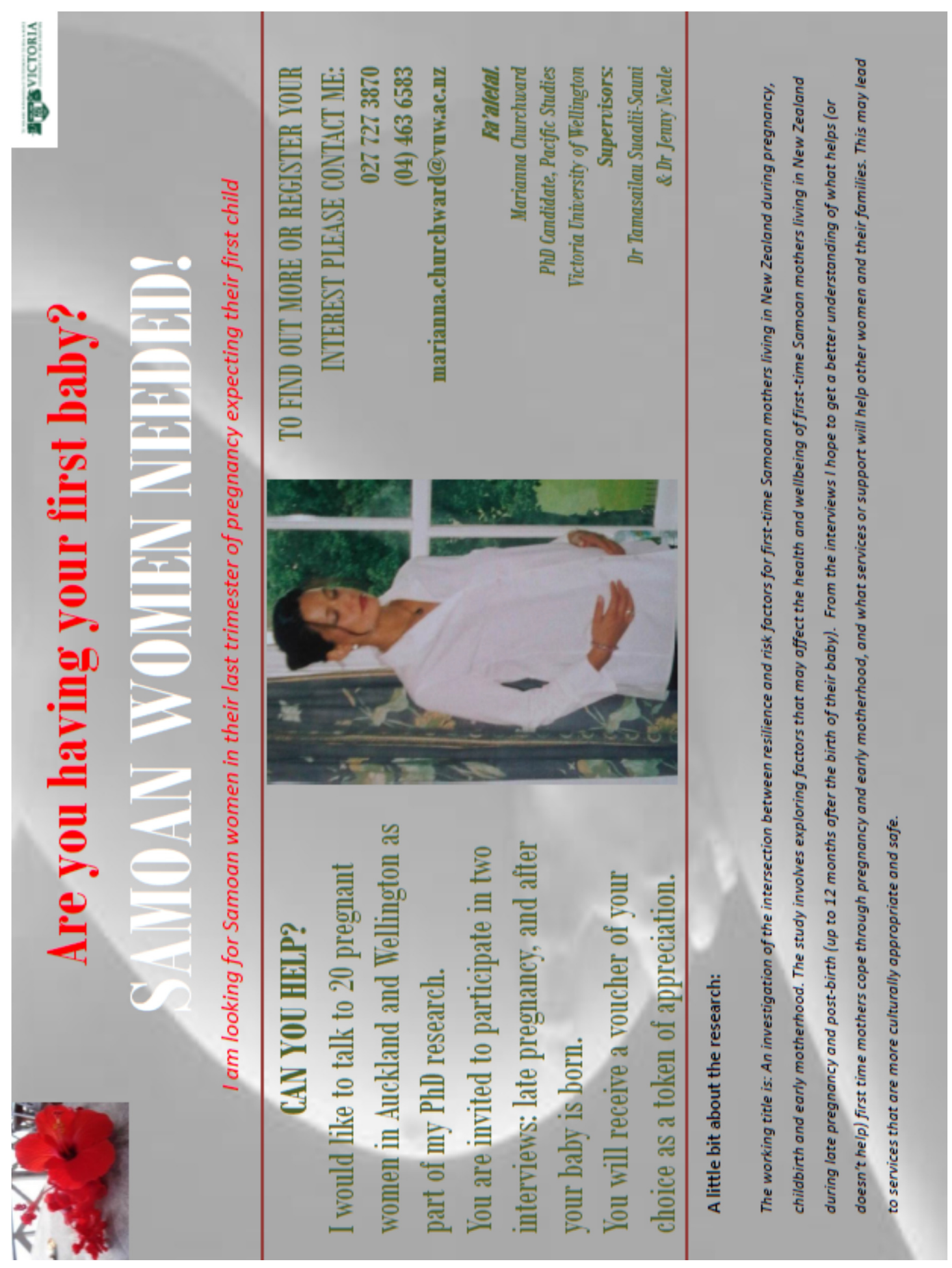




\section{APPENDIX TEN: GENERAL RECRUITMENT FLYER}

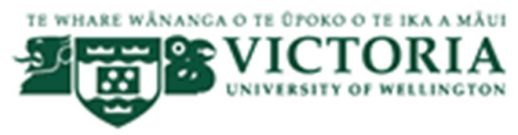

I am looking for:

Samoan first-time mothers in their third trimester of pregnancy (10 X AUCKLAND, 10 X WELLINGTON).

Midwives who have experience with $\underline{\text { Samoan first-time mothers }}$ (3 X AUCKLAND, 3 X WELLINGTON).

- Plunket nurses who have experience with $\underline{\text { Samoan first-time mothers }}$ (3 X AUCKLAND, 3 X WELLINGTON).

- A PhD research project:

An investigation of the intersection between resilience and risk factors for first-time Samoan mothers living in New Zealand during pregnancy, childbirth and early motherhood.

I am looking for Samoan women in their last trimester of pregnancy
expecting their first child
CAN YOU HELP?
I would like to talk to 20
pregnant women as part
of my PhD research.
You are invited to
participate in two
intamionr.

- I am a PhD candidate with Pacific studies at Victoria University of Wellington, I have a Health Research Council scholarship which allows me to study full-time. The research project has been approved by the Multi-Region Ethics Committee, Wellington. 
The research project I am undertaking involves exploring factors that may affect the health and wellbeing of first-time Samoan mothers living in New Zealand during late pregnancy and postbirth (upto 12 months after the birth of their baby), the impact of childbirth on the emotional wellbeing of women; the strategies these women utilize to cope with motherhood; and the range of support systems that Samoan women may utilize and their decision making around accessing these systems.

I am also interested in maternal knowledge that is passed down from mother to daughter; and the influence of 'others' who play an important role during the antenatal and postnatal periods e.g. midwives, plunket nurses. This research will provide an in-depth understanding of the experiences of first-time Samoan mothers.

I am interested in the 'individual experience' of each woman. The interviews will take between 1-1/2 hours and it will be arranged at a time and place of the participants' choice. Participants' are welcome to have a support person(s) with them during the interview. For first-time mothers there will be two interviews - (1) in their last trimester of pregnancy; and (2) upto 12 months post-birth. For mothers of the first-time mothers; midwives and plunket nurses there will be one interview only. All interviews will happen at a convenient time and place for participants. All participants will receive a voucher of their choice as a token of appreciation.

The information provided will be kept confidential, that means participants will not be able to be identified, and the information will be securely stored. All results will be presented in an aggregated form and every attempt will be taken to maintain confidentiality of participants' identity. However, as participants will be drawn from a small community there is always a very slight chance that participants may be recognized by someone who knows them well. Participation in this research is voluntary and withdrawal from this research can be made up to two weeks after your interview.

About the researcher: My name is Marianna Churchward, I was born in New Zealand, both my parents are of Samoan descent, I identify as New Zealand Samoan and I am the mother of three children. My contact details are: Health Services Research Centre, Victoria University of Wellington, PO Box 600, Wellington. Phone: (04) 463-6583. Email: marianna.churchward@,vuw.ac.New Zealand

If you have any further questions please contact myself or either of my supervisors: Dr Tamasailau Suaalii-Sauni, Va'aomanu Pasifika, Pacific studies, Victoria University of Wellington. Or Dr Jenny Neale, HSRC, Victoria Universrity. 


\section{BIBLIOGRAPHY}

Abbott, M., \& Williams, M. (2006). Postnatal depressive symptoms among Pacific mothers in Auckland: prevalence and risk factors. Royal Australian and New Zealand College of Psychiatrists.

Abel, S., Park, J., Tipene-Leach, D., Finau, S., \& Lennan, M. (2001). Infant care practices in New Zealand: a cross-cultural qualitative study. Social Science and Medicine, 53, 1135-1148.

Agnew, F., Pulotu-Endemann, F. K., Robinson, G., Suaalii-Sauni, T., Warren, H., Wheeler, A., ... Schmidt-Sopoaga, H. (2004). Pacific Models of Mental Health Service Delivery in New Zealand ("PMMHSD") Project. Auckland: Ministry of Health, Health Research Council of New Zealand, and Mental Health Commission.

Airini., Anae, M., Mila-Schaaf, K., Coxon, E., Mara, D., \& Sanga, K. (2010). Teu Le Va Relationships across research and policy in Pasifika education: A collective approach to knowledge generation and policy development for action towards Pasifika education success. Wellington: Ministry of Education.

Anae, M. (1997). Towards a NZ-born Samoan identity: some reflections on "labels". Pacific Health Dialog, 4(2).

Anae, M. (1998). Fofoa-i-vao-'ese: The identity journeys of NZ-born Samoans. Anthropology. PhD thesis. University of Auckland. Auckland, New Zealand.

Anae, M. (2002). Papalagi Redefined: Toward a New Zealand-born Samoan Identity. In P. R. Spickard, J. L. Rondilla \& D. H. Wright (Eds.), Pacific diaspora: Island peoples in the United States and across the Pacific. Hawai'i: University of Hawai'i Press.

Anae, M. (2004). From kava to coffee: the 'browning of Auckland'. In I. Carter, D. Craig \& S. Matthewman (Eds.), Almight Auckland? New Zealand: Dunmore Press Ltd.

Anae, M. (2010). Research for better Pacific schooling in New Zealand: Teu le va - a Samoan perspective. MAI Review, 1, 1-24.

Anae, M., Coxon, E., Mara, D., Wendt-Samu, T., \& Finau, C. (2001). Pasifika Education Research Guidelines. Wellington: Ministry of Education.

Anae, M., Lima, I., Mariner, K., Park, J., \& Suaalii-Sauni, T. (2000). Tiute ma Matafaioi a nisi Tane Samoa i le Faiga o Aiga. The roles and responsibilities of some Samoan men in reproduction. Auckland: Pacific Health Research Centre. The University of Auckland.

Archer, M. (2003). Structure, agency and the internal conversation. Cambridge: The University of Cambridge.

Asiasiga, L. (1994). Abortion and Pacific Islands Women: A pilot study for the New Zealand Family Planning Association. Wellington: New Zealand Family Planning Association.

Asiasiga, L. (2007). Influential factors shaping social science research about Pacific peoples. PhD Thesis. Victoria University of Wellington. Wellington.

Baca Zinn, M. (1979). Field research in minority communities: ethical, methodological and political observations by an insider. Social Problems, 27(2), 209-219.

Bae, J., \& Heitkemper, M. (2006). Development of a web-based health information service system for maternal health care. Studies in Health Technology and Informatics, 122, 963 - 964. 
Ball, H. L., Hooker, E., \& Kelly, P. J. (1999). Where Will the Baby Sleep? Attitudes and Practices of New and Experienced Parents Regarding Cosleeping with Their Newborn Infants. American Anthropologist, 101(1), 143-151. doi: 10.1525/aa.1999.101.1.143

Bandura, A. (2001). Social cognitive theory: An agentic perspective. Annual Review of Psychology, 52, 1-26.

Barclay, L., Aiavao, F., Fenwick, J., \& Papua, K. T. (2005). Midwives' Tales: Stories of traditional and professional birth in Samoa. Nashville: Vanderbilt University Press.

Barrett, G., \& Wellings, K. (2002). What is a 'planned' pregnancy? empirical data from a British study. Social Science \& Medicine, 55(4), 545-557. doi: http://dx.doi.org/10.1016/S0277-9536(01)00187-3

Baum, L. (2004). Internet parent support groups for primary caregivers of a child with special health care needs. Pediatric Nursing, 30(5), 381 - 388.

Bedford, R., \& Didham, R. (2001). Who are the 'Pacific Peoples'? Ethnic identification and the New Zealand census. In C. Macpherson, P. Spoonley \& M. Anae (Eds.), Tangata o Te Moana Nui: The evolving identities of Pacific Peoples in Aotearoa/New Zealand. Palmerston North: Dunmore Press Ltd.

Benson, P. L., Leffert, N., Scales, P. C., \& Blyth, A. (1998). Beyond the 'village' rhetoric: Creating healthy communities for children and adolescents. Applied Developmental Science, 2(3).

Berking, T., Fatialofa, C. S., Lupe, K., \& Skipps-Patterson, S. (2007). Being 'Afakasi. In P. Culbertson, M. N. Agee \& C. O. Makasiale (Eds.), Penina Uliuli: Contemporary challenges in Mental Health for Pacific Peoples. Honolulu: University of Hawai'i Press.

Berland, G., Elliott, M., Morales, L., Algazy, J., Kravitz, R., Broder, M., . . McGlynn, E. (2001). Health information on the Internet: accessibility, quality, and readability in English and Spanish. JAMA, 285, 2612 - 2621.

Berne, L., \& Huberman, B. (1999). European approaches to Adolescent sexual behavior and responsibility: Advocates for Youth.

Blackburn, C., Read, J., \& Hughes, N. (2005). Using the Internet? The experiences of parents of disabled children. Child: Care, Health and Development, 5, 507 - 515.

Bluff, R., \& Holloway, I. (1994). 'They know best': women's perceptions of midwifery care during labour and childbirth. Midwifery, 10(3), 157-164.

Boston, M., Ruwe, E., Duggins, A., \& Willging, J. (2005). Internet use by parents of children undergoing outpatient otolaryngology procedures. Archives of Otolaryngology-Head \& Neck Surgery, 8, 719 - 722.

Bouchard, G. (2005). Adult Couples Facing a Planned or an Unplanned Pregnancy: Two Realities. Journal of Family Issues, 26(5), 619-637. doi: $10.1177 / 0192513 \times 04272756$

Braun, V., \& Clarke, V. (2006). Using thematic analysis in psychology. Qualitative Research in Psychology, 3.

Braun, V., \& Clarke, V. (2012). Thematic Analysis. In H. Cooper (Ed.), Handbook of Research Methods in Psychology. Washington: APA books.

Brewis, A. A., \& McGarvey, S. T. (2000). Body image, body size, and Samoan ecological and individual modernization. Ecology of Food and Nutrition, 39(2), 105-120. doi: 10.1080/03670244.2000.9991609 
Brodie, M., Flournoy, R., Altman, D., Blendon, R., Benson, J., \& Rosenbaum, M. (2000). Health Information, the Internet, and the digital divide. Health affairs, 6, 255 265.

Bronfenbrenner, U. (1977). Toward an experimental ecology of human development. American Psychologist, 32(7), 513-531. doi: http://dx.doi.org/10.1037/0003066X.32.7.513

Bronfenbrenner, U. (1986). Ecology of the family as a context for human development: Research perspectives. Developmental Psychology, 22(6), 723-742. doi: http://dx.doi.org/10.1037/0012-1649.22.6.723

Bronfenbrenner, U. (1994). Ecological models of human development. Elsevier Sciences (reprinted with permission from the International Encyclopedia of Education, Vol. 3, 2nd ed., 1994, 1643,1647).

Bronfenbrenner, U., \& Morris, P. A. (2006). The bioecological model of human development. In W. Damon \& R. M. Lerner (Eds.), Handbook of child psychology (Vol. 1).

Brubaker, R. (2005). The 'diaspora' diaspora. Ethnic and Racial Studies, 28(1), 1-19.

Butler, S., Williams, M., Tukuitonga, C., \& Paterson, J. (2004). Factors associated with not breastfeeding exclusively among mothers of a cohort of Pacific infants in New Zealand. The New Zealand Medical Journal, 117(1195).

Campbell, R., \& Wasco, S. M. (2000). Feminst approaches to social science: epistemological and methodological tenets. American Journal of Community Psychology, 28(6), 773-791.

Cassel, K. D. (2010). Using the Social-Ecological Model as a research and intervention framework to understand and mitigate obesogenic factors in Samoan populations. Ethnicity \& Health, 15(4), 397-416. doi: $10.1080 / 13557858.2010 .481330$

Castles, S., \& Miller, M. (2009). The age of migration: International population movements in the modern world (Fourth ed.). United Kingdom: Palgrave and Macmillan.

Central PHO. (n.d.). Pacific Cultural Guidelines. In Central PHO (Ed.), http://www.centralpho.org.nz/Portals/0/Publications/Health\%20Services/Pacifi c\%20Cultural\%20Guidelines\%20(Central\%20PHO).pdf.

Choi, P., Henshaw, C., Baker, S., \& Tree, J. (2005). Supermum, superwife, supereverything: performing femininity in the transition to motherhood. Journal of Reproductive \& Infant Psychology, 23(2), 167-180.

Chu, C., Abella, I. S., \& Paurini, S. (2013). Educational practices that benefit Pacific learners in tertiary education. Wellington: National Project Fund AKO Aotearoa.

Churchward, M. E. (2011). Sophisticated Mediators: New Zealand-born Samoan firsttime mothers and strategies for their health and wellbeing. Faculty of Humanities and Social Sciences. MA (Applied) thesis. Victoria University of Wellington. Wellington.

Clark, A., Skouteris, H., Wertheim, E. H., Paxton, S. J., \& Milgrom, J. (2009). My baby body: A qualitative insight into women's body-related experiences and mood during pregnancy and the postpartum. Journal of Reproductive and Infant Psychology, 27(4), 330-345.

Clendon, J. (2009). Motherhood and the 'Plunket Book': A social history. Nursing. PhD Thesis. Massey University. Auckland. 
Clifford, J. (1994). Diasporas. American Anthropological Association, 9(3), 302-338.

Collins, B. (2005). Missing voices: teenage pregnancy and social policy. Philosophy in social policy. PhD Thesis. Victoria University of Wellington. Wellington.

Crotty, M. (1998). The foundations of social science research: meaning and perspective in the research process. Crows Nest: Allen and Unwin.

Crouch, M., \& Manderson, L. (1993). New motherhood: Cultural and personal transitions in the 1980s. Victoria, Australia: Gordon and Breach Science.

Cyna, A., Andrew, M., Robinson, J., Crowther, C., Baghurst, P., Turnbull, D., . . Whittle, C. (2006). Hypnosis Antenatal Training for Childbirth (HATCh): a randomised controlled trial [NCT00282204]. BMC Pregnancy and Childbirth, 6(1), 5.

Dahlen, H. G., Barclay, L. M., \& Homer, C. S. E. (2008). Preparing for the first birth. The Journal of Perinatal Education, 17(4), 21-32.

Daneback, K., \& Plantin, L. (2008). Research on Parenthood and the Internet: Themes and Trends. Cyberpsychology: Journal of Psychosocial Research on Cyberspace, 2(2), article 2.

Darrah, A. J. (2011). The distressing case of modern mothering: Expectations, losses, and postnatal distress. PhD thesis. Massey University of Wellington. Wellington.

Davidson, C. (2009). Transcription: Imperatives for qualitative research. International Journal of Qualitative Methods, 8(2).

Davidson, C., \& Tolich, M. (2007). Competing traditions. In C. Davidson \& M. Tolich (Eds.), Social Science Research in New Zealand: Many paths to understanding (2nd ed.). 2007: Pearson Education New Zealand.

Davis, D. L., \& Walker, K. (2010a). Case-loading midwifery in New Zealand: making space for childbirth. Midwifery, 26(6), 603-608. doi: http://dx.doi.org/10.1016/j.midw.2009.01.004

Davis, D. L., \& Walker, K. (2010b). The corporeal, the social and space/place: exploring intersections from a midwifery perspective in New Zealand. Gender, Place \& Culture, 17(3), 377-391. doi: 10.1080/09663691003737645

De Andrade, L. L. (2000). Negotiating from the inside: Constructing racial and ethnic identity in qualitative research. Journal of Contemporary Ethnography, 29(3), 268-290.

Denzin, N. K., \& Lincoln, Y. S. (1994). Introduction: Entering the field of qualitative research. In N. K. Denzin \& Y. S. Lincoln (Eds.), Handbook of Qualitative Research. CA: Thousand Oaks.

Denzin, N. K., \& Lincoln, Y. S. (Eds.). (2005). The SAGE handbook of qualitative research. Thousand Oaks: SAGE Publications.

Department of Labour. (2012). Population movement in the Pacific: A perspective on future prospects. In R. Bedford \& G. Hugo (Eds.).

DeSouza, R. (2010). New mothers in a new land: Indian migrant mothers talk. In S. Bandyopadhyay (Ed.), India in New Zealand: Local identities, global relations. Dunedin: Otago University Press.

DeSouza, R. (2011). Migrant Maternity. Nursing PhD, AUT University, Auckland.

Diaz, V. M. (2004). "To 'P' or not to 'P'?": Marking the territory between Pacific Islander and Asian American Studies. Journal of Asian American Studies, 7(3), 183-208.

Diaz, V. M., \& Kauanui, J. K. (2001). Native Pacific Cultural Studies on the Edge. The Contemporary Pacific, 13(2), 315-341. 
Dohmen, T., Falk, A., Huffman, D., \& Sunde, U. (2012). The Intergenerational Transmission of Risk and Trust Attitudes. The Review of Economic Studies, 79(2), 645-677. doi: 10.1093/restud/rdr027

Donley, J. (1986). Save the Midwife: New Women's Press.

Donnelly, P. (1992). Samoan womens' voices: Alternative ways of doing birth. PhD Thesis. University of Otago, Dunedin, New Zealand. Dunedin.

Dwyer, S. (2009). Childbirth education: antenatal education and transitions of maternity care in New Zealand (Vol. 1/09). Wellington: Families Commission.

Ekeroma, A., Craig, E. D., Stewart, A. W., Mantell, C. D., \& Mitchell, E. A. (2004). Ethnicity and birth outcome: New Zealand trends 1980-2001: Part 3. Pregnancy outcomes for Pacific women. Australian and New Zealand Journal of Obstetrics and Gynaecology(44), 541-544.

Ekeroma, A., \& Harillal, M. (2003). Women's choice in the gender and ethnicity of her obstetrician and gynaecologist. Australian and New Zealand Journal of Obstetrics and Gynaecology(43), 354-359.

Eri, T. S., Blystad, A., Gjengedal, E., \& Blaaka, G. (2011). 'Stay home for as long as possible': Midwives' priorities and strategies in communicating with first-time mothers in early labour. Midwifery, 27(6), e286-e292. doi: http://dx.doi.org/10.1016/j.midw.2011.01.006

Evans, R., \& Becker, S. (2009). Parents with HIV and Aids: Global issues and policy responses. Bristol, United Kingdom: The Policy Press.

Everard, C. (1997). Managing the New Zealand cot death study: lessons from between the rock and a hard place. Pacific Health Dialog, 4(2).

Fa'alau, F., Finau, S. A., Parks, J., \& Abel, S. (2003). SIDS among Pacificans in New Zealand: An ecological perspective. Pacific Health Dialog, 10(2).

Fa'alau, F., \& Jensen, V. (2006). Samoan youth and family relationships in Aotearoa New Zealand. Pacific Public Health, 13(2).

Fa'asalele Tanuvasa, A. (1999). The place of contraception and abortion in the lives of Samoan women. Nursing and Midwifery. PhD Thesis, Volume 1. Victoria University of Wellington. Wellington.

Fa'asalele Tanuvasa, A., Cumming, J., Churchward, M., Neale, J., \& Tavila, A. (2013). Samoan women's attitudes towards antenatal and midwifery care. British Journal of Midwifery, 21(10).

Fairbairn-Dunlop, P. T. (1998). Tamaitai Samoa: Their stories. Suva: Institute of Pacific Studies, The University of the South Pacific.

Fairbairn-Dunlop, P. T. (2008a). The impact of PBRF local context, national trends and international comparisons: A Pacific perspective.

Fairbairn-Dunlop, P. T. (2008b). Reconnecting to our sea of islands: Pacific studies in the next decade. AlterNative: An International Journal of Indigenous Peoples, 4(1), 45-56.

Fairbairn-Dunlop, P. T., \& Makisi, G. (2003). Making our place: Growing up PI in New Zealand. Palmerston North: The Dunmore Printing Company Limited.

Families, K. (2010). BirthPlan Retrieved March, 2010, from http://www.kiwifamilies.co.nz/Topics/Birth/Birth-Plan.html

Finau, E., Finau, S. A., Fuamatu, N., \& Tukuitonga, C. (2003). SIDS or Sitisi: Plight and response of Pacificans in New Zealand (Aotearoa). Pacific Health Dialog, 10(2). 
Finfgeld-Connett, D. (2005). Telephone social support or nursing presence? Analysis of a nursing intervention. Qualitative Health Research, 15(1), 19-29.

Firth, S. (2003). Future directions for Pacific Studies. The Contemporary Pacific, 15(1), 139-148.

Forster, D., McLachlan, H., Rayner, J., Yelland, J., Gold, L., \& Rayner, S. (2008). The early postnatal period: Exploring women's views, expectations and experiences of care using focus groups in Victoria, Australia. BMC Pregnancy and Childbirth, 8(1), 27.

Franklin, M. I. (2003). I Define My Own Identity: Pacific Articulations of 'Race' and 'Culture' on the Internet. Ethnicities, 3(4), 465-490. doi:

$10.1177 / 1468796803003004002$

Garbarino, J., \& Benn, J. L. (2009). The ecology of childbearing and childrearing. In J. Garbarino (Ed.), Children and Families in the Social Environment (2nd ed.). New York: Walter de Gruyter.

Gegeo, D. W. (1998). Indigenous knowledge and empowerment: Rural development examined from within. The Contemporary Pacific, 10(2), 289-315.

Gegeo, D. W. (2001). Cultural rupture and indigeneity: The challenge of (re)visioning "place" in the Pacific. The Contemporary Pacific, 13(2), 491-507.

Gershon, I. (2007). Viewing diaspors from the Pacific: What Pacific ethnographies offer Pacific Diaspora Studies. The Contemporary Pacific, 19(2).

Gibbins, J., \& Thomson, A. M. (2001). Women's expectations and experiences of childbirth. Midwifery(17), 302-313.

Glassman, I., \& Eisikovits, R. A. (2006). Intergenerational transmission of motherhood patterns: Three generations of immigrant mothers of Moroccan descent in Israel. Journal of Comparative Family Studies, 37(3).

Griffen, V. (1983). Care for ourselves: A health handbook for Pacific women. Suva: University of the South Pacific.

Griffen, V. (1989). Women, Development and Empowerment: a Pacific Feminist Perspective. A report of the Pacific Women's Workshop, Naboutini, Fiji. Kuala Lumpur: Asian and Pacific Development Centre.

Grundy, E., \& Henretta, J. (2006). Between elderly parents and adult children: a new look at the intergenerational care provided by the 'sandwich generation'. Ageing \& Society, 26(05), 707-722. doi: doi:10.1017/S0144686X06004934

Harding, S., \& Norberg, K. (2005). New Feminist Approaches to Social Science Methodologies: An Introduction. Signs: Journal of Women in Culture and Society, 30(4), 2009-2015.

Harris, K., \& Campbell, E. (1999). The plans in unplanned pregnancy: Secondary gain and the partnership. British Journal of Medical Psychology, 72, 105.

Hattori, A. P. (2006). 'The Cry of the Little People of Guam': American Colonialism, Medical Philanthropy, and the Susana Hospital for Chamorro Women, 18981941. Australian and new Zealand Society of the History of Medicine, 8(1), 4-26.

Hau'ofa, E. (1994). Our sea of islands. In V. Naidu, E. Waddell \& E. Hau'ofa (Eds.), A new Oceania: Rediscovering our Sea of Islands (pp. 2-16). Suva: USP in association with Beake House.

Hau'ofa, E. (1998). The Ocean in Us. The Contemporary Pacific, 10(2), 391-410.

Health Research Council of New Zealand. (2005). Guidelines on Pacific Health Research. Auckland. 
Health Research Council of New Zealand. (2014). Pacific Health Research Guidelines. Auckland.

Hereniko, V. (2000). Indigenous knowledge and academic imperialism. In R. Borofsky (Ed.), Remembrance of Pacific Pasts: An invitation to remake history (pp. 79-91). Honolulu: University of Hawai'i Press.

Hill Collins, P. (1986). Learning from the outsider within: The sociological significance of Black feminist thought. Social Problems, 33(6), 175-191.

Hill Collins, P. (1989). The social construction of black feminist thought. Journal of Women in Culture and Society, 14(4), 745-773.

Hill Collins, P. (1990). Black feminist thought in the matrix of domination Black feminist thought: knowledge, consciousness, and the politics of empowerment (pp. 221238). Boston: Unwin Hyman.

Hill Collins, P. (1997). The meaning of motherhood in Black culture and Black mother/daughter relationships. In M. M. Gergen \& S. N. Davis (Eds.), Toward a New Psychology of Gender. New York: Routledge.

Hitlin, S., \& Elder, G. H. (2007). Time, Self, and the Curiously Abstract Concept of Agency*. Sociological Theory, 25(2), 170-191. doi: 10.1111/j.14679558.2007.00303.x

Hollway, W. (2010). Conflict in the transitions to becoming a mother: A psycho-social approach. Psychoanal Cult Soc, 15(2), 136-155.

hooks, b. (2000). Feminism is for everybody: passionate politics. Cambridge, MA: South End Press.

Howarth, A. M., Swain, N. R., \& Treharne, G. J. (2011). First-time New Zealand mothers' experience of birth: Importance of relationship and support. New Zealand College of Midwives, 45, 6-11.

Howarth, A. M., Swain, N. R., \& Treharne, G. J. (2012). First-time mothers' perspectives on relationships with and between midwives and doctors: Insights from a qualitative study of giving birth in New Zealand. Midwifrey, 28, 489-494.

Hunter, B. (2001). Emotion work in midwifery: a review of current knowledge. Journal of Advanced Nursing, 34(4), 436-444. doi: 10.1046/j.1365-2648.2001.01772.x

Hviding, E. (2003). Between knowledges: Pacific Studies and academic disciplines. The Contemporary Pacific, 15(1), 43-73.

Jackson, E., Karasz, A., \& Gold, M. (2011). Family formation in the inner city: Lowincome men's perception of their role in unplanned conception and pregnancy prevention. Journal of Health Care for the Poor and Underserved, 22(1), 71-82.

Jolly, M. (1997). From point Venus to Bali Ha'i: Eroticism and exoticism in representations of the Pacific. In M. Jolly \& L. Manderson (Eds.), Sites of desire, economies of pleasure: Sexualities in Asia and the Pacific (pp. 99-122). Chicago: The University of Chicago Press.

Jolly, M. (2001). On the Edge?: Deserts, oceans, islands. The Contemporary Pacific, 13(2).

Jolly, M. (2002a). Birthing beyond the confinements of tradition and modernity? In V. Lukere \& M. Jolly (Eds.), Birthing in the Pacific: Beyond tradition and modernity? Hawai'i: University of Hawai'i Press.

Jolly, M. (2002b). Epidemiologies and ethnographies of motherhood in Vanuatu. In V. Lukere \& M. Jolly (Eds.), Birthing in the Pacific: Beyond tradition and modernity? Hawai'i: University of Hawai'i Press. 
Jolly, M. (2005). Beyond the horizon? Nationalisms, feminisms, and globalization in the Pacific. Ethnohistory, 52(1).

Joyce, T., Kaestner, R., \& Korenman, S. (2002). On the validity of retrospective assessments of pregnancy intention. Demography, 39(1), 199-213. doi: 10.1353/dem.2002.0006

Kahaleole Hall, L. (2009). Navigating our own "Sea of Islands" Remapping a theoretical space for Hawaiian women and indigenous feminism. Wicazo SA Review(Fall).

Keddell, E. (2006). Pavlova and pineapple pie: Selected identity influences on SamoanPakeha people in Aotearoa/New Zealand. Kōtuitui: New Zealand Journal of Social Sciences Online, 1(1), 45-63. doi: 10.1080/1177083x.2006.9522410

Kennedy, H. P., Shannon, M. T., Chuahorm, U., \& Kravetz, M. K. (2004). The Landscape of Caring for Women: A Narrative Study of Midwifery Practice. The Journal of Midwifery \& Women's Health, 49(1), 14-23. doi: 10.1111/j.15422011.2004.tb04403.x

Kildea, S., Barclay, L., \& Brodie, P. (2006). Maternity care in the bush: using the Internet to provide educational resources to isolated practitioners. Rural Remote Health, 6(3), 559.

Kincheloe, J. L. (2001). Describing the Bricolage: Conceptualizing a New Rigor in Qualitative Research. Qualitative Inquiry, 7(6), 679-692. doi: 10.1177/107780040100700601

Kingi-Uluave, D., \& Olo-Whaanga, E. (2010). Talking therapies for Pasifika Peoples: best and promising practice guide for mental health and addiction services. Auckland.

Kinloch, P. (1985). Midwives and midwifery in Western Samoa. In C. D. F. Parsons (Ed.), Healing practices in the South Pacific. Hawaii: University of Hawaii Press.

Kirkman, A. (2012). Health practitioners - Nurses and midwives, 2014, from http://www.teara.govt.nz/en/health-practitioners/page-3

Kitzinger, C. (2005). Heteronormativity in action: Reproducing the heterosexual nuclear family in after-hours medical calls. Social Problems, 52(4), 477-498.

Knight, R., \& Thirkettle, J. A. (1987). The relationship between expectations of pregnancy and birth, and transient depression in the immediate post-partum period. Journal of Psychomatic Research, 31(3).

Kohler, P., Manhart, L., \& Lafferty, W. (2008). Abstinence-only and comprehensive sex education and the initiation of sexual activity and teen pregnancy. Journal of Adolescent Health, 42(4), 344-351.

Kokaua, J., Schaaf, D., Wells, J. E., \& Foliaki, S. A. (2009). Twelve-month prevalence, severity, and treatment contact of mental disorders in New Zealand born and migrant Pacific participants in Te Rau Hinengaro: The New Zealand Mental Health Survey. Pacific Health Dialog, 15(1).

Koya-Vaka'uta, C. F. (2012). Cyberspace, place, identity \& relatinships: Are we digitizing the Vā? Retrieved from http://works.bepress.com/cgi/viewcontent.cgi?article=1025\&context=cf koyav akauta

Kvale, S. (1996). Interviews: An introduction to qualitative research interviewing: Sage, Thousand Oaks.

Kvale, S., \& Brinkmann, S. (2009). InterViews: Learning the craft of qualitative research interviewing (2nd ed.): Sage. 
Ladson-Billings, G. (2000). Racialized discourses and ethnic epistemologies. In N. K. Denzin \& Y. S. Lincoln (Eds.), The handbook of qualitative research (2nd ed.). California: Sage Publications.

Lagan, B. M., Sinclair, M., \& George Kernohan, W. (2010). Internet Use in Pregnancy Informs Women's Decision Making: A Web-Based Survey. Birth, 37(2), 106-115. doi: 10.1111/j.1523-536X.2010.00390.x

Lamp, J., \& Howard, P. (1999). Guiding parents' use of the Internet for newborn education. The American Journal of Maternal Child Nursing, 1, 33 - 36.

Lévi-Strauss, C. (1966). The Savage Mind (La Pensée Sauvage). Great Britain: Weidenfeld and Nicolson.

Liamputtong, P. (2007). Situating reproduction, procreation and motherhood within a cross-cultural context: An introduction. In P. Liamputtong (Ed.), Reproduction, childbearing and motherhood: A cross-cultural perspective. New York: Nova Science Publishers.

Lifflander, A., Gaydos, L. M., \& Hogue, C. R. (2006). Circumstances of pregnancy: Low income women in Georgia describe the difference between planned and unplanned pregnancies. Maternal Child Health Journal, 11, 81-89.

Lilomaiava-Doktor, S. (2009). Beyond "migration": Samoan population movement (malaga) and the geography of social space (vā). The Contemporary Pacific, 21(1), 1-12.

Lipine, T. (2010). Education of secondary Samoan students in New Zealand: The road to success. PhD Thesis. Victoria University of Wellington. Wellington.

Low, P., Paterson, J., Wouldes, T., Carter, S., Williams, M., \& Percival, T. (2005). Factors affecting antenatal care attendance by mothers of Pacific infants living in New Zealand. The New Zealand Medical Journal, 118(1216).

Lui, D. (2007). Spiritual Injury: A Samoan perspective on Spirituality's impact on mental health. In P. Culbertson, M. Agee \& C. 'Ofa Makasiale (Eds.), Penina Uliuli: Contemporary challenges in Mental Health for Pacific Peoples: University of Hawai'i Press.

Macfarlane, A. H., Glynn, T., Grace, W., Penetito, W., \& Bateman, S. (2008). Indigenous epistemology in a national curriculum framework? Ethnicities, 8(1).

Macpherson, C. (1984). On the future of Samoan ethnicity in New Zealand. In P. Spoonley, C. Macpherson, D. Pearson \& C. Sedgwick (Eds.), Tauiwi: Racism and ethnicity in New Zealand (pp. 107-127). Palmerston North, New Zealand: The Dunmore Press Limited.

Macpherson, C. (1999). Will the 'Real' Samoans Please Stand Up? Issues in Diasporic Samoan Identity. New Zealand Geographer, 55(2), 50-59. doi: 10.1111/j.17457939.1999.tb00542.x

Macpherson, C., \& Macpherson, L. (1990). Samoan medical belief and practice. Auckland: Auckland University Press.

Macpherson, C., \& Macpherson, L. (2000). The children of Samoan migrants in New Zealand. In P. Spickard \& W. J. Burroughs (Eds.), We are a people: Narrative and multiplicity in constructing ethnic identity. Philadelphia: Temple University Press.

Manhire, K. M., Hagan, A. E., \& Floyd, S. A. (2007). A descriptive account of New Zealand mothers' responses to open-ended questions on their breast feeding experiences. Midwifery, 23, 372-381. 
Marsh, S. T. (1999). Migrating feminisms: Maligned overstayer or model citizen? Women's Studies International Forum, 21(6), 665-680.

Matthey, S., White, T., \& Rice, S. (2010). Women's responses to postnatal self-report mood and experience measures: does anonymity make a difference? Archives of Women's Mental Health, 13(6), 477-484. doi: 10.1007/s00737-010-0159-1

Mauiliu, M. (2014). Outcomes following injury for Pacific Peoples in NZ. Paper presented at the Pacific Post Graduate Talanoa, Access Grid.

Maynard, M. (1994). Methods, practice and epistemology: The debate about feminism and research. In M. Maynard \& J. Purvis (Eds.), Researching women's lives from a feminist perspective. London: Taylor and Francis.

McCourt, C., Page, L., Hewison, J., \& Vail, A. (1998). Evaluation of One-to-One Midwifery: Women's Responses to Care. Birth, 25(2), 73-80. doi: 10.1046/j.1523-536x.1998.00073.x

McKenna, J. J., \& McDade, T. (2005). Why babies should never sleep alone: A review of the co-sleeping controversy in relation to SIDS, bedsharing and breast feeding. Paediatric Respiratory Reviews, 6(2), 134-152. doi: http://dx.doi.org/10.1016/i.prrv.2005.03.006

McLaren, L., \& Hawe, P. (2005). Ecological perspectives in health research. Journal of Epidemiology and Community Health, 59(1), 6-14. doi: 10.1136/jech.2003.018044

McQuillan, J., Greil, A. L., \& Shreffler, K. M. (2010). Pregnancy intentions among women who do not try: focussing on women who are okay either way. Maternal Child Health Journal.

Mead, M. (1928). Coming of Age in Samoa. London: Cox \& Wyman Ltd.

Meara, N., \& Schmidt, L. (1991). The ethics of researching counseling/therapy processes. In J. CE Watkins \& L. Schneider (Eds.), Research in counseling (pp. 237-259). Hillsdale, NJ: Lawrence Erlbaum Associates, Inc.

Meleiseā, M. (1987). Ideology in Pacific Studies: A personal view. In A. Hooper, S. Britton, R. Crocombe, J. Huntsman \& C. Macpherson (Eds.), Class and Culture in the South Pacific (pp. 140-152). Auckland and Suva: Centre for Pacific Studies, University of Auckland, and Institute of Pacific Studies.

Merck, Sharp, \& Dohme Corporation. (2010). Women's Health Issues: Labour. The Merck Manuals: Online Medical Library. Home Edition: For patients and caregivers Retrieved July, 2010, from http://www.merckmanuals.com/home/

Mila-Schaaf, K. (2010). Polycultural capital and the Pasifika second generation: Negotiating identities in diasporic spaces. PhD thesis. Massey University. Albany, Auckland.

Mila-Schaaf, K., \& Hudson, M. (2009a). The interface between cultural understandings: Negotiating new spaces for Pacific mental health. Pacific Health Dialog, 15(1).

Mila-Schaaf, K., \& Hudson, M. (2009b). Negotiating Space for Indigenous Theorising in Pacific Mental Health and Addictions. Auckland: LeVa.

Mila-Schaaf, K., \& Robinson, E. (2010). 'Polycultural' capital and educational achievment among NZ-born Pacific peoples. Mai Review, 1.

Mooney, A., Statham, J., \& Simon, A. (2002). The pivot generation: Informal care and work after fifty. Great Britain.

Morton, S. M. B., Atatoa Carr, P. E., Bandara, D. K., Grant, C. C., Ivory, V. C., Kingi, T. R., . .. Waldie, K. E. (2010). Growing up in New Zealand: A longitudinal study of New 
Zealand children and their families. Report 1: Before we are born. Auckland: Retrieved from http://www.growingup.co.nz/pdf/reports/report01.pdf.

Nabobo-Baba, U. (2006). Knowing and learning: An indigenous Fijian approach. Suva: Institute of Pacific Studies, The University of the South Pacific.

Nash, M. (2012). Weighty matters: Negotiating 'fatness' and 'in-betweenness' in early pregnancy. Feminism \& Psychology, 22(3), 307-323. doi: 10.1177/0959353512445361

National Breastfeeding Advisory Committee of New Zealand. (2008). Protecting, promoting and supporting breastfeeding in New Zealand: Background report.

Nelisi, L. (2004). Ko e vaka fakaako he faiaoga Pasifika he moana Okalana: Teaching from the heart. Unpublished MEd Research Project. University of Auckland. Auckland.

New Zealand College of Midwives Incorporated. (2010). Information for Midwives and Women. Retrieved April, 2010, from http://www.midwife.org.nz/

New Zealand Government. (2008). New Zealand Legislation: Acts. Parental Leave and Employment Protection Act 1987 Retrieved June, 2010

New Zealand Health Information Service. (2014). National Maternity Collection: Maternity Tables 2011. Retrieved 2014, from Ministry of Health

New Zealand Ministry of Health. (2006). Food and Nutrition Guidelines for Healthy Pregnant and Breastfeeding Women: A background paper. Retrieved April, 2013, from

http://www.health.govt.nz/system/files/documents/publications/food-andnutrition-guidelines-preg-and-bfeed.pdf

New Zealand Ministry of Health. (2007). Maternity Services Consumer Satisfaction Survey Report. Wellington: Ministry of Health.

New Zealand Ministry of Health. (2008). Maternity Action Plan 2008-2012: Draft for Consultation. Retrieved September, 2008, from http://www.moh.govt.nz/moh.nsf/pagesmh/8445/\$File/draft-maternity-actionplan.oct08-final.doc

New Zealand Ministry of Health. (2009). National Strategic Plan of Action for Breastfeeding 2008-2012: National Breastfeeding Advisory Committee of New Zealand's advice to the Director-General of Health. Wellington: New Zealand Ministry of Health.

New Zealand Ministry of Health. (2010a). Breastfeeding - The benefits of breastfeeding. Retrieved May, 2010, from http://www.moh.govt.nz/moh.nsf/indexmh/breastfeeding-why

New Zealand Ministry of Health. (2010b). Healthline Retrieved March, 2010, from http://www.moh.govt.nz/healthline

New Zealand Ministry of Health. (2012a). Components of the National Depression Initiative, 2013, from http://www. health.govt.nz/our-work/mental-health-andaddictions/national-depression-initiative/components-national-depressioninitiative

New Zealand Ministry of Health. (2012b). Tupu Ola Moui Pacific Health Chart Book. Wellington: Ministry of Health.

New Zealand Ministry of Health. (2014a). Maternity Services Retrieved April, 2014, from http://www.health.govt.nz/your-health/services-and-support/health-careservices/maternity-services 
New Zealand Ministry of Health. (2014b). Maternity: Your Lead Maternity Carer. Retrieved April, 2014, from http://www.health.govt.nz/your-health/servicesand-support/health-care-services/maternity-services/your-lead-maternity-carer

Ngan-Woo, F. E. (1985). Fa'a Samoa: The world of Samoans. Wellington, New Zealand: The Office of Race Relations Conciliator.

Nystrom, K., \& Ohrling, K. (2006). Parental support: Mothers' experience of electronic encounters. Journal of Telemedicine and Telecare, 4, 194 - 197.

O'Connor, H., \& Madge, C. (2004). 'My mum's thirty years out of date'. Community, Work \& Family, 7(3), 351-369. doi: 10.1080/1366880042000295754

O'Connor, H., \& Madge, C. (2004). 'My mum's thirty years out of date': The role of the Internet in the transition to motherhood. Community, Work \& Family, 3, 351 369.

O'Hare, J., \& Fallon, A. (2011). Women's experience of control in labour and childbirth. British Journal of Midwifery, 19(3), 164-169.

Oakley, A. (1979). From here to maternity: Becoming a mother. Suffolk: Penguin Books.

Oakley, A. (1980). Women confined: Towards a sociology of childbirth. USA: Schocken Books.

Oakley, A. (1992). Social support and motherhood. Oxford: Blackwell Publishers.

Ofahengaue Vakalahi, H. F. (2011). Tongan grandparents and grandchildren: The impact of grandparenting. International Social Work, 54(4), 580-598. doi: $10.1177 / 0020872810382683$

Otsuka, S. (2006). Talanoa research: Culturally appropriate research design in Fiji. Paper presented at the AARE Annual Conference.

Page, L. (2003). One-to-one Midwifery: Restoring the "with Woman" Relationship in Midwifery. The Journal of Midwifery \& Womens Health, 48(2), 119-125. doi: 10.1016/s1526-9523(02)00425-7

Page, L., McCourt, C., Beake, S., Vail, A., \& Hewison, J. (1999). Clinical interventions and outcomes of One-to-One midwifery practice. Journal of Public Health, 21(3), 243-248. doi: 10.1093/pubmed/21.3.243

Park, J., \& Morris, C. (2004). Reproducing Samoans Auckland "in different times": Can habitus help? The Journal of the Polynesian Society, 113(3), 227-261.

Paterson, J., Cowley, E. T., Percival, T., \& Williams, M. (2004). Pregnancy planning by mothers of Pacific infants recently delivered at Middlemore Hospital. The New Zealand Medical Journal, 117(1188).

Patton, M. Q. (2002). Qualitative research and evaluation methods (3rd ed.). California: Sage Publications Inc.

Phinney, J. S. (1990). Ethnic identity in adolescents and adults: Review of research. American Psychological Association Inc., 108(3), 499-514.

Plunket. (2010). PlunketLine. Retrieved March, 2010, from http://www.plunket.org.nz/

PMMRC. (2014). Eight Annual Report of the Perinatal and Maternal Mortality Review Committee: Reporting mortality 2012. In P. a. M. M. R. Committee (Ed.). Wellington: Health Quality \& Safety Commission.

Powell, D. S., Batsche, C. J., Ferro, J., Fox, L., \& Dunlap, G. (1997). A Strength-Based Approach in Support of Multi-Risk Families: Principles and Issues. Topics in Early Childhood Special Education, 17(1), 1-26. doi: 10.1177/027112149701700105

Pulotu-Endemann, F. K., Suaali'i Sauni, T., Lui, D., McNicholas, T., Milne, M., \& Gibbs, T. (2007). Seitapu Pacific mental health and addiction cultural and clinical 
competencies framework. Auckland: The National Centre of Mental Health Research and Workforce Development.

Ramos, K. D., \& Youngclarke, D. M. (2006). Parenting advice books about child sleep: Cosleeping and crying it out. Sleep, 29(12).

Refiti, A. L. (2013). How the Tã-Vā theory of reality constructs a spatial exposition of Samoan architecture. Heretic Papers in Pacific Thought.

Reifsnider, E., Gallagher, M., \& Forgione, B. (2005). Using ecological models in research on health disparities. Journal of Professional Nursing, 21(4), 216-222.

Reinharz, S. (1992). Feminist methods in social research. Oxford: Oxford University Press.

Rich, A. (1977). Of Woman Born: Motherhood as experience and institution. London: W.W. Norton \& Company, Inc.

Richards, H. M., \& Schwartz, L. J. (2002). Ethics of qualitative research: are there special issues for health services research? Family Practice, 19(2), 135-139.

Robertson, E., Celasun, N., \& Stewart, D. E. (2003). Risk factors for postpartum depression. In D. E. Stewart, E. Robertson, C.-L. Dennis, S. L. Grace \& T. Wallington (Eds.), Postpartum depression: Literature review of risk factors and interventions. Canada: University Health Network Women's Health Program 2003.

Robinson, D., \& Robinson, K. (2005). Pacific ways of talk - hui and talanoa. New Zealand Institute for Economic Research. New Zeland. Retrieved from http://nzier.org.nz/static/media/filer public/83/9c/839ccd89-864c-4e12-ad779947e73564e2/nztc no 36.pdf

Rogers, M. (2012). Contextualizing theories and practices of Bricolage research. The Qualitative Report, 17(7), 1-17.

Rosengard, C., Phipps, M. G., Adler, N. E., \& Ellen, J. M. (2004). Adolescent pregnancy intentions and pregnancy outcomes: A longitudinal examination. Journal of Adolescent Health, 35(6), 453-461. doi: http://dx.doi.org/10.1016/i.jadohealth.2004.02.018

Royal New Zealand Plunket Society Inc. (2010). Breastfeeding data: Analysis of 20042009 data.

Rumbold, A. R., Bailie, R. S., Si, D., Dowden, M. C., Kennedy, C. M., Cox, R. J., . . . Connors, C. M. (2011). Delivery of maternal health care in indigenous primary care services: baseline data for an ongoing quality improvement initiative. $B M C$ Pregnancy and Childbirth, 11(16).

Russell, L., Smiler, K., Neale, J., Churchward, M., Grace, N., Buckley, S., \& NaeraBarnett, M. (2013). Rangatahi Māori sexual and reproductive health research report. For Manatū Hauora/Ministry of Health and Te Kaunihera Rangahau Hauora o Aotearoa/Health Research Council of New Zealand Wellington: Health Services Research Centre, Victoria University of Wellington.

Sable, M., \& Libbus, M. K. (2000). Pregnancy Intention and Pregnancy Happiness: Are They Different? Maternal and Child Health Journal, 4(3), 191-196. doi: 10.1023/a:1009527631043

Safuneituuga, P. N. (2005). Statement on behalf of the Government of Samoa. Fortyninth session of the Commission on the status of Women. Retrieved from www.un.org/webcast/csw2005/statements/050307samoa-e.pdf 
Salesa, D. I. (2003). 'Travel-Happy' Samoa: Colonialism, Samoan migration and a 'brown pacific'. New Zealand Journal of History, 37(2).

Sandelowski, M. (1994). Focus on qualitative methods. Notes on Transcription. Research in Nursing \& Health, 17(4), 311-314. doi: 10.1002/nur.4770170410

Sanga, K., \& Pasikale, A. (2002). Research for Pacific empowerment: researching with Pacific communities. Paper presented at the Pacific Economics Symposium, Auckland.

Sarantakos, S. (2005). Social Research (3rd ed.). New York: Palgrave MacMillan.

Schluter, P. J., Carter, S., \& Percival, T. (2006). Exclusive and any breast-feeding rates of Pacific infants in Auckland: data from the Pacific Islands Families First Two Years of Life study. Public Health Nutrition, 9(06), 692-699. doi: doi:10.1079/PHN2005925

Schmidt, J. M. (2014). Primary care decision making among first-time parents in Aotearoa/New Zealand. Women's Studies Journal, 28(1).

Schoon, I. (2006). Risk and resilience: adaptations in changing times. Cambridge: Cambridge University Press.

Shore, B. (1981). Sexuality and gender in Samoa: conceptions and missed conceptions. In S. B. Ortner \& H. Whitehead (Eds.), Sexual meanings: The cultural construction of gender and sexuality. New York: Cambridge University Press.

Shuval, J. T. (2000). Diaspora migration: Definitional ambiguities and a theoretical paradigm. International Migration, 38(5).

Singh, S., Sedgh, G., \& Hussain, R. (2010). Unintended Pregnancy: Worldwide Levels, Trends, and Outcomes. Studies in Family Planning, 41(4), 241-250. doi: 10.1111/j.1728-4465.2010.00250.x

Skouteris, H., Carr, R., Wertheim, E. H., Paxton, S. J., \& Duncombe, D. (2005). A prospective study of factors that lead to body dissatisfaction during pregnancy. Body Image, 2(4), 347-361. doi: http://dx.doi.org/10.1016/j.bodyim.2005.09.002

Small, R., Taft, A. J., \& Brown, S. J. (2011). The power of social connection and support in improving health: lessons from social support interventions with childbearing women. BMC Public Health, 11((Suppl 5) 54).

Smith, J. L., Skinner, S. R., \& Fenwick, J. (2013). Preconception reflections, postconception intentions: the before and after of birth control in Australian adolescent females. Sexual Health, 10(4), 332-338. doi: http://dx.doi.org/10.1071/SH13020

Smith, L. T. (1999). Decolonizing Methodologies: research and indigenous peoples. London and Dunedin: Zed Books and University of Otago Press.

Smith, L. T. (2005). On tricky ground: researching the native in the age of uncertainty (3rd, Trans.). In N. K. Denzin \& Y. S. Lincoln (Eds.), The Sage Handbook of Qualitative Research (pp. 85-107). Thousand Oaks: Sage.

Southwick, M. (2001). Pacific women's stories of becoming a nurse in New Zealand: A radical hermeneutic reconstruction of marginality. PhD Thesis. Victoria University of Wellington. Wellington.

Stanfors, M., \& Scott, K. (2013). Intergenerational transmission of young motherhood. Evidence from Sweden, 1986-2009. The History of the Family, 18(2), 187-208. doi: $10.1080 / 1081602 x .2013 .817348$ 
Statistics New Zealand. (2003). Teenage fertility in New Zealand. Wellington: Statistics New Zealand.

Statistics New Zealand. (2004). Household access to the internet. Wellington: Statistics New Zealand.

Statistics New Zealand. (2008a). Abortion Statistics, 2014, from http://www.stats.govt.nz/browse for stats/health/abortion/abortionstables.aspx

Statistics New Zealand. (2008b). Pacific Peoples: A Snapshot. Retrieved May, 2008

Statistics New Zealand. (2008c). Samoan People in New Zealand: 2006. Retrieved September, , 2013

Statistics New Zealand. (2010a). Household Use of Information and Communication Technology: 2009. Retrieved May, 2011, from http://www.stats.govt.nz/browse for stats/industry sectors/information tech nology and communications/HouseholdUseofICT HOTP2009.aspx

Statistics New Zealand. (2010b). Pacific Profiles: Samoan - Families and households : 2001 Retrieved 2010, April, from http://www2.stats.govt.nz/domino/external/web/nzstories.nsf/fb471f7feb8c8d 5fcc256af1000fa1c1/f375f35d8c64be01cc256ccb006862f0?OpenDocument

Statistics New Zealand. (2013a). National population estimates: At 30 June 2013 Retrieved April, 2014, from http://www.stats.govt.nz/browse for stats/population/estimates and project ions/NationalPopulationEstimates HOTPAt30Jun13.aspx

Statistics New Zealand. (2013b). Pacific peoples ethnic group. Retrieved June 2014, from Statistics New Zealand http://www.stats.govt.nz/Census/2013census/profile-and-summary-reports/quickstats-culture-identity/pacificpeoples.aspx

Statistics New Zealand. (2014a). 2013 Census ethnic group profiles: Samoan. Wellington: Statistics New Zealand.

Statistics New Zealand. (2014b). 2013 Census QuickStats about Māori. Wellington: Statistics New Zealand.

Stevens-Simon, C., Beach, R. K., \& Klerman, L. V. (2001). To be rather than not to be that is the problem with the questions we ask adolescents about their childbearing intentions. Archives of Pediatrics \& Adolescent Medicine, 155, 1298-1300.

Stewart-Withers, R. (2007). Contesting development: The experience of female-headed households in Samoa. PhD Thesis. Massey University. Palmerston North.

Stewart-Withers, R. (2011a). Contesting a Third World development category: Femaleheaded households in Samoa. Women's Studies International Forum, 34, 171184.

Stewart-Withers, R. (2011b). Re-positioning the experiences and situation of single mothers: Accounts from Samoa. Women's Studies Journal, 25(1).

Stewart, M. (2004). Feminisms and the body. In M. Stewart (Ed.), Pregnancy, birth, and maternity care: Feminist perspectives. London: Elsevier Butterworth Heinemann.

Stojanovic, J. (2010). Midwifery in New Zealand, 1904-1971. Birthspirit Midwifery Journal(5). 
Suaali'i-Sauni, T. (2000). Deconstructing the 'Exotic' female beauty of the Pacific Islands. In Alison Jones, Phyllis Herda \& Tamasailau M Suaalii (Eds.), Bitter Sweet: Indigenous Women in the Pacific. Dunedin: University of Otago Press.

Suaali'i-Sauni, T. (2007). E Faigata le Alofa: The Samoan Fa'amatai - Reflections from afar. In A. So'o (Ed.), Changes in the Matai system - O suiga i le Fa'amatai.

Suaali'i-Sauni, T. (2014). Prioritising 'the Va' in value and evaluation: An Aotearoa Pasifika perspective. Paper presented at the Aotearoa New Zealand Evaluation Association (ANZEA) Wellington Branch Seminar, Wellington.

Sword, W. (1999). A socio-ecological approach to understanding barriers to prenatal care for women of low income. Journal of Advanced Nursing, 29(5), 1170-1177. doi: 10.1046/j.1365-2648.1999.00986.x

TAHA. (2014). Tapuaki: Pacific pregnancy and parenting education. Retrieved May, 2014, from http://www.tapuaki.org.nz/

Tajfel, H., \& Turner, J. (1979). An integrative theory of intergroup conflict. In W. G. Austin \& S. Worchel (Eds.), The Social Psychology of Intergroup Relations. Monterey, California: Brooks-Cole.

Tamasese, K., Peteru, C., \& Waldegrave, C. (1997). Ole Taeao Afua: The New Morning A qualitative investigation into Samoan perspectives on mental health and culturally appropriate services. Wellington: The Family Centre.

Tamasese, K., Peteru, C., Waldegrave, C., \& Bush, A. (2005). Ole Taeao Afua, the new morning: a qualitative investigation into Samoan perspectives on mental health and culturally appropriate services. Australian and New Zealand Journal of Psychiatry, 39, 300-309.

Teaiwa, T. (1999). Reading Gauguin's Noa Noa with Hau'ofa's Nederends: Militourism, Feminism and the 'Polynesian Body'. In V. Hereniko \& R. Wilson (Eds.), Inside Out: Literature, Cultural Politics and Identity in the New Pacific (pp. 249-264). Colorado: Rowman and Littlefield.

Teaiwa, T. (2001). L(o)osing the edge. The Contemporary Pacific, 249-264.

Teaiwa, T. (2006). On analogies: Rethinking the Pacific in a global context. The Contemporary Pacific, 18(1).

Teaiwa, T. (2009). For or before an Asia-Pacific studies agenda? Specifying Pacific Studies. Specific Pacific Studies. Victoria University of Wellington.

Teaiwa, T. (2010a). For or Before an Asia-Pacific Studies Agenda? Specifying Pacific Studies. In T. Wesley-Smith \& J. Gos (Eds.), Remaking Area Studies: Teaching and learning across Asia and the Pacific. Hawai'i: University of Hawai'i Press.

Teaiwa, T. (2010b). [Personal Communication: Re: publication Caring for Ourselves, Vanessa Griffen].

Teaiwa, T., \& Mallon, S. (2005). Ambivalent Kinships? Pacific People in New Zealand. In J. Liu, T. McCreanor, T. McIntosh \& T. Teaiwa (Eds.), New Zealand Identities: Departures and Destinations (pp. 207-229). Wellington: Victoria University Press.

Thaman, K. H. (2003). Decolonizing Pacific Studies: Indigenous perspectives, knowledge, and wisdom in higher education. The Contemporary Pacific, 15(1), 1-17.

Thaman, K. H. (2008). Challenges for Pacific research: A personal view. Paper presented at the Building Pacific research capacity and scholarship in Aotearoa, New Zealand fono, Auckland, New Zealand. 
Thaman, K. H. (2009). Towards cultural democracy in teaching and learning with specific references to Pacific Island Nations (PINs). International Journal for the Scholarship of Teaching and Learning, 3(2).

The Health and Disability Commissioner. (2009). The Code of Rights http://www.hdc.org.nz/the-act--code/the-code-of-rights. Wellington.

The Royal New Zealand Plunket Society Inc. (2012). Annual Report 2013. Wellington.

Thomson, R., Kehily, M. J., Hadfield, L., \& Sharpe, S. (2008). The making of modern motherhood: Memories, representations, practices: Full research report. United Kingom: The Open University.

Tiatia, J. (1998). Caught between cultures: A New Zealand-born Pacific Island perspective. Auckland: Christian Research Association.

Tiatia, J. (2003). Reasons to live: NZ-Born Samoan young people's responses to suicidal behaviours. PhD Thesis. University of Auckland. Auckland.

Tinkler, A., \& Quinney, D. (1998). Team midwifery: the influence of the midwife-woman relationship on women's experiences and perceptions of maternity care. Journal of Advanced Nursing, 28(1), 30-35. doi: 10.1046/j.13652648.1998.00769.x

Tölölyan, K. (2012). Diaspora studies: Past, present and promise Working Paper. University of Oxford: International Migration Institute.

Trutnovsky, G., Haas, J., Lang, U., \& Petru, E. (2006). Women's perception of sexuality during pregnancy and after birth. Australian and New Zealand Journal of Obstetrics and Gynaecology, 46(4), 282-287. doi: 10.1111/j.1479828X.2006.00592.x

Tuafuti, P. (2011). Multiple challenges in research within the fa'asamoa context. Pacific-Asian Education, 23(2), 33-42.

Tui Atua, T. T. T. E. (2005). Clutter in indigenous knowledge, research and history: A Samoan perspective. Social Policy Journal of New Zealand(25).

Tui Atua, T. T. T. E. (2009). Bioethics and the Samoan indigenous reference. International Social Science Journal, 60(195), 115-124.

Tupuola, A.-M. (1998). 'Adolescence': myth or reality for 'Samoan' women? Beyond the stage-like toward shifting boundaries and identities. PhD thesis. Victoria University of Wellington. Wellington.

Tupuola, A.-M. (2000). Learning sexuality: Young Samoan Women. In Alison Jones, P. Herda \& T. M. Suaalii (Eds.), Bitter Sweet: Indigenous Women in the Pacific. Dunedin: University of Otago Press.

Tupuola, A.-M. (2002). What's in a name? Western terms and non-western experiences. International Journal of Critical Psychology, 5, 158-172.

Tupuola, A.-M. (2004a). Editorial: cultural ways of knowing within global contexts. Journal of Intercultural Studies, 25(1), 3-6.

Tupuola, A.-M. (2004b). Pasifika edgewalkers: complicating the achieved identity status in youth research. Journal of Intercultural Studies, 25(1), 87-100. doi: 10.1080/07256860410001687045

Tupuola, A.-M. (2004c). Talking sexuality through an insider's lens: The Samoan experience. In A. Harris (Ed.), All about the girl: Culture, power, and identity. New York: Routledge. 
Tupuola, A.-M. (2006). Participatory research, culture and youth identities: An exploration of indigenous, cross-cultural and trans-national methods. Children, Youth and Environments, 16(2), 291-316.

Ungar, M. (2004). A constructionist discourse on resilience: Multiple contexts, multiple realities among at-risk children and youth. Youth \& Society, 35(3), 341-365.

Ungar, M. (2008). Resilience across cultures. British Journal of Social Work, 38, 218235.

Ungar, M., Brown, M., Liebenberg, L., Othman, R., Kwong, W. M., Armstrong, M., \& Gilgun, J. (2007). Unique pathways to resilience across cultures. Adolescence, 42(166), 287-310.

University of Hawaii: ADAP Project. (2001). Samoan medicinal plants and their usage. In L. Castro \& K. Tsuda (Eds.). Hawaii: University of Hawaii.

Utumapu, T. L. P. (1998). O le poutu: Women's roles and Samoan language nests. PhD Thesis. University of Auckland. Auckland.

Vaioleti, T. M. (2006). Talanoa research methodology: A developing position on Pacific research. Waikato Journal of Education, 21-34.

Vaughan, G., \& Hogg, M. (2002). Introduction to Social Psychology (3rd ed.). Sydney: Pearson Education.

Walsh, D. (1999). An ethnographic study of women's experience of partnership caseload midwifery practice: the professional as a friend. Midwifery, 15(3), 165176. doi: http://dx.doi.org/10.1016/S0266-6138(99)90061-X

Walsh, F. (1996). The Concept of Family Resilience: Crisis and Challenge. Family Process, 35(3), 261-281. doi: 10.1111/j.1545-5300.1996.00261.x

Walsh, F. (2006). Strengthening family resilience. New York: The Guilford Press.

Walsh, F. (2010). Keys to family resilience. The Social Ecology of Resilience. University of Chicago. Chicago.

Walsh, S. P., White, K. M., \& Young, R. M. (2008). The Phone Connection: A qualitative exploration of how belongingness and social identification relate to mobile phone use amongst Australian youth. Journal of Community \& Applied Social Psychology, 19, 225-240.

Well Child. (2011). Well Child Tamariki Ora. Retrieved January, 2013, from http://www.wellchild.org.nz/?t=34

Wendt, A. (1982). Towards a new oceania. In G. Amirthanayagam (Ed.), Writers in eastwest encounter: new cultural bearings (pp. 202-215): Macmillan Press Ltd.

Wendt, A. (1999). Afterword: Tatauing the post-colonial body. In V. Hereniko \& R. Wilson (Eds.), Inside out: Literature, cultural politics, and identity in the new Pacific. USA: Rowman \& Littlefield

Wesley-Smith, T. (1995). Rethinking Pacific Island Studies. Pacific Studies, 18(2), 115137.

Whitford, H. M., \& Hillan, E. M. (1998). Women's perceptions of birthplans. Midwifery, 14, 248-253.

Williams, L., McCreanor, T., \& Barnes, H. M. (2003). A review of Mental Health promotion literature and analysis of evidence to inform mental health promotion practice in Aotearoa/New Zealand. Wellington: Mental Health Foundation of New Zealand. 
Wilson, H. V. (2001). Power and partnership: a critical analysis of the surveillance discourses of child health nurses. Journal of Advanced Nursing, 36(2), 294-301. doi: 10.1046/j.1365-2648.2001.01971.x

Winter, C. (2002). How do independent midwives assess the progress of labour? Master of Science Master, University of Dundee, United Kingdom. Retrieved from http://discovery.dundee.ac.uk/portal/files/1292162/Winter msc 2002.pdf

Wood, B. (2008). 'Tui Tu'u Heilala': Konai Thaman talks to Briar Wood. Wasafiri, 12(25), 6-10.

World Health Organization. (2006). Sexual and reproductive health: Defining sexual health - working definitions. Retrieved July, 2014, from

http://www.who.int/reproductivehealth/topics/sexual health/sh definitions/e $\underline{\mathrm{n} /}$

World Health Organization. (2014). Breastfeeding. Retrieved January, 2014, from http://www.who.int/topics/breastfeeding/en/

Yancura, L. A., \& Greenwood, H. (2013). Raising Grandchildren as an Expression of Native Hawaiian. In B. H. Jr \& G. C. Smith (Eds.), (pp. 105-120): Resilient Grandparent Caregivers: A strengths-based perspective. 